SCientific Publications of the American Museum of Natural History

AMERICAN MUSEUM NOVITATES

Bulletin of the American Museum of Natural History

anthropological Papers of the american Museum of Natural History

Publications Committee

ROBERT S. VOSS, CHAIR

BOARD OF EDITORS

Jin Meng, Paleontology

LORENZO PRENDINI, INVERTEBRATE ZOOLOGY

ROBERT S. VOSS, VERTEBRATE ZOOLOGY

Peter M. Whiteley, ANTHROPOLOGY

MANAGING EDITOR

MARY KNIGHT

Submission procedures can be found at http://research.amnh.org/scipubs

All issues of Novitates and Bulletin are available on the web from http://digitallibrary.amnh.org/dspace

Order printed copies from http://www.amnhshop.com or via standard mail from: American Museum of Natural History-Scientific Publications

Central Park West at 79th Street

New York, NY 10024

(2) This paper meets the requirements of ANSI/NISO Z39.48-1992 (permanence of paper).
NEW TAXA AND CRYPTIC SPECIES OF NEOTROPICAL SNAKES (XENODONTINAE), WITH COMMENTARY ON HEMIPENES AS GENERIC AND SPECIFIC CHARACTERS

CHARLES W. MYERS AND SAMUEL B. MCDOWELL
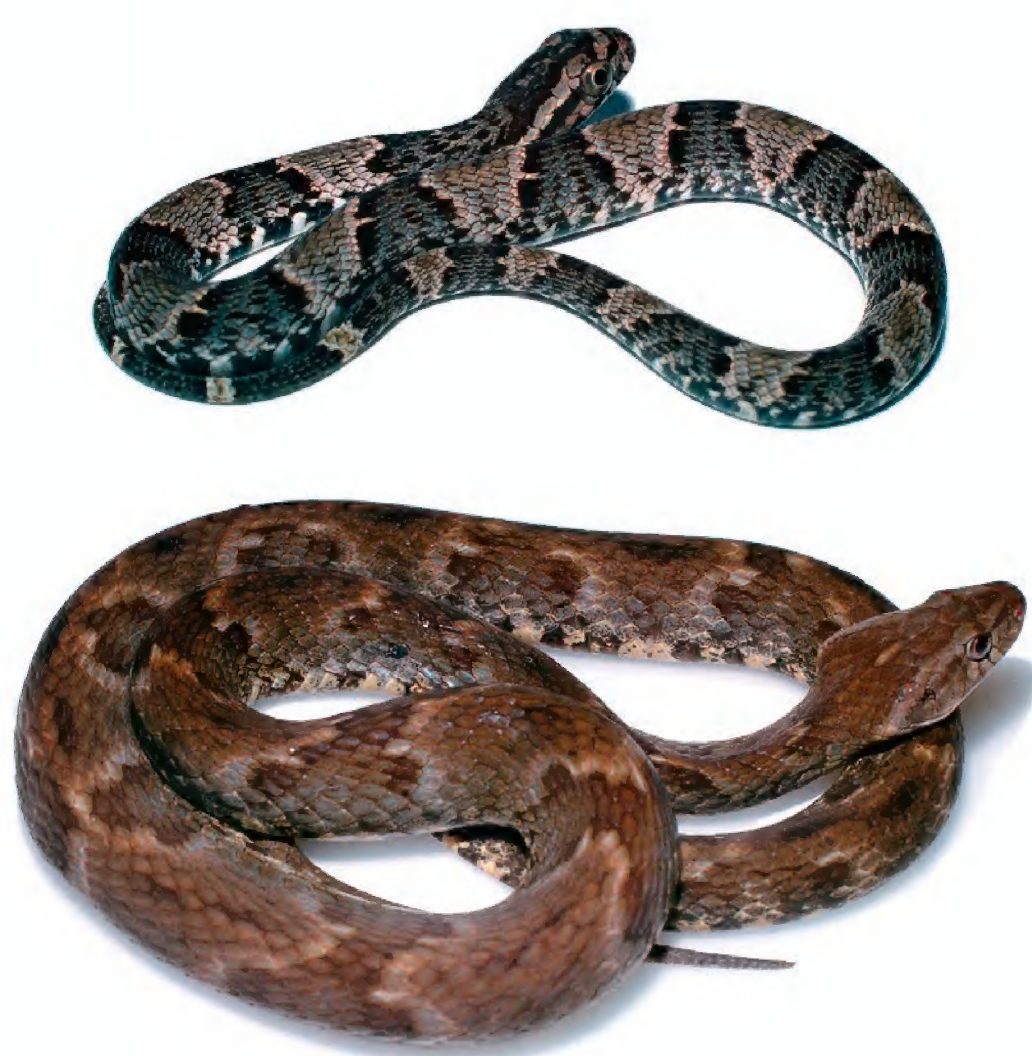

ON THE COVER: JUVENILE AND ADULT COLORATIONS OF XENODON "RABDOCEPHALUS," A GEOGRAPHICALLY WIDESPREAD COMPLEX OF CRYPTIC SPECIES AND FER-DE-LANCE MIMICS. PHOTOS BY C.W. MYERS. 


\title{
NEW TAXA AND CRYPTIC SPECIES OF NEOTROPICAL SNAKES (XENODONTINAE), WITH COMMENTARY ON HEMIPENES AS GENERIC AND SPECIFIC CHARACTERS
}

\author{
CHARLES W. MYERS \\ SAMUEL B. MCDOWELL \\ Division of Vertebrate Zoology \\ Department of Herpetology \\ American Museum of Natural History \\ New York, New York
}

BULLETIN OF THE AMERICAN MUSEUM OF NATURAL HISTORY

Number 385, 112 pp., 40 figures, 1 map

Issued March 6, 2014 


\section{CONTENTS}

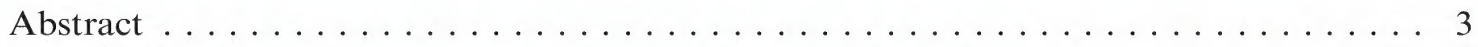

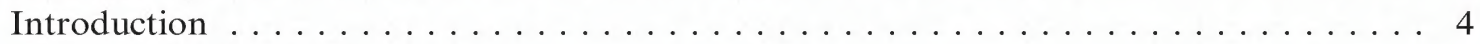

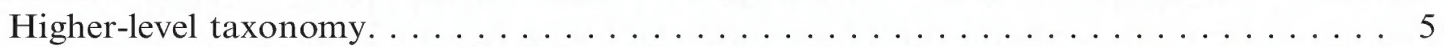

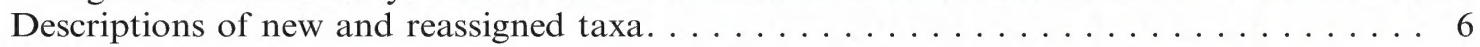

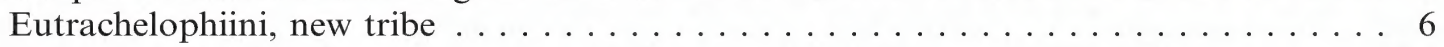

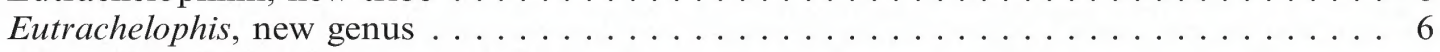

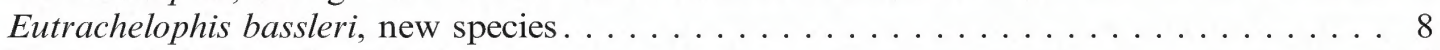

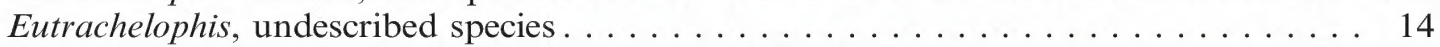

Eutrachelophis steinbachi (Boulenger), new combination . . . . . . . . . . 14

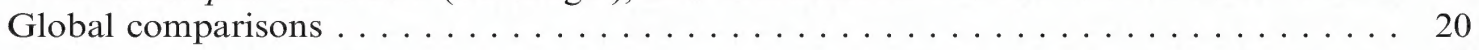

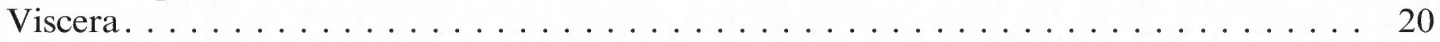

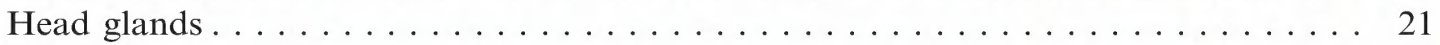

Head muscles . . . . . . . . . . . . . . . . . . . . . . 22

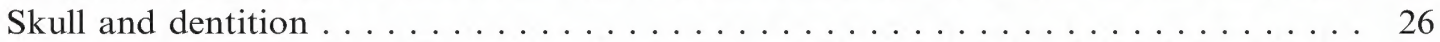

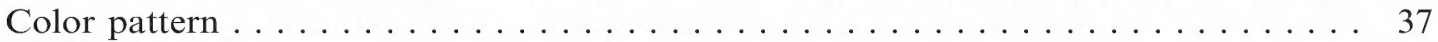

Hemipenes . . . . . . . . . . . . . . . . . . . . . . . . 39

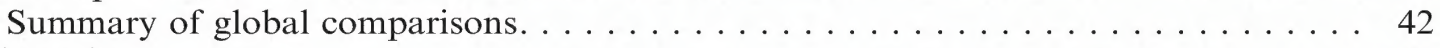

Discussion . . . . . . . . . . . . . . . . . . . . . . 43

Hypothesis for hemipenial transformation in Eutrachelophis . . . . . . . . . 45

On the apical disc . . . . . . . . . . . . . . . . . . . . . 47

Loss of a "generic character" - the apical disc . . . . . . . . . . . . . . . . 49

Commentary on hemipenes as generic and specific characters. . . . . . . . . 52

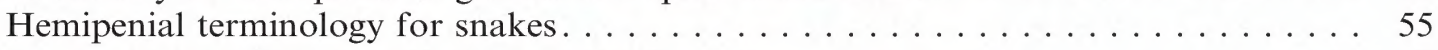

Are hemipenes "conservative" characters? . . . . . . . . . . . . . . . . . . . . . . . . . . . . . . . .

Examples of intraspecific variation in snake hemipenes and cloacae. . . . . . . . . 61

Evolutionary plasticity and extreme divergence of snake hemipenes . . . . . . . 67

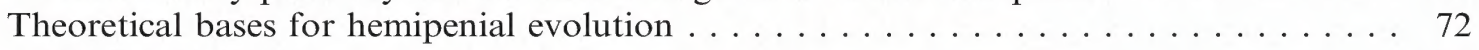

Eberhard's thesis. . . . . . . . . . . . . . . . . . . . 72

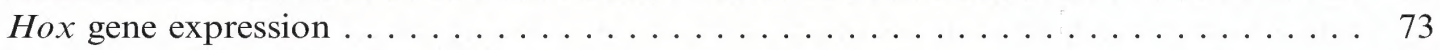

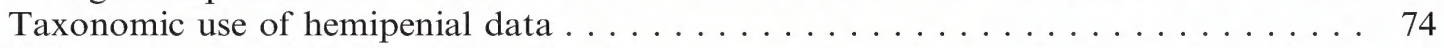

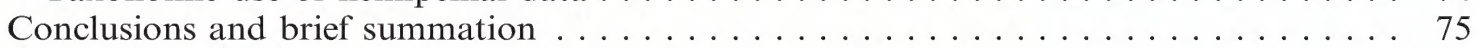

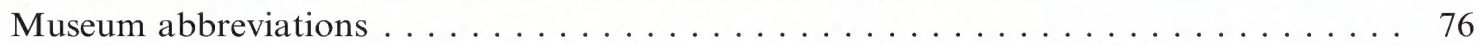

Acknowledgments . . . . . . . . . . . . . . . . . . . . 77

Appendix 1: Nomenclatural considerations, by C.W. Myers . . . . . . . . . . . . . 77

Notes on the tribe Xenodontini Bonaparte . . . . . . . . . . . . . . 77

Color pattern variation in Xenodon rabdocephalus, sensu lato, with $X$. suspectus

Cope removed from synonymy . . . . . . . . . . . . . . . . . 79

Lectotype designation for Xenodon rabdocephalus $($ Wied) $\ldots \ldots \ldots \ldots \ldots \ldots$

Xenodon angustirostris W. Peters removed from synonymy . . . . . . . . . . . . 89

Named genera based on loss of the apical disc. . . . . . . . . . . . . . 90

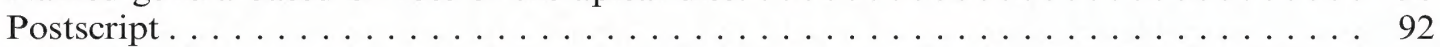

Appendix 2: The Vidian canal and venous foramina in the prootic of alethinophidian

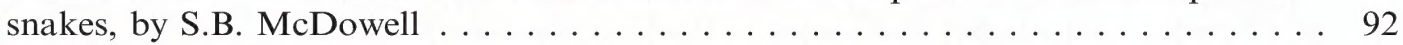

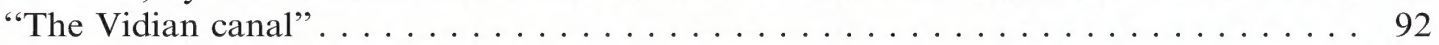

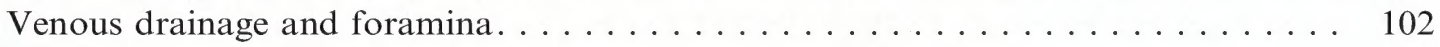

References ................................. 104 


\begin{abstract}
Eutrachelophis, new genus is established to accommodate $E$. bassleri, new species, and $E$. steinbachi (Boulenger), new combination; a third species close to E. bassleri awaits naming. These taxa are placed in the Eutrachelophiini, new tribe, to express hypothesized relationship with the Xenodontini, which are defined by presence of hemipenial apical discs (a character lost in several species). The acalyculate spiny hemipenis of Eutrachelophis bassleri is unique among "xenodontines" in having a noncapitate, well-formed capitulum in the form of a nude dome; bifurcation is lacking even in the insertion of the major retractor muscle; the sulcus spermaticus is centrolineal in the retracted organ but becomes centrifugal during eversion.
\end{abstract}

The hemipenis of Eutrachelophis steinbachi is strikingly different in being deeply divided, with long spiny lobes tipped with tufts of sender spines, but it resembles those of some other colubrids (e.g., South American Xenodon suspectus; African Mehelya poensis). Based on hemipenial comparisons, E. bassleri and E. steinbachi seem unlikely congeners. Nonetheless, global comparisons of viscera, head glands, head muscles, color pattern, skull, and dentition indicate that they are congeneric despite hemipenial differences. Neither E. bassleri nor E. steinbachi shows sufficient resemblance to any other "xenodontine" that would suggest an alternative phylogeny. Overall resemblance in so many details, especially of the skull, is not reasonably explained by convergence.

Therefore, contrary to dogma, the hemipenes in this case provide no clues to generic affinity. An explanatory hypothesis has Eutrachelophis bassleri and E. steinbachi derived from common stock, but with hemipenial lobes in the bassleri lineage suppressed during embryonic development. It further suggests that the unusual broad, hemispherical nude apex in E. bassleri is homologous with the interlobular smooth, expandable terminal basin in E. steinbachi. The hemipenial differences in Eutrachelophis are not inconsistent with growing awareness that evolution of male genitalia may outpace changes in other characters without predictable limits to complexity. Fine-scale Hox gene expression might account for the novel hemipenis of $E$. bassleri.

Although it is well established that snake hemipenes generally give at least a hint of relationship, a widely held belief that they are taxonomically stable and relatively free of selection pressures must be abandoned. Hemipenes (and probably female cloacae) are not "neutral" or "uncorrelated" characters but are subject to intense selection pressure requiring successful copulation, hence successful reproduction. The belief that one description or illustration suffices to typify a species (or genus) has no merit without proper sampling. Intraspecific variation is commonplace in geographically widespread species - sometimes, not always, signaling the presence of unnamed cryptic species.

Examples are given of intraspecific variation in different kinds of hemipenial features. Also provided are examples of evolutionary plasticity and extreme divergence in snake hemipenes, with a few references to female cloacae, about which much less is known. The hemipenes of two apparent sister species, Enulius flavitorques and "Enuliophis" sclateri, might represent a case of hemipenial divergence as extreme as seen between Eutrachelophis bassleri and E. steinbachi. Attention is called to examples of extraordinary folding and coiling of retractor muscles and even a folding hemipenis, all of which enable long hemipenes to fit within short tails in both Scolecophidia (Typhlina) and Alethinophidia (Prosymna). Folding of the hemipenis and retractor muscle is illustrated for the African Prosymna ambigua bocagii, which has hemipenes longer than the tail. Axial architecture and limblessness of snakes have been attributed to Hox gene expression, which we suggest may also be the mechanistic basis for the appearance of hemipenial novelties without gradual change.

Myers (1986) and the late Garth Underwood (2001, letters published herein), working with biometrician Clive Moncrieff, had independently concluded that the apical disc - the defining character of tribe Xenodontini-has been lost in some populations of the geographically widespread Xenodon "rabdocephalus" (Wied). That finding is here extended also to Xenodon suspectus Cope, which is resurrected from the synonymy of $X$. "rabdocephalus" based on a variable but cohesive color pattern and a hemipenis tipped with slender apical spines. A 
lectotype is designated for $X$. rabdocephalus, sensu stricto, which has been said to lack apical discs; the lectotype, however, has small apical discs on long slender lobes.

Underwood and Moncrieff did not find the apical disc on hemipenes in Central American or in most South American populations of Xenodon "rabdocephalus." Its absence is confirmed for populations in Central America and northwestern Colombia, for which the name Xenodon angustirostris W. Peters, 1864 (type locality Veragua) is tentatively resurrected. But sample sizes are small and hemipenial characteristics need to be elucidated for more populations. In addition to unrecognized species, South American "rabdocephalus" overall includes $X$. angustirostris, $X$. suspectus, and $X$. rabdocephalus sensu stricto.

Xenodon rabdocephalus sensu lato is a complex of an unknown number of cryptic or "hidden" species, in which speciation events appear to be signaled by hemipenial changes. However, hemipenial data are too sparse at this time to allow separation of taxa because color patterns maintain a degree of consistency throughout an enormous geographic range (Mexico to Bolivia). These fer-de-lance mimics presumably are under strong selection pressure to maintain a Bothropslike color pattern. A comprehensive study is needed, with molecular input to the extent possible.

Loss of the apical disc among species of Xenodon may have been confined to species like "rabdocephalus" that have long-lobed hemipenes primitively tipped with small discs. Such loss characters can helpfully define species, but do not suffice for genera. Junior synonyms of Xenodon include Acanthophallus Cope, 1894 (type species Xenodon colubrinus Günther, 1858); and Thalesius Yuki, 1993 (type species Xenodon werneri Eiselt, 1963), both based on absence (loss) of the apical disc. Waglerophis Romano and Hoge, 1972, with apical discs on long hemipenial lobes, also is a synonym. (These interpretations of Xenodon synonymy agree with Zaher, 1999, and Zaher et al., 2009.)

Terminology applicable to snake hemipenes is reviewed, particularly for a few characters needing clarification. Illustrations show the difference between capitation and noncapitation of hemipenes or hemipenial lobes with distinct capitula ("heads"). A commonly overlooked character-the smooth terminal basin of some bilobed hemipenes is described. The simple tripartite system for describing the orientation of sulci spermatici is updated. Complementary comparisons of retracted and everted hemipenes are encouraged, to provide better understanding and sometimes to increase the number of taxonomically useful characters.

A discussion is appended of the Vidian canal and venous foramina in the prootic of Alethinophidian snakes. The Vidian canal in Pythonidae and the fossil Dinilysia shows the most lizardlike, presumably primitive, pattern. Anilioids show departures from this pattern, as do Acrochordoidea and Colubroidea. Boidae differ from Pythonidae in the loss of a true basipterygoid process (replaced, at least embryonically, by a cartilaginous nodule). Among the variable colubroid conditions, the Vidian canal in Eutrachelophis bassleri and E. steinbachi is similar to that of Liophis in being short and entirely enclosed in the sphenoid, with its anterior orifice set well in from the sphenoid-parietal suture.

\section{INTRODUCTION}

This is a study in which we originally set out to discover the affinities of two South American snakes. One was an unnamed species from the upper Amazon drainage of Peru and Ecuador; the other was Rhadinaea steinbachi Boulenger (1905) of east-central Bolivia-a snake not assignable to any currently defined genus (fide Myers, 1974: 22). These are small slender colubrids that share a low number (15) of dorsal scale rows and similar nuchal color patterns, by which they are readily distinguished from nearly all other snakes. Externally they easily appeared congeneric, but differences in the male genitalia would seem to place them in different tribes or even in different genera. The hemipenis of $R$. steinbachi is long, deeply divided, and spinose to the tips, whereas that of the new species is short, undivided, proximally spinose, and distally nude.

The systematic problem is an old one: Do the resemblances reflect affinities or do 
striking differences in a taxonomically important structure indicate lack of kinship? We initially thought the latter and suspected convergence in external features, but after looking to many additional characters we concluded that there actually is a close relationship. We think that the affinities between the two species are best expressed by placing them in a single new genus, to which a third, more recently discovered species is added. At the same time, we erect a new tribe in the subfamily Xenodontinae.

Although the hemipenial differences between the first two species are striking, they are not inconsistent with growing awareness that evolution of male genitalia may proceed in advance of changes in other characters, without predictable limits to complexity (Eberhard, 1985, 2004). The taxonomic decision is based on morphology; tissue samples have not been collected, although we hope that molecular data will eventually provide additional insight.

This study also led to broad comparisons on use of the hemipenis for systematic purposes-leading to conclusions that it sometimes is worthless as a generic character, but that, on the other hand, it often is indispensable in defining species, particularly those in which hemipenial evolution has outpaced change in other characters. The first situation applies to cases of extreme hemipenial diversity, as illustrated in this paper. The second is applicable to the cryptic species of Xenodon "rabdocephalus," a complex of fer-de-lance mimics distributed from Mexico to Bolivia; these "hidden" species are presumably under heavy selection pressure to maintain their Bothrops-like coloration.

First, however, we provide a brief historical framework and the rationale for our practical approach to the higher-level taxonomy of "colubrid" and "xenodontine" snakes.

\section{Higher-Level TAXONOMY}

The vast majority of Neotropical colubrid snakes have long been considered to belong to the poorly characterized subfamily Xenodontinae. Two large assemblages have been informally called Central American and South American xenodontines, although there is broad geographic superposition.
These two groups received suggestive support as clades from early microcomplement fixation studies of serum albumins (Cadle, 1984a, 1984b, 1984c, 1985). Some hemipenial differences were pointed out by Myers and Cadle (1994: 27-28), who thought that the hemipenes of the South American clade were relatively primitive compared with the Central American clade, which is characterized by several derived hemipenial features.

Zaher (1999) recognized the mainly South American clade as Xenodontinae, sensu stricto, based on two hemipenial synapomorphies (enlarged calyces on the asulcate sides of the lobes, and enlarged lateral spines), which are seen either individually or together in most species. Zaher (1999) recognized the mainly Central American clade as subfamily Dipsadinae, based on several hemipenial synapomorphies suggested by Myers and Cadle (1994: 27).

Zaher et al. (2009) subsequently reworked the classification of caenophidian snakes based on a new molecular phylogeny. The family Colubridae was greatly restricted from "its long-standing use [for] all caenophidians that were not acrochordids, elapids, or viperids" (Zaher et al., 2009: 132). In addition to confirming removal of a number of Old World groups whose relationships had been questioned, the name Colubridae in its common sense was most significantly affected by raising its main subfamilies (colubrines, natricines, dipsadines) to familial level. The subfamily Xenodoninae was returned to its earlier concept of a single group of New World "xenodontines" by submersing it within family Dipsadidae. The Xenodoninae were then judged to have no known synapomorphies because those presented by Zaher (1999) were moved to the Dipsadidae (see Zaher et al., 2009: 140). The Xenodoninae were nonetheless retained as a subfamily in order to avoid "changing the well-established taxonomic hierarchy for this group" (Zaher et al., 2009: 141-142).

Myers (2011: 11ff.) responded narrowly to Zaher et al. (2009) by arguing that the aforesaid familial changes were unnecessary. He believed that "discussion is hampered and becomes confused when new taxonomies are generated from new (uncorroborated) phylogenetic hypotheses, especially when familiar 
groups are renamed and redefined in major ways" (Myers, 2011: 12). As a practical reason for retaining Colubridae, sensu lato, Myers (2011: 13) noted that he could not unambiguously assign the new genus Amnesteophis to any of four subfamilies to which he had compared it.

We agree with Zaher and others that sound classification should reflect phylogeny, but we disagree fundamentally as to whether taxonomy needs to be changed almost automatically with new phylogenetic insight. We value any insights provided by the molecular phylogeny generated by Zaher et al. (2009), but for practical reasons (sensu Myers, loc. cit.) we continue to recognize the Dipsadinae, Xenodontinae, and Colubrinae as subfamilies of Colubridae. We continue to use "colubrid" as a sort of common name for snakes in or closely related to members of these subfamilies. We follow Zaher (1999: 3) in using, for pragmatic reasons, the term "xenodontines" in quotes for many dipsadine and xenodontine genera of uncertain assignment, including some colubrids used herein for anatomical comparisons (e.g., Diadophis, Rhadinophanes, Taeniophallus).

It must not be thought that our few critical comments are directed solely at Zaher et al. (2009); we are suspicious of all phylogenies that are published rapidly in order to yield "provisional" taxonomies (e.g., Kelly et al., 2011; see fn. 17 herein). Although new genera and new species must be dealt with in a timely fashion, "provisional" higher-level classifications can and should compete among themselves before new taxonomies are accepted by biologists who actually use them. Nonsystematists need at least "provisional" stability; we find it admirable when authors of molecular phylogenies (e.g., Vidal et al., 2008) decline to make taxonomic decisions straightaway whenever data are insufficient for resolving lineages adequately. Snake taxonomy remains unstable and more than ever it is in a state of change, and so should be approached as flexibly and as conservatively as possible.

The new taxa are named and described forthwith. Additional global comparisons relevant to the taxonomy and intensive discussion, including resurrection of a few previously named cryptic species, are given in sections following.

\section{DESCRIPTIONS OF NEW AND REASSIGNED TAXA}

Colubridae Oppel, 1811: 50 (as “Colubrini”)

Xenodontinae Bonaparte, 1845a: 377; 1845b: 4 (as

"Xenodontina")

\section{Eutrachelophiini, new tribe}

Type Genus: Eutrachelophis, new genus.

CONTENT: One genus with three species from western and middle Amazonia (map 1).

Definition And Diagnosis: Distinguished from all other snakes by the generic definition below. Tribal status is conferred primarily to express hypothesized relationship with the Xenodontini, which are defined mainly by the presence of hemipenial apical discs (lost in a few species as demonstrated herein). The Eutrachelophiini and Xenodontini have hemipenes (divided except in one species) with noncapitate capitula ornamented solely with spines and spinules and with the apices either nude or spiny; the sulcus spermaticus is divided proximally, with branches centrifugal or becoming so. Most "xenodontine" genera are characterized by hemipenes that are distally calyculate or flounced, frequently with some form of capitation. Few other genera of "xenodontines" are characterized by acalyculate spiny hemipenes.

REMARKS: The new tribe Eutrachelophiini is assigned to the Xenodontinae primarily on the basis of hemipenial comparisons with a cluster of genera (tribe Xenodontini) that includes Liophis and the type genus Xenodon. Relationships among the various genera remain to be clarified.

\section{Eutrachelophis, new genus}

TyPE SPECIES: Eutrachelophis bassleri, new species.

ETYMOLOGY: The intended meaning of the generic name is "beautiful-necked snake." It is compounded from the prefix $e u$ - (beautiful) + trachelos (neck) + ophis (a serpent), all from the Greek. Gender masculine.

Content: Two named species, as described or redescribed below: Eutrachelophis bassleri, new species, E. steinbachi (Boulenger, 


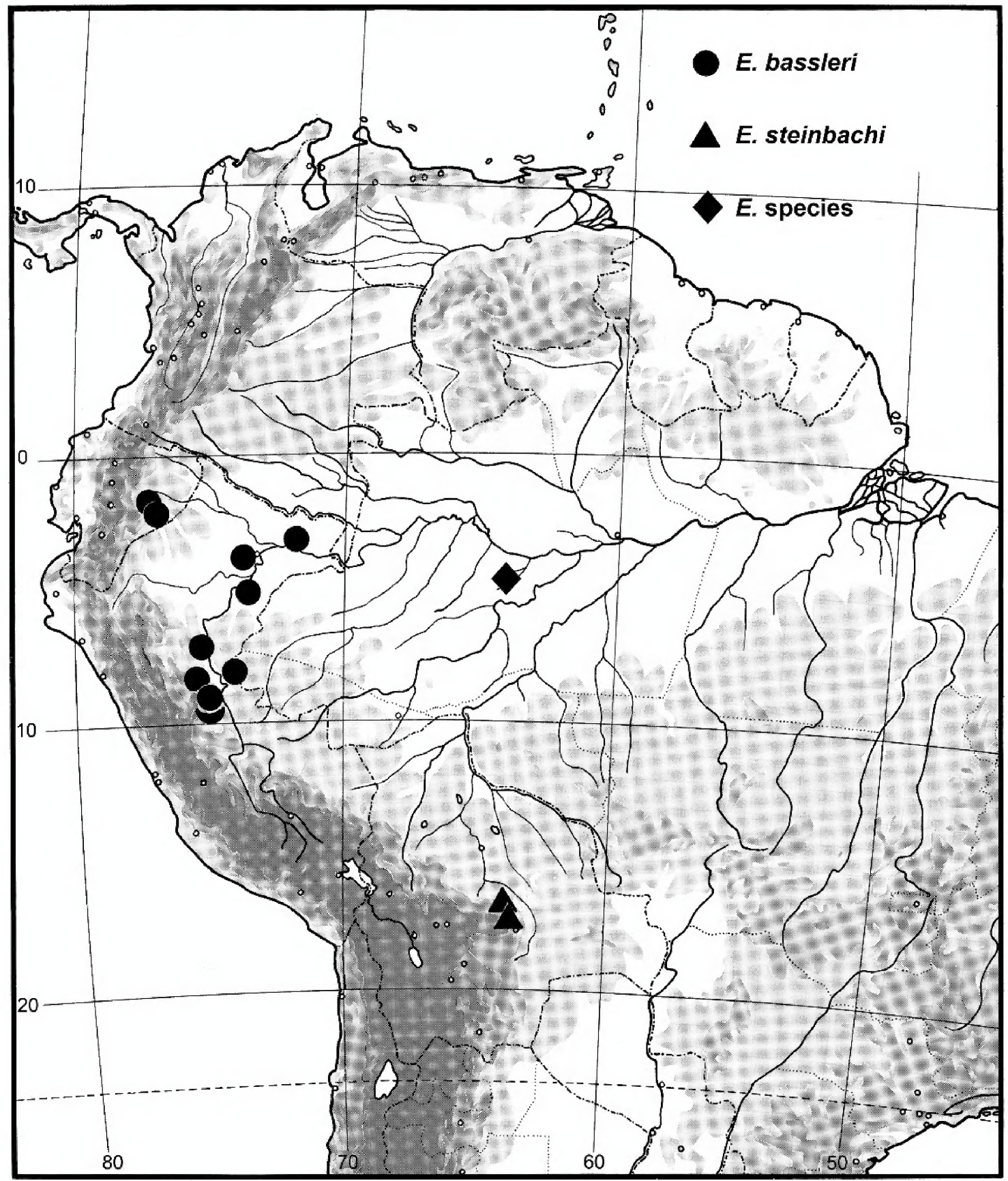

Map 1. Locality records for three species of Eutrachelophis, new genus, in western and middle Amazonia.

1905), new combination. A new species related to $E$. bassleri awaits description.

Definition AND Diagnosis: Small terrestrial colubrids lacking hypapophyses (hemal keel present) on posterior trunk vertebrae. High number (about 25-30) of prediastemal maxillary teeth followed by diastema and two enlarged, ungrooved teeth (the last offset 
laterad $\left.^{1}\right)$; differentiated rear maxillary teeth not accompanied by correspondingly conspicuous differentiation of Duvernoy's gland. Spiny hemipenis either divided, with spines to apices of lobes, or single with distal nude area; hemipenis lacking calyces, flounces, or apical discs; sulcus spermaticus forked proximally, with branches centrifugal (at least when organ is everted). Eye large, with round pupil. Habitus slender, with smooth dorsal scales in 15-15-15 rows; single scale pits present or absent; no anal ridges. Normal complement of colubrid head plates; $<150$ ventrals; anal plate divided, $<90$ subcaudals, paired. Color pattern with black-rimmed pale ocelli or elongated spots on head or on head and neck; dorsum with dark stripes or spots anteriorly, becoming nearly uniform posteriorly.

The above combination of traits is unique. Externally, the species of Eutrachelophis are readily differentiated from most other New World snakes by the combination of 15 dorsal scale rows and the presence of conspicuous ocellar markings on head or on head and neck. There may be a vague resemblance in pattern with some specimens of the variable Taeniophallus occipitalis, which also has 15 scale rows, but occipitalis differs in having a white canthal line (fig. 15B), more ventrals $(>160)$, fewer maxillary teeth (about $13-17+2$ ), and a calyculate hemipenis.

DisTRIBUTION: Lowland rain forest, in western Amazonia - in Ecuador, Peru, Bolivia-and middle Amazonia in Brazil (map 1).

\footnotetext{
${ }^{1}$ That is, offset laterad from a straight line through the posterior several teeth or offset laterad from a line from the last "prediastemal" tooth to the first enlarged tooth (Myers, 1974: 28; 2011: 9-10, 27-28). Posteriorly offset teeth, whether grooved or not, characterize most "xenodontines," although there is great variability in maxillary shape and the first enlarged tooth ("fang") sometimes may better be described as offset mediad to the general line of the tooth row. Presence or absence of a diastema often is diagnostic, but in occasional "xenodontines" (e.g., Rhadinaea decorata) it also seems to be correlated with the total number of maxillary teeth. The offset of the ultimate enlarged tooth ("fang") is relatively slight in Eutrachelophis.
}

Eutrachelophis bassleri, new species Figures 1-3, 10

Leimadophis sp., Dixon and Soini, 1977: 54. cf. Liophis sp., Dixon and Soini, 1986: 114-115.

HolotyPe: AMNH R-52926, an adult male from Pisqui Hills, [upper] Río Pisqui, Province of Loreto, Peru, obtained by Harvey Bassler on January 15,1927 . The type locality is situated west of the Río Ucayali in the region of $8^{\circ} 00$ $8^{\circ} 22^{\prime} \mathrm{S}, 75^{\circ} 30-75^{\circ} 50^{\prime} \mathrm{W}$ (see Remarks). This specimen (fig. 1A) is in good condition except that the maxillae and mandibles have been dissected out (possibly by Bassler), although still associated with the specimen. Total length $345 \mathrm{~mm}$, tail length $101 \mathrm{~mm} ; 2$ preventrals (gulars wider than long), 133 ventrals + half ventral at anal plate, 67 pairs of subcaudals not counting terminal spine.

PARATYPes (11): ECUADOR: Pastaza Province: mouth Río Pucayacu, between Sarayacu and Montalvo, USNM 232826 (R. Olalla, Aug. 1948); Sarayacu, Río Bobonaza, USNM 232825 (R. Olalla, Nov. 1962). PERU: Huánuco Province: [Río] Pachitea, AMNH R-52682 (H. Bassler, date?); Serranía de Sira, ridge above Río Llullapichis, $510 \mathrm{~m}$ $\left(9^{\circ} 29^{\prime} \mathrm{S}, 74^{\circ} 49^{\prime} \mathrm{W}\right)$, NMW 31795 (M. Henzl and B. Wallnöver, May 20, 1988). Loreto Province: Mishana, TCWC 40555, 41424, 41425 (P. Soini; collected over an eight year period fide Dixon and Soini, 1986: 114); Pampa Hermosa, Río Cushabatay, AMNH R-55786 (H. Bassler, Sept. 1927); ${ }^{2}$ Pebas, Río Ampiyacu, 250 ft., AMNH R-25193 (collector?); Río Tapiche, AMNH R-52441 (H. Bassler, Jan. 1928); upper Río Utuquinia, AMNH R-53473 (H. Bassler, Feb. 1928).

ETYMOLOGY: The species is named in memory of Harvey Bassler (1883-1950), a former Research Associate in the American Museum's Department of Herpetology. Bassler accumulated five of the 12 known specimens of this rare species during a decade devoted to petroleum exploration and zoo-

\footnotetext{
${ }^{2}$ A catalog later compiled by Bassler at the American Museum bears an unexplained note indicating that this and three other snakes "may" have been obtained on the upper Río Marañón in September 1924. The Pampa Hermosa record is more in keeping with Bassler's other Eutrachelophis records (all in Río Ucayali drainage) for this species, however, and it is the one plotted on the distribution map.
} 
A
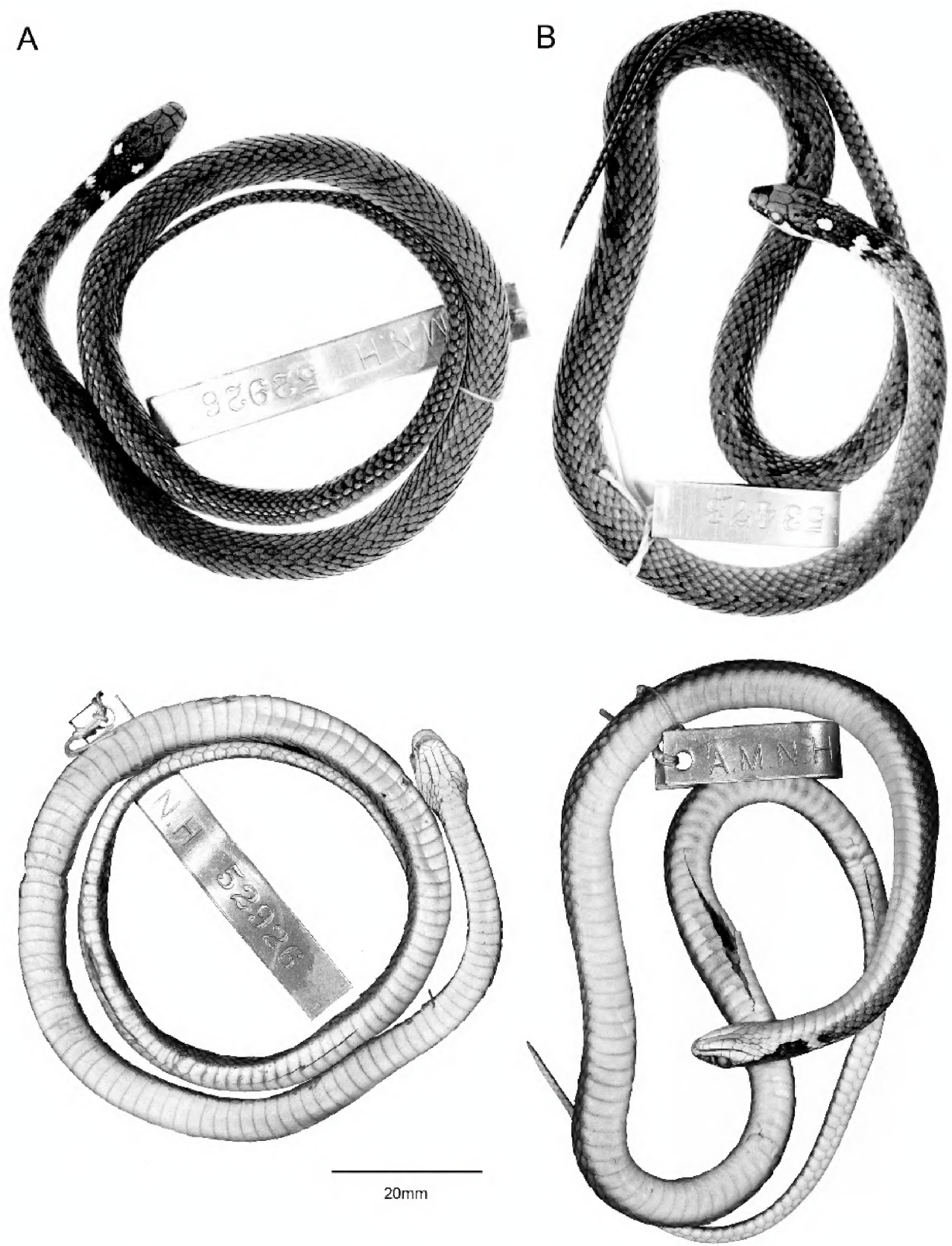

Fig. 1. Eutrachelophis bassleri, new species. Dorsal and ventral views of adult specimens: A. AMNH R52926 (male holotype), from upper Río Pisqui, Peru. B. AMNH R-53473 (female paratype), from upper Río Utuquinia, Peru, near border with Brazil. The conspicuous nuchal markings are "cream" or "yellow" in life. Specimens shown life size. 
logical and ethnographic collecting in eastern Peru. ${ }^{3}$

DiAgNosis: Eutrachelophis bassleri is a small snake $(<400 \mathrm{~mm}$ total length) that resembles the somewhat larger E. steinbachi (to $558 \mathrm{~mm}$ ) in having 15 dorsal scale rows and conspicuous paired ocelli on the nape. It differs from steinbachi in having a postocular wedge of pale color extending dorsad from the lip, and in having a pale broken, posterior collar (the rounded upper ends of which often resemble a second pair of ocelli when viewed from above), and in lacking oblique pale dorsolateral markings touching the eye. E. bassleri further differs in having dorsolateral lines of vague dark spots (or fused crossbars) rather than dark anterior stripes; a lateral line of pale dashes or dots lies on scale row 4 in bassleri, on row 6 in steinbachi. Eutrachelophis bassleri differs radically from steinbachi in having an undivided hemipenis with a nude, dome-shaped apex.

DISTRIBUTION: Lowland rain forest in the western part of the Amazonian basin (map 1). Known localities for Eutrachelophis bassleri range from Pebas, Peru, on the upper Amazon River, northwestward to east-central Ecuador in the Río Bobonaza drainage, and southward in Peru through the Río Ucayali drainage to nearly $10^{\circ} \mathrm{S}$. The species probably occurs also in extreme western Brazil and possibly in southern Colombia. There is an unnamed, clearly related species in central Amazonia, Brazil (see comments and illustration under Eutrachelophis species following Remarks).

\section{Description of Type SPECIMENS}

Eutrachelophis bassleri is a small slender snake that probably is sexually mature by

\footnotetext{
${ }^{3}$ Harvey Bassler was a petroleum geologist who spent a decade (1921-1931) exploring the upper tributaries of the Amazon, all the while making a magnificent herpetological collection, including 4200 snakes. His base of operations for upriver expeditions was Iquitos, where specimens were also obtained. He brought his collection to the American Museum in 1934, where he worked on his snakes up to World War II, when he was called away by the U.S. Government to work on the urgent need to increase rubber production in the Amazon Basin, Bassler left no scientific publications, but his collections have been repeatedly mined over the years and continue to provide new insight. (Bassler, ms.; Myers, 2000: 139-141).
}

$300 \mathrm{~mm}$ total length, with a maximum known length of $377 \mathrm{~mm}$. Following is a combined description of the 12 specimens in the type series.

Proportions and Scutellation: Head wider than high and wider than neck; eye large, its diameter greater than distance from its anterior edge to nostril in adults (relatively larger in juveniles, which have eye diameter $>$ distance to snout tip). Body slender, slightly higher than wide, with rounded ventrolateral edges; tail slenderly tapering. Less than $400 \mathrm{~mm}$ total length, with tail comprising $27 \%-30 \%$ of the total. Five adult males $320-377 \mathrm{~mm}(\overline{\mathrm{x}}=$ $350.8 \mathrm{~mm}$ ) total length, tail/total length $0.281-$ $0.296(\overline{\mathrm{x}}=0.2894)$; two adult females 339 and $369 \mathrm{~mm}$ total length, tail/total $0.268,0.271$. Smallest specimen with complete tail, $160 \mathrm{~mm}$ total length (42 mm tail), a juvenile male with threadlike vasa deferentia and unenlarged kidney tubules. Two subadults approaching maturity at $245 \mathrm{~mm}$ ( ( ) ) and $259 \mathrm{~mm}$ ( 8 ) total length, as evidenced by enlarging ova in the female and enlarging vasa deferentia and kidney tubules in the male.

Dorsal scales smooth, in 15-15-15 rows; anal ridges lacking; a few specimens with single apical pits (situated either medially or off center) discernible on some scales, especially on neck. Ventral plates 128-139 (8 males $128-138, \bar{x}=133.3$; 4 females $134-139$, $\overline{\mathrm{X}}=136.8)$. Anal plate divided. Subcaudals in $62-70$ pairs ( 7 males $65-70, \overline{\mathrm{x}}=67.9 ; 3$ females $62-66, \bar{x}=63.7$ ).

Rostral plate wider than high, tipped forward, readily visible from above. Internasal and prefrontal plates paired, each prefrontal laterally in contact with nasal, loreal, and preocular. Supraocular large, about as long as frontal and more than half as wide. Frontal pentagonal or slightly hexagonal, about two times longer than wide, longer than distance to snout. Interparietal suture shorter than length of frontal. Loreal higher than wide, variable in shape (e.g., tipped forward and rhomboidal, or vertical and rectangular). One high, narrow preocular, rarely two preoculars (on one side only in two specimens); two postoculars, the lower one varying in size, distinctly smaller than or nearly equal to the upper. Temporals $1+2$ in eight specimens; two other individuals with this basic pattern but having the primary and 

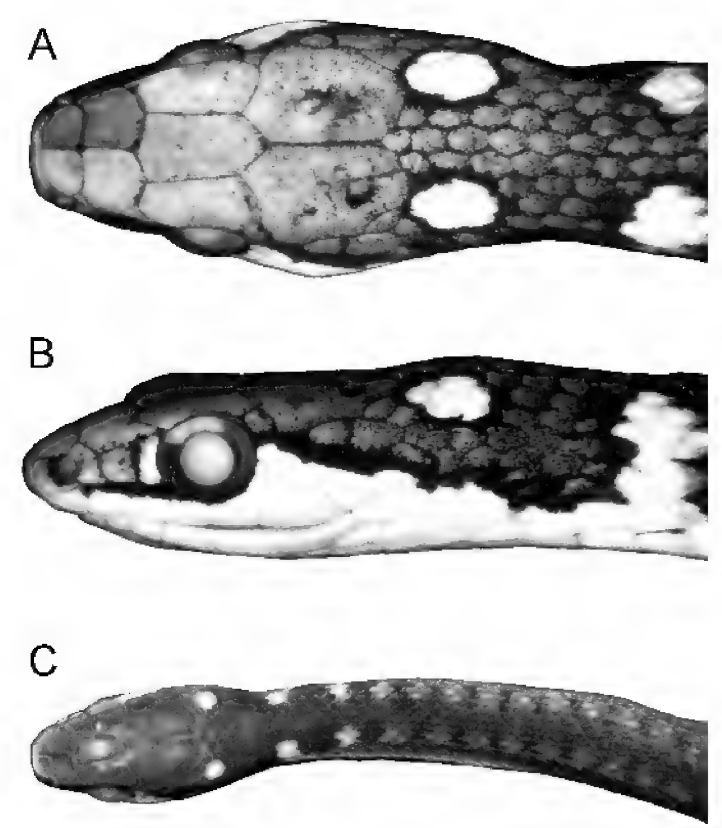

Fig. 2. Heads of Eutrachelophis bassleri, new species. A, B. AMNH R-53473, adult female (369 $\mathrm{mm}$ total length), in dorsal and lateral view, $\times 3.9$. C. TCWC 41425, juvenile male $(160 \mathrm{~mm}$ total length), $\times 2.5$. In addition to the white or yellow nuchal markings, the postocular extension of white or yellow labial color (B) is diagnostic of $E$. bassleri and its unnamed sister species (cf. fig. 4); the white preocular bar is present or absent in E. bassleri.

upper secondary temporals fused into one long scale; one specimen with $1+1+1 / 1+1$ (left/right) temporals. Eight supralabials $(8 / 7$ in one), with labials 2 (usually) or 2-3 touching loreal and 3-5 bordering eye. Eight, nine (usually), or rarely 10 (one with 10/9) infralabials, of which $1-4$ (if only 8 infralabials) or 1-5 touch anterior genials and 4-5 or 5-6 touch posterior genials. First infralabials in contact behind mental except in one juvenile, where widely separated. Anterior and posterior genials long and narrow, subequal. Tiny, inconspicuous tubercles (presumed sensory organs) on head plates and chin.

Color And PAttern in Preservative: Brown or gray-brown above-gray after loss of stratum corneum-with head and neck usually darker than body for length of 9-11 scales behind parietal plates. A pair of conspicuous, black-rimmed white ocelli atop nape, occupying parts of several dorsal scales (usually not including a complete scale) just behind each parietal plate. A second pair of often conspicuous albeit incomplete ocelli situated farther back, dorsolaterally at about level of ventrals 4-5; in lateral view these markings are seen to be the expanded, rounded dorsal ends of an incomplete white collar that is medially broken by a space of several dorsal scales (fig. 2B). ${ }^{4}$ Most of rostral plate and supralabials immaculate white, this color extending dorsad as a triangular wedge just behind each eye (a rectangular wedge in one juvenile); a black streak across tops of anterior supralabials, extending thinly under and up behind eye, then becoming wider and dropping obliquely along the white postocular wedge to lower side of neck (fig. 2B). A few specimens with a vertical white preocular bar (fig. 2B), but this region dark in most. One juvenile with an illdefined whitish blotch on frontal plate and a pair of vague whitish parietal blotches (fig. 2C).

A pair of dorsolateral lines of irregular and often vague black spots, spaced about every other scale, mainly on scale rows 6 and/or 7 on each side (fig. 1). Aforesaid dark spots not always discernible throughout body and virtually absent on some specimens (possibly due to method of preservation); often largest behind the broken collar cum ocelli on neck, where spots may fuse into vague dark crossbars that, in some juveniles, may separate vague dorsolateral pale spots (fig. 2C). A lateral line of white dashes or dots on scale row 4, sometimes weakly indicated along side of neck but more often nearly confined to rear half of body, where the pale dashes are accentuated by black pigmentation along their lower edges. Inconspicuous dorsolateral dark spots (when present) and lateral line of pale dashes extending onto tail for most of its length. Dark body color encroaching slightly onto sides of ventrals and subcaudals. Ventral surfaces immaculate pale yellow or white.

\footnotetext{
${ }^{4}$ This feature may be geographically variable. The dorsal ends of the broken collar are narrow in the two paratypes from Ecuador-not conspicuously rounded as in the Peruvian specimens.
} 
COLOR IN LIFE: Based on a few color notes quoted below, this is a prettily colored snake in life, with black head and nape bearing conspicuous white or yellow ocellar markings; white or yellow lips and a triangular postocular marking; ventral surfaces cream or changing from white to yellowish. Body and tail in at least one individual sea green anteriorly, then reddish brown, and grayish brown posteriorly.

Dixon and Soini (1977: 54; 1986: 115) published color notes on one or more of the three paratypes from Mishana, Peru.

Dorsum light brown with dorsolateral pair of small black spots from posterior body to tail tip; an irregular yellowish, dotted lateral line on 4th scale row, bordered below by black; venter and subcaudals cream; extreme edge of ventrals with grayish black flecks; top of head black, lips bright yellow; yellow triangular spot behind eye; pair of yellow spots behind parietals; incomplete yellow nuchal collar.

Eye color was not given, but some preserved specimens retain a pattern of a pale upper sector that is distinct from the dark lower part (fig. 2B); see also below.

Martin Henzl (letter, March 17, 1990) kindly provided the following color notes on a Peruvian specimen (NMW 31795) collected on a ridge above the Río Llullapichis, in the Serranía de Sira.

Head and nape black, upper lips white, small white triangle laterally behind eyes, pair of dorsolateral cream spots on occiput, another pair of similar spots on the nape contacting the white ventral color in a small channel. Anterior third of body sea-green, second third of body reddish brown, posterior third and tail grayish brown. Indistinct dark paravertebral blotches that soon join in a zigzag stripe becoming more and more indistinct posteriorly; thin light lateral stripe from midbody onto tail. Chin and anterior third of venter white, posterior twothirds and underside of tail yolky yellow. Iris dark brown with bronze blotch in upper part; oral cavity greyish, tongue dark with pink tips.

\section{HEMIPENIS}

RETRACTED ORGAN OF EUTRACHELOPHIS BASSLERI: The following description is based on the uneverted left hemipenis of AMNH
R-55786, which was opened by midventral incision and then removed and pinned flat for illustration (fig. 3A). Data also were taken from the uneverted right organ of TCWC 41424, which was examined in situ.

Major retractor muscle originating at level of subcaudals 27 or 28 , and anteriorly inserting without division on end of single (unbifurcated) hemipenis at level of subcaudals 10 or 12 . The distal fourth of the uneverted organ (fig. 3A) is a nude area of folded tissue - the proximal part of this area being somewhat puckered and the whole region apparently capable of considerable expansion. The midsection (about $40 \%$ of length of organ) is densely spinulate and less folded than the distal fourth, although the area between the branches of the sulcus spermaticus appears capable of greater expansion than the rest of the midsection. There is a densely spiculate section around the proximal part of the otherwise distal nude section. There are roughly 30 large to very small spines from the basal region distad into the densely spiculate area. ${ }^{5}$ The extreme base of the organ (proximal $10 \%$ ) is nearly nude, with only a few spinules. There are no basal spines obviously enlarged compared with the others and no basal naked pocket (sensu Myers, 1974: 32). The deeply incised sulcus spermaticus divides low on the organ and its branches terminate abruptly about two-thirds of the way onto the distal nude section. The sulcus lies mostly on the lateral wall of the uneverted organ (fig. 3A).

EVERTED ORGAN OF EUTRACHELOPHIS BASSLERI: The right hemipenis of AMNH R-25193 (paratype) was manually everted by Myers in the late 1970s, using the "Waite Gibson Technique" later described in Myers and Cadle (2003: 299). The distal nude section (fig. 3A) everted as a domelike head or capitulum that lacks a free overhanging edge (fig. 3B-D). The dome is nude, except for branches of the sulcus spermaticus and except proximally, where it is densely spiculate as seen in the retracted organ (fig. 3A). Owing to differential tissue expansion, the

\footnotetext{
${ }^{5}$ Tiny, usually mineralized, hemipenial spines are commonly called "spinules," but spicules and spiculate seem to be more appropriate terms for these even tinier structures that also are mineralized (they can be "felt" with a very fine teasing needle and transiently stained with Lugol's iodine solution).
} 

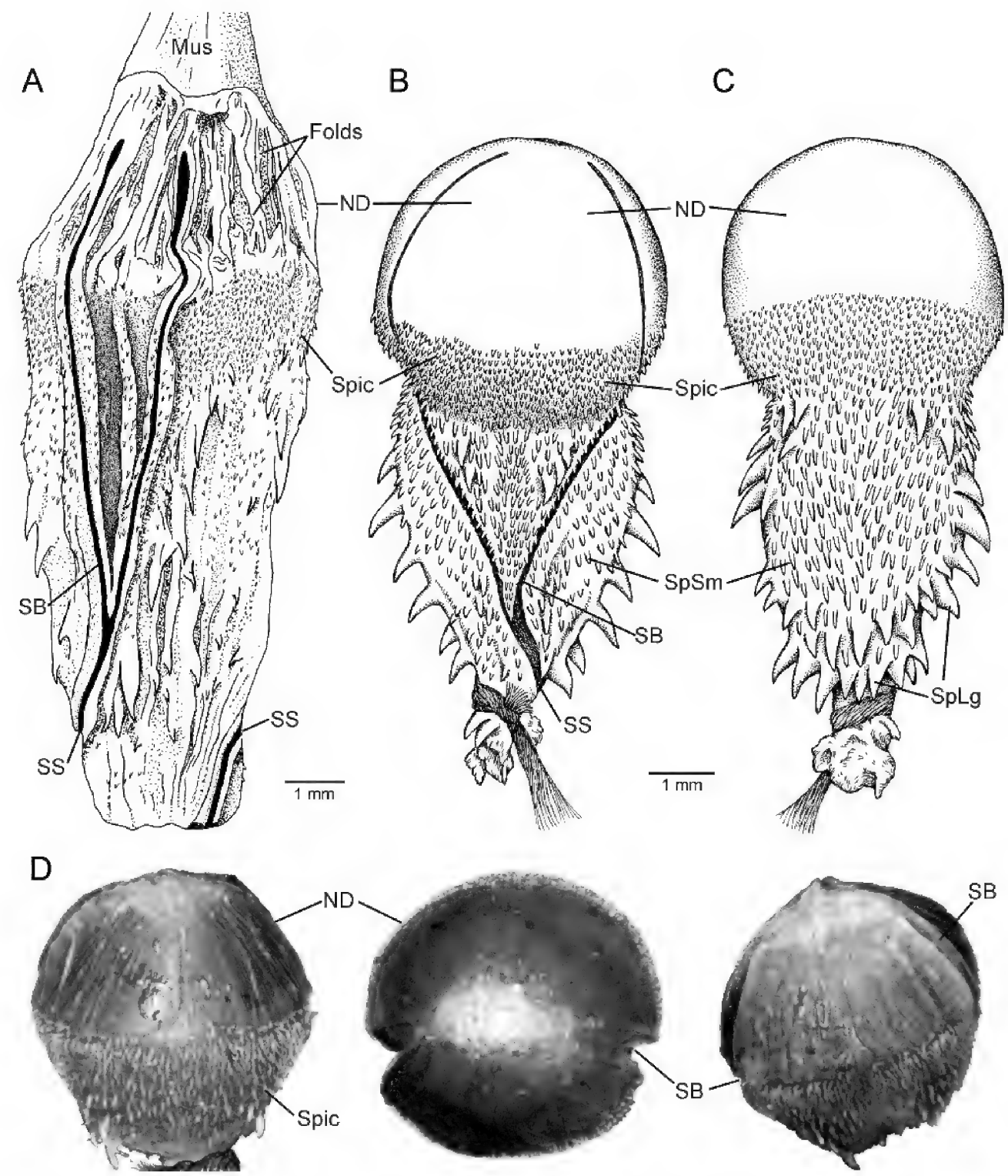

Fig. 3. Hemipenes of Eutrachelophis bassleri, new species. The distal nude section is greatly distensible, becoming hemispherical on eversion. Because of differential tissue expansion, the close-lying branches of the sulcus spermaticus diverge and acquire a centrifugal orientation, entering onto the nude dome from nearly opposite sides of the everted organ. A. Uneverted left hemipenis of AMNH R-55786 (paratype), opened by midventral incision. B. Everted right hemipenis in sulcate view, AMNH R-25193 (paratype; depiction of the manually everted organ). C. Same organ as in B, in asulcate view. D. Distal half of everted hemipenis showing appearance of the maximally inflated, mostly nude dome, from left to right: asulcate side, apex, and sulcate side. Left organ of TCWC 41424, paratype. (This organ previously had been manually turned inside out, but, because the base had been badly damaged, only the distal half was tied off and injected with petroleum jelly in an attempt to determine maximum inflation). Abbreviations: Folds, expansion folds; Mus, major retractor muscle; ND, nude dome; SB, a branch of the sulcus spermaticus; SS, sulcus spermaticus (proximal to bifurcation); Spic, densely spiculate area below and around base of nude dome; SpLg, large lateral and basal spines; SpSm, small spines on sulcate and asulcate faces. 
sulcus branches acquired a centrifugal orientation upon hemipenial eversion, entering onto the bulbous dome nearly from opposite sides of the organ (see figs. 3B, D). There are no greatly enlarged spines, only relatively large spines that are positioned laterally and basally, with numerous small spines or spinules on the sulcate and asulcate sides of the hemipenial body (fig. 3B,C).

The left organ of TCWC 41424 had been manually turned inside out prior to our examination, and, although the base had been torn in the process, it was possible to tie off and temporarily inflate the distal half (see views in fig. 3D). This partly everted hemipenis appears to have the apical nude dome fully expanded, although manually everted organs often do not retain their original elasticity (Myers and Cadle, 2003: 295, 300).

Skull AND Dentition: The skull was removed from AMNH R-55786. See figure 10 and text under Global Comparisons. Ten maxillae in 10 specimens bear $26-29(\overline{\mathrm{x}}=$ 27.3) small, subequal teeth, followed by a distinct diastema and two ungrooved fangs, the last fang slightly offset laterad. The maxillary fangs are about twice as large as the prediastemal teeth and are further differentiated by having knifelike rear edges. AMNH R-55786 has 19 palatine teeth, followed by about 30-31 pterygoid teeth; 34 dentary teeth. The holotype has 32 (right) or 34 (left) dentary teeth on the previously excised mandibles.

Vertebrae, Head Muscles, Glands, AND VISCERA: See under Global Comparisons.

\section{REMARKS}

The general location of Bassler's "Pisqui Hills" - the type locality of Eutrachelophis bassleri - can be determined from an unpublished report (Bassler, MS.). Bassler first explored and mapped the Río Pisqui in 1923, traveling $186 \mathrm{~km}$ by river from its mouth (149 m elev.) to the head of canoe navigation $(259 \mathrm{~m})$, followed by an additional $18 \mathrm{~km}$ on foot beyond the first cataractsa straight-line distance of $93 \mathrm{~km}$ by Bassler's careful reckoning. He determined latitude and longitude as $7^{\circ} 42^{\prime} \mathrm{S}, 75^{\circ} 00^{\prime} \mathrm{W}$ at the mouth of the Río Pisqui and as $8^{\circ} 22^{\prime} \mathrm{S}$, $75^{\circ} 30^{\prime} \mathrm{W}$ at the end of his traverse; it may be noted that the first set of coordinates agrees within a few minutes to recent maps and gazetteers. Bassler described the first $45 \mathrm{~km}$ (by river) as "a flood plain subject for the greater part to a period of inundation each year and the channel here is not permanent for lateral erosion is active." Upriver, "this recent flood plain merges into a plain determined by firmer though still practically unconsolidated sediments and here the channel is deeper and appears to change very little even over long periods of time." Somewhere on this upper plain Bassler wrote that,

hills $200 \mathrm{ft}$. high were observed but between these and the mountains [to westward] the hills are usually under $100 \mathrm{ft}$ in altitude above the general level of the plain. Beyond the plain the mountains [evidently the northern end of Cordillera Azul, an Andean front range] rise abruptly with stupendous cliffs and a very rugged skyline, with relief of $3000 \mathrm{ft}$. or more.

The $200 \mathrm{ft}$-high $(60 \mathrm{~m})$ hills on the higher flood plain of the upper Río Pisqui must certainly be what Bassler gave as "Pisqui Hills" for specimens collected on this and subsequent trips, and the locality can with confidence be placed within the area bounded by parallels $8^{\circ} 00^{\prime}-8^{\circ} 22^{\prime} \mathrm{S}$ and meridians $75^{\circ} 30^{\prime}-75^{\circ} 50^{\prime} \mathrm{W}$.

\section{Eutrachelophis, undescribed species Figure 4}

In 1993, the late Paulo E. Vanzolini sent to Myers what he recognized as a new species of snake from Cabeceira do Rio Urucu, Amazonas, Brazil. It clearly is closely related to Eutrachelophis bassleri and seemed likely to be a different species. But it could not be so identified with assurance because (1) ocellar head and neck patterns in Eutrachelophis and other genera are somewhat variable, and (2) because it is a female collected at about $5^{\circ} \mathrm{S}, 65^{\circ} \mathrm{W}$-far to the east of known bassleri localities (see map 1). Ana Lucia C. Prudente fortunately has obtained additional material that she will describe separately.

\section{Eutrachelophis steinbachi (Boulenger), new combination Figures 5-9, 11-12}

Rhadinaea Steinbachi Boulenger, 1905: 454 (two syntypes, female and young, from "the Province 

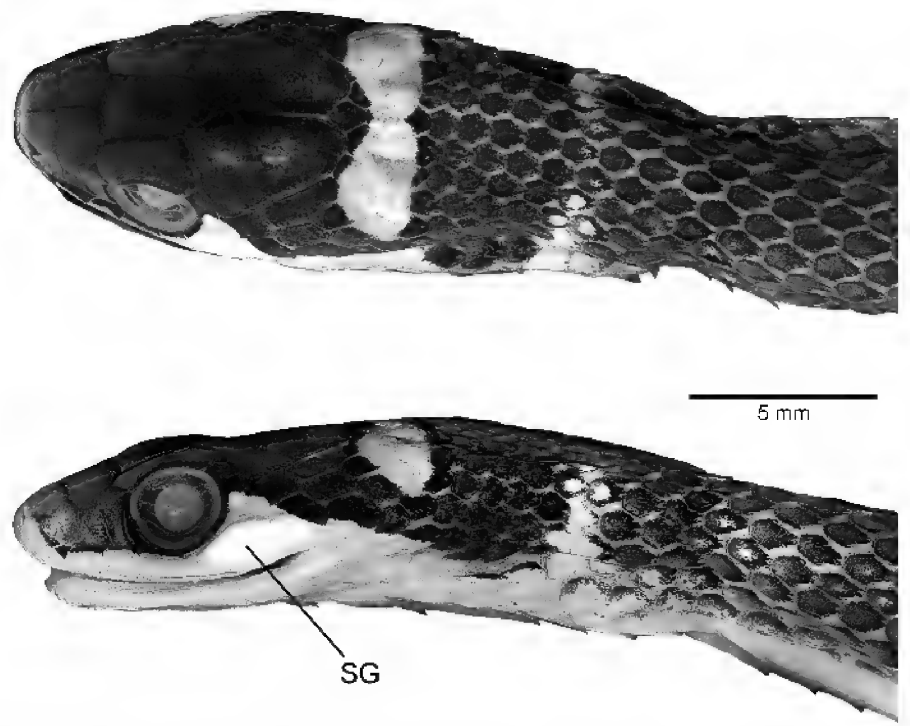

Fig. 4. Eutrachelophis species (MZUSP 10530, head in dorsal and lateral view; a female from Cabeceira do Rio Urucu, central Amazonian Brazil). This unnamed snake appears to be the sister species of $E$. bassleri. See Remarks and compare with figure 2. Formalin preservation caused the integument of this specimen to become slightly translucent, giving visibility to a large "supralabial" gland (SG); this large gland (similarly positioned in all three species of Eutrachelophis) is adherent to the medial side of the supralabial integument. The mucous and serous (Duvernoy's) parts of the gland cannot be distinguished in Eutrachelophis without histological examination.

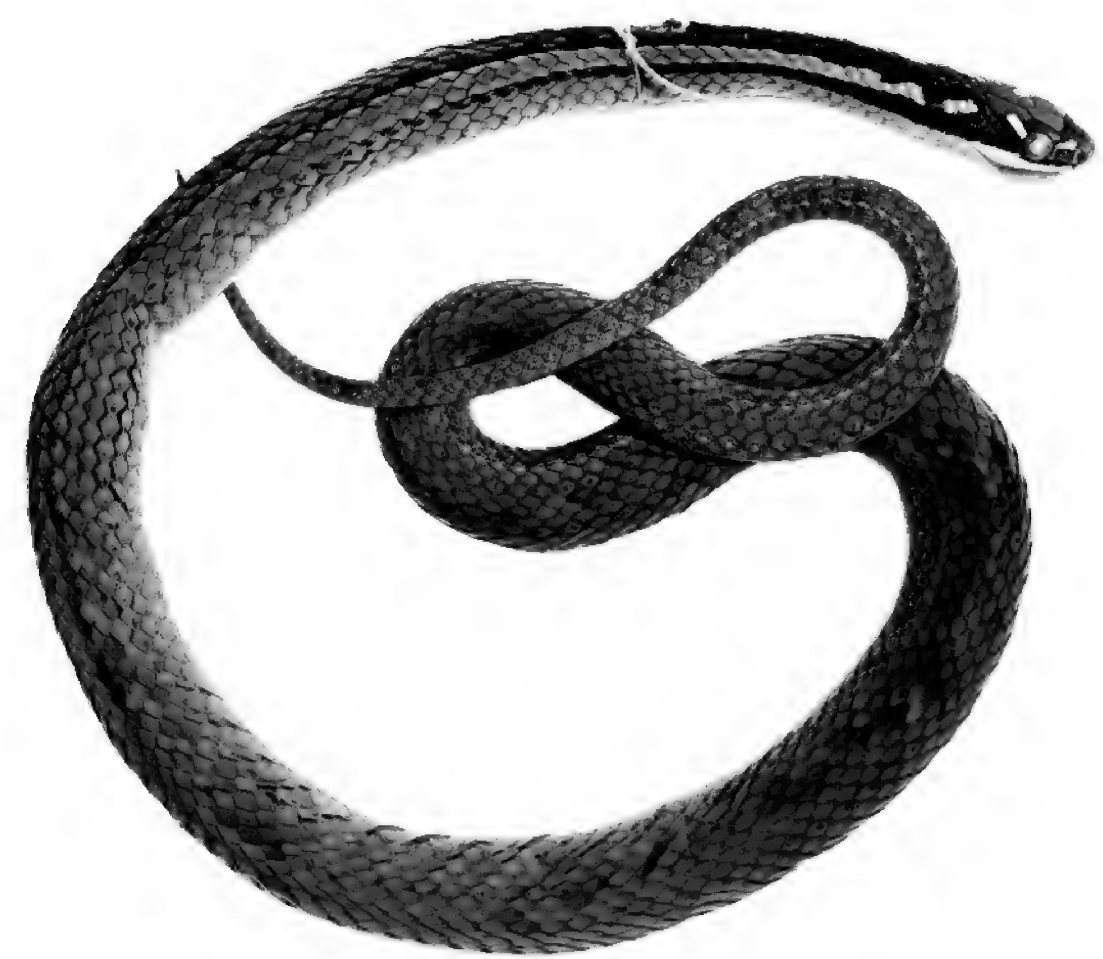

Fig. 5. Eutrachelophis steinbachi (Boulenger). Adult female shown approximately life size (BMNH 1946.1.21.62, lectotype by present designation). 


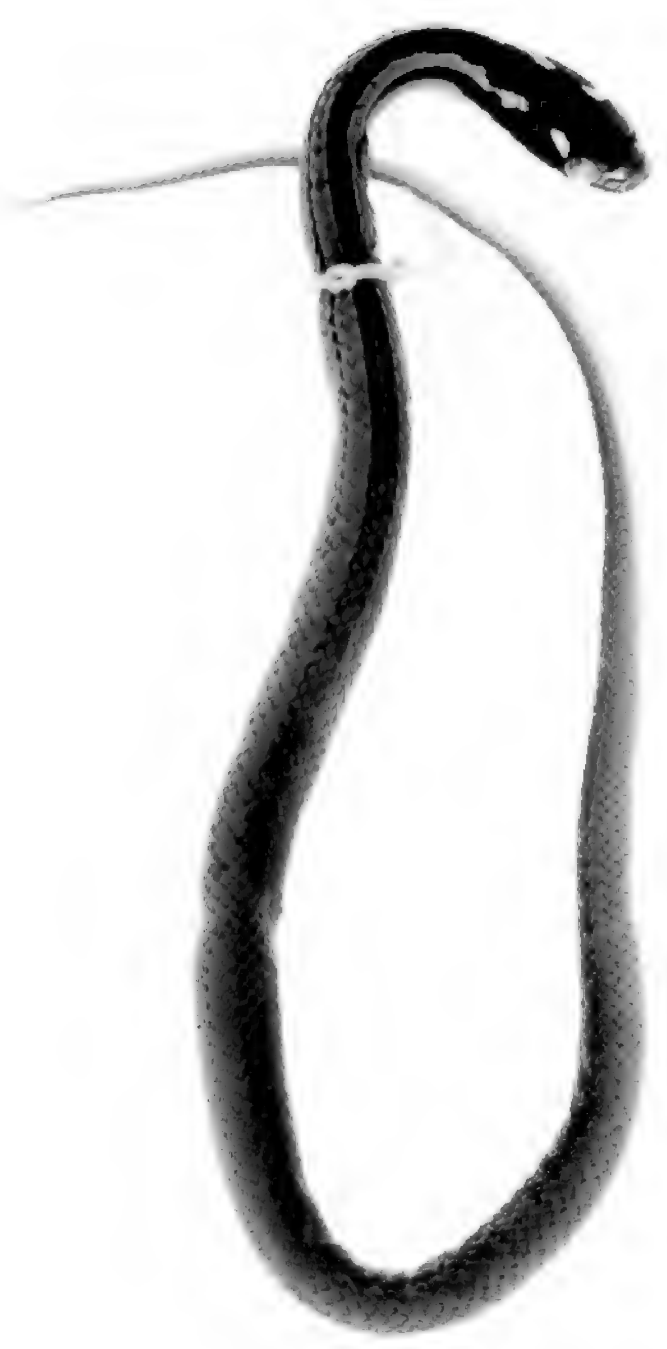

Fig. 6. Eutrachelophis steinbachi (Boulenger). The paralectotype (BMNH 1946.1.21.63), a juvenile male shown $1.6 \times$ life size.

Sara, Department Santa Cruz de la Sierra, collected by Hr. J. Steinbach").

Aporophis melanocephalus Griffin, 1916: 171-172

(holotype CM R-18, "a female, taken at Las Juntas, Bolivia, 250 M. above sea-level, by José Steinbach in December, 1913").

Rhadinea steinbachi Boulenger: Dunn, 1922: 220 (Aporophis melanocephalus placed in synonymy).

Liophis steinbachi (Boulenger): Amaral, "1929b" [1930]: 174. Peters and Orejas-Miranda, 1970: 179. Myers, 1974: 22 (comment on unsatisfactory generic assignment); Myers and Cadle, 1994: 2. Dixon, 1980: 15, 20 (listed as incertae sedis).

Rhadinea steinbocki (misspelling): Clark, 1945: 428 (mention of hemipenis).
LECTOTYPE: The lectotype (fig. 5) by present designation is BMNH 1946.1.21.62, one of the two original syntypes. It is an adult female $558 \mathrm{~mm}$ total length ( $150 \mathrm{~mm}$ tail length), with one preventral, 140 ventrals, 67 subcaudals. The second syntype (paralectotype) is BMNH 1946.1.21.63, a juvenile male (fig. 6).

DiAGNOSIS: Eutrachelophis steinbachi is like E. bassleri in having 15 dorsal scale rows and a usually conspicuous pair of ocellar markings $^{6}$ on the nape. It is a larger snake (to $558 \mathrm{~mm}$ total length) than bassleri $(<400 \mathrm{~mm})$ and is readily differentiated by details of color pattern. E. steinbachi has a pair of oblique pale markings touching the upper anterior and upper posterior edges of the eye (both lacking in bassleri), and the dark head color extends onto the neck as unbroken dorsal and lateral stripes. E. steinbachi lacks the broken, ocellarlike nuchal collar (present in bassleri). A lateral line of pale dashes, where present, lies on scale row 6 in steinbachi, on row 4 in bassleri. E. steinbachi differs absolutely in having a divided hemipenis with spinose tips.

DISTRIBUTION: Eutrachelophis steinbachi is known only from a small section of central Bolivia near the eastern base of the Cordillera Oriental, at elevations of perhaps $250-500 \mathrm{~m}$ (map 1). Its habitat has not been recorded, but presumably it is a forest species.

SPECIMENS EXAMINED: All 12 specimens seen by us were obtained by the Bolivian collectors José Steinbach and his son Francisco Steinbach over a span of years (circa 1904-1928); these were sold to several museums. Museum data for these and one additional specimen (13 total) follow (see Remarks for commentary): BOLIVIA: no data, FMNH 35662 (F. Steinbach). Department Santa Cruz: no other data, UMMZ 69550; Buena Vista, no elevation, FMNH 35641 (F. Steinbach, April-May, 1928); Buena Vista, $450 \mathrm{~m}$, AMNH R-125695, UMMZ 60736 (J. Steinbach, Nov. 1923 and Jan. 1924); Buena Vista, $500 \mathrm{~m}$, UMMZ 60734-60735 (J. Steinbach, May and Sept. 1923); Las Yuntas [= Las Juntas?], 50 m, CM

\footnotetext{
${ }^{6}$ In the variational repertory of $E$. steinbachi, the postparietal (nape) ocelli may lack dark edges posteriorly and be confluent with (but usually paler than) the light ground color between dorsal and lateral stripes (e.g., fig. 6).
} 


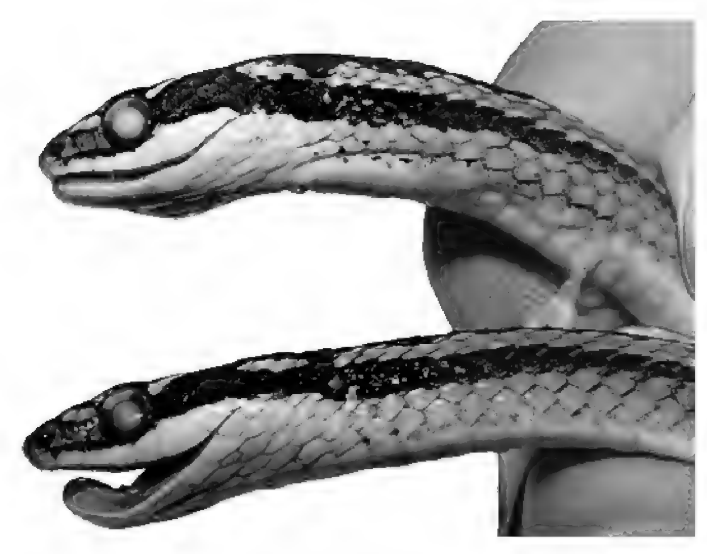

Fig. 7. Eutrachelophis steinbachi (Boulenger), handheld preserved specimens. Upper. A specimen (NMW 23106) cited as "syntypus" by Tiedemann and Häupl (1980: 61) but not mentioned in Boulenger's (1905: 454) original description. Lower. The syntype (BMNH 1946.1.21.63) designated lectotype in this paper (photograph courtesy of James R. Dixon).

R-18 (holotype of Aporophis melanocephalus, J. Steinbach, Nov.-Dec. 1913). Province Sara, BMNH 1946.1.21.62ㅇ, 1946.1.21.63 ( + lectotype and juvenile 8 paralectotype of Rhadinaea steinbachi, J. Steinbach, no date, received at BMNH Oct.17, 1904, fide A.F. Stimson, in litt.); Province Sara, Río Sirutu [= Río Surutú?], UMMZ 63216 (J. Steinbach, Jan. 1925).

AdDitional SPECIMEN: "Syntypus: NMW 23106 ( ̋) Bolivia; gekauft von ROSENBERG (?)" fide Tiedemann and Häupl (1980: 61). Only two BMNH specimens (see above) were mentioned in the original description, so this specimen certainly is not a syntype as stated; there seems also a question as to whether it was purchased from Rosenberg. The specimen is correctly identified, however, based on scale counts and photographs kindly supplied by J.R. Dixon (see fig. 7); some of Dixon's data on NMW 23106 are incorporated in the following description.

\section{DESCRIPTION}

Proportions AND SCUTEllation: Eutrachelophis steinbachi is a slender snake that attains a maximum known length of $558 \mathrm{~mm}$. Head wider than neck; eye large, its diameter greater than distance from its anterior edge to nostril, going about $1.3-1.5$ times into length of snout. Body higher than wide, with rounded ventrolateral edges; tail slenderly tapering. The only adult male having a complete tail is $454 \mathrm{~mm}$ in total length, with a tail/total length ratio of 0.313 ; the snoutvent length of this specimen is $312 \mathrm{~mm}$, which is exceeded by a broken-tail male of $345 \mathrm{~mm}$ SVL. Two adult females are 531 and $558 \mathrm{~mm}$ total length, with tail/total ratios of 0.273 and 0.269 , respectively.

Juveniles have relatively shorter tails: Two females are each $185 \mathrm{~mm}$ total length, with identical tail/total ratios of 0.254 . Two males of 211 and $222 \mathrm{~mm}$ total length have tail ratios of 0.270 and 0.284 , respectively. A larger male $251 \mathrm{~mm} \mathrm{SLV}$ and $363 \mathrm{~mm}$ total length (tail/total $=0.308$ ) is still immature, as judged from soft hemipenial spines and unenlarged kidney tubules and vasa deferentia-suggesting that sexual maturity in this species is not attained before roughly $400 \mathrm{~mm}$ total length.

Dorsal scales smooth, in 15-15-15 rows; anal ridges lacking; apical pits absent on several specimens carefully examined. Ventral plates 134-140 (6 males 134-136, $\overline{\mathrm{x}}=$ 134.8; 6 females $137-140, \bar{x}=137.7)$. Anal plate divided. Subcaudals in 66-81 pairs (4 males, 70-81, $\bar{x}=76.0 ; 5$ females $66-73, \bar{x}$ $=68.8$ ).

Rostral plate wider than high, visible from above. Internasal and prefrontal plates paired, each prefrontal laterally in contact with nasal, loreal, and preocular. Supraocular large, about as long as frontal and more than half as wide. Frontal pentagonal or slightly hexagonal, over 1.5 times longer than wide, equal or slightly longer than distance to snout. Interparietal suture varying from conspicuously shorter than to nearly equal length of frontal. Loreal higher than wide, tending in shape toward a slanting rhomboid. One high, narrow preocular, rarely two (on one side only in one specimen); two postoculars, the lower being smaller. Temporals $1+2$ (one specimen with $2+2+3$ on one side of head). Eight supralabials, with labial 2 touching loreal and labials 3-5 bordering eye. Infralabials variable, range 9-11, but counts differing on left and right sides in six of seven specimens; first pair in contact behind mental. Tiny inconspicuous tubercles on head plates and chin. 


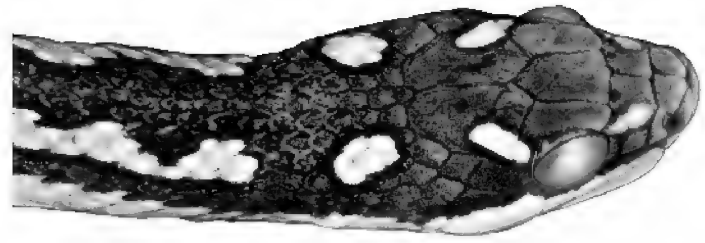

Fig. 8. Head of Eutrachelophis steinbachi (Boulenger) (UMMZ 60736), showing details of color pattern. The oblique alignment of the pale ocelli differentiates $E$. steinbachi from $E$. bassleri and its unnamed sister species (cf. figs. 2 and 4).

Color And Pattern in Preservative: In alcohol, Eutrachelophis steinbachi is grayish brown (gray where stratum corneum has fallen away). Top and sides of head darker brown, with the dark head coloring extending posteriorly as a middorsal and pair of lateral stripes for a distance of about a fourth to a third of the body length before fading out. There are three pairs of conspicuous, blackedged white spots atop the head and nape (figs. 5-8), as follow: (1) An elongated white spot slants anterodorsally in front of the upper edge of each eye (from top of preocular onto side of prefrontal). (2) A similarly elongated white spot slants posterodorsally behind the upper edge of each eye (from upper postocular onto parietal). The oblique postocular marking may be better defined and more vivid than its preocular counterpart. (3) The third pair of black-rimmed white markings are on the nape and may appear as rounded ocelli (fig. 8) or elongated spots (fig. 5), situated posterolaterally about one scale-length behind each parietal. The pale nape ocelli, however, are not always discrete, but are often fused posteriorly with the light dorsolateral ground color adjacent to the dorsal stripe (fig. 6); this fusion occurs in eight of 12 specimens, either on one side only (3 specimens) or on both sides (5 specimens), partly determined by the undulatory courses of the dark neck stripes. The lower parts of the supralabials and underside of the head are white.

The middorsal dark stripe undergoes one to several undulations anteriorly on the neck, where it varies in width from about four to seven scale rows and sometimes fuses briefly with the lateral stripe. As the middorsal stripe straightens out it becomes edged by a line of white dashes along the middle of the sixth scale row; posteriorly the middorsal stripe starts to fade first in the center, and in some specimens may be represented all the way to the tail by a double line of black dots (sixth scale row on each side) marking its former edges. At its start, the lateral dark stripe occupies scale row 3 and adjacent halves of rows 2 and 4, but it soon narrows to a line confined to row 3 before breaking up into a series of dark dots, which extend (inconspicuously) far posteriad in a few specimens. In some individuals the lower sides posteriorly are somewhat darker than the dorsum. The body color extends onto the edges of the ventral and subcaudal plates; ventral surface otherwise immaculate white. No information is available on coloration in life.

\section{HEMIPENIS}

The following description is entirely based on retracted hemipenes (fig. 9). The uneverted left organs of AMNH R-125695 and FMNH 35662 had been opened midventrally; they were removed and pinned flat for detailed study and illustration. Supplementary notes were provided by examination of in situ organs in UMMZ 60734 and 63216.

Major retractor muscle originating at level of subcaudal 37 for the right hemipenis of FMNH 35662, anteriorly dividing at the levels of subcaudals 20 ( 1 specimen), 19 (2), or 15 (1), and inserting on the ends of the hemipenial lobes at subcaudals 17 (1), 15 (2), or 14 (1). The hemipenis therefore is relatively long, spanning 14-17 subcaudals. The two lobes are narrow and long, comprising nearly twothirds the total length of the hemipenis, which bifurcates at the level of subcaudal 6 in three specimens and at subcaudal 7 in another.

The extreme base of the organ is virtually nude except for a sparse distribution of spinules; a relatively deep basal groove on the dorsal wall might persist on the everted hemipenis as a basal naked pocket (sensu Myers, 1974: 32), but this is uncertain. Two large and two medium-sized spines arise across the middle of the undivided base of the organ; these spines are nearly straight, and the tips of the two largest extend nearly to the base of the hemipenis, on either side of the sulcus (fig. 9). Above the big spines are numerous small, 


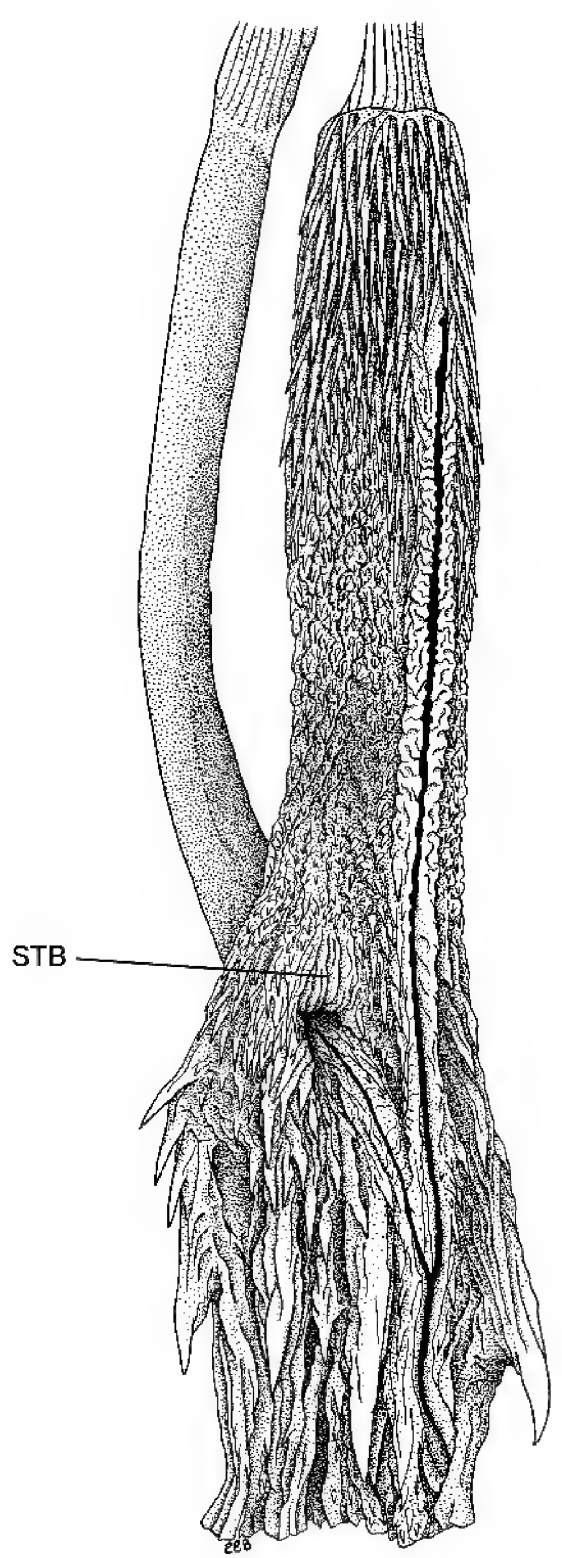

Fig. 9. Uneverted hemipenis of Eutrachelophis steinbachi (Boulenger); right organ of AMNH R-125695, opened by midventral incision, $\times 5$. Abbreviation: STB, smooth terminal basin.

straight to slightly recurved spines, those close to the sulcus being very small. The proximal $40 \%-50 \%$ of each hemipenial lobe is profusely covered by short, thick spinules. The distal $50 \%-60 \%$ of a lobe is densely covered with straight, relatively long thin spines, and the sulcus branch ends abruptly in this region, at a length about $80 \%$ up the lobe.
There is at the base of the lobes an interlobular nude space - the STB, or "smooth terminal basin" (see Hemipenial Terminology for Snakes) - which is closely edged by small, short spines (fig. 9). This "basin" has apparent expansion folds and therefore lacks the sulcuslike smoothness seen in some other taxa (e.g., compare with the STB shown in fig. 18). The expansion folds suggest that the basin will be considerably enlarged after eversion. ${ }^{7}$

Outside the STB, the long hemipenial lobes are completely spiny as described above. The sulcus proximally lies on the lateral wall (both on left and right organs) and divides halfway up the base, at the level of subcaudal 3. The branches of the sulcus are deeply incised and have a centrifugal orientation, lying on the ventral wall of the ventral lobe and on the dorsal wall of the dorsal lobe; each sulcus branch terminates well short of the apex.

SKull AND Dentition: The skull was removed from one specimen of Eutrachelophis steinbachi (AMNH R-125695). See figure 11 and text under Global Comparisons. Eight maxillae in as many specimens bear 25-28 ( $\overline{\mathrm{x}}=25.6)$ small, subequal teeth, followed by a diastema and two offset, ungrooved fangs (fig. 12); maxillary fangs about twice as large as the prediastemal teeth, with knifelike rear edges. AMNH R-125695 has $19 / 20$ palatine teeth, followed by about $34 / 36$ pterygoid teeth; dentary teeth $35 / 33$.

Vertebrae, Head Muscles, Glands, AND VISCERA: See under Global Comparisons.

\section{REMARKS}

As indicated above, Eutrachelophis steinbachi (Boulenger) is known to us from a dozen specimens. Excluding one specimen of

\footnotetext{
${ }^{7}$ The AMNH specimen of Eutrachelophis steinbachi was obtained by exchange. Both hemipenes had been opened, so it was not possible to obtain a manual eversion as was done for $E$. bassleri. The organ depicted in figure 9 suffered the same fate as that of another important specimen (see appendix 1: Hemipenis of Lectotype), but in each case there is a contralateral organ to save the day. A check of the left in situ hemipenis of AMNH R-125695 verifies that the STB was accurately drawn in figure 9. Hussam Zaher (personal commun.) manually everted the hemipenis of a MZUSP specimen of E. steinbachi; a description or illustration showing the STB is awaited with interest.
} 
questionable provenance, all originated over a period of time (circa 1903-1928) from the Bolivian collectors José Steinbach and his son Francisco Steinbach. Their locality designations are of a somewhat general nature, but the several Steinbach localities for this species seem to lie at the eastern base of the Andes in the department of Santa Cruz.

Buenavista ( $=$ Buena Vista of modern maps and gazetteers) and Provincia Sara are the only localities for Eutrachelophis steinbachi shown on map 1, although the old "Province Sara" [Provincia Gutiérrez] - the type locality - is a region rather than a single collecting site. $^{8}$ José Steinbach lived in Buena Vista $\left(17^{\circ} 27^{\prime} \mathrm{S}, 63^{\circ} 40^{\prime} \mathrm{W}\right)$, the most frequently mentioned locality. His locality Río "Sirutu" for a UMMZ specimen may be one of several spelling variants of Río Surutú, a known Steinbach locality (Paynter, 1992: 142-143). According to Sydney Anderson (personal commun.), "The most probable collecting areas near the Río Surutú would have been reasonably near the town of Buenavista ... probably to the west or southwest of that village."

The locality for one specimen sent to the Carnegie Museum was given by Steinbach as Las Yuntas, 250 m., Dpto. Santa Cruz de la Sierra (fide C.J. McCoy, in litt.). ${ }^{9}$ this became the type of Aporophis melanocephalus, described by Griffin (1916), who failed to publish the department and who changed "Las Yuntas" to "Las Juntas." The last is in fact the modern Bolivian name for at least one town previously with the former spelling, but there are at least two places with the name "Las Juntas" in the western part of the department of Santa Cruz, ${ }^{10}$ and we are

\footnotetext{
${ }^{8}$ This subdivision of Depto. Santa Cruz has not had stable borders. The Province of Sara was larger in the early part of the 20th century than at present. It included the more recent provinces of Sara, Santiesteban, and Ichilo, which were shown on a map published in 1980 (S. Anderson, personal commun.). The name Provincia Gutiérrez appears to be a more recent replacement for Provincia Sara (Paynter, 1992: 59, 138).

9 The Steinbachs' "Depto. Santa Cruz de la Sierra" apparently is a descriptive phrase specifying the western part of the large Department of Santa Cruz-not to be confused with "Santa Cruz de la Sierra" as applied to the city in the same region.

${ }^{10}$ One Las Juntas is about $120 \mathrm{~km} \mathrm{SW}$ Buena Vista, and another is about $140 \mathrm{~km}$ SSE Buena Vista on the Río Grande (from Mapa de la República de Bolivia, 1:1,500,000, R. Zumelzu y Cia., La Paz, 1947).
}

uncertain which (if either) of them is the type locality of $A$. melanocephalus. The holotype of melanocephalus is a juvenile female only $185 \mathrm{~mm}$ in total length (tail $=47 \mathrm{~mm}$ ) rather than " $291 \mathrm{~mm}$ " (tail $47 \mathrm{~mm}$ ) as given by Griffin; the right maxilla has been subsequently removed and shows $25+2$ teeth; there are about 137 ventrals and 69 subcaudals.

\section{GLOBAL COMPARISONS}

Despite striking differences in their hemipenes, the very considerable external similarity between Eutrachelophis bassleri, new species, and E. steinbachi (Boulenger) is accompanied by great similarity in skull and dentition, head muscles and glands, and general visceral anatomy. The vertebrae are also similar, with a ventral keel but no hypapophysis on the posterior vertebrae; neither species shows any suggestion of winglike or shelflike expansions on the zygapophyses or any expansion of the distal edge of the moderately high neural spine. These vertebral similarities are not so impressive, however, because they are shared with the majority of colubrid snakes. ${ }^{11}$

\section{VISCERA}

In both species the tongue is long and extends back nearly (E. steinbachi) or quite ( $E$. bassleri) to the heart. There is no left lung in the two specimens dissected and the trachea ends opposite the apex of the heart in both specimens. ${ }^{12}$ In each species the pulmonary (right) lung has the usual reticulation of raised alveolar rims on its lining (rather than the essentially smooth lining surface seen in a few colubrids such as Amastridium, Compsophis, and Psammodynastes); this alveolar reticulation is continued forward on the membranous dorsal wall of the trachea to fade into pitting and then into quite smooth membrane

\footnotetext{
${ }^{11} \mathrm{An}$ unfortunate consequence of this is that it is unlikely that the fossil record, which is almost entirely of vertebrae for snakes, will ever give any useful information about Eutrachelophis and the many other genera whose vertebrae are too nondescript to be surely recognizable.

${ }^{12}$ Data on viscera, head glands and muscles, skull, and vertebrae were obtained by dissection of AMNH R-55786 (E. bassleri) and AMNH R-125695 (E. steinbachi); both adult males.
} 
anteriorly, but in neither does this forward extension of alveolar reticulation bulge out beyond the dorsal tips of the cartilaginous tracheal semirings to form a conspicuous "tracheal lung." In E. bassleri the forward extension of alveolar reticulation reaches within a head length of the head, but in $E$. steinbachi it reaches only about a heart length anterior to the heart. Thus, both species of Eutrachelophis seem to fall in the intermediate range, between Neotropical "xenodontines" that unequivocally have a tracheal lung (e.g., Coniophanes, Conophis, Darlingtonia, Hydrops, Rhadinaea decorata, $R$. laureata, Urotheca godmani) and those that unequivocally lack a tracheal lung (e.g., Atractus major, Ialtris, Taeniophallus brevirostris, T. occipitalis); probably the majority of "xenodontines" fall into the intermediate range with Eutrachelophis. The liver is separated from the heart by a moderate interval (eight ventrals in both specimens examined), as in most "xenodontines." (But in a broad range of dipsadines, including Amastridium, Arrhyton vittatum, Darlingtonia, Rhadinaea calligaster, and Urotheca godmani, for example, the liver reaches forward nearly or quite to the level of the apex of the heart. At the opposite extreme, in Pseudoeryx plicatilis [AMNH R-52229] the liver is separated from the heart by 30 ventrals.)

As in other colubrids, with the exception of a few Old World genera (e.g., Boaedon, Bothrophthalmus, Liophidium, Pareas, Pseudoxyrhopus), the rectal caecum is absent in Eutrachelophis bassleri and E. steinbachi.

The general evidence from the viscera is consistent with a close affinity between $\mathrm{Eu}$ trachelophis bassleri and E. steinbachi, but cannot be considered convincing evidence for close relationship because the two species are not at all unusual in visceral features and the resemblances between them are shared with many other "xenodontines." It is the head structure that shows a sufficient number of shared unusual characters to make a special common ancestry the most likely explanation for the resemblances between Eutrachelophis bassleri and E. steinbachi.

\section{Head Glands}

Both species show an unusually large temporal extension of the Harderian gland, exposed behind the orbit but posteriorly inserted deep to the muscle adductor mandibulae externus superficialis and superficial to the adductor externus profundus (sensu Zaher, 1994). An equally large (and similarly placed) temporal extension of the Harderian gland also occurs in Rhadinophanes monticola (UTA R-4176) and Contia tenuis (AMNH R69062). In all these snakes, the deep insertion of the gland between adductores externus superficialis and profundus seems to form a functional complex, with the two muscles acting to compress and evacuate the gland; the profundus retains its usual function as a powerful adductor of the lower jaw, but the superficialis is reduced to a thin layer of fibers across the lateral surface of the rear portion of the gland and probably functions mostly - or entirely - as a compressor of the gland. Secretions from the Harderian gland discharge into the subbrillar space to lubricate the eye; the secretions also pass through the lachrymal duct into the vomeronasal (Jacobson's) organ, for a function still speculative (e.g., Bellairs and Boyd, 1947, 1950; Minucci et al., 1992; Rehorek et al., 2003: 358 [the last authors do not identify a method for lubricating the eyeball under the brille, and only observe that "there is no nictitating membrane in the orbit of either snake species"]).

In neither Eutrachelophis bassleri nor E. steinbachi could a rictal gland (sensu McDowell, 1986) be found, nor could any infolding of the oral mucosa just medial to quadrato-maxillary ligament that might represent a rictal gland; the quadrato-maxillary ligament ends anteriorly on the skin of the last supralabial, and so does not reach forward to the region where a rictal gland might be expected. McDowell (1986) argued that the "rictal gland" is the homolog of the "anterior temporal gland" and of at least the sheath of the venom gland of various other snakes, and that these are, in turn, homologous to the Mundplatte, or rictal fold, of lizards. Furthermore, he stated that since the lizard rictal fold is normally a long and deep invagination of oral mucosa deep to the quadrato-maxillary ligament, the absence of the rictal gland (and even of the portion of the ligament that should accompany it) in the two species of Eutrachelophis would be less 
lizardlike (and presumably, more specialized) than the presence of the gland; this absence would represent an unusual, but not unique, shared specialization. The gland is a minute vestige or absent in Taeniophallus brevirostris, and it could not be found in Conophis vittatus (AMNH R-65108), Contia tenuis (AMNH R-73392), Farancia abacura (AMNH R110941), Helicops angulatus (AMNH R52746), or Thamnodynastes pallidus (AMNH $\mathrm{R}-4446)$. In Urotheca multilineata (AMNH $\mathrm{R}-98288$ ), at the opposite extreme, the rictal gland has become greatly expanded as a floccular, thin-walled glandular structure covering most of the temporal region just beneath the skin; although large, it is a solid mass of glandular tissue rather than a hollow pocket (thus, it is quite different in appearance from the lizard rictal fold) and may represent a secondary enlargement of the small to very small pocket seen in most "xenodontines."

All three species of Eutrachelophis have a well-differentiated "supralabial gland," the outline of which in some preserved specimens can easily be seen through the postorbital supralabial integument, as in figure 4 (unnamed species). The gland is similarly positioned in E. bassleri and E. steinbachi, in which it is adherent to the medial side of the supralabial integument. The serous (Duvernoy's) portion of this gland is not (to gross examination, at least) clearly differentiated from the mucous part of the gland in either species. Enlargement of the rear maxillary teeth is not accompanied by a correspondingly conspicuous differentiation of the gland, which tapers posteriorly rather than showing enlargement behind the level of the eye. Unfortunately, the serous and mucous contributions to this gland in Eutrachelophis and many other "xenodontines" are not distinguishable without histological preparation (Taub, 1966, 1967).

In both named species of Eutrachelophis the lateral nasal gland is well defined and lies in a clearly defined aditus conchae of the nasal capsule - that is, in an invagination of the lateral wall of the cartilaginous capsule that forms a vertically oriented protrusion (the concha) into the lateral wall of the nasal passage; the vertical edge of this protrusion defines a lateral diverticulum (the paracapsular recess, or sakter) of the nasal cavity, housed in the prefrontal bone, with the facial wing of the prefrontal forming a partial lateral wall for the paracapsular recess, the intraorbital wing of the prefrontal forming a posterior wall for the recess, and the roof of the lachrymal canal of the prefrontal forming the floor of the recess. Two bony processes define the rim of the aditus conchae: the conchal process of the septomaxilla rises along the anteromedial rim of the aditus; and the conchal process of the prefrontal, rising from dorsomedial rim of the anterior orifice of the lachrymal canal of the prefrontal, lies along the posterolateral rim of the aditus. The above conditions are as in the great majority of "xenodontines," and Colubroidea in general. But some "xenodontines" have reduced the nasal conchae and its aditus, so that the bulk of the lateral nasal gland lies more superficially: in Tretanorhinus nigroluteus (AMNH R70222) and in Coniophanes quinquevittatus (AMNH R-74493) the concha is present, but with a reduced aditus, so that much of the gland lies in a shallow depression on the side of the nasal capsule; in Apostolepis, Carphophis, Farancia, Hydrops, and Pseudoeryx, the concha (and its aditus) is only vaguely defined and the conchal process of the prefrontal is a blunt vestige or absent.

\section{Head Muscles}

Both Eutrachelophis bassleri and E. steinbachi have unusually weak jaw adductors, with the adductor externus medialis essentially confined to the lateral surface of the braincase, leaving a broad exposure of the parietal and supraoccipital between the left and right muscles.

The adductor externus superficialis (sensu McDowell, 1986 = adductor externus profundus of most authors) and the adductor posterior are also weak muscles, so that the bony crests of the compound mandibular bone lateral (for the adductor externus superficialis) and medial (for the adductor posterior) to the mandibular adductor fossa are both low. These two mandibular adductors arise from the quadrate to insert on the mandible and therefore have the same mechanical force whether the quadrate is in 
the vertical (relaxed) position or is rotated outward (as when engulfing large prey); the weakness of these muscles, and of the mandibular crests for their insertion, indicates that neither species is well adapted to engulfing relatively large prey while exerting much force.

The conversion of the levator anguli oris into a compressor of the Harderian gland is mentioned above in discussion of the gland. Another unusual feature of this muscle shared by Eutrachelophis bassleri and $E$. steinbachi is that only the more posterior fibers of the usual colubrid levator anguli oris are retained; only those fibers that originate on the parietal are present and no fibers originate on the postorbital, nor do any fibers extend to the oral mucosa at the corner of the mouth or curve forward beneath the corner of the mouth. Diadophis punctatus (AMNH R-121701) and Liophis melanotus (AMNH R-98179) have a similar muscle, but usually the postorbital bears part of the origin of the levator anguli oris, with some of the anteriormost fibers bent forward around the corner of the mouth or inserted on the mucosa of the corner of the mouth. In some "xenodontines," such as Atractus major (AMNH R-53782), Dipsas indica (AMNH R53780), and Helicops angulatus (AMNH R52746), these anterior recurrent fibers may be set off as a distinct muscle and loss of this distinct "1a" muscle would give the pattern seen in the two species of Eutrachelophis; however, there is no evidence to suggest that loss of the anterior fibers in bassleri and steinbachi was preceded by segregation of the fibers in a distinct muscle.

The pterygoideus in both species is of normal colubrid form, with both the pars major and pars minor joined anteriorly at their attachment to the anterolateral corner of the ectopterygoid (directly above the enlarged rear pair of maxillary teeth), but distinct at their posterior attachment to the mandible, the insertion of pterygoideus accessorius lying just behind the mandibular attachment of the pars minor.

In both Eutrachelophis bassleri and $E$. steinbachi, the retractor arcus palatini is unusually slender, its origin (from the sphenoid) being slightly narrower than the origin of the retractor vomeris (also on the sphenoid, immediately anteromedial to the origin of the retractor arcus palatini). In other colubrids examined, both New and Old World, the retractor arcus palatini is at least slightly larger (usually conspicuously larger) than the retractor vomeris. The insertion pattern of the retractor arcus palatini in both bassleri and steinbachi is the pattern that is most common among colubrids: fleshily, upon the posterior shaft of the palatine and, by tendon only, upon the choanal process of the palatine. The retractor vomeris and retractor arcus palatini have origins side by side on a nearly transverse (but arched forward anteriorly) muscular line on the sphenoid, and the protractor pterygoideus arises posterior to this muscular line; thus, the protractor pterygoideus lies behind the levator bulbi group (retractor vomeris and retractor arcus palatini), as in many "xenodontines" (e.g., Heterodon, Thamnodynastes), rather than extending forward on the sphenoid between the right and left levator bulbi groups (as in Atractus, Farancia, Helicops, Tretanorhinus, and many others).

Because the origins of the retractor vomeris and retractor arcus palatini muscles are

Fig. 10. Skull of Eutrachelophis bassleri, new species (AMNH R-55786), ×8.8. Abbreviations: A, angular; B, basioccipital; CB, compound bone; ct, foramen for chorda tympani of facial nerve; ic, foramen for internal carotid artery; D, dentary; E, ectopterygoid; EX, exoccipital (+ opisthotic); F, frontal; ic, foramen for internal carotid artery; $\mathbf{M}$, maxilla; $\mathbf{N}$, nasal; $\mathbf{O F}$, orbital fenestra, containing ophthalmic $\left(\mathrm{V}_{1}\right)$, oculomotor (III), trochlear (iv) nerves; PA, parietal; PF, prefrontal; PL, palatine; PM, premaxilla; PO, postorbital; PR, Prootic; PT, pterygoid; pv, foramen for pituitary vein and retractor pterygoideus nerve; Q, quadrate; S, stapes; SM, septomaxillary; SO, supraoccipital; SP, sphenoid (fused basisphenoid and parasphenoid); SPL, splenial; T, tabular; V, vomer; Vc, foramina for Vidian canal; Vlp, foramen for levator pterygoideus ramus of trigeminal nerve; Vpt, foramen for protractor pterygoideus ramus of 

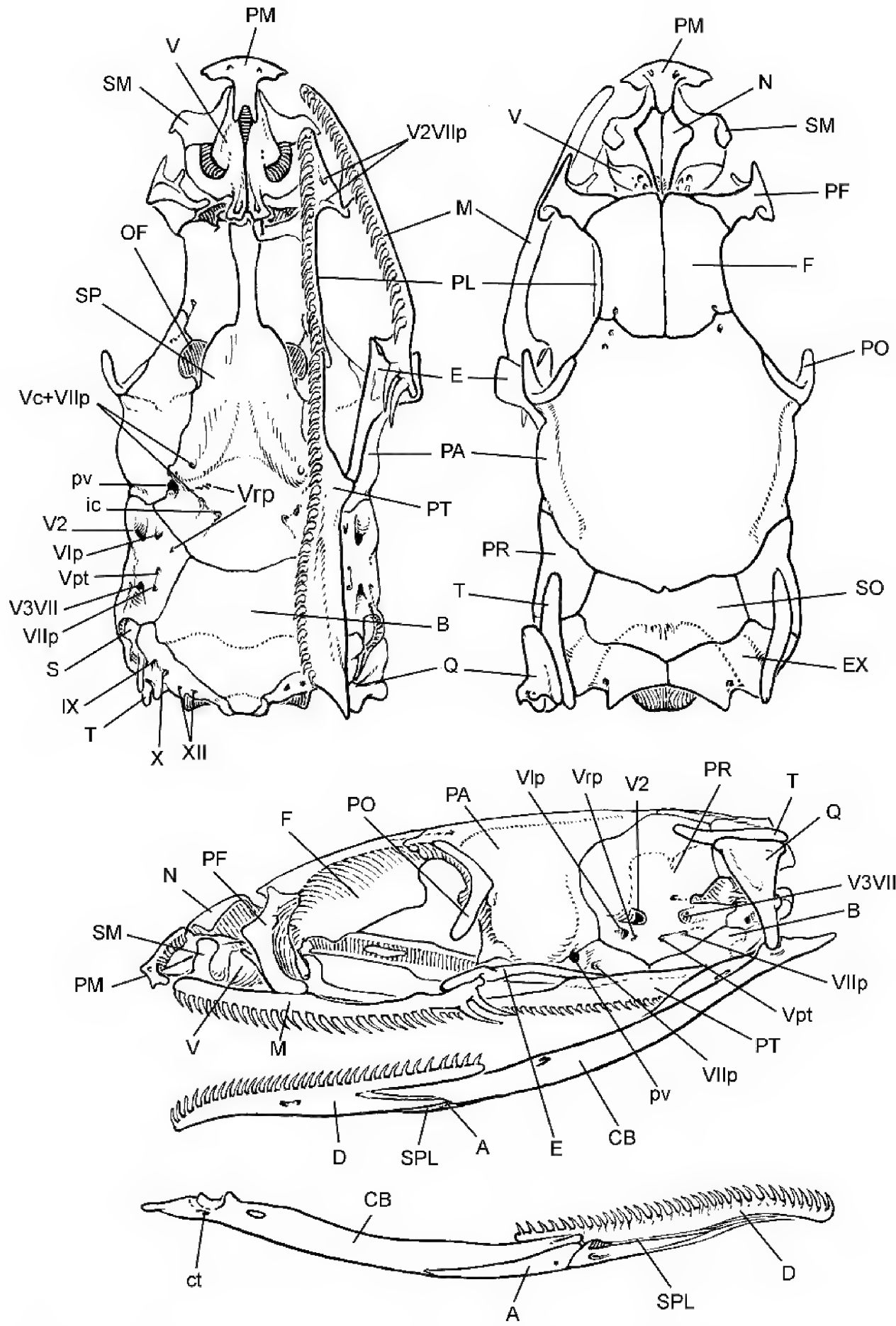

Fig. 10. Continued. trigeminal nerve; Vrp, foramen for retractor pterygoideus ramus of trigeminal nerve; V2, foramen for maxillary ramus of trigeminal nerve; V2VIIp, foramina for combined maxillary ramus of trigeminal nerve and palatine ramus of facial nerve (= orbitopalatine nerve); V3VII, foramen for mandibular ramus of trigeminal nerve and facial nerve; VIIp, foramina for palatine ramus of facial nerve; IX, foramen for glossopharyngeal nerve; X, foramen for vagus nerve; XII, foramina for hypoglossal nerve. 


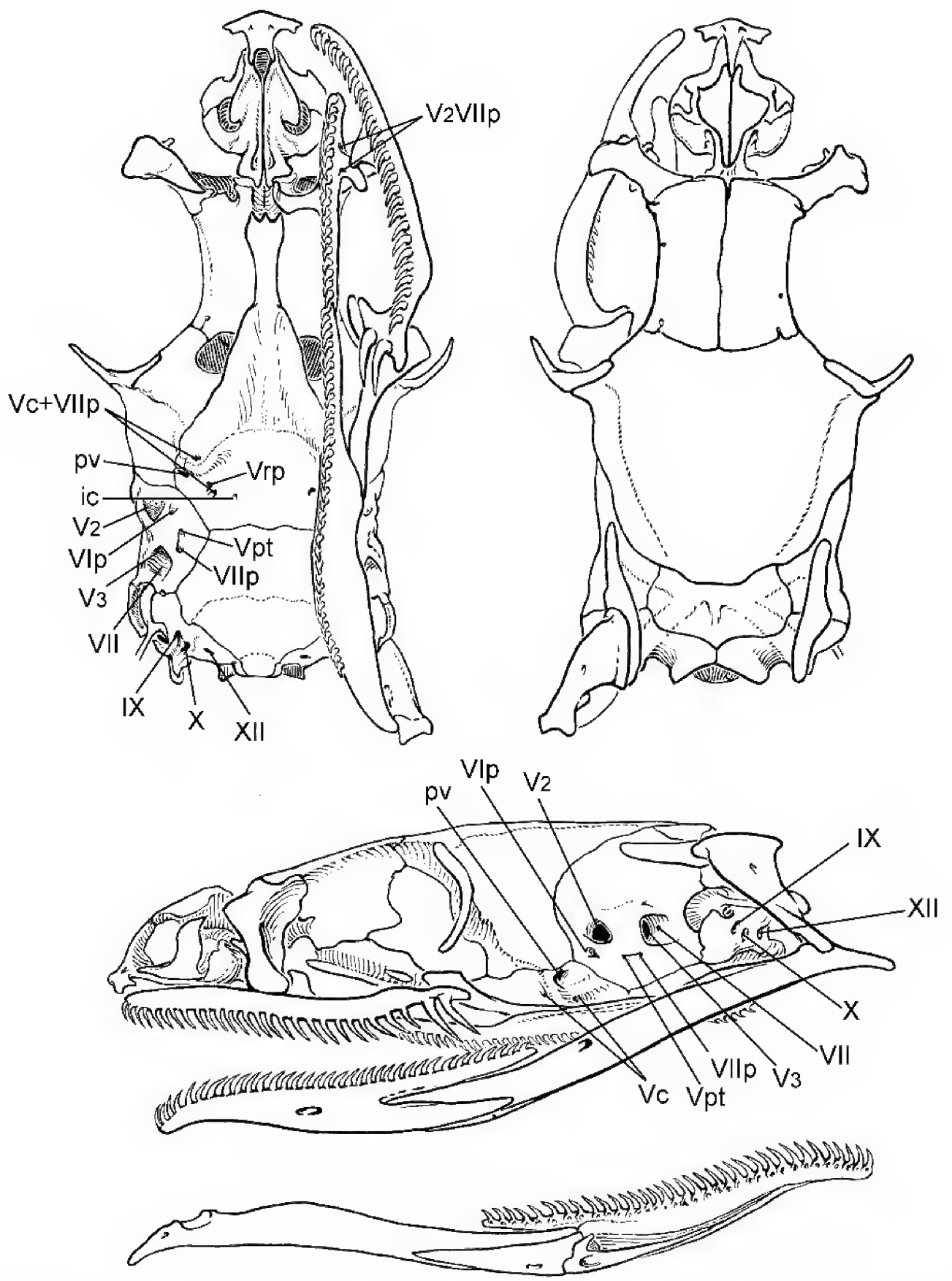

Fig. 11. Skull of Eutrachelophis steinbachi (Boulenger) (AMNH R-125695), ×7.7. Abbreviations: Same as for figure 10 , but here repeated only for nerve and venous foramina. With only one skull each of $E$. bassleri and $E$. steinbachi, no significance can be attached to any slight differences in positioning of these foramina, which are so labile that even the left and right sides of the same skull may sometimes differ. 
arranged transversely across the sphenoid (rather than along the sphenoid-parietal contact, as they are in Diadophis, Farancia, Oxyrhopus, and many others), with the anterior orifice of the Vidian canal between the two muscles (as in Colubroidea generally), the anterior orifice of the Vidian canal is set well in from the border of the sphenoid (rather than near or on the sphenoid-parietal suture, as it is in Diadophis, Oxyrhopus, Tantalophis, and many others). The pattern of palatal muscles, both relative to one another and to the Vidian canal system of the sphenoid, is the same in both $E u$ trachelophis bassleri and E. steinbachi, but far from unique to them (for example, among genera related at the subfamilial level, the same pattern is seen in Thamnodynastes, but the pattern occurs also in the Madagascan Liopholidophis and Asiatic Pseudoxenodon and many other genera that probably are not closely related to the South American Eutrachelophis). This pattern seems to indicate only a moderate forward and backward movement of the palatine-pterygoid arch and very limited (if any) ability to rotate the palatine in the vertical plane. This is in keeping with the form of the palatine bone, with a long but slender choanal process closely applied to the vomer and a long shaft of the palatine extending posterior to the attachment of the palatine to the prefrontal. The opposite extreme would be seen in those genera with the origin of the protractor extending forward to the level of the eye and the origin of the retractor arcus palatini displaced far backward behind the level of the origin of the protractor; such a pattern allows considerably greater forward and backward movement of the palatine-pterygoid arch and is usually associated with loss of the choanal process of the palatine (as in Atractus) or with this choanal process becoming uncoupled from the vomer (as in Tretanorhinus, where the process is behind the choanae and attached by a long tether of connective tissue to the rear of the vomer).

In both Eutrachelophis bassleri and $E$. steinbachi, the protractor quadrati originates on the fascia covering the anterior end of the rectus capitis ventralis and there is no direct attachment to the basioccipital. In this, they resemble many other "xenodontines," such as Conophis, Crisantophis, Hydrops, Liophis melanotus, Pseudoeryx, Rhadinaea decorata, and Thamnodynastes - but differ from some others, such as Adelphicos, Atractus, Dipsas indica, Heterodon, Rhadinaea flavilata, $R$. taeniata, Rhadinophanes, Taeniophallus brevirostris, and Tretanorhinus, where at least the most anterior fibers of the muscle are attached to the basioccipital. This seems to be a very unstable character of little taxonomic significance.

In both Eutrachelophis the cervicomandibularis has the usual colubrid insertion on the lower end of the quadrate (as a colubrid "retractor quadrati"); in both, the depressor mandibuli has a small but distinct occipital head, broadly separated from its fellow.

Except possibly for the narrowness of the retractor arcus palatini, none of the above features of the head musculature are unique to Eutrachelophis; overall, the head musculature of E. bassleri and E. steinbachi is much the same as in Liophis melanotus (AMNH R98179) and many other "xenodontines." What is most impressive, however, is the close agreement between bassleri and steinbachi in the muscular details that are known to vary even among other species that appear to be closely related. The unusual common features (15 scale rows and pale head and nuchal markings), which led to our comparing these two species in the first place, do not have any obvious functional correlation with details of the head musculature and it seems implausible that bassleri and steinbachi could bear such detailed correspondence in head musculature as a result of mere coincidence of random variations.

\section{SkUll AND Dentition}

The same argument just presented for head muscles, that concordance in characters known to be variable among "xenodontines" is too great to be accounted for by coincidence, has still greater force when considering the skulls of Eutrachelophis bassleri and $E$. steinbachi. To summarize in advance, the single skulls compared are so similar that coincidental resemblance must be rejected as an explanation.

What is most striking is that the skulls of bassleri and steinbachi combine an unusually short tabular, such as seen in some small-eyed burrowers (e.g., Atractus and Carphophis) 

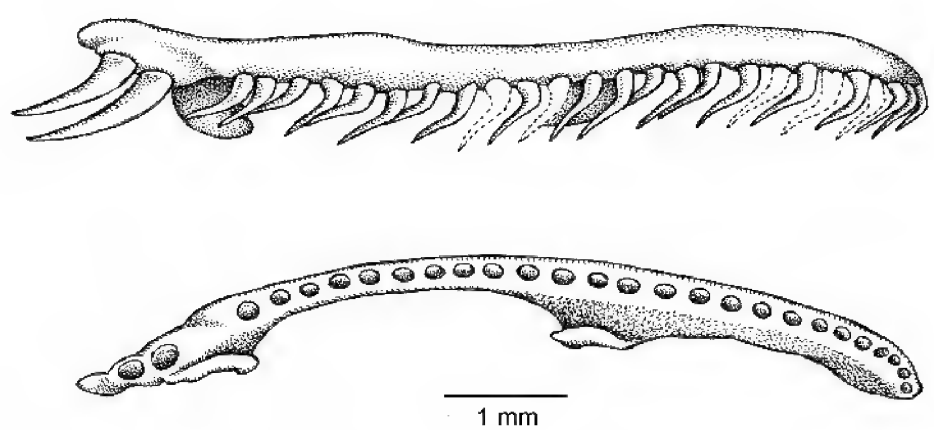

Fig. 12. Maxillary dentition of Eutrachelophis steinbachi (Boulenger). Right maxilla of AMNH R125695, in lateral and ventral view. Arrangement of tooth sockets shows a slight lateral offset of the last tooth behind the diastema; the offset is more pronounced in most other "xenodontines," although a few genera have the posterior maxillary teeth arranged in a straight line configuration.

with a construction of the orbit associated with large-eyed snakes (e.g., Dromicodryas, Psammodynastes, Thamnodynastes). When the details of foramina of the sphenoid and prootic are considered, there is a virtual identity between the skulls of Eutrachelophis bassleri and E. steinbachi, even though these foramina are so labile that closely related snakes may differ or, for that matter, even the left and right sides of the same skull may differ. Indeed, except for one character of the sphenoid in the orbital region (see pp. 32, 43), the single bassleri skull examined differs no more from the one steinbachi skull than might be expected for individual (including ontogenetic) variation within a single species.

This similarity is evident in the dentition, where the two skulls are nearly identical in form. In both species, the maxilla has a long series of small, evenly spaced teeth $(\bar{x}=25.6$ in E. steinbachi, 27.4 in E. bassleri), followed by a diastema that is longer than the space occupied by a tooth socket, then two conspicuously enlarged, ungrooved teeth that are about twice as long as the prediastemal teeth; in both species, one of the enlarged pair of rear maxillary teeth is offset to the general line of the tooth row (fig. 12; see also fn. 1) as is usually the case in "xenodontines," but as noted in the discussion of head glands, there is no correspondingly conspicuous differentiation of Duvernoy's gland in either species to accompany the offset rear maxillary teeth. Eutrachelophis bassleri tends to have one or two more prediastemal maxillary teeth than the larger E. steinbachi. In both skulls, the palatine (with about 19-20 teeth) and pterygoid (about 30 teeth in bassleri, 34/ 36 in steinbachi) tooth rows form a continuous arcade of small teeth, longest on the anterior part of the palatine (where they are about equal to the adjacent maxillary teeth) and grading imperceptibly into much smaller teeth on the rear of the pterygoid. The last pterygoid tooth is approximately level with the occipital condyle in both skulls and the first palatine tooth lies just in advance of the orifice of the organ Jacobson and well behind the anterior end of the maxilla. The dentary teeth (34/32 in the bassleri skull, 35/33 in steinbachi) very gradually diminish posterior$1 y$, but are small even at the anterior end of the bone (about equal to the prediastemal maxillary teeth). As usual in "xenodontines" (Apostolepis, Atractus, and Carphophis are among the exceptions), the last six ( $E$. bassleri) or seven (E. steinbachi) dentary teeth are on a free posterior dentigerous limb of the dentary, behind the intramandibular hinge. None of the teeth is hinged at the base and all are of the usual pointed and recurved form.

The bones bearing the dentition are also nearly identical in E. bassleri and E. steinbachi. The maxilla has the form that is usual in colubrids, with a triangular anterior medial process that is applied to the ventral surface of the prefrontal and also is closely attached to the lateral edge of the lateral (maxillary) 
process of the palatine; this process of the palatine is also applied to the ventral surface of the prefrontal, just medial to the maxilloprefrontal articulation. The maxilla has a well-developed posterior medial process with its apex, directed forwardly and medially, opposite the diastema anterior to the enlarged posterior maxillary teeth. The usual (for Colubroidea) ligament runs from the apex of this posterior medial process and the adjacent medial anterior process of the ectopterygoid to the apex of the anterior medial process of the maxilla and adjacent maxillary process of the palatine. As in most "xenodontines," but unlike most proteroglyphs and a number of (mostly African) colubrids, such as Boaedon, Lycophidion, and Pseudaspis, this ligament is long and runs for most of the length of the orbit; this is not merely a consequence of a long maxilla, for although a short maxilla (e.g., Heterodon, Xenodon) will, of course, result in a short ligament, the converse is not true: Boaedon, for example, has a long maxilla but a short ligament because the posterior medial process of the maxilla (and adjacent medial anterior process of the ectopterygoid) lies well anterior to the rear of the maxilla, and the maxillary process of the palatine, which receives the anterior end of the ligament, lies well posterior to the prefrontal and to the tip of the anterior medial process of the maxilla (see appendix 2: fig. 39). In a number of snakes with a relatively short maxilla, such as Carphophis, the posterior medial process of the maxilla is extended backward, behind the tooth row, with its apex at the rear of the level of the orbit, so that the ligament (only feebly defined) is of moderate length.

The palatine is also very similar in Eutrachelophis bassleri and E. steinbachi. There is a long, narrow, transverse choanal process lying at nearly the exact middle of the palatine. This choanal process is positioned distinctly behind the level of the maxillary process and the ventral end of the prefrontal. The choanal process is entirely medial to the ventral end of the prefrontal, as usual in colubroids, in which no medial process of the prefrontal extends close to the frontal-septomaxillary joint dorsal to the palatine choanal process (unlike Dipsas indica [AMNH R-53780], Homalopsis, etc.) or functionally replaces the choanal process (as in Atractus).

The maxillary process has a similar triangular form in both Eutrachelophis bassleri and E. steinbachi, with a sphenopalatine canal for the nerve formed by fusion of the Vidian nerve with the infraorbital branch of the maxillary $\left(\mathrm{V}_{2}\right)$ nerve, as in many, probably most, "xenodontines." The posterior shaft of the palatine (that is, the portion projecting behind the choanal process to meet the pterygoid) is unusually (but not uniquely) long and slender in both species and articulates with the pterygoid at the same transverse level as the ectopterygoid-maxillary articulation, rather than well anterior to the ectopterygoid-maxillary articulation (as in, for example: Amastridium veliferum, AMNH R-114309; Hydrops marti, AMNH R-52031; Manolepis putnami, AMNH R58355; Oxyrhopus petola, AMNH R-52640; Rhadinaea decorata, AMNH R-107588; Taeniophallus brevirostris, AMNH R-15207) or well posterior to the ectopterygoid-maxillary articulation (as in, for example: Apostolepis flavotorquata, AMNH R-93559; Carphophis amoenus, AMNH R-75711). The articulation between the palatine and pterygoid involves a simple anterior end of the pterygoid (as usual in "xenodontines") that is clasped by a short ventral lip of the palatine, bearing the last palatine tooth, and a longer dorsal finger of the palatine that extends back along the dorsal surface of the pterygoid; this is the most common palatine-pterygoid articulation among "xenodontines" (and colubrids in general), but other forms exist, such as simple end-to-end abutment (e.g., Heterodon, Apostolepis), or having the posterior finger of the palatine run along the medial, rather than dorsal, surface of the pterygoid (e.g., Farancia), or subequal posterior prongs of the palatine that fit, respectively, against the medial and the lateral surfaces of the pterygoid (e.g., Hydrops). The form of the palatine in both Eutrachelophis bassleri and $E$. steinbachi is very similar to that of Rhadinaea decorata (AMNH R-107588), $R$. fulvivittis (AMNH R-100890), and $R$. taeniata (AMNH R-106933), but quite different from that of Taeniophallus brevirostris (AMNH R-15207), where the choanal process has a broad base extending back almost 
to the level of the prongs for the pterygoid, or Urotheca multilineata (AMNH R-98288), where the slender choanal process has a distinct forward hooking of its apex and the shaft behind it is short.

Eutrachelophis bassleri and E. steinbachi have very similar pterygoid bones, as shown in the figures, but this is of less weight than the similarities in the palatine bone because differences in pterygoid bone shape are minor and subtle in "xenodontines" generally. The similarity in shape of the ectopteryoid between $E$. bassleri and E. steinbachi is more impressive, because this bone shows a wide range of form within the Xenodontinae. In both, the bone is moderately long (but conspicuously shorter than the maxilla), with a curved and cylindroid shaft that is free of the pterygoid for more than half its length and is not expanded in its posterior portion that is applied against the dorsal surface of the pterygoid. In both, the anterior end is abruptly expanded and flattened and is very asymmetrically divided, by a broadly rounded anterior emargination, into an acutely triangular medial anterior process and a nearly rectangular lateral anterior process; the medial anterior process extends conspicuously anterior to the lateral anterior process. Thus, the two species differ from, for example, Carphophis, Contia, and Farancia, in which the medial anterior process is greatly reduced; they also differ from such "xenodontines" as Conophis vittatus (AMNH R65108) and Manolepis putnami (AMNH R-58355), in which the medial anterior process is broader-and longer-than the lateral anterior process. Downs (1967) has documented the considerable range in ectopterygoid form within the genus Geophis, where the form of the bone is distinctive of species groups within the genus. This seems to be true also of Atractus: some species (e.g., $A$. elaps, AMNH R-28843) have lost the lateral anterior process of the ectopterygoid but retain a long free shaft of the bone; others (e.g., A. major, AMNH R-53782) retain anterior furcation of the bone but have so shortened the free shaft that the maxilla is probably immovable relative to the pterygoid; and still others (e.g., $A$. trilineatus, AMNH R-101336) retain a long free shaft and also anterior furcation of the ectopter- ygoid. This variation within a single genus suggests that the form of the ectopterygoid is easily modified and that differences between two species might be expected even if the species are closely related; however, in the case of E. bassleri and E. steinbachi it is the great similarity between the two species that must be accounted for, and close phyletic relationship seems the simplest explanation.

The great similarity in the compound bone of the mandible has been noted in the discussion of the head muscles. It may be added that both species agree in having a long (for Colubroidea) retroarticular process and in the details of the splenial-angulardentary complex. In both, the Meckelian canal is open anterior to the splenial nearly to the anterior end of the dentary, as in, for example, Amastridium, Rhadinophanes, and Coniophanes fissidens (AMNH R-69977). However, in such "xenodontines" as Coniophanes quinquevittatus (AMNH R-74493), Rhadinaea laureata (AMNH R- 68380), and Tantalophis, the lips of the dentary forming the dorsal and ventral edges of the Meckelian exposure meet, but leave a suture, and in Liophis melanotus (AMNH R-98179), Farancia abacura (AMNH R-110941), and Apostolepis flavotorquata (AMNH R-93559) this suture fuses, at least anteriorly.

The splenial and angular are equal and moderately long; each of the bones contains a mylohyoid foramen; the splenial extends about halfway forward from the splenialangular hinge articulation to the anterior end of the dentary and the dorsal edge of the splenial is separated by a fissure from the dentary (and so, the Meckelian canal is narrowly open, even opposite the splenial). This is as in many other "xenodontines," but in some others (e.g., Hydrops marti, AMNH R-52031; Oxyrhopus petola, AMNH R52640) the splenial is smaller, relative to the dentary, and falls well short of the halfway point between the splenial-angular hinge and the tip of the dentary; in Apostolepis, Hydrops, and Thamnodynastes, the splenial is distinctly shorter than the angular; variations in the opposite direction are seen in Coniophanes imperialis (AMNH R-77064), whose splenial is conspicuously longer than the angular, and in Farancia the splenial is unusually large relative to the dentary (but 
subequal in length to the angular) and extends well anterior to the midpoint between the splenial-angular hinge and the tip of the dentary. In both Eutrachelophis bassleri and E. steinbachi, the splenial has a narrow, fingerlike process that extends upward along the anterior edge of the angular; excluding that bone from the rim of the Meckelian exposure; this posterior dorsal process of the splenial is present and sharply defined in many other "xenodontines" (e.g., Carphophis amoenus, AMNH R-121650; Farancia abacura, AMNH R-110941; Oxyrhopus petola, AMNH R-52640; Rhadinaea decorata, AMNH R-107588; Urotheca multilineata, AMNH R-98288), but the process is absent in many others (e.g., Amastridium veliferum, AMNH R-114309; Coniophanes imperialis, AMNH R-77064; Conophis vittatus, AMNH R-65108; Hydrops marti, AMNH R-52031; Pseudoeryx plicatilis, AMNH R-52229; Thamnodynastes pallidus, AMNH R-4446). It should be noted that this tiny sliver of the splenial bone is probably of more functional importance to the feeding mechanism than its size would suggest; the posterior dorsal process of the splenial lies immediately dorsal to the condyle-cotyle articulation between the splenial and angular, a circular universal joint, the edge-to-edge contact of the posterior dorsal process of the splenial with the anterior border of the angular limits the plane of rotation of the hinge. In most "xenodontines" that have this process of the splenial, including Eutrachelophis bassleri and E. steinbachi, this edgeto-edge contact is diagonal to the long axis of the jaw, and so imparts a rotation of the dentary around the long axis when the intramandibular hinge is flexed (in Farancia, where the edge-to-edge contact is vertical, no such rotation around the long axis is permitted).

The construction of the orbit in both Eutrachelophis bassleri and E. steinbachi shows a pattern that has developed independently among natricines (e.g., Psammodynastes, Rhabdophis miniatus), pseudoxyrhophiines (e.g., Dromicodryas, Thamnosophis lateralis but not Liopholidophis sexlineatus), and other colubrids in association with a large eye and small olfactory forebrain. It may be considered a consequence of secondary enlargement of the eye, but it is not a necessary or automatic consequence, since such notably large-eyed snakes as Boiga do not show this pattern; that Leioheterodon, a relatively small-eyed Madagascar snake, shows many features of the pattern can perhaps be explained as the result of derivation from a large-eyed ancestor similar to Dromicodryas and Thamnosophis lateralis. The conspicuous features of the pattern are: ${ }^{13}$

1. Broad entry of the parietal into the orbital rim, separating the frontal and postorbital bones but not restricting entry of the frontal into the orbital rim;

2. Elevation of the forebrain chamber, formed by the descending laminae of the frontals, well above the trabeculae (and so, there are no supratrabecular crests of the frontals or frontal contributions to the trabecular grooves);

3 . The paired trabeculae lie close together, with the lamina of the [para]sphenoid that separates them thin and compressed (often, as in E. bassleri and $E$. steinbachi, with a defect in ossification of this thin bone, so that there is an oval fenestra in the trabecular groove of the sphenoid), and the [para]sphenoid rostrum is narrow at mid-orbit (as seen in a ventral view of the skull), but with conspicuous suborbital flanges that extend lateral to the trabeculae and lie beneath the more posterior part of the eyeball and dorsolateral to the retractor vomeris muscles [the suborbital flange of the sphenoid provides cranial attachment for the rectus groups of eye muscles and is continued anteriorly and laterally beneath the eye by the tough but flexible orbital obturator membrane that is probably of greatest functional importance in protecting the eye from the contents of the mouth];

4. Usually (as in E. bassleri and $E$. steinbachi), but not always (e.g., Conophis vittatus), there is deficient ossification in the region of the usual frontalparietal contact in the medial wall of the orbit, dorsal to the orbital foramen

\footnotetext{
${ }^{13}$ Since this was written, features of some of the numbered points can be seen as corroborated in Cadle (1996a: 443, figs. 38-40). -C.W.M.
} 
(this fenestration, closed by tough connective tissue in life, makes the forebrain chamber of the frontals continuous with the orbital cavity in the dried skull);

5. Often (e.g., Dromicodryas, Psammodynastes, Thamnodynastes pallidus) the space between the elevated forebrain chamber of the frontals and trabeculae (in grooves on the lateral surface of the [para]sphenoid rostrum) is filled in by a median crest of the [para]sphenoid, forming a functional "orbital septum" (but not homologous to the orbital septum of lizards, which is formed from the orbital cartilages, absent in snakes except for the portions used in construction of the cartilaginous olfactory capsules).

Of the features of the pattern just listed, Eutrachelophis bassleri does not show number 5 above; the [para]sphenoid rostrum is flat dorsally. In E. steinbachi there is a distinct crest on the dorsal side of the [para]sphenoid rostrum, but the crest is less developed than in Conophis, Crisantophis, Manolepis, and Thamnodynastes, and meets the frontals only anteriorly, leaving a triangular open chink between the [para]sphenoid crest and the frontals more posteriorly. Except for the better development of the keel on the sphenoid and the absence of a fenestra in the trabecular groove of the sphenoid, Thamnodynastes pallidus (AMNH R-4446) closely resembles $E$. bassleri and E. steinbachi in the construction of the orbit, but Conophis and Manolepis (these points are uncertain for Crisantophis, observed by dissection only, on AMNH R-112402) lack fenestration between the frontal and parietal, have only feeble suborbital laminae of the [para]sphenoid, and have a narrower entry of the parietal into the orbital rim, but they do have a perforation in the trabecular groove. Liophis melanotus (AMNH R-98179) approaches the pattern of E. bassleri and E. steinbachi in a different way: there is a similar fenestration between frontal and parietal, similar development of the [para]sphenoid suborbital laminae, and a similarly broad entry of the parietal into the orbital rim, but the forebrain cavity of the frontals is only slightly raised above the trabeculae posteriorly (nevertheless, the sphenoid has a low but quite distinct dorsal crest to meet the frontals here, and there is no open chink between frontals and sphenoid such as is seen in E. steinbachi); anteriorly, the frontals rest upon the trabeculae and form weak supratrabecular ridges. A third, slighter approach to the orbital pattern of E. bassleri and E. steinbachi is made by Taeniophallus brevirostris (AMNH R-15207): the forebrain chamber is only slightly elevated above the trabeculae, but, nevertheless, the frontals are narrowly - but completely - excluded from the trabecular grooves by a narrow dorsal lip of the trabecular groove of [para]sphenoid; the parietal rather broadly excludes the frontal from the postorbital, but otherwise the orbit is quite different from that of $E$. bassleri and $E$. steinbachi, without frontal-parietal fenestration and with only feeble suborbital flanges of the [para]sphenoid.

Most Rhadinaea, sensu lato, such as $R$. decorata (AMNH R-107588), R. flavilata (AMNH R-50491), R. laureata (AMNH R68380), R. taeniata (AMNH R-106933), and Urotheca multilineata (AMNH R-98288), have frontals that rest upon the trabecular cartilages and form strong supratrabecular crests that even descend, lateral to the trabecula, to meet the ventral lip of the [para]sphenoid groove for trabecula at the front of the orbit. Many other "xenodontines" (and other colubroids) show this pattern, such as Amastridium, Coniophanes fissidens (AMNH R69977), C. imperialis (AMNH R-77064), Rhadinophanes, and Tantalophis; or the contact of the frontal with the [para]sphenoid lateral to the trabecular cartilage may be much longer and extend for most or all of the length of the frontal supratrabecular crest as in Coniophanes quinquevittatus (AMNH R74493, by dissection), Adelphicos, Atractus, and Tretanorhinus. Such long contact of the frontal with the trabecula can lead to contact of the supratrabecular crest of the frontal with ventral end of the parietal beneath the orbital foramen, excluding the sphenoid from that foramen, as in Nothopsis and Hydrops. This is the usual condition in noncolubroid snakes and in many proteroglyphs and seems to be associated with a relatively small eye, at least relative to the size of the forebrain and snout. In all forms showing this "small-eyed pattern" the suborbital lamina of the [para]sphenoid is absent and there is no fenestration between the frontal and parietal in the medial 
wall of the orbit. The same may be said for those "xenodontines" with the "moderateeyed pattern." such as Coniophanes and Rhadinaea, except that a slight suborbital flange of the [para]sphenoid may be present.

There seems, then, to be a series from the "small-eyed pattern." as seen in such "xenodontines" as Hydrops, to the "largeeyed pattern" as seen in such "xenodontines" as Thamnodynastes. The series will not describe all the intermediates precisely, since there can be extensive fenestration of the wall of the orbit combined with the forebrain cavity resting on the trabeculae (as in Liophis melanotus) or lack of this fenestration in combination with high elevation of the forebrain cavity above the trabeculae (as in Manolepis putnami). Heterodon is hard to place, since it has enormous suborbital flanges of the [para]sphenoid and there is fenestration of the cranial-orbital wall (but mainly by retraction of the anterior edge of the parietal); however, the forebrain cavity seems to have been secondarily depressed toward the trabeculae (but does not touch them), so that the crest on the [para]sphenoid is concealed from external view by the frontals. Because of its long snout, Heterodon has only a "moderately" large eye relative to total head length, but the orbit is large relative to the unusually short braincase. In spite of these complications in surveying all "xenodontines," the central point of these comparisons remains: Eutrachelophis bassleri and E. steinbachi are extremely similar to each other in orbit construction, and however the series from "small-eyed pattern" to "large-eyed pattern" is arranged, the two species under special consideration are at nearly the same step in the series, near the "large-eyed pattern" extreme; this in spite of the fact that neither species has exceptionally large eyes. However, the only significant skull difference between the two species occurs in the orbital regionEutrachelophis steinbachi has a dorsal crest of the parasphenoid rostrum that is exposed below the frontals and E. bassleri does not.

Entry of the parietal into the orbital border occurs in Amastridium, Taeniophallus brevirostris (AMNH R-15207), and some Rhadinaea ( $R$. decorata, AMNH R-107588; $R$. taeniata, AMNH R-106933), but most Rhadinaea, like Adelphicos, Atractus, Coniophanes, Tantalophis, Rhadinophanes, and
Tretanorhinus, have a postorbital-frontal contact excluding the parietal from the rim of the orbit. In Apostolepis (notably smalleyed snakes), the parietal enters the orbit extensively, nearly ( $A$. flavotorquata, AMNH R-93559) or very much (A. erythronotus, AMNH R-62192) excluding the frontal. Parietal entry into the orbital rim is thus not a simple function of orbit size. This increases the significance of parietal entry into the orbital rim in both Eutrachelophis bassleri and E. steinbachi as a special resemblance between the two species and not a mere duplication of another character.

Eutrachelophis bassleri and E. steinbachi have very similar prefrontal bones that are unusually short anteroposteriorly, so that the vertical (frontal-to-maxillary) height is more than twice the anteroposterior dimension; this anteroposterior shortness largely reflects the weak development of the facial wing of the bone that extends forward over the lateral surface of the paracapsular (sakter) region of the cartilaginous nasal capsule. The facial wing of both E. bassleri and E. steinbachi lacks the forward extension and dorsad hooking (apomorphies of Pseudoboini) seen in Drepanoides anomalus, AMNH R-53419, and Oxyrhopus petola, AMNH R-52640; moreover, it does not cover the preorbital area as in Hypsirhynchus ferox, AMNH R40124, and Manolepis putnami, AMNH R58355. However, the facial wing is small and obtusely pointed, with the result that the prefrontal does not have the simple and broadly convex anterior border seen in Helicops angulatus, AMNH R-56031, or the straight and vertical anterior border seen in Farancia abacura, AMNH R-110941. The attachment of the prefrontal to the frontal is as in most other "xenodontines" (and the great majority of colubrids): dorsally and superficially, there is a tongue-in-groove articulation, with the edge of the prefrontal fitting into a groove on the frontal; deep and ventral to this, there is a squamous overlap, with the intraorbital wing of the prefrontal fitting just behind a transversely oriented lateral eversion of the part of frontal that forms the lateral rim of the olfactory foramen (this lateral eversion of the frontal lies against the rear wall of the olfactory capsule, thus partially separating the intraorbital wing of the prefrontal from the capsule, and prevents 
forward rotation of the prefrontal). In both Eutrachelophis bassleri and E. steinbachi, the superficial tongue-in-groove articulation is about $30^{\circ}$ from transverse in its orientation relative to the axis of the skull, with the prefrontal extended along the anterior border of the frontal (but falling far short of the midline or of the nasal and permitting broad entry of the frontal into the rim of the dorsal exposure of the nasal capsule); there is no suggestion of posterior extension of the prefrontal along the lateral (orbital) border of the frontal. This is as in some other "xenodontines" such as Liophis melanotus (AMNH R-98179), Coniophanes fissidens (AMNH R-69977), and C. imperialis (AMNH R-77064), but the majority have the tongue-in-groove articulation oriented at $45^{\circ}$ and in several (e.g., Carphophis amoenus, AMNH R-121650; Conophis vittatus, AMNH R-65108; Manolepis putnami, AMNH R-58355; Pseudoeryx plicatilis, AMNH $\mathrm{R}-52229$ ) it is nearly longitudinal (but without backward extension of the prefrontal over the eye). In Hydrops marti (AMNH R-52031), the tongue-in-groove articulation is perfectly longitudinal and the deeper squamous articulation is absent (the lateral eversion of the frontal is missing), so that some transverse rotation of the prefrontal probably is permitted.

In both Eutrachelophis bassleri and $E$. steinbachi, the facet of the parietal bone bearing the postorbital bone is moderately long and oriented diagonally, approaching a vertical orientation. This is as in most "xenodontines" (e.g., Alsophis, Liophis, Manolepis, Rhadinaea decorata, Taeniophallus brevirostris, Urotheca multilineata, and Thamnodynastes) and imparts an anteroposterior motion to the tip of the postorbital when that bone rotates; since the tip of the postorbital is bound by ligament to a low but distinct elevation on the dorsal edge of the maxilla (just in front of the maxillary diastema in $E$. bassleri and E. steinbachi and most of the others), the angle of attachment of the postorbital to the parietal probably has an indirect control over the movements of the rear of the maxilla. In some "xenodontines" (e.g., Atractus) the attachment of the postorbital to the parietal is so short that it is a virtual pivot joint, and in others (e.g., Apostolepis and, according to Downs, 1967, some Geophis) the postorbital is absent, so that the maxillary is tethered to the braincase only by a long and quite flexible ligament; this seems to be associated with a short maxilla, but is not an "automatic" consequence of a short maxilla, since Heterodon and Xenodon (see Kardong, 1979), both with an unusually short maxilla (but a maxilla that rotates strongly in a vertical plane), have a more or less vertical hinge attachment of the postorbital to the parietal. In some "xenodontines" (e.g., Adelphicos, Carphophis, Contia, Diadophis, Farancia, Hydrops, Pseudoeryx) there is a long postorbital-parietal hinge, but oriented nearly or quite horizontally, so that rotation of the postorbital is transverse; probably this acts, through the maxillary-postorbital ligamentous connection, primarily as a check preventing excess lateral displacement of the rear of the maxilla. Still others (e.g., Amastridium, Coniophanes, Oxyrhopus, Rhadinaea flavilata) are intermediate, with the attachment of the postorbital closer to the horizontal than in Eutrachelophis bassleri and E. steinbachi, but nonetheless distinctly inclined.

In both Eutrachelophis bassleri and $E$. steinbachi, the rostral complex of bones (premaxilla, nasals, septomaxillae, and vomers) is very similar and the rostral complex in both is small relative to the skull. The premaxilla has quite distinct lateral processes, but the bone is rather small (about as in Liophis melanotus, AMNH R-98179). As in Amastridium, Farancia, Hydrops, Liophis, Pseudoeryx, Rhadinaea decorata, Urotheca multilineata, and others, the premaxilla and vomer make an overlapping contact, so that the vomer participates in the support of the premaxilla (but, as is true of Colubroidea in general, is less important than the septomaxilla in this support); in many other "xenodontines" (e.g., Adelphicos, Apostolepis, Atractus, Carphophis, Conophis, Heterodon, Manolepis, Oxyrhopus, Rhadinaea flavilata, $R$. laureata, $R$. taeniata), the vomer makes only a point-topoint contact with the premaxilla or is separated from that bone. In both Eutrachelophis bassleri and E. steinbachi, there is a large intervestibular fenestra, between the narial vestibules of the opposite sides and bounded anteriorly by the ascending process of the premaxilla, ventrally by the septomaxillae, and posterodorsally by the nasals; a similar intervestibular fenestra is seen in 
many other "xenodontines" (e.g., Adelphicos veraepacis, Liophis melanotus, Rhadinaea taeniata, Thamnodynastes pallidus), but in many others (e.g., Amastridium, Apostolepis, Carphophis, Farancia, Hydrops, Rhadinaea decorata, $R$. laureata, Urotheca multilineata) the intervestibular fenestra is small or absent.

Both Eutrachelophis bassleri and E. steinbachi have the usual form of hinge between the rostral complex and the frontals for "xenodontines": Along the cartilaginous nasal septum the septomaxilla sends back a posterior process, whose posterior tip bends strongly outward behind the passage for the vomeronasal portion of the olfactory nerve. The lateral flexure of the posterior process of the septomaxilla forms a posteriorly convex facet for the corresponding septomaxillary facet of the frontal that, in turn, is well defined by a distinct peduncle facing forward and slightly but distinctly mediad; the nasals touch the interolfactory pillar of the frontals, but without forming any articular surface, between the frontal-septomaxillary articulations and do not make any contact with the septomaxillary facets. Although most "xenodontines" (and other colubrids) have a similar hinge between the rostral complex and the frontals, there are some exceptions. Thus, in Apostolepis, the posterior process of the septomaxilla is stout and abuts end to end with the frontal facet; in Carphophis, the nasals are expanded and fused at their contact with the interolfactory pillar of the frontals, forming an articulation addition to the septomaxillary-frontal articulation; in Pseudoeryx and Hydrops, the nasals do not reach the frontals, nor is there any nasalfrontal contact in Atractus crassicaudatus (AMNH R-24235) or Adelphicos veraepacis (AMNH R-66961).

In both Eutrachelophis bassleri and E. steinbachi, the tip of the [para]sphenoid, just ventral to the fusion of the paired trabeculae that forms a trabecula communis, is distinctly expanded laterally and shallowly trilobated by a pair of obtuse notches. This is true also of Coniophanes, Farancia, Rhadinaea flavilata, $R$. laureata, $R$. taeniata, and many other "xenodontines." It is seen also, so far as the tip of the parasphenoid is concerned, in Atractus, but in that genus the entire anterior end of the parasphenoid is broad, as in
Adelphicos, Ninia, Tretanorhinus, and others, and so the tip of the parasphenoid does not appear broad relative to the interorbital portion. In others, such as Rhadinophanes and Tantalophis, as well as Adelphicos, Ninia, etc., the apex of the parasphenoid is convexly rounded anteriorly; in Amastridium and Thamnodynastes pallidus, and others, the tip of the parasphenoid is simply forked by a shallow median emargination; in Apostolepis, Carphophis, Conophis vittatus, Contia, Diadophis, Heterodon, Manolepis, and Nothopsis, the parasphenoid is pointed anteriorly.

The suborbital flanges of the parasphenoid have been noted in the preceding comparisons of the orbit; as is probably true of all snakes with a parasphenoid that is broadened to form suborbital flanges, the parasphenoid of both Eutrachelophis bassleri and E. steinbachi rises to meet the parietal lateral to the trabecular cartilages, so that the ossified bases of the trabeculae (radices trabeculae) are concealed intracranially; this is the usual condition in "xenodontines" (even in genera such as Atractus, Hydrops, and Pseudoeryx, with little or no development of suborbital flanges), but in some (e.g., Apostolepis, Carphophis, Farancia), the parasphenoid appears to be narrower in this region, failing to surround the radices trabeculae laterally, and so the radices trabecular are exposed externally, lateral to the contact of the sphenoid with the more anterior part of the parietal.

The parasphenoid of both Eutrachelophis bassleri and E. steinbachi seems somewhat shorter posteriorly than in the majority of "xenodontines," since it leaves the foramen for entry of the carotid artery into the pituitary fossa separate from the more lateral foramen for entry of the palatine ramus of the facial nerve into the rear of the Vidian canal. This is seen also in Liophis melanotus (AMNH R-98179) and Urotheca multilineata (AMNH R-98288), as well as in many non"xenodontines," but usually the parasphenoid of "xenodontines" extends back beneath these two foramina to define a common palatine nerve-carotid artery canal that forks within the sphenoid into a carotid and a Vidian canal. (In Heterodon, there is an anomalous condition, in which the posterior end of the Vidian canal is in the prootic and the single foramen in the rear of sphenoid is 
for the carotid artery alone. Atractus and Apostolepis also appear to have the posterior orifice of the Vidian canal within the chamber of the prootic for the trigeminal ganglion, so that only the carotid enters the large foramen in the posterior part of the sphenoid; in these forms it is probably impossible to guess the precise limits of the parasphenoid relative to the perichondral sphenoid posteriorly.) The relationships of the Vidian canal system of the sphenoid to the protractor pterygoideus and levator bulbi group of muscles have been discussed in connection with those muscles, but it may be added here that the bony canal for the palatine nerve is unusually short, as compared with other "xenodontines," in both Eutrachelophis bassleri and E. steinbachi.

In both species, there is a rather large foramen (pv) in the lateral edge of the sphenoid, immediately adjacent to the sphenoid-parietal suture and well anterior to the sphenoid-prootic contact (boldface abbreviations indicate foramina shown in figs.10-11). This foramen, presumably for the pituitary vein and for the entry of the retractor pterygoideus ramus of the trigeminal nerve $\left(\mathrm{V}_{4}\right.$ levator bulbi) into the cranium is larger than that of any Rhadinaea examined, or that of Amastridium, Coniophanes, Liophis melanotus, Rhadinophanes, and Tantalophis, but similarly placed; Farancia and Thamnodynastes show close agreement with Eutrachelophis bassleri and E. steinbachi both in size and position of the foramen; in Pseudoeryx the foramen is large but more posteriorly placed, just anterior to the sphenoid-prootic contact, and in Oxyrhopus petola (AMNH R52640) and Hydrops marti (AMNH R-52031) the foramen lies in the parietal-prootic suture. In both Eutrachelophis bassleri and E. steinbachi, the foramen on the left side appears to be as large as that on the right side, probably indicating that the drainage from the pituitary and middle cerebral veins through this foramen is approximately equal on the left and right sides, but in Carphophis amoenus (AMNH R-75711), Contia tenuis (AMNH R-69062), and Rhadinaea flavilata (AMNH R-50491) the right pituitary vein foramen is conspicuously larger than the left, a frequent asymmetry in colubroids related to a tendency to have blood enter the pituitary on the left (from the functional carotid) and leave on the right, through a large pituitary vein.

Eutrachelophis bassleri and E. steinbachi have very similar prootic bones, including the pattern of foramina in the region of the trigeminal and facial foramina. This pattern is imposed by the fusion of the alethinophidian bridge, or "Gaupp's bone," to the outer side of the prootic - external to branching of the trigeminal and to the petrosal sinus or network of veins around the trigeminal ganglion. The precise pattern of foramina depends on just where the edges of the alethinophidian bridge lie relative to a complex pattern of veins and nerves that cross one another. The pattern appears to be the same in the single skull each of Eutrachelophis bassleri and E. steinbachi, a remarkable coincidence if they are not closely related, particularly given that it was impossible to match this pattern with any of the other "xenodontine" (or other colubrid) skulls compared. In both Eutrachelophis bassleri and E. steinbachi, foramen $\mathbf{V}_{\mathbf{2}}$ for the maxillary nerve is broadly separated from foramen $\mathbf{V}_{\mathbf{3}} \mathbf{V I I}$ for the mandibular and facial nerves by the more dorsal portion of the alethinophidian bridge, as in Apostolepis, Oxyrhopus, Rhadinaea, and others; in Hydrops, Manolepis, Tantalophis, and others, the two foramina are closer together, and in some Heterodon (e.g., H. nasicus, AMNH R109431) the two foramina are confluent because of failure of the dorsal part of the alethinophidian bridge to extend between $V_{2}$ and $V_{3}$. Dorsal to the aperture for $V_{3}$, both have a small foramen opening posterodorsally, probably for the vein connecting the petrosal sinus with the main stem of the vena capitis lateralis. Urotheca multilineata (AMNH R-98288) has a similar foramen, but also another, probably venous, foramen just posterodorsal to the aperture for $\mathrm{V}_{2}$. A venous (?) foramen posterodorsal to the $V_{2}$ aperture, but no venous foramen near the $\mathrm{V}_{3}$ aperture, was found in Rhadinaea laureata (AMNH R-68380) and Thamnodynastes pallidus (AMNH R-4446); most of the "xenodontines" compared had no venous foramina dorsal to the apertures for $\mathrm{V}_{2}$ and $\mathrm{V}_{3}$. Ventral to the aperture for $\mathrm{V}_{3}$, both Eutrachelophis bassleri and E. steinbachi have a small foramen facing downward and forward, 
probably for the palatine ramus of the facial nerve (VII pal.) just anterior to this foramen (and sharing a common longitudinal groove with it) is a small foramen facing downward and backward. To judge from dissection of Coniophanes quinquevittatus (AMNH R76693) this foramen is for the small trigeminal ramus to the protractor quadrati muscle $\left(\mathrm{V}_{4}\right.$ pro. quad.); dissection of Tantalophis discolor (AMNH R-103130) revealed two similarly placed foramina, but with the VII pal. foramen anterior to the $\mathrm{V}_{4}$ pro. quad. foramen; since the two nerves cross in this region, just which foramen is the more anterior depends on precisely how far ventrally (i.e., to just above or to just below the crossing) the alethinophidian bridge extends. The direction the foramina face indicates that Eutrachelophis bassleri and E. steinbachi are more like Coniophanes than like Tantalophis in this aspect of the pattern.

Ventral to foramen $\mathbf{V}_{\mathbf{2}}$, Eutrachelophis steinbachi has a rather large foramen, but $E$. bassleri has a slightly larger foramen with a conspicuously smaller foramen immediately behind it; probably the larger foramen of $E$. bassleri is for the venous connection of the pituitary-middle cerebral vein to the petrosal sinus and the smaller foramen immediately behind it is for the retractor pterygoideus nerve $\left(\mathrm{V}_{4}\right.$ levator bulbi). The confluence of the two foramina in Eutrachelophis steinbachi is by far the more usual condition. Most "xenodontines" (apart from the anomalous Heterodon, whose foramina associated with the alethinophidian bridge are difficult to homologize with other snakes) have a $V_{4}$ levator bulbi foramen similar to that of Eutrachelophis steinbachi, but in Urotheca multilineata (AMNH R-98288) and Rhadinophanes the foramen is very small, suggesting it is for the nerve alone and the vein is absent, and, to judge from the size of the foramen, the vein must have been very small in Rhadinaea flavilata (AMNH R-50491) and Coniophanes fissidens (AMNH R-69977). In Pseudoeryx plicatilis (AMNH R-52229) the $\mathrm{V}_{4}$ levator bulbi foramen is confluent with the aperture for $\mathrm{V}_{2}$ and in Hydrops marti (AMNH R-52031) the $\mathrm{V}_{4}$ levator bulbi foramen is anterior to, rather than below, the $\mathrm{V}_{2}$ aperture.

In summary, the presence of venous (?) foramina dorsal to the trigeminal ganglion, together with the details of the pituitary vein foramen, contribute to the unusual pattern of the two Eutrachelophis skulls examined.

As in most "xenodontines," both Eutrachelophis bassleri and E. steinbachi have a large and longitudinally oval footplate of the stapes that is overhung by a dorsal crista circumfenestralis, formed about equally by the prootic and exoccipital, and partially covered from below by the longissimus crest of the exoccipital, which conceals the recessus scalae tympani from lateral view. Although the skull of each was prepared from a male with well-mineralized hemipenial spines and with a strongly convoluted vas deferens (thus, presumably mature), in neither species does the dorsal crista circumfenestralis touch the longissimus crest to enclose the stapedial footplate entirely (such complete enclosure is uncommon in "xenodontines," but occurs in Apostolepis flavotorquata, AMNH R-93559, Arrhyton taeniatum [see Maglio, 1970], Taeniophallus brevirostris, AMNH R-15207, and in Urotheca multilineata, AMNH R-98288). At the opposite extreme is Heterodon, where the stapes is almost entirely exposed to direct lateral view.

In both Eutrachelophis bassleri and $E$. steinbachi, the tabular (supratemporal or squamosal of some authors) is small and barely projects posteriorly beyond the sheath (in the exoccipital bone) of the posterior semicircular canal; anteriorly, it falls well short of the parietal bone, but, nevertheless, it is exposed anterior to its contact with the quadrate and is about equal in length to the quadrate. Thus, the reduction of the tabular, which results in the suspension of the quadrate lying opposite, rather than behind, the rear of the otic capsule, is more as in Apostolepis, Atractus, and Carphophis, than as in Dipsas and Sibon. As in other "xenodontines" (but unlike genera such as Boaedon, Elapoidis, Lycophidion, and Psammodynastes), the lateral margin of the tabular is gently sinuate, without a distinct and angular lateral lobe extending onto the dorsal crista circumfenestralis. Further, as in most "xenodontines" (even those, such as Oxyrhopus and Thamnodynastes, with a strong backward extension of the tabular), there is no tubercle or ridge or countersinking of the cranial surface for the tabular and that bone would seem to have a slight mobility in its 
cranial attachment. Hence, since the quadrate makes no direct contact with the cranium, some slight adjustment in the angle of rotation of the quadrate (relative to the cranium) seems possible, although the lack of backward projection of the tabular would make the leverage for this adjustment very small in the case of Eutrachelophis bassleri and $E$. steinbachi. In genera with an angular notch in the lateral border of the tabular (such as Psammodynastes and Lycophidion), a tubercle of the prootic fits into this notch and locks the tabular into position. In contrast, the xenodontine Oxyrhopus (as noted during preparation of the skull of $O$. petola, AMNH R-52640), although having a long tabular projecting well behind its contact with the cranium, has the tabular held in position by "guy wires;" that is, strong ligaments, one from the nuchal crest of the supraoccipital to the medial edge of the tabular and another from a longitudinal ridge on the prootic to the lateral edge of the tabular, hold the tabular in place. A few "xenodontines" seem to have a rigidly locked tabular: in Heterodon platyrhinos (AMNH R-63590), the surface of the prootic for the tabular is corrugated, and in Apostolepis flavotorquata (AMNH R-93559), the tabular is strongly S-shaped, with an irregular outline that fits a countersunk depression on the exoccipital behind the crista circumfenestralis.

The quadrate is of similar triangular form in Eutrachelophis bassleri and E. steinbachi, but less backswept in the latter; in both, the stapedial facet (processus internus module) is at almost the exact center of the posterior profile of the bone, rather than conspicuously ventral to the center (as in Farancia) or distinctly above the center (as in Rhadinaea decorata, AMNH R-107588).

Both Eutrachelophis bassleri and E. steinbachi have the most common form of occipital condyle among "xenodontines" and other colubrids: conspicuously narrower than the foramen magnum, but transversely oval in form, with the exoccipitals well separated by the basioccipital, and without distinct peduncle or neck; in some "xenodontines," such as Farancia abacura (AMNH R-110941) and Carphophis amoenus (AMNH $\mathrm{R}-121650$ ) the condyle may be much broader, as broad as the foramen magnum; in others, such as Apostolepis flavotorquata (AMNH R93559) and Pseudoeryx plicatilis (AMNH R52229), the condyle is distinctly pedunculate and the exoccipitals meet above the basioccipital.

\section{Color Pattern}

The color pattern of snakes can be as useful in phylogenetic studies as it is in identification, but authors tend to yield precedence when conflicting hemipenial data are involved. For example, the sister genera Pliocercus and Urotheca (the latter equivalent to the former lateristriga group of Rhadinaea) share the characters of a long, disproportionately thick tail and a hemipenis having a small, naked pocket in the asulcate edge of the capitulum (Myers, 1974: 273, fig. 4). On this basis, Savage and Crother (1989) united the two genera. Myers and Cadle (1994: 3) disagreed with that action, saying that:

Present evidence suggests that Pliocercus and Urotheca s.s. are monophyletic sister groupseach of which is characterized by synapomorphies of color pattern, including Micrurus-like rings in the former and a longitudinal white line(s) [sometimes secondarily lost] in the latter. ... there is no indication that Urotheca s.s. is paraphyletic with respect to Pliocercus. Inasmuch as the evolutionary history of Pliocercus is linked via mimicry complexes with venomous coral snakes ... we prefer to regard it and Urotheca s.s. as evolutionarily distinct sister genera.

One wonders whether "mimicry" of a sort might also have been involved in the evolutionary development of the distinctive color pattern of Eutrachelophis. This pattern includes striking dark-rimmed whitish ocelli or elongated spots on the head, or head and neck, with a weak semblance of dorsal dark spots/stripes anteriorly, becoming nearly uniform posteriorly. See figures $1-2$ and 4-8 in the species accounts. There is both inter- and intraspecific variation in the alignment of the pale ocellar markings, but the variation seems relatively minor and the combined patterns seem to us diagnostic at the generic level. Eutrachelophis bassleri and E. steinbachi differ from one another in the alignment of their postocular and nuchal markings (compare figs. 2 and 8)-but this minor 


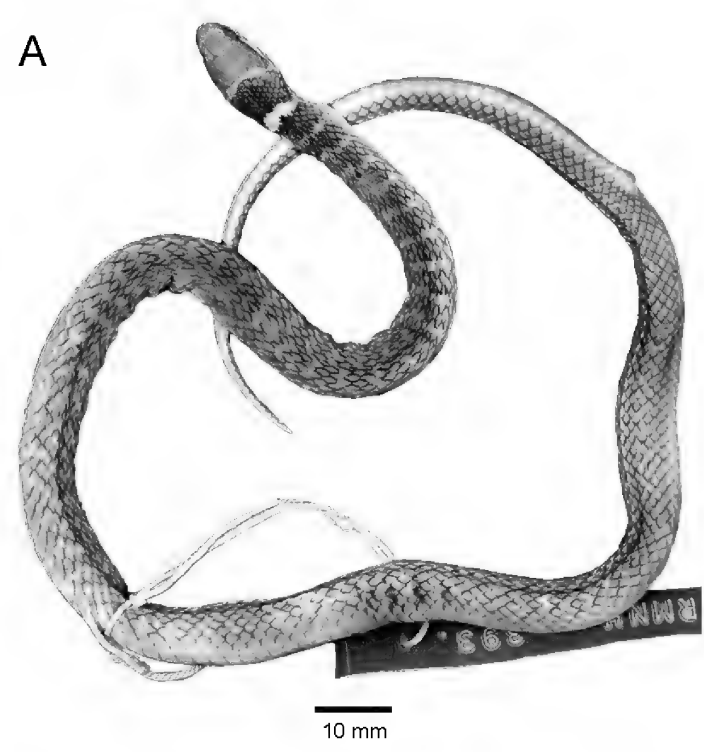

B

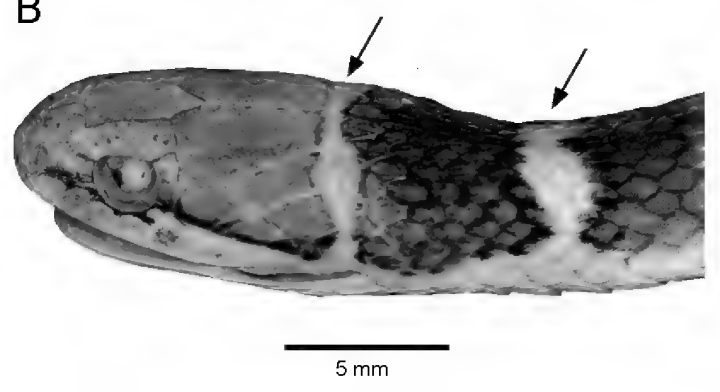

C

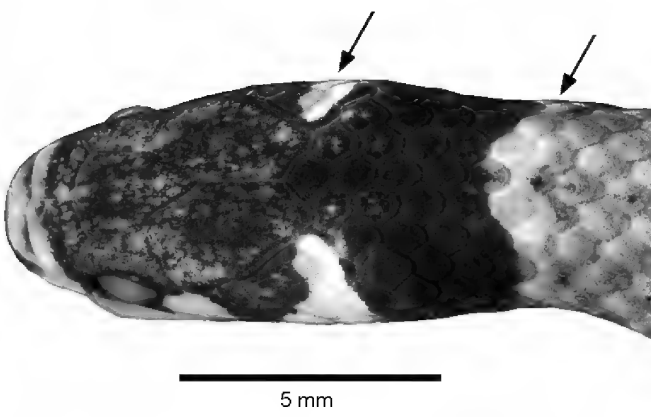

Fig. 13. Two unrelated small Brazilian snakes that are similar to Eutrachelophis spp. in nuchal markings and in having 15 dorsal scale rows, but they differ from each other and from Eutrachelophis spp. in fundamental hemipenial and maxillary characters. Color-pattern similarities in these and a few other small snakes include an anterior band or spots (first arrow), followed by paired spots or a fused pale crossbar (second arrow) that is medially constricted like the fused ocelli in some specimens of Eutrachelophis (compare with figs. 2 and 4). A, B. Amnesteophis melanauchen (Jan), a Brazilian variation is in total greatly exceeded in the similar markings of Rhadinaea decorata, as portrayed in Myers (1974: fig. 15A-E).

Although the head and nuchal patterns in Rhadinaea decorata include all the variants seen in the combined head and neck patterns of Eutrachelophis spp., parts of the overall color pattern of Eutrachelophis are shared with other snakes as well. The overall appearance of the head and neck pattern is reminiscent, for example, of Amnesteophis melanauchen (fig. 13A, B) and Tantilla melanocephala (fig. 13C). The pattern is intraspecifically variable in the last species and probably in the first (known from a single specimen). In figure 13 an anterior band or spots (first arrow) are followed by paired spots or a fused pale crossbar (second arrow) that is medially constricted like the fused ocelli in some specimens of Eutrachelophis (compare with figs. 2 and 4).

Postparietal and nuchal ocellar markings appear in Rhadinaea and other genera of "Rhadinaea-like snakes," 14 but only in a few, such as Echinanthera undulata, are they as conspicuous to the human eye as in Eutrachelophis (fig. 14A). More often, as in species of Taeniophallus, the markings represent the anterior terminus of a stripe or other body

\footnotetext{
14،"The Rhadinaea-like snakes are mainly tropical species of similar habits and habitus--terrestrial in forest, usually diurnal (always with round pupils), small and slender, often striped, and with a generalized colubrid morphology" (Schargel et al., 2005: 12). They include but are not limited to genera recently removed from Rhadinaea (i.e., Rhadinella, Taeniophallus, Urotheca; see Myers, 2011: 26-19). Some Old World snakes also are Rhadinaea-like in the above sense, as pointed out by Cadle (1996a: 374) when he named the new Liopholidophis rhadinaea from Madagascar; the males of this species have extraordinarily long tails, but SVL of males and total lengths of females are comparable to many Rhadinaea. Although species of Rhadinaea generally are smaller, more delicate snakes, $R$. taeniata approaches some Liopholidophis in size.
}

snake that is known only from the type specimen collected in or at "Bahia" prior to 1863 (reproduced from Myers, 2011). C. Tantilla melanocephala (Linnaeus). AMNH R-101970 from Amazonas, Manjuru River ( $\left.4^{\circ} \mathrm{S}, 57^{\circ} \mathrm{W}\right)$. Head and nuchal patterns probably are intraspecifically variable in all. 
color (fig. 14B) or simply the anteriormost of a series of similar spots (fig. 15A). On the other hand, a distinct white canthal-postocular line occurs in different species of Rhadinaea and Taeniophallus but seems absent in the variational repertory of Eutrachelophis. Some of these snakes, such as Taeniophallus bilineatus (fig. 14B), share with Eutrachelophis a lateral line of whitish dashes emphasized by black edging, found on row 4 in $E$. bassleri (fig. 1A) and row 6 in E. steinbachi (figs. 5, 6), although these lines are nonhomologous (being edging to a dark lateral stripe in steinbachi). Similar species-specific differences in positioning of this line of pale dashes (and the black edging, which may show as a continuous narrow stripe) also occur in other genera (e.g., the decorata group of Rhadinaea).

Generalities BASEd ON EUtracheloPHIS-LIKE COLOR PATTERnS: A few correlations based on this section seem of interest. First, all the examples given are of little serpents that are mostly (entirely?) inhabitants of leaf litter in humid forest. All are small, relatively slender snakes with usually smooth dorsal scales (some weakly keeled in Amnesteophis), usually in 15 rows or 17 rows in a few. Of particular interest is the variation usually present in the head and nuchal color patterns of clearly unrelated species. These patterns seem exceptionally variable within species. There is little or no evidence showing the patterns to be strongly constrained by natural selection-leading to the notion that selection may actually favor the variability, especially of ocellar markings. (Reader: construct your own explanatory scenario.) Neck "rings" (simple collarlike markings) seem somewhat less variable within species, the best example being perhaps the familiar, geographically widespread North American ring-necked snakes (Diadophis); even in this genus, however, the neck ring is sometimes broken or even absent. Color patterns of the head and neck may have potential for active evolutionary change in small leaf-litter snakes.

\section{HEMIPENES}

Eutrachelophis bassleri has an extremely unusual hemipenis when compared with "colubrid" and "xenodontine" snakes generally. E. bassleri originally was thought to be a species of Leimadophis (now $=$ Liophis), although that was ruled out once the hemipenis and its retractor muscle were seen to be unbifurcated. Nonetheless, from the appearance of the distal nude section of the retracted hemipenis (fig. 3A), it still seemed possible that it might evert as a large flattened or centrally depressed apical disc. If that were the case, it might somehow support a relationship with the Xenodontini (which have apical discs on bifurcated hemipenes). Instead, the E. bassleri organ everted with a domelike head or capitulum (fig. 3BD) ${ }^{15}$ Although there are some similarities with the hemipenis of its unnamed sister species (fig. 4 and associated text), we have seen nothing quite like the hemipenis of $E$. bassleri among Neotropical snakes. A resemblance to the general physiognomy of the bassleri hemipenis is found in the Malagasy Compsophis infralineatus, as shown in figure 21; this species also has a pronounced hemipenial head or capitulum without being capitate.

On the other hand, although the deeply divided hemipenis of Eutrachelophis steinbachi (fig. 9) is markedly different from, E. bassleri, it has parallels in other taxa. Genera with similarly long-lobed hemipenes include the South American Xenodon suspectus, X. rabdocephalus, and the African, Mehelya poensis, all to be discussed and illustrated later.

Consideration of such differences might begin with the concept of a "random walk" (sensu Raup and Gould, 1966). ${ }^{16}$ The analogy

\footnotetext{
${ }^{15}$ This hemipenis is not "capitate" in the usual sense because the capitulum lacks "a free overhanging edge" (Myers, 1974: 31) or "capitular groove" (Zaher, 1999: 9).

${ }^{16}$ Raup and Gould (1966) give an idea of how much similarity might be produced by random computer changes in morphology. A punctuated equilibrium model was imposed that did not allow phyletic change in the ancestral species and permitted "morphological change" only in association with the speciation process. Interspecific evolutionary effects and adaptation to unexploited niches were intentionally omitted, since one purpose was to determine how much of the pattern usually interpreted as adaptation to coexistence of species could be produced by chance.

The characters generated in Raup and Gould's simulation of "morphology" are not comparable to "morphological characters" as used by most herpetologists, but are more analogous to growth rates,
} 

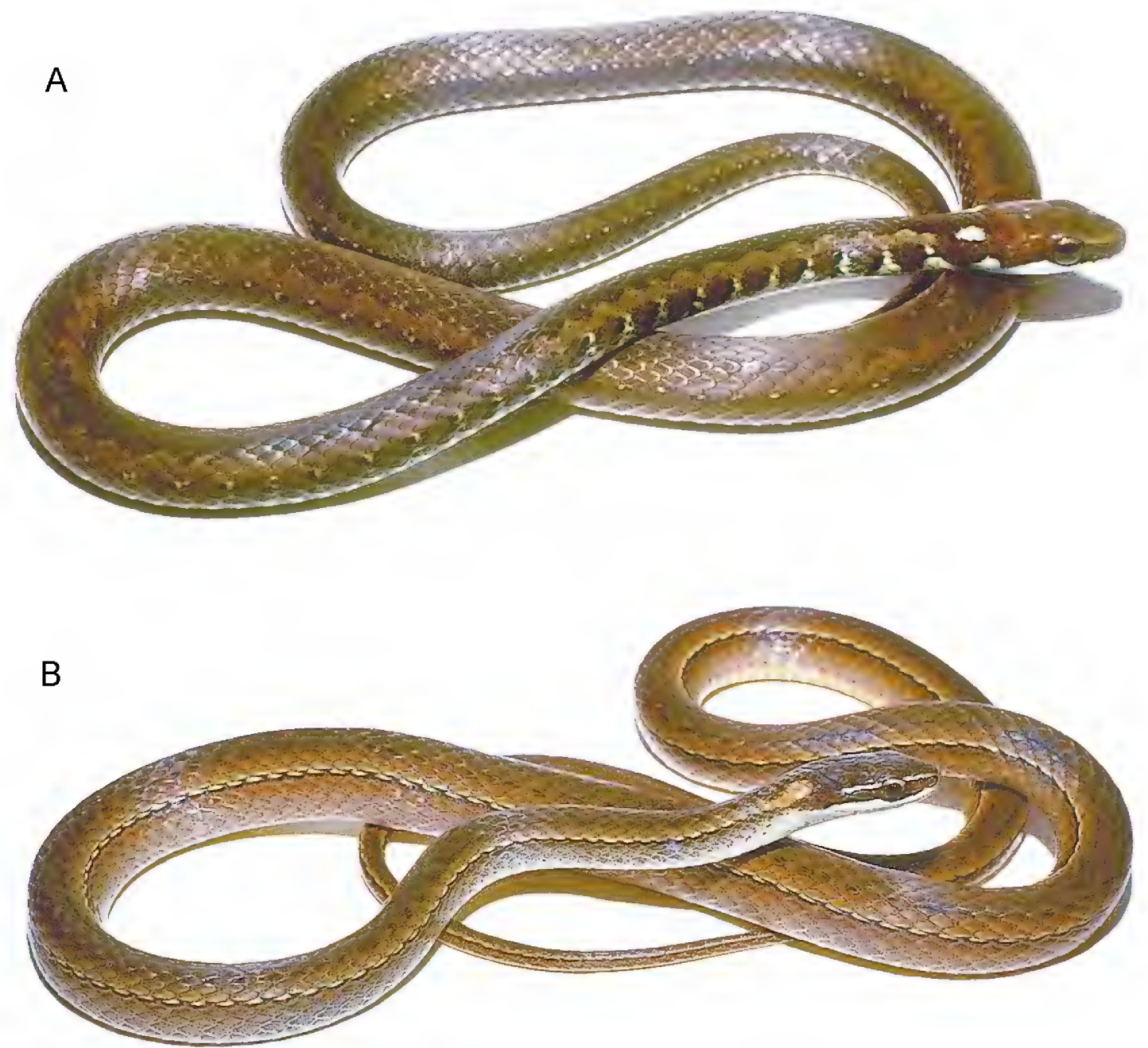

Fig. 14. A. Echinanthera undulata (Wied). Vivid pale nuchal spots - similar to Eutrachelophis spp.characterize some xenodontine (and dipsadine) snakes such as this Brazilian snake (AMNH R-119764). B. Taeniophallus bilineatus (Fischer). A distinct lateral line of whitish dashes emphasized by black edging characterize Eutrachelophis spp. and other xenodontines (and dipsadines) such as this Brazilian species (AMNH R-119769); the pale canthal line seen here is variably present in "xenodontines," but does not occur in Eutrachelophis (photographs by C.W. Myers).

\section{$\leftarrow$}

tissue differentiation rates, cell migration rates, hormone production rates, hormone response rates, etc.; that is, the analogy is to quantitatively variable developmental processes. Taxonomists prefer "characters" that are binary and Raup and Gould's simulation does not describe the way taxonomists like to use "characters." Their simulation reflects Raup's (1966) virtuoso performance in explaining most of the morphology of snail shells by three independent growth rates.

Therefore, a vertebrate taxonomist can take little comfort from Raup and Gould's ability to recover most "phylogeny" from the "morphology" of their "species."
This "morphology" was relatively well known, since each generating "growth rate" was known. Yet, with this perfect knowledge of the determiners of form, Raup and Gould could obtain only a close, but imperfect, reconstruction of the "phylogeny." Their simulation of a phylogeny with morphological change was a random walk model, and. as they discuss, it did not produce a general convergence of all "phyletic lineages" on some average morphology. Instead, various "lineages" acquired distinctive "morphologies" and a recognizable suite of "morphological characters" (at least for their clade 91, discussed and figured with some detail). 


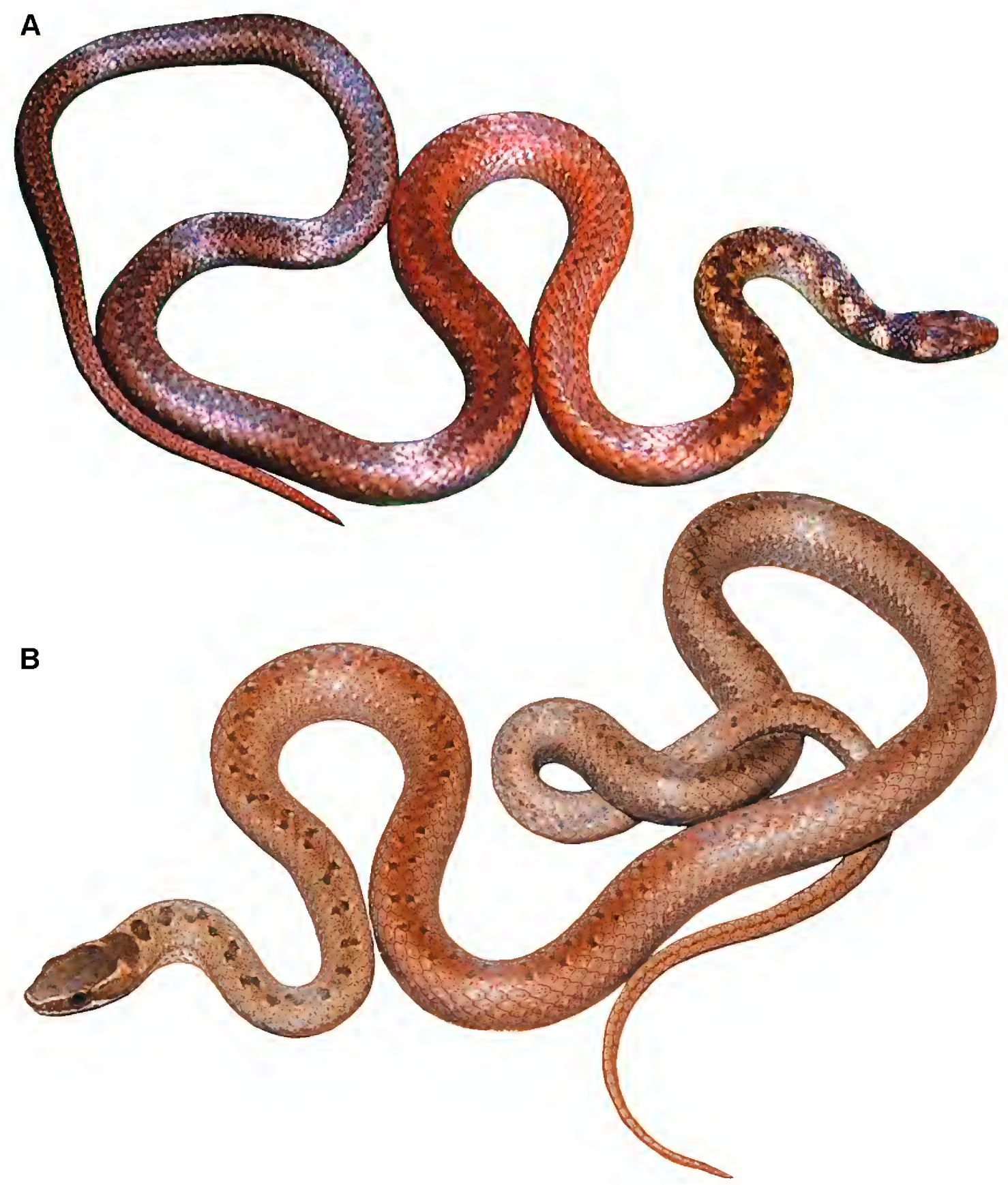

Fig. 15. A. Taeniophallus nicagus (Cope). This small Brazilian snake resembles Eutrachelophis in having 15 dorsal scale rows and an ocellar nuchal pattern. It differs in hemipenial characters from closely related congeners and from all other xenodontines (and nearly all dipsadines) in having an unforked sulcus spermaticus. B. Taeniophallus occipitalis (Jan), a Brazilian specimen. This species displays considerable variation in the head and nuchal color pattern, sometimes resembling $T$. nicagus above (cf., T. occipitalis in Myers, 1974: fig. 48) (photographs by Marcio Martins). 
between a random walk and what appears to be the phylogeny of colubrids is striking. The analogy is particularly apparent when $\mathrm{Eu}$ trachelophis bassleri, E. steinbachi, and other "xenodontines" are compared with the colubrids of Madagascar. One Madagascan colubrid, Mimophis, differs from other Madagascan forms, as well as from all "xenodontines," in the greatly reduced hemipenis; it is a psammophiid and seemingly represents an independent Madagascan invasion separate from other colubrids (Cadle, 2003; Nagy et al., 2003; Kelly et al., 2008). Putting aside Mimophis, all the other Madagascan colubrids represent a monophyletic clade (Pseudoxyrhophiinae), all members of which differ from Eutrachelophis bassleri and E. steinbachi in the presence of strong hypapophyses on the posterior vertebrae, even though these two Neotropical snakes agree with all Madagascan colubrids in lack of hemipenial calyces and show a particular resemblance to Thamnosophis lateralis (but not to Liopholidophis sexlineatus) and to Dromicodryas in the construction of the orbital region of the skull. Although lack of posterior hypapophyses distinguishes many "xenodontines" from Madagascan colubrids that resemble them (e.g., the xenodontine Liophis and the Madagascar Liopholidophis), it is not absolutely diagnostic, since some "xenodontines" (e.g., Amastridium, Ninia, Nothopsis) have posterior hypapophyses, but these "xenodontines" with hypapophyses do not happen to have any counterpart in Madagascar that resembles them (the "xenodontines" mentioned have hemipenial calyces, for example). Even though the Madagascan Thamnosophis lateralis is more like Eutrachelophis steinbachi than it is like the Madagascan Liopholidophis sexlineatus in construction of the orbit, and also in the maxillary dentition with a broad diastema anterior to the enlarged last pair of teeth and in the terminal expansion of the parasphenoid, it differs from Eutrachelophis steinbachi and resembles Liopholidophis sexlineatus in a feature of the hemipenis: the organ forks only a short distance distal to the furcation of the sulcus, whereas in Eutrachelophis steinbachi the sulcus forks near the base of the organ, while the organ itself forks well distal to this, and in Eutrachelophis bassleri the unforked organ ends far distant from the sulcus furcation. But this hemipenial difference fails when we compare Eutrachelophis steinbachi with Dromicodryas (probably closely related to Thamnosophis lateralis, and with a similar orbit and with a distinctly expanded tip of the parasphenoid [expanded and also forked in the specimen illustrated by Cadle, 1996a: fig. 39, bottom]), since Dromicodryas also has the furcation of the sulcus far proximal to the terminal bilobation of the organ. However, Dromicodryas is not a "morphological intermediate," since its maxillary dentition lacks posterior enlarged teeth and diastema (thus suggesting the Madagascan Liophidium and Micropisthodon, which it also resembles in having a reduced splenial bone, but these genera have the sulcus furcation near the furcation of the organ).

In spite of a search involving details of the skull, lungs, hemipenial morphology, and head muscles, no character has emerged that will distinguish all Madagascan colubrids from all "xenodontines." This is precisely what would be expected if both the Madagascan radiation and the "xenodontine" radiation represent random walks with similar rules for morphological change. The same characters might easily arise here and there in both radiations, but for the same character combinations to arise in both radiations would be quite improbable.

Even without taking the comparisons to Madagascar, the question remains: How can one conceive Eutrachelophis bassleri and E. steinbachi as congeners when they have such markedly different hemipenes? We explore this question further in the Discussion below. See also the Commentary on Hemipenes as Generic and Specific Characters.

\section{Summary OF Global COMPARISONS}

Various details have been noted in the preceding anatomical and color comparisons; few of these details need be considered important in themselves, since they involve characters known to vary among "xenodontine" snakes. However, as summarized here, some shared traits are rare or uncommon and, in total, these appear indicative of close relationship between Eutrachelophis bassleri and E. steinbachi. 
Viscera AND HEAd Glands: Characters of the viscera are widely shared and provide nothing of special interest. Among features of the head glands, both species (1) show an unusually large temporal extension of the Harderian gland; and (2) lack evidence of a rictal gland (sensu McDowell, 1986). Finally, (3) both species, plus the unnamed sister species of $E$. bassleri, have a well-differentiated, similarly positioned "supralabial gland," the outline of which can easily be seen through the postorbital supralabial integument in some preserved specimens (fig. 4). The serous (Duvernoy's) portion of this gland is not clearly differentiated (to gross examination) from the mucous part of the gland, and enlargement of the rear maxillary teeth is not accompanied by a correspondingly conspicuous differentiation of the gland.

HeAd Muscles: (1) Both Eutrachelophis bassleri and E. steinbachi have unusually weak jaw muscles and neither species is well adapted to engulfing relatively large prey while exerting much force. (2) The levator anguli oris of both species is converted into a compressor of the Harderian gland; only the more posterior fibers of this muscle are retained, with only those originating on the parietal being present; no fibers originate on the postorbital and none extend to the corner of the mouth or curve forward beneath the corner. (3) The insertion pattern of the retractor arcus palatini in both bassleri and steinbachi is the pattern that is most common among colubrids, but in both species this muscle is unusually slender, its origin from the sphenoid being slightly narrower than the origin of the retractor vomeris (also on the sphenoid). In most New and Old World colubrids, the retractor arcus palatini is at least slightly larger, usually conspicuously larger, than the retractor vomeris.

SKull AND Dentition: (1) The skulls of E. bassleri and E. steinbachi have an unusually short tabular, such as seen in some small-eyed burrowers, but it is combined with a construction of the orbit associated with largeeyed snakes. (2) When details of foramina of the sphenoid and prootic are considered, there is a virtual identity between the two skulls, even though the foramina are so labile that closely related snakes, or even the left and right sides of the same skull, may differ.
The only significant skull difference between the two is that E. steinbachi has a dorsal crest of the parasphenoid rostrum that is lacking in E. bassleri. (3) The presence of venous (?) foramina dorsal to the trigeminal ganglion, together with the details of the pituitary vein foramen, result in an exceptional pattern not duplicated in any other "xenodontine" examined. (4) The dentition and shapes of the dentigerous bones show a near identity in E. bassleri and $E$. steinbachi. Also to be included is the form of the ectopterygoid, which is so easily modified that differences often are seen between closely related species; both species agree in having a long (for Colubroidea) retroarticular process.

COLOR PATTERN: The distinctive color pattern of Eutrachelophis includes striking dark-rimmed whitish ocelli or elongated spots on the head and neck, with a weak semblance of dorsal dark spots/stripes anteriorly, becoming nearly uniform posteriorly. Eutrachelophis bassleri and E. steinbachi differ from one another mainly in the species-specific alignment of the postocular and nuchal markings (this variation is in total exceeded by similar markings of Rhadinaea decorata). As discussed, other small leaf-litter snakes share elements of the Eutrachelophis color pattern and some also have 15 rows of smooth dorsal scales, but none is likely to be mistaken for Eutrachelophis and all differ fundamentally in features of dentition and hemipenes.

\section{DISCUSSION}

Eutrachelophis bassleri and E. steinbachi are very similar or identical in all anatomical details except for the hemipenes. The most convincing similarities concern the skulls. That the single skull examined of Eutrachelophis steinbachi should agree with the single skull examined of $E$. bassleri in so many details is not reasonably explained by convergence or "accidental resemblance." Because only a single skull of each was examined, we cannot even be sure that the few differences between them are constant. What can be said is that one individual of Eutrachelophis steinbachi is extremely similar in all cranial details to one individual of $E$. bassleri, and such close adult anatomical similarity is most easily explained by a very close similarity in the 


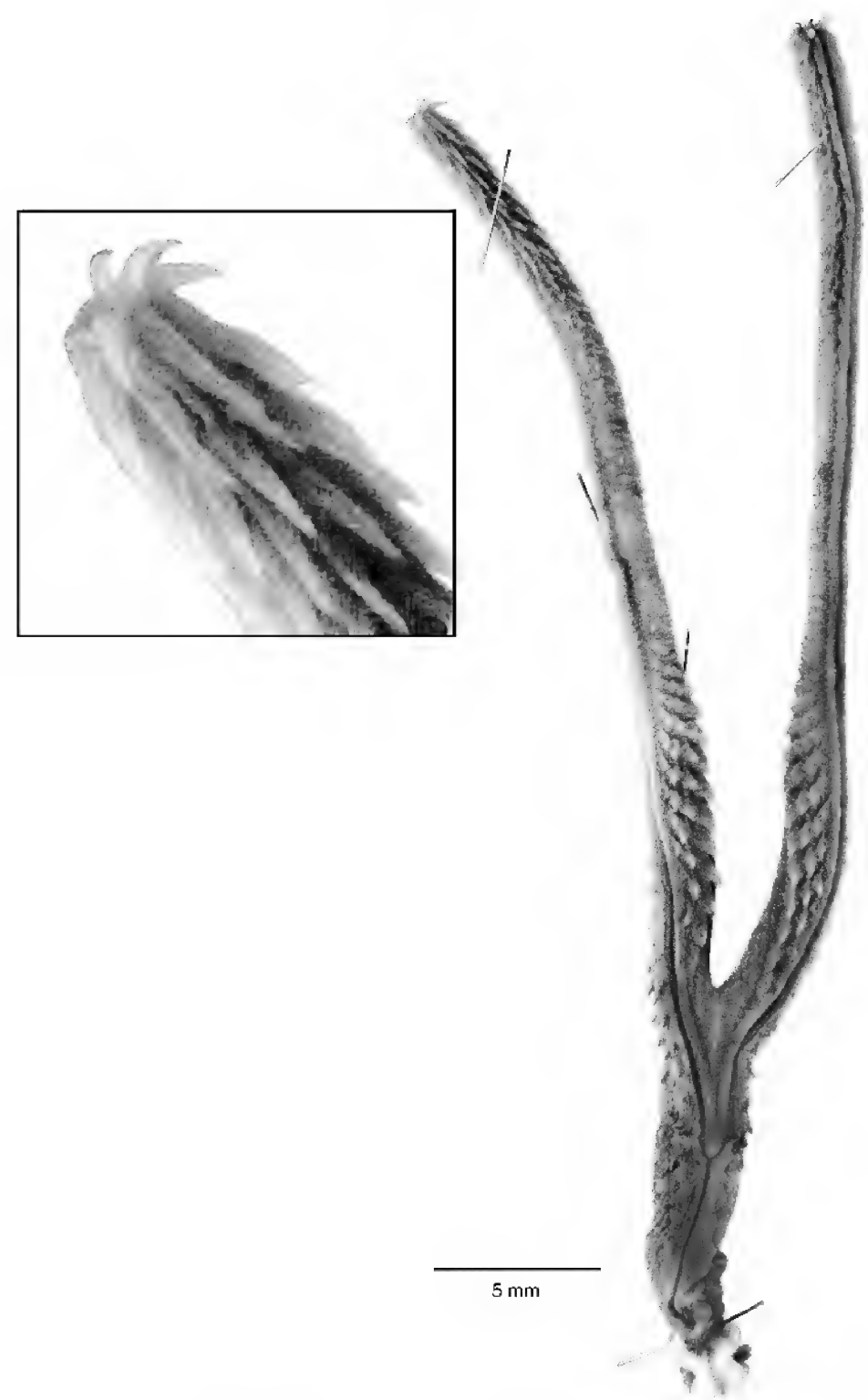

Fig. 16. Everted hemipenis of Mehelya poensis (Smith). (AMNH R-12053, left organ.) This is a slight, deeply forked hemipenis with long slender lobes and a very long retractor muscle that originates close to the tail tip. This organ divides at subcaudal 4, with the lobes terminating at about subcaudal 21 (an indistinct join between lobe and retractor); the two slips of retractor muscle fuse at subcaudal 29 , but the long muscle continues posteriorly to a broad attachment between caudals $46-49$, only 10 subcaudals before the terminal caudal spine.

development of the head and, by inference, in the genes regulating this development.

Among taxa compared in this study, Liophis is most like Eutrachelophis bassleri and E. steinbachi in the following characters of skull and dentition:
Two posteriormost maxillary teeth conspicuously enlarged, with the ultimate one set off laterad; diastema usually present;

Frontals raised above the trabecular;

Parasphenoid rostrum narrow but with expanded tip and shallowly trilobated; 
Vidian canal short, with anterior orifice set well in from border of sphenoid;

Palatine with long posterior shaft and a narrow but long and transverse choanal process; and

Relatively long splenial.

Perhaps better stated, these cranial similarities make Liophis least dissimilar among "xenodontines" that also show some similarity in hemipenial morphology to Eutrachelophis.

\section{HYPOTHESIS FOR HEMIPENIAL \\ TRANSFORMATION IN EUTRACHELOPHIS}

A few hemipenial characters seem to provide the only major structural differences between Eutrachelophis bassleri and E. steinbachi. In E. steinbachi, the hemipenis has long lobes, each lobe bearing a branch of the sulcus in a strictly centrifugal position, but with the lobe extending well past the termination of the sulcus. In E. bassleri neither the organ nor its retractor divides, although the sulcus does divide and its branches almost reach the end of the uneverted organ in a centrolineal position, becoming centrifugal upon eversion owing to differential tissue expansion. There is certainly no striking resemblance that would suggest close relationship solely on the basis of hemipenial morphology, but neither of these two species shows striking resemblance to any other "xenodontine" that would suggest an alternative phylogeny. There are slight colorpattern differences between $E$. bassleri and $E$. steinbachi, but these are common sorts of species-specific differences found in other genera and sometimes even exceeded in the variational repertory of single species (see above under Color Pattern).

Since molecular data cannot be brought to bear, the only differences conceivably of generic value are the hemipenes. The hemipenis of $E$. bassleri seems to be unique, that of E. steinbachi uncommon, simply because of the extent of its bilobation. In the latter, a pair of long and rather narrow organ lobes extend distally, with each long lobe having a peculiar prolongation that extends past the end of the sulcus and ends in elongated spines. The hemipenis of E. steinbachi may be concisely described as a deeply divided (longlobed), spinose, acalyculate noncapitate hemipenis, with an apical tuff of differentiated spines and a bifurcate centrifugal sulcus spermaticus.
This description also well fits the African colubrid Mehelya poensis, ${ }^{17}$ which differs mainly in size of the lobular spines (fig. 16). On the hemipenis description alone, one could claim that that Eutrachelophis steinbachi and Mehelya poensis were congeneric, but clearly the hemipenis fails at this point.

If growth were to stop before development of the long lobes, the organ of E. steinbachi might not be very different from that of $E$. bassleri. The hemipenes of Eutrachelophis spp. differ overall in appearance from hemipenes of most other "xenodontines"-lacking the apical disc of Liophis and other Xenodontini or lacking a calyculate region that is set off or not by a free edge (capitate). Both Eutrachelophis bassleri and E. steinbachi have the sulcus forked near the base of the organ, presumably indicating that the sulcus forks early in its development as it extends out onto the hemipenial rudiment. ${ }^{18}$ The

\footnotetext{
${ }^{17}$ Kelly et al. (2011: 425) treat this species as Gonionotophis poensis in their "new provisional membership of Gonionotophis" because "it is reasonable to predict that species of Mehelya and Gonionotophis not included in our taxon sample will prove to be part of the Mehelya - Gonionotophis clade." They usefully summarize partial hemipenial data for Gonionotophis, Inyoka, Hormonotus, Boaedon, and Lycodonomorphus - but it is worth noting that Gonionotophis grantii (McDowell, unpubl.) differs from congeners in having a long, unilobed (undivided) hemipenis. They (loc. cit.: 424) revive the genus Boaedon for a strongly supported monophyletic group, although there are no clear morphological synapomorphies.

${ }^{18}$ Clark (1945) found the sulcus of Diadophis to fork in development after the major retractor muscle divided and suggested that the division of the retractor was, in some fashion, responsible for the forking of the sulcus. This might be true for Diadophis, with short but distinct terminal lobes and a sulcus that forks in the distal part of the organ, but it is unlikely to be true of Eutrachelophis bassleri, with a sulcus forking far below the tip of an organ that is undivided and that also has an undivided major retractor (unless some sort of secondary refusion of a divided retractor muscle has taken place).

Clark observed that the rudiments of the spines develop simultaneously with the sulcus rudiment, on transverse folds of the organ surface. If this pattern were to persist throughout life, it would yield transverse rows of spines, perhaps retaining enough of the fleshy transverse folds between their bases to be described as "transverse spinose flounces." In many "xenodontines" with a short and broad hemipenis, such as Rhadinaea flavilata and Coniophanes fissidens, the spinose zone of the adult organ clearly shows a few transverse tiers of spines. In Diadophis (the "xenodontine" studied by Clark), the adult organ
} 
proximal furcation of the sulcus and the moderately divergent (rather than nearly parallel) rami of the sulcus permit the distal ends of the rami to reach a position farther from the midline than in, for example, Hydrops marti or Rhadinaea flavilata. In Eutrachelophis steinbachi and in the everted hemipenis of $E$. bassleri, the rami of the sulcus reach fully lateral (centrifugal) positions on the sides of the organ; this does not simply reflect the greater length of the sulcal rami in E. steinbachi, where the sulcus branches extend onto long organ lobes missing in E. bassleri.

In Eutrachelophis bassleri the entire distal part of the simple organ is nude, but in $E$. steinbachi the distal lobes of the organ bear spines. However, the crotch of the organ in $E$. steinbachi is smooth except for small expansion folds and we suggest that this "smooth" crotch area (i.e., the smooth terminal basin) probably is homologous with the entire distal end of the organ of E. bassleri. Although the major pattern of the hemipenis develops before hatching (or birth), when the organ is everted, some details of the pattern probably arise later and may involve considerable rearrangement by differential growth. For example, mineralization of hemipenial spines to form stiff structures, rather than flexible papillae, seems to occur with sexual maturity, rather than with birth or hatching, and the definitive adult pattern of major hemipenial spines often differs from species to species, or genus to genus, in a manner suggesting differential growth superimposed on a com-

shows the spines on longitudinal rugae or pleats when the inverted organ is dissected, but there is a correspondence from pleat to adjacent pleat allowing assignment of the individual spines to transverse tiers, probably representing the transverse flounces on which the spines first formed, but with this transverse arrangement now erased by superimposed longitudinal pleating; the development of distally directed roots of the spine mineralizations, these roots lying in the fleshy rugae or pleats, strengthens these pleats and a staggered pattern is imposed on the spines by spatial constraint (presumably these spines develop their rigidity in the inverted organ of the juvenile after hatching and probably crowd one another in this restricted space. mon pattern, presumably that laid down in early development.

THE EXPLANATORY HyPOTHESIS: Eutrachelophis bassleri and E. steinbachi are derived from common stock in which embryonic development of the hemipenial lobes was suppressed. The resulting broad, hemispherical nude apex (dome) in E. bassleri is homologous with the interlobular smooth terminal basin in E. steinbachi. Judging from the presence of expansion folds in the retracted hemipenis, the interlobular basin of E. steinbachi when everted may acquire a size comparable to that of the nude dome of $E$. bassleri. Thus, very different looking hemipenes appear to have resulted from a simple change in the hemipenial growth rate. Compare figures 3 and 9, and see follow-up commentary under Evolutionary Plasticity and Extreme Divergence of Snake Hemipenes.

Thoughts on Hemipenial ORNAMENTATiON AND Armature: Calyces and flounces are structures formed from the superficial epithelium, whereas spines are formed in the mesenchymal layer of the hemipenial wall (Clark, 1945). There seems to be a proximal-distal gradient in most colubrid hemipenes in the degree of formation (or, at least, retention in the adult organ) of epithelial ornamentation. At the base ornamentation in the adult organ is entirely by spines and spinules of the mesenchymatous layer, but distally epithelial structures form the chief or only ornamentation, whether as flounces, coarse and smooth calyces, more subdivided and papillose calyces, or papillose calyces so subdivided and closely packed that only the papillae are visible. A frequent feature is a terminal region (in simple organs) or a region in the crotch (in bilobate organs) where the epithelium fails to form (or maintain?) ornamentation and, instead, forms a smooth terminal basin. A terminal basin occurs in so many colubrids, both New and Old World, that one may suspect it is a primitive colubrid feature, but it might be produced by suppressing the last stages of epithelial ornamentation, since Clark's (1945) work suggests that ornamentation develops from the base distad.

In Eutrachelophis, the adult organ shows no sign of any epithelial ornamentation 
(unless the sulcus itself represents epithelial ornamentation) and has only spines, presumably of mesenchymatous origin. This may be the extreme of a quantitative trend seen in many "xenodontines," most South American, as well as in many other Colubroidea: reduction of epithelial ornamentation to the distalmost part of the organ (as calyculate capitations on the distal lobes in Pseudoboini, or as apical discs on the tips of the lobes in most Xenodontini), and total suppression of epithelial ornamentation in some specimens of Xenodon (see below, Loss of a "Generic Character" - the Apical Disc) and in Diaphorolepis (in contrast to its probable relative Synophis, with crenulated calyces on the lobes; Bogert, 1964). Unfortunately, no developmental data are available on whether epithelial ornamentation is so restricted or lacking from initial embryonic formation of the organ or represents a later flattening of the epithelium; quite possibly, both methods of loss of epithelial ornamentation may occur. Nor is there any necessity (or even probability) for loss of epithelial ornamentation to occur only once in phylogeny (the failure of the epithelium to form folds is very likely an independently acquired characteristic of the Madagascan colubrids, for example, and probably also of natricine colubrids and of some species of Lycodon). It scarcely needs mention, considering the paucity of simple observations of development of snake hemipenes, that there seems to be no experimental evidence at all on possible inductive relationships between the epithelium and the mesenchyme. Such data would be invaluable in interpreting the evolution of the hemipenial characters that have been utilized so extensively by taxonomists in the 19 th and early 20 th centuries.

\section{ON the Apical DisC}

It must be remembered that all that can be said of Eutrachelophis is that the hemipenial epithelium does not form projecting folds or papillae in the adult organ; just what sort of epithelial ornamentation might have been lost cannot be observed in the adult organ. Nevertheless, it is attractive to interpret the derivation of the hemipenis of Eutrachelophis from that of a Xenodontini such as Liophis for the following reasons:
1. The sulcus diverges far proximally and spines form in the region between the sulcal rami, suggesting that this divergence occurs early in ontogeny, when the sulcal rudiment and spine rudiments are laid down. (An additional Xenodontini resemblance of Eutrachelophis is that the sulcus is fully centrifugal in E. steinbachi and becomes so ontogenetically in E. bassleri, but this might be a direct consequence of the very proximal divergence of the sulcus rudiment, and so cannot be counted as a separate character.)

2. The total absence of epithelial ornamentation in Eutrachelophis is strongly approached among Xenodontini whose only epithelial ornamentation is the apical disc. Since the apical disc of Xenodontini appears to be a specialization of the lips of the tip of the sulcus, presumably tissue that is somehow differentiated from the general epithelium of the hemipenis, loss of any other epithelial ornamentation in such Xenodontini as Liophis represents a strong approach to Eutrachelophis. Furthermore, Eutrachelophis bassleri lacks hemipenial lobes and $E$. steinbachi has the tip of the sulcus ramus falling well short of the tip of the hemipenial lobe: that is, the portion of the sulcus (the ramus at the tip of the organ lobe) that shows a capacity in Xenodontini to form an apical disc does not exist in Eutrachelophis. The apical disc, with a free edge, is a very peculiar structure, known only in the New World Xenodontini and in a few Boidae.

Whatever the mechanics of the development of the Xenodontine apical disc may be, they would seem to be complex and unlikely to be duplicated by chance (but nonetheless duplicated by the nonhomologous apical or apicolateral discs on the hemipenial lobes of a few Asiatic and North American boids, as well illustrated in Branch, 1986: fig. 5A, B). Derivation from a stock ancestral to Xenodontini that had assembled all but one of the necessary genes for formation of discs could yield a clade very closely related to Xenodontini but lacking the taxonomic character that most clearly demonstrates this relationship. 


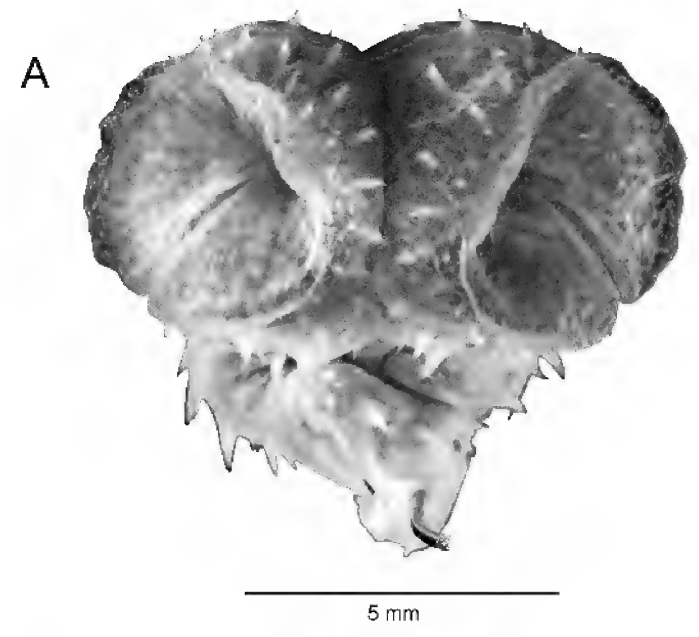

B
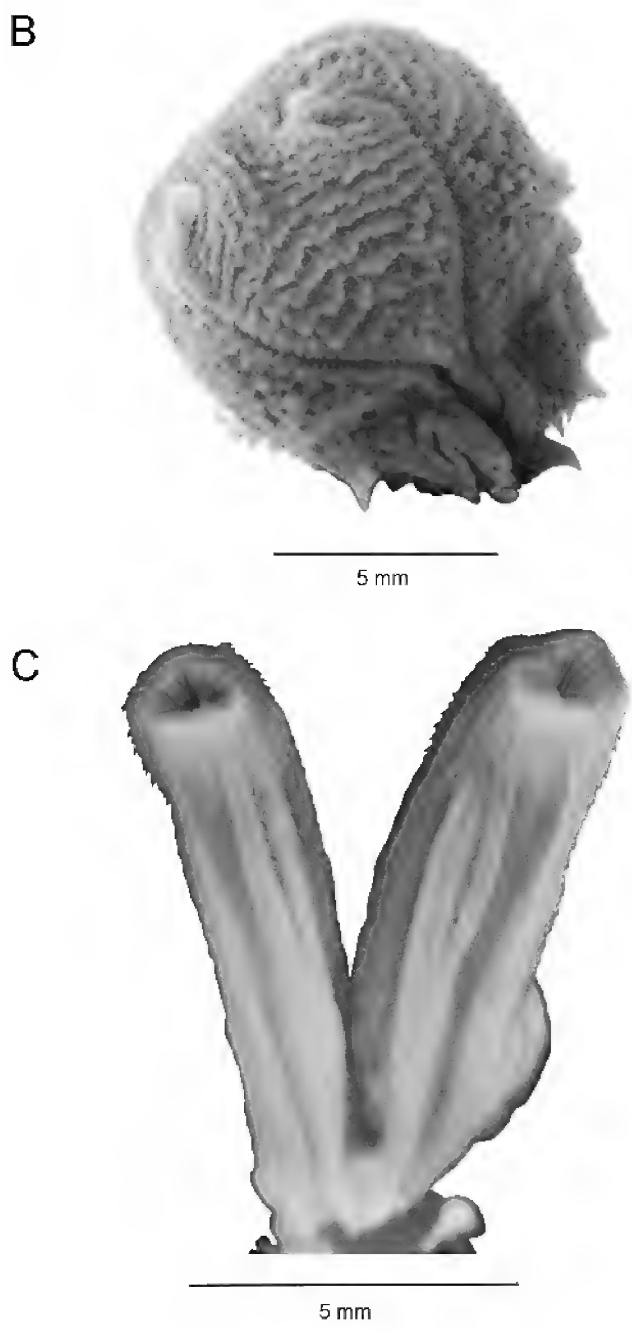

The apical disc (fig. 17A) is a clear-cut character that nonetheless is occasionally mistaken for some other apical nude area or, perhaps more frequently, for a hemipenial lobe with an "apical depression or dimpled tip"- -which usually indicates an incompletely everted lobe (but see fig. 17C caption and discussion in Myers and Cadle, 2003: 301); field eversions of some Malagasy Liopholidophis (including Thamnosophis in part) hemipenes might be thought to have apical discs except for lack of the defining, encircling lips (illustrations in Cadle, 1996a). Dowling (2004: 326) recently complained that Zaher's (1999) study of xenodontine hemipenes ignored two published descriptions of apical discs in the Middle American Conophis. For the first mentioned description, however, Myers (1986: 5: fn. 4) had already corrected it, noting:

Wellman (1963, p. 289) incorrectly described the everted organs of Conophis as being moderately calyculate with tiny apical discs on the short lobes. The spinose hemipenis of Conophis has neither calyces nor discs, being conspicuously flounced distally (flounces with spinulate to

Fig. 17. The tips of diverse bilobed hemipenes. A. Apical discs on the hemipenis of Liophis williamsi (Roze). The apical disc is a conspicuous depressed or somewhat flattened nude area that is defined by an encircling wall, which is broached only by intrusion of the sulcus spermaticus. It resists further eversion and is a defining character of the tribe Xenodontini that has been lost in a few species (AMNH R-117671, right organ). B. An almost completely everted hemipenis of Conopsis vittatus Peters. The dimpled tips on the short lobes each conceal a small nude projection that has been confused with the apical disc (UMMZ 82650, right organ). C. Apical view showing the "umbelliform depressions" on the tips of the deeply lobed hemipenis of Thamnosophis lateralis (Duméril, Bibron, and Duméril). The umbelliform depressions resemble "dimpled tips" that usually are certain signs that the lobes are not fully everted, but in Thamnosophis the apical depressions reflect broad internal attachments of the retractor muscles and do not conceal uneverted tissue (fide Cadle, 1996a: 439, 441). (Manually everted left organ of AMNH R-60691-not completely expanded but believed to be almost completely everted with minimal dimpling). 
papillate edges) and having a centrolineal sulcus spermaticus. The tips of most Conophis organs I examined are not quite everted ..., but, in the one illustrated by Wellman (UMMZ 82650), the apex of each short bilobation has at the terminus of the sulcus a hard, nearly nude (slightly papillate) bump or projection - the mistaken disc.

Wellman (loc. cit.) illustrated the left hemipenis, but the right organ is still attached and shows a small dimple at the apex of one lobe and the nearly nude uneven apex on the other (fig. 17B). Although he mentioned some interspecific variation, Wellman (loc. cit.) stated, "There are no apparent hemipenial differences among the species of the genus Conophis" - a statement attributed by Dowling (loc. cit.) to a later paper by Auth et al. (1998), which was Dowling's second example of a published reference to an apical disc in Conophis. ${ }^{19}$

Clearly one must not be led astray by misinterpretation or faulty description and must remember that an apical disc is a more or less centrally flattened or inwardly sloping structure within a defining, nearly encircling wall, or lip. Cope (1894: 840) initially called the structure "a membranous disc (Disciferi)," but in 1895 he coined the term "apical disc" for use in diagnoses and keys; he clearly illustrated it with drawings of inverted organs from nine xenodontines (Cope, 1895: pls. 26 [figs. 1-6], 27 [1-2], 28 [1]). The structure has been more recently illustrated photographically by Myers (1986: fig. 7) and by Zaher (1999: figs. 81 lower, 83 lower, and 83 upper). But although seemingly reliable as a taxo-

\footnotetext{
${ }^{19}$ This last paper (Auth et al., 1998: 109-110) described a "fully everted" hemipenis" of [another specimen of] Conophis vittatis from El Salvador, which purportedly has "two flat apical discs, centrally indented, in contact with each other, without a notable depression between; the calyces [emphases added!] on the discs are unornamented." This was almost certainly based on inaccurate observation of an incompletely everted hemipenis; the cited specimen (KU 183865) can be reexamined by anyone believing the description to be credible.

Myers (2011: 16) had additional comments on Dowling's (2004: 325-327) error-prone critique of Zaher (1999), including the charge that "it seems strange that Zaher failed to illustrate the hemipenis of the type genus of xenodontine snakes (Xenodon)." It was not "strange"-Zaher published photographs of hemipenes for three species of Xenodon, two of which show the defining encircling lips (see definition above and Zaher, 1999: 154-156).
}

nomic indicator, it does not follow that absence of apical discs proves lack of relationship to Xenodontini. Unless controlled by "simple" Hox gene switches, the probable developmental complexity of these structures would mean that a considerable number of things could go wrong in their formation, leading to secondary loss of discs, as appears to have happened in several species of Xenodon, as discussed below for Xenodon suspectus. See appendix 1 for additional populations of named and unnamed species of Xenodon that have lost the apical disc.

\section{LOSS OF A "Generic ChARACTER" - THE ApICAL Disc}

HEMIPENIS OF XENODON "RABDOCEPHALUS" (WIED): The taxonomic value of hemipenial characters is well known, but there is limited merit to the occasionally expressed belief that they are "better" or more "reliable" than other morphological features. We call attention here to the apical disc, which is used as a novel character to define tribe Xenodontini, whose type genus is Xenodon. Myers (1986: 1) noted that the tribe had been based "essentially on a single character - the paired apical discs, which may have been lost in some populations but which are accepted as a defining synapomorphy pending further study." See figures 17A and 18.

Myers' (1986: 1) published statement elicited a letter in 2001 from the late Garth Underwood (1919-2002). Underwood correctly assumed that Myers was referring to the hemipenis of Xenodon rabdocephalus, an exceptionally wide ranging snake that occurs from southern Mexico throughout Central America to Bolivia and northern Brazil. Underwood had been working with biometrician Clive Moncrieff and kindly summarized their work up to the year before his death:

Our holding of rabdocephalus [in the BMNH] consists of 52 specimens from southern Mexico to Bolivia and Brazil.... The most remarkable variation relates to the hemipenis; sixteen males are large enough for the retracted organ to be dissected. In all the hemipenis is symmetrically bilobed; it extends to subcaudals 12 to 20 , with the cleft between the lobes from 4 to 8 . Setting aside one from Honduras, the sulcus spermaticus forks at levels 2 to 4 , mostly 3 (12). Spines 


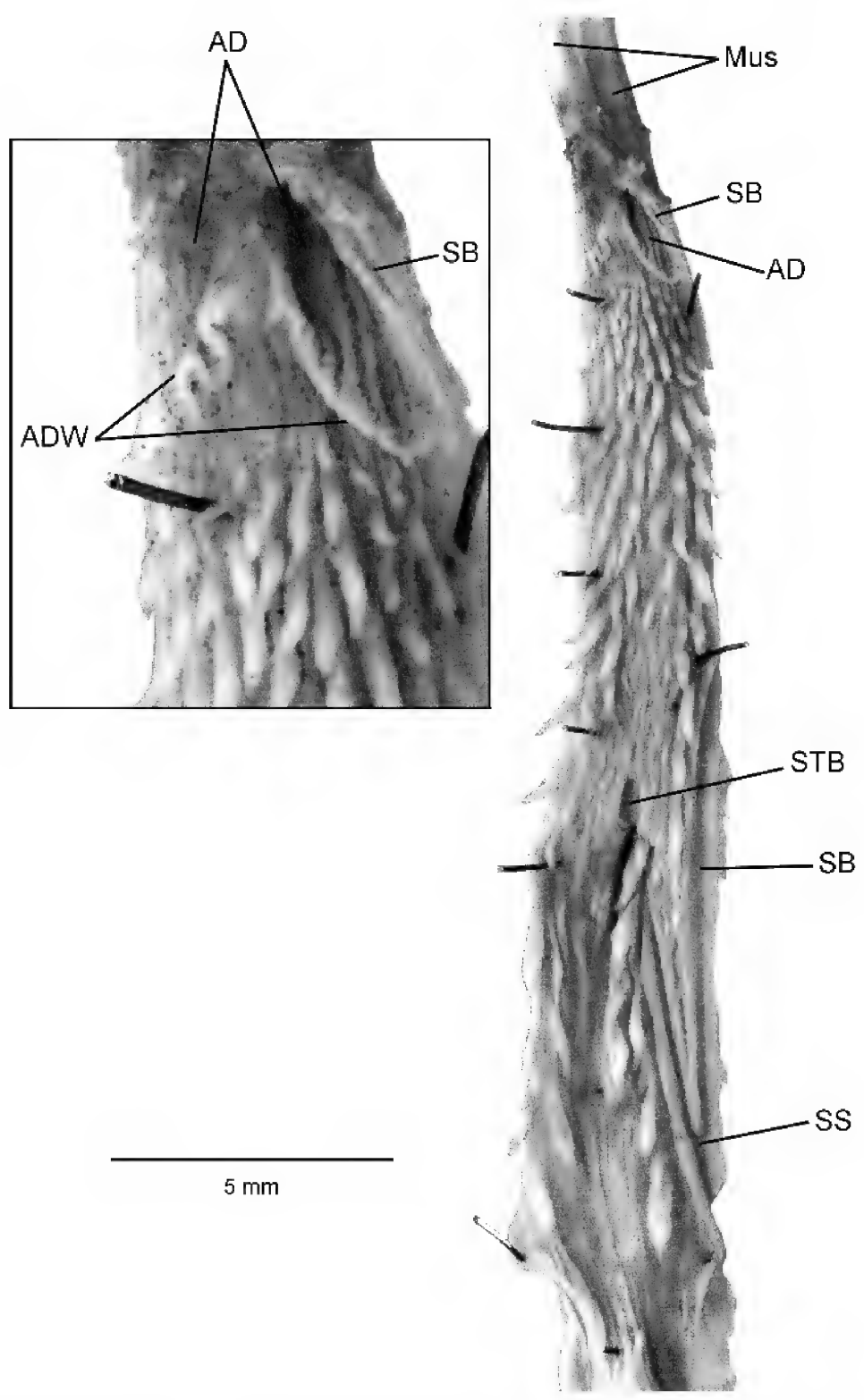

Fig. 18. Hemipenis of Xenodon rabdocephalus, sensu stricto. Right retracted organ of AMNH R-3609, from Bahia, Brazil; designated lectotype herein). Abbreviations: AD, apical disc; ADW, apical disc wall or lip; Mus, dorsal and ventral slips of the major retractor muscle; SB, branch of sulcus spermaticus; SS, sulcus spermaticus below fork; STB, smooth terminal basin.

start at level 2 or 3 ; the basal spines are from one to two subcaudals in length and diminish to fine spines distally on the lobes. Twelve hemipenes terminate in a bare tip; of these, five span Central America, from Belice [ $=$ Belize $]$ to Panama (4 8911 14), two are from Colombia (24 27) and five from Peru to Bolivia (31 3335 37 38). One, from Manáos [= Manaus] (45) has lobes that terminate in a tuft of small spines. The hemipenis of the specimen from Honduras (8) extends to subcaudal ten, with the cleft at five. In the right hand organ the sulcus fork is close to the base at level one, on the left the branch sulci effectively start separately from the base of the organ! Only two specimens, $\mathbf{4 3}$ from Guyana and 48 from Ilhéus, Brazil, have a 


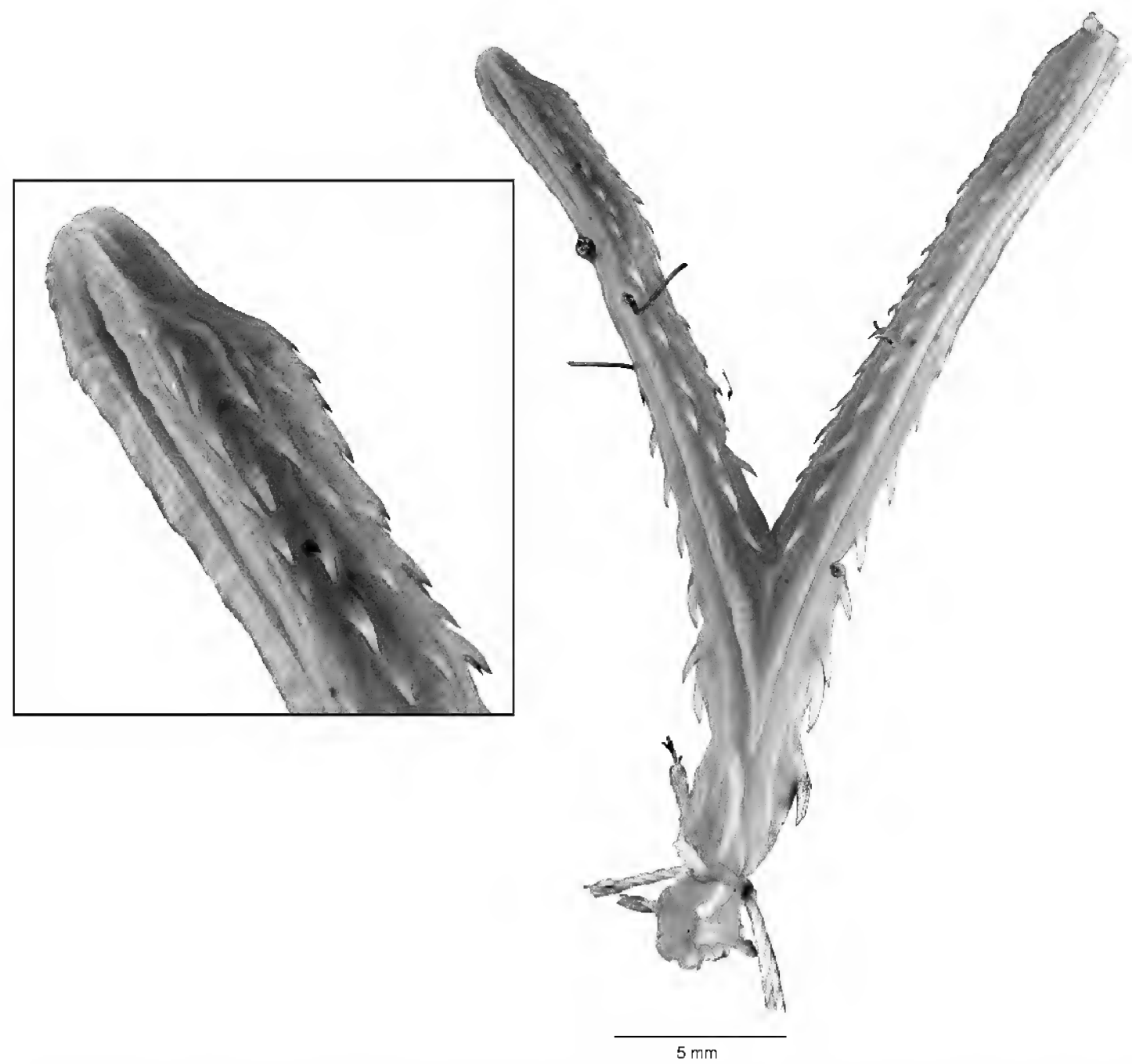

Fig. 19. Everted hemipenis of Xenodon rabdocephalus, sensu lato, in sulcate view. Right organ of AMNH R-81935, manually everted (terminus of right lobe burst), from central Panama. Inset: Greatly enlarged terminus of left lobe, showing nude tip lacking an apical disc. The name Xenodon angustirostris W. Peters, 1864, is resurrected herein for populations of $X$. "rabdocephalus" characterized by this kind of hemipenis (compare hemipenis with apical disc in fig. 18).

hemipenis that bears a terminal disc on ... each lobe ... This is how I come to be writing to you. I picked up that you had already noticed something strange about some Xenodon hemipenes. (letter, Underwood to C.W.M., August 19, 2001. AMNH Herpetology Archives, Myers Collection)

Regarding Underwood's reference to apical discs being present in only two (of 52) specimens-one each from Guyana and Brazil-we can add an additional specimen from Brazil. One of Wied's syntypes, herein designated lectotype has terminal discs (fig. 18). A published record (McCranie, 2011: 434) of a Honduran specimen having an "apex disc" is in error; the specimen (USNM 559716) has incompletely everted hemipenial lobes, with dimpled tips.

Myers quit pursuing the Xenodon rabdocephalus project after hearing from Underwood, who had managed to uncover an extraordinary amount of hemipenial variation in a 
named species that had appeared to maintain phenotypic similarity over an enormous geographic range. Underwood's largest sample of hemipenes (Middle America and Colombia to Bolivia), with lobes terminating in a "bare tip," is descriptive of several additional specimens prepared by Myers. Such examples from Panama and western Colombia have spiny lobes terminating in irregular bare tips that are not disclike (e.g., fig. 19).

Underwood also mentioned a specimen of Xenodon "rabdocephalus" from Amazonian Brazil (Manaus), with lobes terminating in tufts of small spines. That specimen may (or may not) represent a previously unnamed species, but it nonetheless is reminiscent of the following species, Xenodon suspectus, currently in the synonymy of $X$. "rabdocephalus."

HEMIPENIS OF XENODON SUSPECTUS COPE: This is an uncommon snake from the upper Amazonian drainage and Andean foothills. Myers dissected the left retracted hemipenes of two Peruvian $X$. suspectus (AMNH R52175,52244 ) from Chanchamayo and Contamana. Both have lobes slightly longer than the base of the hemipenis, which has large spines that are replaced distally by small spines over the entire lobe except the tip, which terminates in a cluster of longer, thin spines; there is no apical disc or other nude area at the tip. The first specimen is a juvenile with nonmineralized hemipenial spines; the second specimen is an adult, whose hemipenis is shown in figure 20 .

See appendix 1 for formal resurrection of Xenodon suspectus, lectotype designation for $X$. rabdocephalus, resurrection of $X$. angustirostris, and comments on the nomenclatural status of generic names based on apical disc loss.

\section{COMMENTARY ON HEMIPENES AS GENERIC AND SPECIFIC CHARACTERS}

The fact that taxonomists can often find greater differences between related species in genitalia than in other structures implies that relative to the other structures the genitalia have diverged rapidly. (Eberhard, 1985: 2-3)

At the end of the 19th century E.D. Cope truly broke new ground by demonstrating that the snake hemipenis varies greatly among taxa and is a systematic character of great value. Cope (1895) dissected and depicted the inverted (retracted) hemipenes of 233 species in stylized view and, for one species (Pseudaspis cana), two views of an everted organ "in natural erection [with one lobe] not fully evaginated." ${ }^{20}$ Cope (1896) also discussed and compared the hemipenes of lizards, but he spent most effort on snakes, writing that:

It had long appeared to me that ... the hemipenes ... probably present structural variation expressive of affinity or diversity. In 1893 I examined these structures in many of the leading types and was gratified by the discovery of a great many structural characters. In fact these organs exhibit a variety of ornamentation and armature beyond any part of the anatomy in the Ophidia, and I am satisfied that they furnish more important indication of near affinity than any other part of these reptiles yet examined. No one hereafter can be sure of the place of a serpent until the hemipenis has been examined. (Cope, 1895: 187)

Considering especially the state of microscopy and microscope lighting, this was an extraordinary achievement that surveyed many taxa, including a few (e.g., Trimetopon) with minute hemipenes only 5-9 $\mathrm{mm}$ in length. It would have been even more extraordinary if Cope had not made mistakes or misinterpreted some structures, such as failing to see that tiny

\footnotetext{
${ }^{20}$ Cope's seminal 1895 work was prefaced by an earlier paper (Cope, 1894) that is a partial preprint of the 1895 text; the last two (of 11) generic names on the 1894 sample hemipenis plate were updated in 1895, from Clotho and Uropsopus to Bitis and Crotalus. All the 1895 hemipenial illustrations were reprinted in smaller size in the Crocodilians, Lizards, and Snakes of North America (Cope, 1900). Nonetheless, Cope's 1895 publication is by far the most useful because it gives, in the plate listings, an enlargement for each hemipenis $(\times 1.5-4)$ and a few explanatory notes that were omitted in 1900. Although Cope's 1895 publication is printed in folio, the illustrations in the plates are not themselves reduced when the work is downloaded to $8.5 \times 11$ inches from the internet (through www.jstor.org).

Bogert (1966) prepared a useful index for the hemipenes reproduced in Cope's massive 1900 treatise. This index also works for Cope's 1895 illustrations - if one adds " 2 " to each plate number given by Bogert (Cope's 1900 hemipenis plates are numbered 12-31, compared with 14-33 in the 1895 work.) Cope's hemipenis collection is at the Academy of Natural Sciences of Philadelphia.
} 

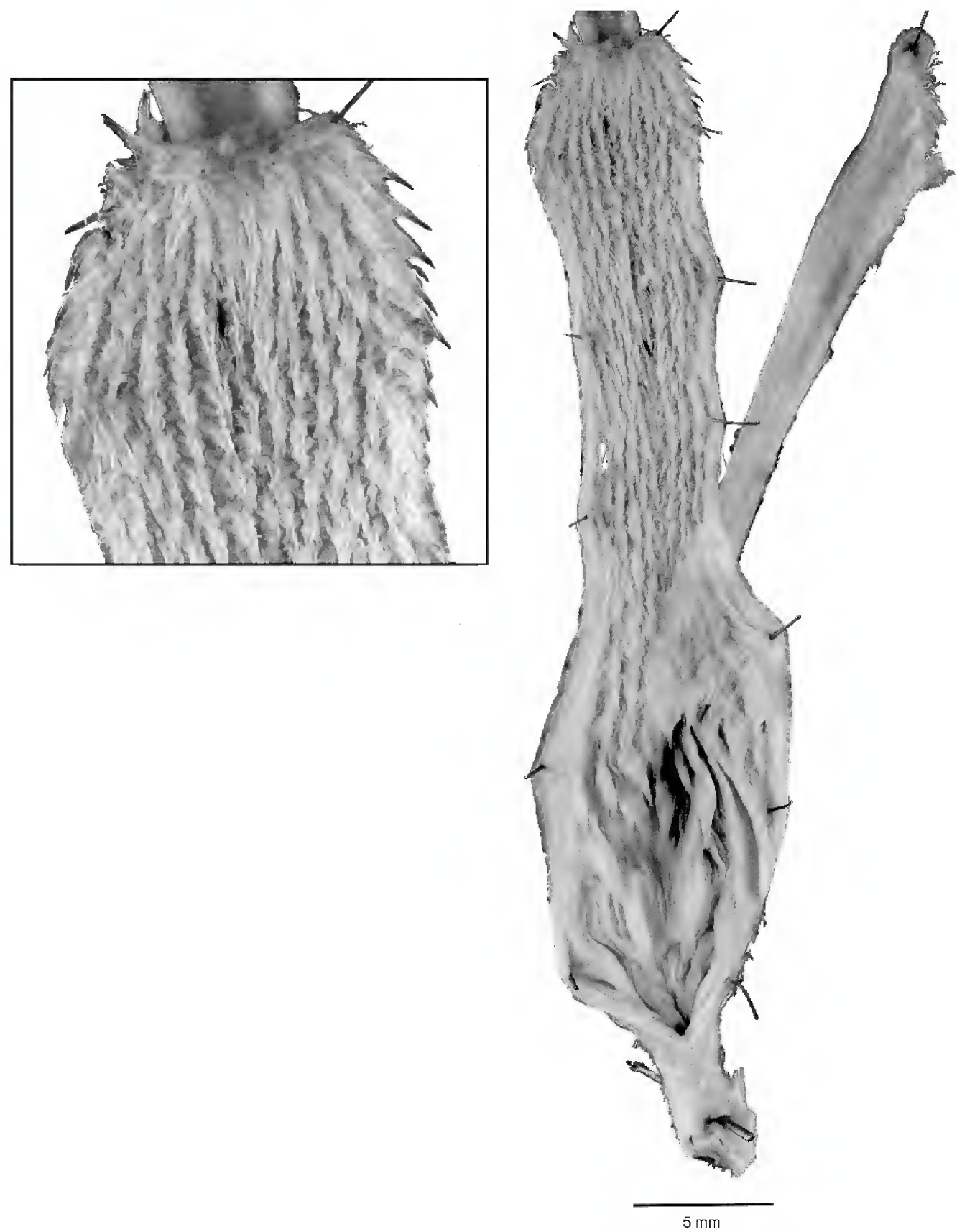

Fig. 20. Hemipenis of Xenodon suspectus Cope; left retracted organ of AMNH R-52175 (see fig. 32). The basal half of the organ and the left lobe were opened midventrally, essentially along (and destroying) the sulcus spermaticus. Inset: Greatly enlarged terminus of left lobe, showing an apical cluster of narrow spines. 
Trimetopon has a bifurcated sulcus spermaticus. Cope's work was not used as extensively as it should have been during the first half of the 20th century (major exceptions: Dunn, 1928, and Bogert, 1940).

The terminology used by Cope has sometimes been considered difficult, but, with a few exceptions, the terms adopted or coined by Cope are the same as used in hemipenis descriptions today; master anatomist Cope not only laid out the genitalic diversity, he also provided the basic terminology needed to describe it. The following words and phrases are extracted from his 1894 and 1895 papers:

Copeian terms still in use (parentheses enclose his less-used synonyms and latinized terms): Apical disc (membranous disc, disciferi); armature, i.e., spines, and ornamentation, i.e., calyces etc.; awn; basal hooks; capitate (capitati); bifurcate; bifurcation - of sulcus and of hemipenis; calyces, calyculi, calyculate (ruched, calyculati); flounced; hemipenis-single, undivided, double, divided; papillae, papillose; retractor muscle; sulcus spermaticus - simple, furcated, or bifurcate; spines, spiniferous, spinous (spinosi).

Copeian terms generally not in use: ala, diverticulum, fasiculi (i.e., bundles); laminae; pinnate; plicae, plicate (as well as longitudinally, transversely, or obliquely plicate; Flabellati); osseous or ossified papillae and spines [vs. calcified or mineralized].

Perhaps the only significantly difficult or ambiguous of Cope's terms were "laminae" and "plicae" and derivatives. As summarized by Savage (1997: 24),

Cope's ... descriptions are based on uneverted hemipenes, which led him to adopt an ambiguous terminology for the longitudinal and transverse or pinnate folds that he observed in his preparations. He referred to these folds collectively as laminae. In addition he called both the longitudinal and transverse folds plicae. Dowling and Savage (1960) standardized Cope's terms to "flounce" for non-calyculate transverse or pinnate folds because they could make no distinction between flounces and plicae in this context. In addition they pointed out that Cope's longitudinal plicae are folds of membranous tissue that disappear when the organ is everted.

Cope (1895: 196) recognized that some folds are on expansible tissue when he wrote "temporary longitudinal folds ... which can be removed by stretching," but other times he clearly did not, as when writing of groups "with calyces, ribs or welts having a longitudinal direction [on which] the calyces are crowded and closed" (loc. cit.: 195). Cope was not much of a field man and had virtually no experience with everted hemipenes. He illustrated the partly everted one mentioned above and had seen other museum specimens that had everted the spinous (proximal) parts of their hemipenes when subjected to violent death from being clubbed or hacked. Cope (1895, and especially 1894: 833-834) had been led to believe that hemipenes could be used defensively:

Snakes sometimes partially project this organ, apparently in some instances for defense, as the spines are very pungent, and are sometimes curved like cats' claws. ... Snakes are, however, very careful not to present these organs fully evaginated so as to expose the delicate structures near the apex. I have never seen this to be the case in an alcoholic specimen (with one possible exception), and I should judge that this was the general experience, from the figures given by authors.

Over half-a-century after Cope's groundbreaking publications, Dowling and Savage (1960) published their influential guide to the snake hemipenis that emphasized the everted condition. They did not disparage study of inverted hemipenes but correctly observed that "information taken from a dissected specimen is incomplete" (Dowling and Savage, 1960: 22). They summarized (op. cit.: 26): "An adequate description of the hemipenes of snakes may be based upon either in situ or everted organs. The later are much to be preferred." However, Myers (1974: 30) claimed that the hemipenis preferably "should be examined in both states, because different kinds of data are thus obtainable" a thought followed up by Myers and Cadle (2003: 297-298) who emphasized that "better understanding is gained when retracted and everted hemipenes are compared [and that] complementary comparisons in some cases [examples given] increase the number of taxonomically useful characters." Additional advantages include the ability to detect slight bilobation that may disappear during eversion, as in some Trimetopon (Myers, MS.). 
Nonetheless, it is true that everted organs are relatively more important for showing the expanded form that must somehow function during copulatory events. The hemipenis also develops in the everted position, not retracting until shortly before hatching or birth (e.g., Beuchelt, 1936; Clark, 1945, ${ }^{21}$ Underwood, 1967: 45). Hemipenes everted in the field during preservation, or in the laboratory afterward, are more readily available nowadays than in Cope's time and seem somewhat easier to interpret. Few workers have taken the time or trouble to make complementary comparisons even with common species. Before commenting on the present state of the science, some of the terminology needs revisiting.

\section{Hemipenial Terminology for Snakes}

Hemipenes are basically similar in snakes and most lizards, but enough differences have accrued among some groups of lizards to call for different sets of terms; see starting references in Savage (1997) and Ziegler and Böhme (1997). Myers and Cadle (2003: 301) provided a few references to "a recognizable hemipenial homologue" in female snakes. Eversible female genitalia are embryological rudiments and are better known in lizards, being especially well developed in varanoids. The terms hemiclitoris and the supporting structure hemibaubellum (plurals hemiclitores and hemibaubella) have been established for varanoids. More attention has been given to hemipenial and cloacal musculature of lizards than that of snakes (Arnold, 1984).

By using good illustrations, Dowling and Savage (1960) were able to standardize much of Cope's descriptive terminology for snake hemipenes. But their "medial" and "lateral" sides of the everted hemipenis have been widely replaced by "sulcate for that side of an extended hemipenis bearing the greatest length of the sulcus spermaticus, and asulcate for the opposing side" (Myers and Trueb, 1967: 236). The terms medial and lateral

\footnotetext{
${ }^{21}$ Myers (1974: 30) noted that "Although containing material of basic interest, Clark's paper has rarely been cited." Probably no other paper of hemipenial importance has been so widely overlooked. See fn. 18 herein.
}

should be reserved for (1) the inner and outer sides of the inverted hemipenis in situ, and (2) for a pinned-flat dissected organ that has been opened along the ventral midline. Other subsequent references tweaking hemipenial terminology for snakes include Cadle (2010, 2012a), McDowell (1961), Myers and Campbell (1981), Branch (1986), Savage (1997, 2002), and Zaher (1999).

The orientation of the sulcus spermaticus is of taxonomic importance. In the case of simple (single) sulci, much evolution has involved loss of one branch of a forked sulcus-normally the left branch in colubrines, the right branch in natricines. The descriptors sinistral sulcus and dextral sulcus are useful for designating simple sulci extending, respectively, either to the left or to the right hemipenial lobe (Rossman and Eberle, 1977: 40). The term centrolineal sulcus applies to an unforked sulcus that appreciably declines neither to the left nor to the right. Savage (2002: 539) coined the term semicentripetal for a simple sulcus in the center of a simple (unlobed) hemipenis when the right and left hemipenes are mirror images; Cadle (2012a: 219-220) thought that "semicentripetal" is likely to be confused with "centripetal hemipenes" (most common among natricines) and that "centrolineal" better serves the situation described by Savage, even though that name originally was proposed by Myers and Campbell (1981) for use with forked sulci on bilobed organs (see Cadle and Savage, 2012: 36).

'The 'left' and 'right' hemipenial lobes and/or sulcus branches refer to the everted hemipenis as viewed looking toward its sulcate side (hemipenial lobes are dorsal and ventral when retracted)" (Myers, 2011: 14, fn. $6)$. Whether the paired hemipenes are symmetrical or asymmetrical should be included in descriptions more often: Underwood (1967: 45-46) thought that asymmetry defined his family Colubridae and that symmetry his family Dipsadidae ("with the exception of the Sibynophinae"). A common situation in either group is for the sulcus spermaticus to enter the hemipenial base in mirror image but to become symmetrical or nearly so distally (e.g., showing the sulcus entering from the left on the left organ and from the right on the 
right organ: Dowling and Savage, 1960: fig 1; this paper fig. $25 \mathrm{~A}, \mathrm{~B}$ ).

McDowell (1961) and Myers and Campbell (1981) coined a set of three terms to describe the orientation of forked sulci spermatici in either bilobed or single hemipenes-centripetal, centrolineal, and centrifugal. That usage (at least for the first two terms) has been extended also to cover simple or unforked sulci. Most workers seem to have found these terms applicable for a variety of snakes (e.g., McDowell, 1987, in discussion of colubroid subfamilies). McDowell (1968: 570) had earlier suggested the terms revolute-centripetal and orthro-centripetal for a few configurations. Branch (1986: 287) believed that "a fuller standardized terminology is necessary" and elaborated on McDowell's approach with the following eight descriptors (having "sulcus" hyphenated to each): semicentrifugal, centrifugal, semirevolute, revolute-centrifugal, semicentripetal, centripetal, semirevolute-centripetal, and revolute-centripetal. The system, however, can be hard to remember and lacks generality for snakes globally. To paraphrase Savage (1997: 23), there appears no need to coin any special terms for features that may be simply described.

We suggest keeping the simple tripartite system summarized in Myers and Campbell (1981: 16-17) by extending coverage to simple (unforked) sulci spermatici and by appending just a few extreme conditions for use only when needed, thus without sacrificing generality (i.e., usefulness):

(1) Centripetal. Branches of the sulcus spermaticus diverge minimally and extend up the center of the hemipenis, to lie on facing (medial) sides of the hemipenial lobes (e.g., Myers and Campbell, 1981: figs. 11, 12A); or, if the sulcus is undivided, the single sulcus extends up the center to terminate in a nude area in the crotch or in an apical nude area on an unlobed hemipenis (e.g., Rossman and Eberle, 1977: figs. 4E, 4H).

1a. Centripetal-revolute. Each branch continues around to the asulcate side of the hemipenis. Acanthophis antarcticus, AMNH R-66760 (left); Pseudohaje nigra, AMNH R-29703. 1b. Centripetal-orbital. Each branch continues and orbits the lobe one or more times. We have no examples.

(2) Centrolineal. Branches of the sulcus spermaticus diverge moderately and extend in relatively straight lines, to lie on the same side of the hemipenis as the forking point of the sulcus (e.g., figs. 21A, $\mathrm{B}, 25 \mathrm{~B})$. This is a common condition. Usage is extended to include simple (unforked) sulci running in a relatively straight line toward the crotch of a bilobed hemipenis or the apex of a simple one, but not terminating in a nude area (McDowell, 1987; Cadle, 2010: 18-19).

(3) Centrifugal. Branches of the sulcus spermaticus diverge outward from the center, to lie ultimately on opposite (lateral) sides of the hemipenis (fig. 3B; Myers and Campbell, 1981: fig. 12C).

3a. Centrifugal-revolute. Each branch continues around to the asulcate side of the hemipenis (e.g., Myers, 2003: fig. 14).

3b. Centrifugal-orbital. Each branch continues and orbits the lobe one or more times (e.g., fig. 28).

Sulci spermatici are not constrained by such classification. Unusual or unique variations can be simply described with as little jargon as possible.

Attention also needs to be given to single descriptors that are in use and that need some clarification in our opinion. The terms capitulum and capitate have a common root and could be (and have been) treated as synonymous. But a capitulum (plural capitu$l a$ ) is simply a "head" - a visually differentiated part of the distal end of the hemipenis (e.g., as in Eutrachelophis bassleri, fig. 3). The terms capitate and capitation (literally "having a head" or "headed") were redefined or restricted by Myers (1974: 31) in order to refer to the common condition where a capitulum is set off by an overhang. This reflects Cope's (1895: 201) usage-“capitate (or pocketed at base of calculate portion)" and is the only meaning of "capitate" in Dowling and Savage (1960: 25, fig. 6B). But ornamentation of well-defined capitula is not 

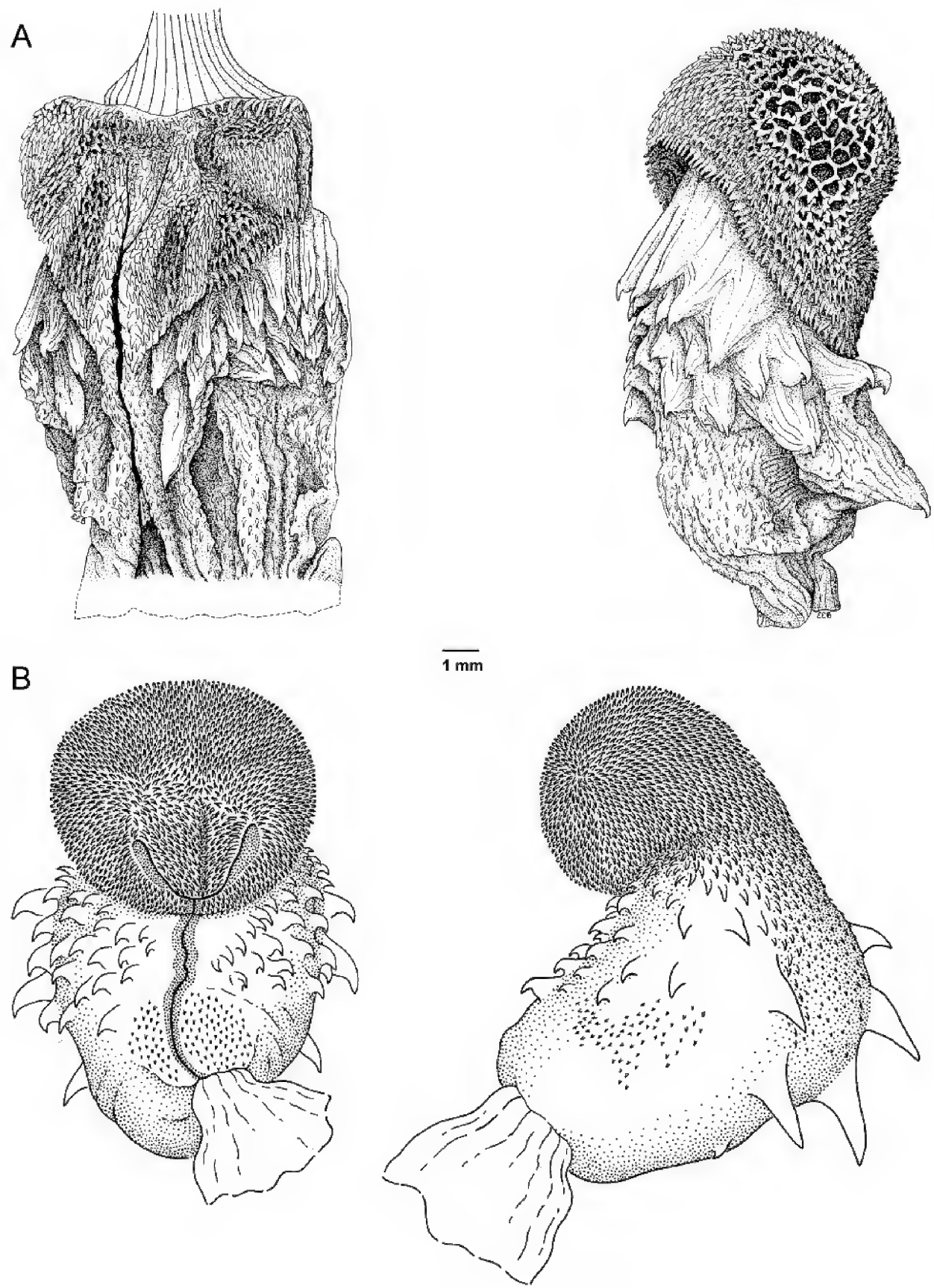

Fig. 21. Distinct hemipenial capitula (heads) with and without capitation. A. Rhadinaea taeniata (Peters). Retracted and everted views showing a capitate capitulum set off by a well-developed overhang that is interrupted only by entrance of the sulcus spermaticus (UMMZ 121522, left retracted and right everted organs; from Myers, 1974: 107, fig. 23A, B). B. Compsophis infralineatus (Günther). Sulcate and three-quarters views of a well-developed capitulum lacking capitation (MZC 181153, everted; from Cadle, 1996b: 75, fig. 17, as Geodipsas). The capitula are ornamented with calyces in A and with small spines in B. (See also fig. 3 for a distinct noncapitate capitulum that is distally nude and proximally spiculate.) 
confined to those that are capitate, as shown in figures 3 and 21.

If bilobed organs have separate (noncontinuous) capitula, they are bicapitate if each capitulum is separately set off by an overhang. Although this "overhang" or "edge" is not a groove like a sulcus, Dowling and Savage (1960: 26) used the term "deep groove" and Zaher (1999: 9) coined "capitular groove" for Myers" "free overhanging edge except where crossed by the sulcus spermaticus" (Myers, 1974: 31). The term semicapitate was used by Myers (1973: 7-8) for retracted hemipenes of Saphenophis, in which the calyculate area was predicted to retain a slight overhang on eversion (as shown by Zaher, 1999, fig. 76). "Semicapitate" is now commonly used for describing a weak or interrupted overhanging edge of a capitulum. Zaher (1999: 8-12, fig. 1) combined and illustrated many hemipenial terms involving degree of capitation and calyculation, distribution of spines, etc., which allowed him to summarize and contrast generic characteristics.

Dowling and Savage (1960: 26) mentioned that some "Atractus have what appears to be a third type of basal ornamentation, a basal naked pocket. However, no fully everted hemipenes ... are available, and the true appearance of this structure is not known." The basal naked pocket is now known to occur widely in everted organs of some Atractus and other genera and "often is conspicuous even when the hemipenis is fully everted" (Myers, 1974: 32). Various distal naked pockets are associated with the edges of the capitular overhang, as in some Imantodes (Myers, 1982: figs. 4, 18, 19), and Pliocercus and Urotheca (Myers, 1974: 273, fig. 4).

An ignored, possibly primitive character needing attention is the smooth terminal basin in the crotch region of some bilobed hemipenes; it is shown as STB in figures 9 (drawing) and 18 (photograph). Although the crotch is smooth in many colubroids, in the case of the STB it is well defined by an abrupt change to spinules or calyces at its rim. It is like the sulcus in being smooth, but it is composed of much thicker tissue. The sulcuslike smoothness can be seen in figure 18; direct examination of the inverted organs of Eutrachelophis steinbachi reveal what appear to be expansion folds in the STB (as shown in fig. 9), suggesting that the basin is relatively large in the everted hemipenis (fn. 7). In many species the sulcus spermaticus forks and runs centrolinearly or centrifugally to bypass the terminal basin or meet it at its most distal ends.

Other terms for the ornamentation and armature (spines) of the everted hemipenis are well covered in Dowling and Savage (1960) and are transferable to the anatomy of retracted organs. Without complementary comparisons of retracted and everted organs, it may be impossible to imagine hemipenial shape acquired during either eversion or retraction (e.g., compare fig. 25C, D). Differential tissue expansion during eversion sometimes leads to unimaginably large and odd shapes, but on retraction there has to be a method of folding and storing the tissue. Retraction may provide a few additional characters, such as whether the asulcate side of the capitulum makes a single or a double fold, a usually interspecific character but sometimes intraspecifically variable (Myers, 1974: table 2 and various figs.).

The ontogenetic stiffening of spines and/or spinules is an indication of sexual maturity, as recognized by Cope's (1895: 189) assertion that "spines are not ossified in young snakes." Following Cope, Myers (1974: 31et passim) incorrectly used "ossified" and "unossified," but bony structures in squamate hemipenes seem to occur mainly in varanids (Shea and Reddacliff, 1986; Ziegler and Böhme, 1997). The term calcification is commonly (and probably correctly) used for the stiffening of spines and spinules, but mineralization perhaps is better in not presupposing the nature of the hardening.

The retracted organ rarely needs new terms, but Myers and Cadle (1994: 12-13) coined pseudocalyculation and pseudocalyces for calyxlike structures that disappear on eversion. Zaher (1999: 11) viewed pseudocalyces as "reduced calyces"; Dowling (2004: 321) flatly asserted that "the disappearing calyces" were simply "an artifact of incomplete specimen preparation" (i.e., apparently by not injecting or somehow filling the "blood sinus (or the central cavity) ... and then the 
outer lymph sinus" [emphasis added]). ${ }^{22}$ In response to Dowling, Myers (2011: 16, fn. 11) provided further description of pseudocalyces and carefully explained that "Normal calyces have walls of varying flexibility but do not disappear no matter how the organ is everted or to what extent it is inflated." Myers and Cadle (1994: 13) stated that they could not "disprove possibilities that [pseudocalyces] are either primitive or vestigial calyces, [but suspected] that they simply represent a method of folding expansible tissue when the ... hemipenis is inverted for storage." In any case, pseudocalyces have since been detected in: (1) Dendrophidion brunneum, with a subtle difference that the transverse walls are retained as circumferential flounces in the everted condition (Cadle, 2010: 19-20), and (2) Phyllorhynchus browni (Cadle: 2011: 6).

\footnotetext{
${ }^{22}$ The lymph sinus and the blood sinus in the wall of the hemipenis are shown in Frances Waite Gibson's diagrammatic cross sections (Dowling and Savage, 1960: pl. 1, fig. 2; and Dowling, 2004: fig. 2). Gibson wrote that, after preparation (softening), a retracted hemipenis of a preserved specimen can be manually everted. After cutting the retractor muscle, the hemipenis is pushed forward "as it would normally evert." The process is continued with injection of petroleum jelly, by slipping a hypodermic needle "into the sinus of the hemipenis ... between the walls of the inverted and everted portions [emphasis added]." Afterward a "better specimen is obtained if the needle can be inserted into the lymph sinus and this inflated also [but] the tissue is so thin [that this may be] difficult to do without puncturing the outer wall" (from Waite Gibson's manuscript published in Myers and Cadle, 2003: 299). Dowling and Savage (1960: 22) may have confused the issue by saying that eversion is effected by injecting "fluid into the blood sinus at the base of the hemipenis." Dowling (2004: 321) later was less clear in speaking of the "blood sinus (or the central cavity)" but reemphasized that "the outer 'lymph sinus' must be filled to fully evert the calyces and flounces."

The aforementioned blood sinus is not an uninterrupted space within the hemipenial wall; in the hemipenis of a little snake it must be thinner than the diameter of a small hypodermic needle. And Gibson surely could inject the lymph sinus only when working with large snakes; it cannot be done with small snakes except when fluid breaks into the sinus under pressure. In most field work, hemipenes of a properly euthanized snake (i.e., with muscles relaxed) are everted by pressure simply from injecting fluid (preferably water) into the tail. After that the tail ideally should be slit and the retractor muscles severed in order to prevent any degree of postmortem retraction--it is that simple, but for a few finer points see Myers and Cadle (2003: 298).
}

And there may be many taxa with very enlarged and/or weakly defined calyx-shaped structures that cannot be confused with "normal calyces" on either retracted or everted organs (e.g., see Cadle, 2010: 19-20). The term "pseudocalyces" proved to have first been used by Broadley (1980: 492, 506, pl. IIA) for the quite different, peculiar anastomosing hemipenial flounces in two subspecies of Prosymna sundevallii (Broadley's illustration reproduced herein as fig. 29C).

Finally, now that techniques are available for everting hemipenes of preserved snakes, it must be remembered that such "manual eversions" often are less rotund when compared with "field eversions" obtained from freshly killed specimens. The organ is fully everted if all surfaces and structures are visible, including the terminus or termini of the sulcus spermaticus. It is maximally expanded if it is fully everted and inflated to the fullest extent allowed by its original elasticity (discussion in Myers and Cadle, 2003: 295).

\section{Are Hemipenes \\ "Conservative" Characters?}

The question whether the hemipenis is a conservative character poses a conundrum. Answers probably will depend on the taxonomic groups with which one has had experience. Bogert (1940) and Arnold (1986) are among the few herpetologists who have wrestled with the problem specifically, for snakes and lizards respectively.

Many recent (younger) workers seem to have accepted Dowling and Savage's (1960: 19) assertion that "It has been amply demonstrated that the features of the [snake] hemipenis are rather stable for a particular species or species group." Since then, it seems commonplace to assume that examination of one or a few hemipenes is sufficient to typify a species or a genus. Dowling (1967: 138) later followed up with the statement that the hemipenis "has no obvious correlation with the ecology, food habits, or locomotion of the animal. Such an uncorrelated structure may give better information on genetic relationships than some habit or habitat-correlated characteristic." This is in marked contrast to conclusions reached by Bogert (1940: 9-10) 


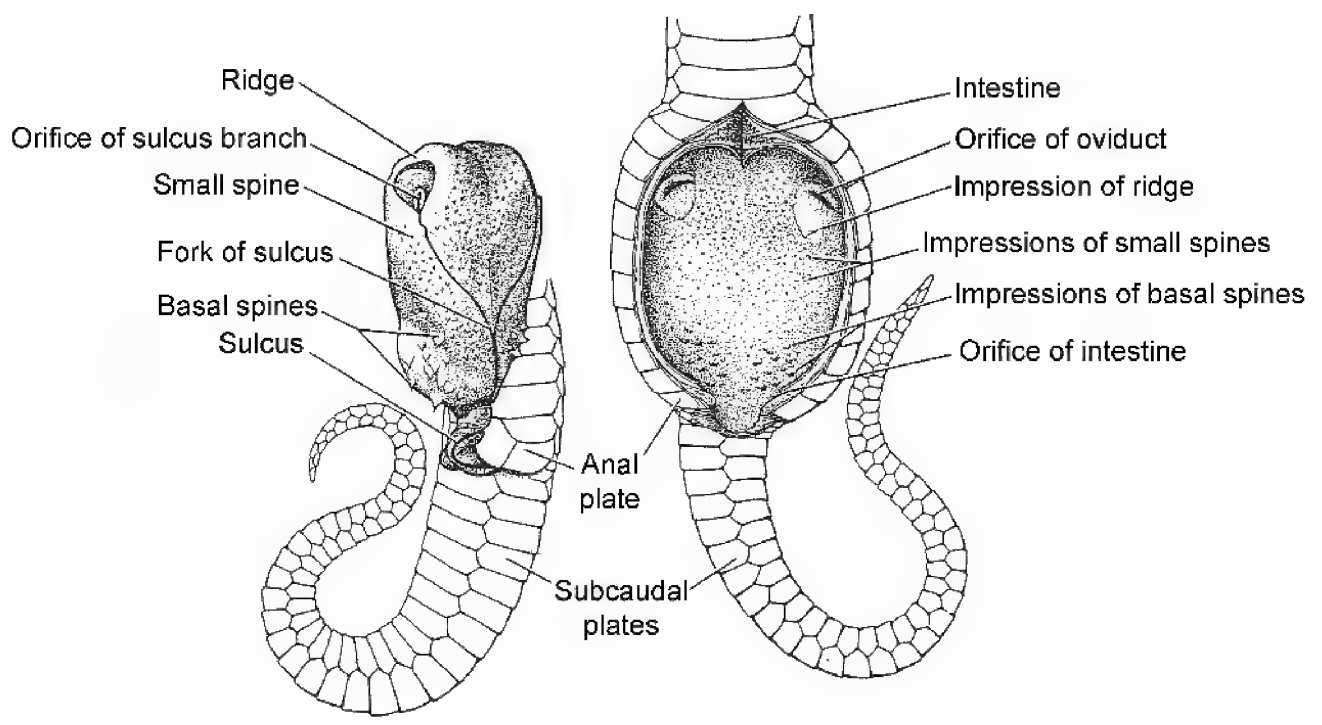

Fig. 22. Illustration (from Pope, 1941: 251), showing copulatory adjustment between hemipenis (left) and female cloaca (right) of Liophis poecilogyrus, as seen by dissection after the snakes had been killed while mating. Pope commented: "The ventral body wall of the female has been bisected and its halves spread apart to expose the interior of the cloaca, from which the turgid hemipenis was removed. The exposed side of the latter lay against the dorsal wall of the cloaca so that each sulcus spermaticus opened at the orifice of an oviduct." Species of Liophis have an apical disc on each hemipenial lobe (as in fig. 17A), which should confine the flow of seminal fluid to the opening of the oviduct; in this case there may have been a slight postmortem retraction of the discs. The area labeled "ridge" in this figure corresponds to the apical disc itself, which contains the terminus of the sulcus spermaticus.

after his survey of hundreds of hemipenes (and other characters) in African snakes; Bogert noted Noble's belief that the courtship pattern of snakes "has not undergone a great change in phylogeny" 23 and then went on:

Any assumption that evolution of the copulatory organs has been similarly conservative is not borne out by investigation. Whereas groups of species or groups of genera usually possess similar or sometimes nearly identical hemipenes, there is reason to believe that adaptations to specialized habitats have been concomitant with modifications of the penes. Dunn ... notes that 'wide peneal variation in closely related snakes is found chiefly among arboreal and among burrowing forms,' and a similar observation may be made for African burrowing snakes.... Aside from this evidence that male genitalia are at least indirectly affected by adaptive changes, there is reason to believe that the single sulcus has been derived from the bifurcated sulcus, not

\footnotetext{
${ }^{23}$ As an aside, this assumption should have seemed at odds with the fragmentary data compiled by Davis (1936).
}

once, as a classification based on this feature should imply, but numerous times.... The conclusion is inevitable that peneal characters, although extremely useful in gaining an understanding of generic relationships, are unsatisfactory as subfamily characters.

Bogert's descriptions had to be based almost entirely on retracted hemipenes since techniques of manual eversion had yet to be developed. Comparisons of Bogert's descriptions of retracted hemipenes with organs actually everted reinforce the reality that hemipenes are evolutionarily dynamic. Generalities implying that genitalia are relatively free of selection pressure are wrong. In addition to Bogert's observations correlating hemipenes with habits and habitat, there is a growing body of evidence pointing to the existence of powerful sexual selection on male genitalia over a wide range of organisms. It will be noteworthy to show whether there are any closely related species of snakes that can not be differentiated by hemipenial characters (not the same thing as pointing to related 
species in which the hemipenes seem almost identical). At least for species with large distributions, intraspecific variation-part of the stuff of evolution-seems to us to be the rule, as suggested by the following examples where investigators have bothered to look at more than a few specimens; examples are given in chronological order.

\section{EXAMPLES OF INTRASPECIFIC VARIATION IN Snake Hemipenes and Cloacae}

SOME BASICS: Browsing through chapters in a recent book on reproduction in snakes (Aldridge and Sever, 2011), one finds the following sentence: "Each hemipenis is equipped with two lobes (bifid), each with a sperm transferring branch (the sulcus spermaticus) which fits exactly into the female cloaca, the spines on the hemipenis holding it in the correct position for transferring sperm into the two oviducts in the bilobated cloaca." That simple declaration was derived from an important paper by Pope (1941). But, in that paper, Pope himself had commented: "One unfamiliar with snake genitalia might conclude that [my] observation ... virtually closes the problem of hemipenial adjustment, whereas actually the problem is barely opened."

Indeed, 70 years later we really are not much further along. Accomodation to the hemipenis by the female cloaca or vice versa remains a subject virtually untouched. When viewing the diversity of hemipenes illustrated in this paper and elsewhere, one should wonder: How does it fit? And in what way, if any, is the cloaca modified? Ultimately such questions lead to the topic of sexual selection and "sperm competition," with growing awareness that there are degrees of difference between snake and lizard hemipenes, both in anatomy and functional use (see the extended treatment by Olsson and Madsen, 1998; also referenced below under Conclusions and Brief Summation).

Pope (1941) illustrated the hemipenis and the cloaca of two snakes (Liophis poecilogyrus) "killed while copulating and preserved without dislodging the penis." His illustration is instructive and reproduced herein as figure 22. Pope probably did not realize that the shallowly bilobed Liophis hemipenes terminate in apical discs (as in fig. 17A), which, however, fit his description that: "Dissection shows that each branch of the sulcus ends in a lip surrounded by a ridge which is firmly pressed against an area of the cloaca, in the center of which an oviduct opens." The "ridge" labeled in figure 22 is the outer part of the apical disc that is broached by the inwardly sloping sulcus spermaticus. The apical disc thus makes a snug fit against the opening to the oviduct and helps pool seminal fluid. Pope (op. cit.: 250) drew attention to Cope's (1900) comments on the comparative anatomy of the cloacal region:

a common chamber or vagina, which is above the rectum, and opens into the cloaca. This vaginal chamber is large, and is divided more or less completely in the Solenoglyph snakes, is about half divided or deeply bilobate in the Colubroidea, and is undivided in the Peropoda. Its external wall is deeply longitudinally grooved, and the internal wall is transversely grooved in Crotalus. In Colubroidea generally it is deeply longitudinally grooved on all sides. In the Peropoda it is nearly or quite smooth. The cephalic extremity of the oviduct is for a short distance transversely plicate or lobate, the labia being held in place by simple unfolded bands of the inferior and superior edges. The fontanelle is immediately cephalad of this region, and has very thin simple walls. Being only a slit, it is sometimes difficult to discover. The oviducts do not accompany the ureters so closely as do the vasa deferentia, and approach nearer the middle line for a short distance below the rectum. (Cope, 1900: 700)

Pope (op. cit.: 250-251) gave his own observations on matching hemipenial and cloacal fit in two species of Asiatic Trimeresurus in which females could not be distinguished by external characters alone.

Edgren (1953) published a second article on copulatory adjustment, based on two specimens of Heterodon platyrhinos that were killed and preserved in coitus. However, Edgren (op. cit.; 163-164) failed to find the intimate relationship between hemipenis and cloaca reported by Pope; the hemipenis partially everted "through the area of distal large spines and only slightly into the calyculated area. The terminations of the sulcus branches ... were near the openings of the oviducts, but there was no close applica- 

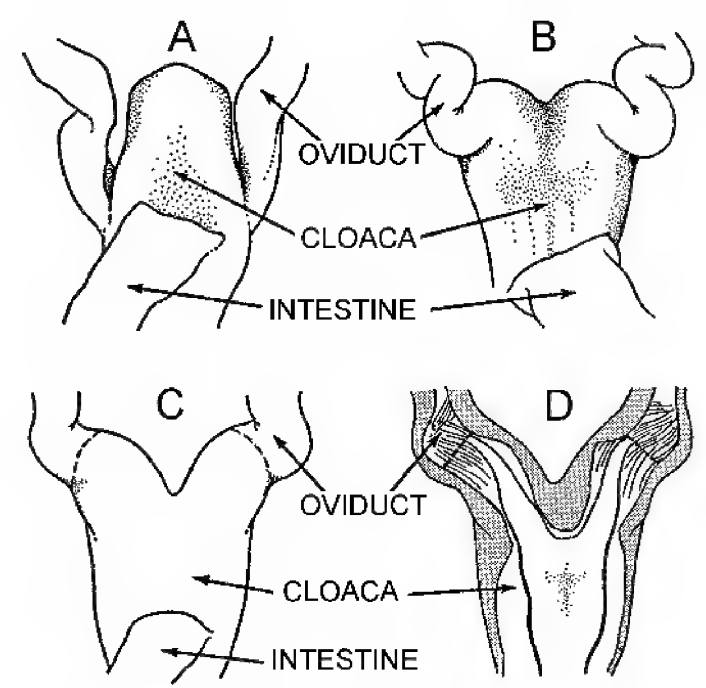

Fig. 23. Illustration (after Inger and Marx, 1962: 36) showing intraspecific variation in the female cloaca of Calamaria lumbricoidea. Diagrammatic ventral views, with intestine cut and reflected. A. Bulbous cloaca. B. Cardioid type. C. Bilobed type. D. Bilobed type with ventral wall removed.

tion [and the hemipenis] filled only about three-fourths of the cloaca ... and may represent a post-mortem artifact." The method of killing was not mentioned, but it does seem likely that the hemipenis had started to relax and retract.

Even the fact that only a single hemipenis is used in a copulatory event did not become established until the 20th century (see Pope, 1941: 249). An erroneous report of simultaneous use of both hemipenes (Brain, 1959: 71, fig. 1) was based on a mating by Pseudaspis cana, which has extraordinarily long hemipenial lobes that are joined close to the base, as can be seen in figure 28. Zweifel (1997) compiled data for Lampropeltis suggesting that hemipenes are alternated if a mating occurred within several days, but that choice probably is random after "longer periods of [enforced] abstinence."

VARIATION IN Hemipenis AND CloACA OF CALAMARIA LUMBRICOIDEA: Shortly after the appearance of Dowling and Savage's survey, Inger and Marx (1962: 37) warned that "individual and geographic variation should be analyzed before undue taxonomic weight is given to the hemipenis and cloaca." They described remarkable variation in the hemipenis and cloaca of the widespread Southeast Asian snake Calamaria lumbricoidea H. Boie. They found three types of hemipenes (simple, smooth; forked, smooth; and forked, papillate) and three types of cloaca (bulbous, cardioid, and bilobed). But they found no correlation between the type of hemipenis and form of the cloaca, which "appears to be constant within populations, but variable between populations." This was a rare study to consider cloacal shape and their illustration is reproduced here as figure 23. In their follow-up generic monograph, Inger and Marx (1965: 85) said the "hemipenis of lumbricoidea shows variation not seen in other species of Calamaria."

Hemipenial VARiation in the Vine SNAKE OXYBELIS AENEUS: Keiser (1969: 117; 1974: 16-17, fig. 1) examined the ornamentation of one or both hemipenes for about $60 \%$ of the available males and determined origins of the paired major retractor muscles for 68 specimens. ${ }^{24}$ Keiser (1974: 16) noted considerable variation "in the number, size, and arrangement of the basal spines, the caudal level at which the spines occurred, the size of the hemipenes, the arrangement of the denticulated calyces, the nature of the apex, and the caudal level at which the retractor penis magnus muscles originate." His figure 3 shows photographs of two very different looking hemipenes on Mexican specimens; one is robust with welldeveloped basal spines, the other is slender with reduced basal spines - these variants are geographically correlated, but the nature of the interpopulational variation "necessitates a degree of subjectivity when comparing them" (Keiser, 1974: 16-17). Keiser (loc. cit.) described the sulcus spermaticus as "deep, single, and situated laterally on the inverted hemipenis. It occasionally forks near the apex." The last statement, for a long time

\footnotetext{
${ }^{24}$ Keiser (1969: 117) "examined the hemipenes of over 400 male $O$. aeneus from Arizona, México, Central America, and South America." Over 1235 specimens examined are mentioned in the introduction to his later review; specimens in good enough condition for counting ventral plates consisted of 483 males and 675 females as tabulated in his table 12 (Keiser, 1974).
} 


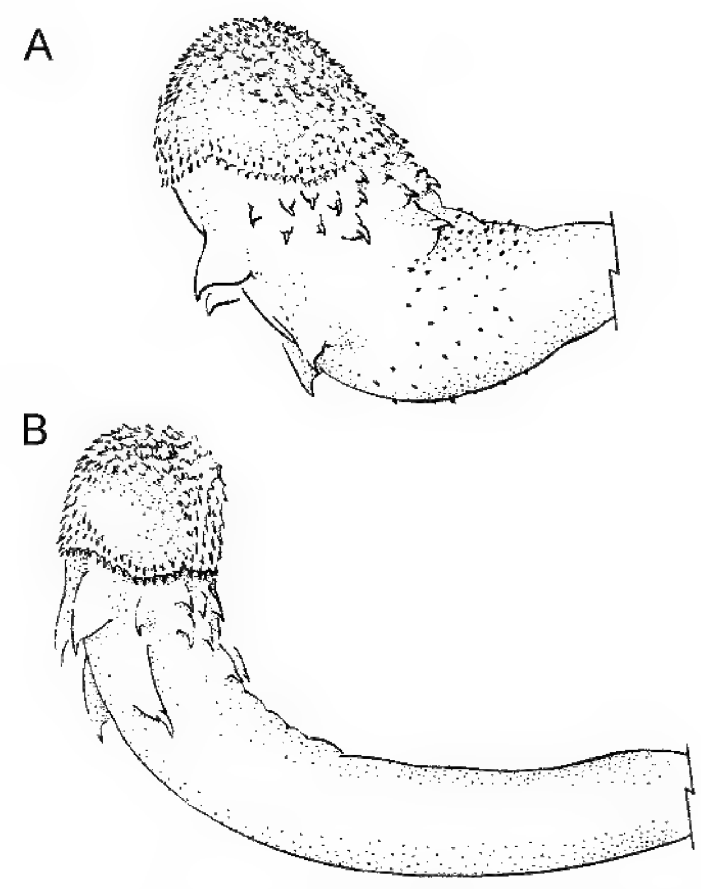

Fig. 24. Inter- and intrapopulational hemipenial variation in Rhadinaea decorata (Günther). A. Short bulbous hemipenis, 7 subcaudals long, Veracruz, Mexico (TCWC 21391, right organ). B. Long slender hemipenis, 11 subcaudals long, Costa Rica (USNM 120832, right organ). Geographic variation is complex, comprising lengths of 5-8 subcaudals in Mexico and 6-14 subcaudals in Costa Rica through Panama. Field eversions, drawn to same scale, from Myers, 1974: 74-75.

overlooked, was in fact surprising, inasmuch as Oxybelis has always seemed firmly ensconced in the Colubrinae. More recently, however, forking, including terminal forking and/or terminally divergent lips of the sulcus have been documented for some other Neotropical colubrines (Dendrophidion spp.: Cadle, 2010, 2012a, 2012b; Freire, et al., 2010); forking also occurs in some Asiatic Ahaetulla (McDowell, 1987: 41), so a simple, unforked sulcus might seem not to be as universal a colubrine trait as has been supposed (e.g., Dowling and Duellman, "1974-1978" [1978]: 112c.1; Underwood, 1967: 46, 149). In any case, the Oxybelis hemipenis could use further attention, particularly concerning the nature of the small type of hemipenis as well as variation in the sulcus spermaticus.
Keiser (1974: 41) concluded that "Variation in hemipenial size and ornamentation is great in all parts of the range, but most striking in individuals from southern Zacatecas, Sinaloa, and the Tres Marías Islands." Despite questions raised, Keiser clearly found significant inter- and intrapopulational variation in this Neotropical vine snake.

EXAMPLES IN "RHADINAEA": Myers (1974: 30) thought that

the hemipenis frequently seems to provide proof of relationship when divergence and convergence have obscured the usefulness of scutellation, color pattern, and dentition ... [but] this is not to claim that taxonomic use of the hemipenis is not liable to the same pitfalls that beset other characters. Evolution does not permit universally reliable taxonomic criteria, and even the snake hemipenis is not so conservative as formerly thought.

Myers surveyed hemipenial structure in "Rhadinaea" and some Rhadinaea-like snakes (supra, fn. 14), using both retracted and everted hemipenes when possible. The eight resulting species groups appear to be mostly (if not entirely) monophyletic. The groupings received hemipenial support as summarized in Myers' tables 2 and 3 (Myers, 1974: 34f., 42f.), but species differences were also pointed out and become more obvious when viewing some of his figures (especially figs. 9, 20, $30) .{ }^{25}$ Two intriguing examples of variation in Rhadinaea can be mentioned here: (1) The retracted hemipenes of Rhadinaea vermiculaticeps and "R." schistosa seem virtually identical even to the unusual straight spines; the former is the generic type species; the latter, formerly in the Rhadinaea godmani group, is the type species of Rhadinella. The correspondence between their hemipenes can be seen by comparison of figures $30 \mathrm{G}$ and 39 of Myers (1974: 133, 165). When material becomes available, it will be interesting to compare the everted organs. (2) The snake Rhadinaea decorata has a large distribution

${ }^{25}$ In a treatise on Sexual Selection and Animal Genitalia, Eberhard (1985: fig. 1.5) republished eight of these illustrations, which subsequently have been split between Rhadinaea and Urotheca sensu stricto (Myers, 2011: 26-27). Eberhard's interest, however, was not taxonomic. He wished to show a variety of hemipenial sizes that must be accommodated in the female cloaca. 
(Mexico to Ecuador) and considerable variation in head and nuchal color pattern that exceeds the variation in genus Eutrachelophis of this paper. And the hemipenis of $R$. decorata varies extraordinarily in length, so much so that that some southern specimens seem to call out for status as a separate species (see fig. 24). However, nomenclatural action was not taken because of the nature of geographic variation in the length of retracted organs, which span the lengths of 5 to 8 subcaudals in Mexico, and 6 to 14 subcaudals in Costa Rica and Panama (Myers, 1974: 75). DNA evidence and more everted organs may someday provide insight.

Pythoninae, Boinae, And AcrochorDOIDEA IN NEW GUINEA AND THE SOlOMONS: McDowell $(1975,1979)$ included these groups in his catalogs of noncolubroid snakes in New Guinea and the Solomons and summarized intraspecific hemipenial variation when there were sufficient specimens. In a sample of 30 Python amethistinus there was variation in length of hemipenis (7-10 subcaudals), point of forking, extent of calyculation, and number of flounces (3-6). A sample of 19 Chrondropython viridis varied in length of hemipenis (5-13), whether feebly bilobated or single, and extent of calyculation. The hemipenis in species of Liasis varies from bilobate to deeply forked; the tip of the sulcus on each lobe is "prolonged on a smooth papilla that projects abruptly and in nipple-like or loop-like fashion from the untapered lobe" (McDowell, 1975: 31); in some specimens of $L$. albertisii the retractor muscle is attached not to the extreme tip of the papilla but to the base, so that the papilla remains everted within the inverted organ. There is variation in length of the hemipenis at least in L. papuanus (8-12 subcaudals).

Among the Boinae, the hemipenis of Candoia bibroni varies in length from 9 to 20 subcaudals, but there are no significant differences between islands and the two extremes come from the same island (Santa Cruz). C. carinata and C. aspera also vary in hemipenial length (7-18 and 5-11 subcaudals, respectively), with significant differences between some localities for the former but not the latter. There are substantial differences in the hemipenes of the three species of Acrochordus, as treated under below under Evolutionary Plasticity and Extreme Divergence.

\section{VARIATION IN NORTH AMERICAN SNAKES} RELATED TO TANTILLA PLANICEPS: Cole and Hardy (1981) examined inter- and intraspecific variation in eight species They found intraspecific variation in aspects of calyculation and in the distribution and numbers of spines and spinules, but each was found to have a species-specific combination of traits that characterize its hemipenis. The physiognomy of all but two hemipenes was each quite different, varying in number of spines, nature of the apical calyces, and presence or absence of capitation (see their fig. 6). The two most similar species ( $T$. atriceps and $T$. nigriceps) were usually separable by the place of origin of the major retractor muscle. The origin of this muscle varies intraspecifically in $T$. hobartsmithi, the externally most distinctive species with a capitate capitulum. Cole and Hardy (1981: 203) summarized that "The most useful characters for distinguishing species of Tantilla, particularly in North America, appear to be in the hemipenes and head coloration." That generalization seems likely to hold for most of this large genus.

Loss of THE Bifurcated Sulcus SperMATICUS IN TRIBE IMANTODINI: As cited above, Bogert (1940: 9) believed that an unforked sulcus spermaticus had evolved numerous times in Old World snakes. But the only New World "xenodontines" known to have an undivided sulcus spermaticus are several species of Dipsadinae (i.e., Imantodes spp. and a few Leptodeira spp., the sole members of tribe Imantodini; see Myers, 2011: 21-26). ${ }^{26}$ Imantodes and some Leptodeira are defined by an unforked sulcus spermaticus, whereas other Leptodeira may retain a tiny terminal fork or have the sulcus distally expanded without forking-i.e., both inter- and intraspecific variation are evident. In that analysis, Myers (2011: 23) concluded that there generally appears "to be at least four ways in which primitively sulci spermatici can become single": (1) by simultaneous shortening of both branches; (2) by shortening of a single branch; (3) by shortening and/ or loss of a single hemipenial lobe; and (4) by

\footnotetext{
${ }^{26}$ Formerly known by the improperly published, hence invalid and unavailable name "Leptodeirini," most recently used for a nonmonophyletic assemblage including Eridiphas and Hypsiglena (Myers, 2011: 2122).
} 

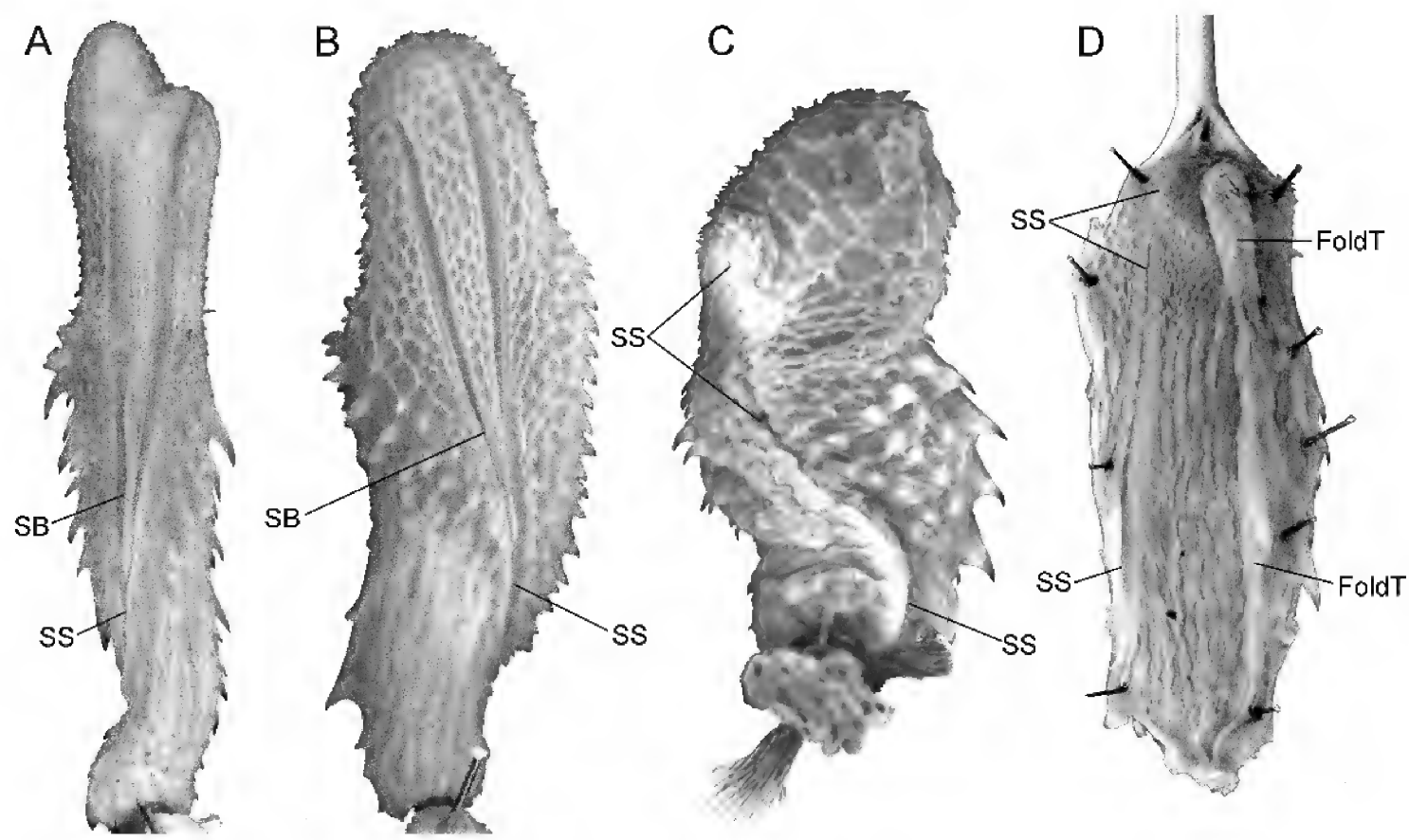

Fig. 25. Evolutionary loss of a bilobed hemipenis and a forked sulcus spermaticus, demonstrated by apparent sister species. A. Taeniophallus brevirostris (W. Peters) showing retention of weak bilobation (right lobe incompletely everted) and shortening of the left branch of the sulcus spermaticus (MZUSP 8484 , left organ). B. $T$. brevirostris showing complete loss of bilobation and similar shortening of the left branch of the sulcus spermaticus (AMNH R-28799, right organ). C. Taeniophallus nicagus (Cope) showing complete loss of bilobation and complete loss of bifurcation in the now-single sulcus spermaticus, which extends from the base to one side of the apex (AMNH R-138683, right organ). D. T. nicagus, an uneverted hemipenis, showing the unbifurcated sulcus spermaticus that extends to the apex, where it is largely concealed by the close-pressed sulcus lips (MCZ 149545, left organ). The first three hemipenes were manually and fully everted (except for one resistant lobe in A), but they probably are not completely expanded as is commonplace with eversions made from preserved specimens. Not to same scale.

weakening and loss of the medial sulcus lips, leaving only a tissue divide separating the lateral branches. The first and fourth mechanisms seemed to apply to Leptodeira spp., whereas the second method fits the evidence for Taeniophallus immediately below.

Loss of The Bifurcated Sulcus SperMATICUS IN TAENIOPHALLUS: In the New World, a forked sulcus spermaticus has long been recognized as a defining character of the Xenodontinae, sensu stricto, including at times a few other "xenodontines" (i.e., Dipsadinae, tribe Imantodini, see above). However, an exception for Xenodontinae has been confirmed. Despite the "remarkable similarity" of Lygophis nicagus to "Rhadinaea" brevirostris, Myers (1974: 208) had concluded they were not congeneric and that nicagus probably was not a South American snake. Myers and Cadle (1994: 5-6), however, proved the South American provenance of nicagus. Although Myers (1974: 32) had commented that shortening one branch of the sulcus spermaticus could lead to a simple, unforked sulcus, he had retained enough faith in hemipenial characters not to make the speculative leap required for placing nicagus in the same genus with brevirostris.

As now recognized Taeniophallus nicagus and $T$. brevirostris appear to be sister species that demonstrate evolutionary stages from a bilobed hemipenis with a forked sulcus to a unilobed hemipenis with a simple sulcus. See figure 25.

INTRASPECIFIC VARIATION IN HEMIPENIAL Eversion: Zaher and Prudente (1999) 

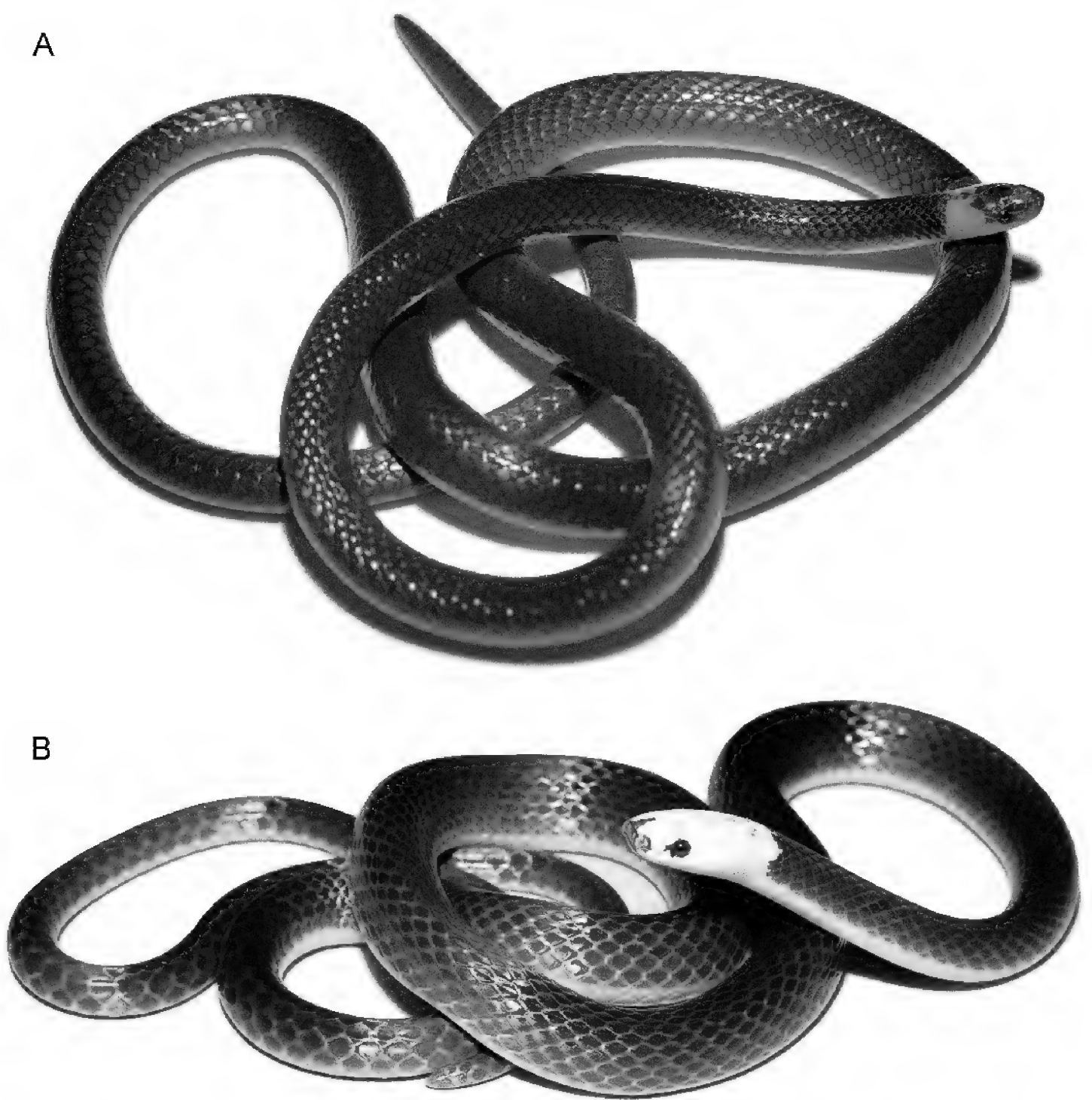

Fig. 26. Two small Panamanian snakes, genus Enulius - anatomically similar and apparently closely related - but recently separated generically on the basis of what appears to be extreme variation in the hemipenes (see text and fig. 27). A. Enulius flavitorques (Cope), with a yellow nape band (AMNH R109600, Canal Zone, Ancon). B. "Enuliophis" sclateri (Boulenger), with an enamel white head (KU 112619, San Blas, Camp Sasardí. Both photographed larger than life by C.W. Myers).

found that species of Siphlophis and the related Tripanurgos compressus evert their bilobed hemipenes in both $\mathrm{Y}$-shaped and $\mathrm{T}$ shaped conditions. Dowling (2002) asserted that the apparent polymorphism was simply an artifact of preservation, caused by tension of the major retractor muscle (which can indeed sometimes affect the shape of a preserved hemipenis [e.g., Myers and Cadle, 2003: fig. 1]). However, Zahr and Prudente (2003) satisfactorily answered Dowling by further demonstrating that the eversion polymorphism is real, not artifactual.

Unusual Hemipenial Morphology in PHYLLORHYNCHUS: Cadle (2011: 4-6) described an unusual morphology in hemipenes 

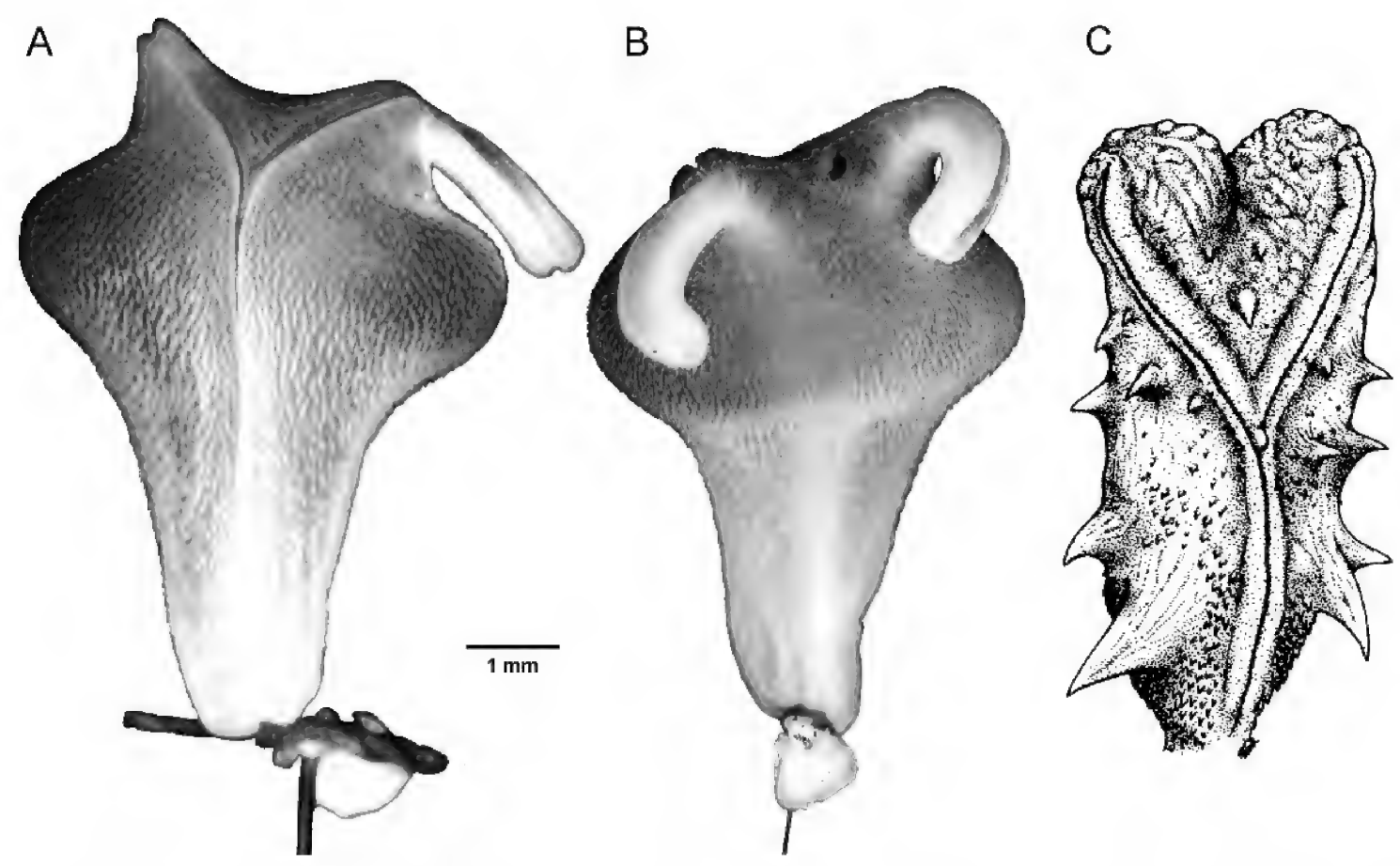

Fig. 27. A, B. Hemipenis of Enulius flavitorques in sulcate and asulcate view. Left organ of AMNH R107406, measuring $6.5 \mathrm{~mm}$ from base to crown between apical projections, which are about $2.5 \mathrm{~mm}$ long. C. Hemipenis of "Enuliophis" sclateri, roughly $\times 6.3$. From McCranie and Villa (1993: fig. 1, "organ $10.6 \mathrm{~mm}$ ").

of North American Phyllorhynchus, in which the sulcus is not divided as previously reported, but in which the sulcus lips distally diverge and open onto an extensive apical nude region. He also reported intrageneric variation in which calyces were either reduced or absent. He described and illustrated presumed intraspecific variation for $P$. browni, which has two distinct hemipenial morphs, differing in presence or absence of bilobation and nature of the spines.

INTER- AND INTRASPECIFIC VARIATION IN DENDROPHIDION: Cadle (2012a) discovered cryptic species of the Middle American Dendrophidion vinitor complex based on hemipenial characters. He expected, but did not find, something similar in his redefined Dendrophidion percarinatum, which ranges from Honduras to Colombia. As he concluded for $D$. percarinatum, "there is variation in virtually all aspects of hemipenial morphology, including the form of the spines and the degree to which fully formed apical calyces are developed" (Cadle: 2012b: 319).

\section{Evolutionary Plasticity and ExTREMe Divergence of Snake Hemipenes}

Genitalia are often much more elaborate than seems necessary for the simple function of gamete transfer to the female. What could be responsible for such an evolutionary pattern? (Eberhard, 2010: 40)

EUTRACHELOPHIS AND ACROCHORDUS: Despite contradictory hemipenial evidence, global comparisons of anatomy and color pattern show that Eutrachelophis bassleri and E. steinbachi are so closely related as to be considered congenerous in our opinion. It is certainly a case of extreme divergence in hemipenes, as seen by comparing figures 3 and 9. As stated, our simple explanatory hypothesis involves embryonic suppression of the hemipenial lobes in the bassleri lineage and homology between the hemispherical nude apex of $E$. bassleri and the interlobular smooth terminal basin in E. steinbachi.

A similar scenario might also be applicable to major hemipenial differences between 
Acrochordus arafurae, A. javanicus, and $A$. granulatus, as set forth by McDowell (1979: 69, fig. 26). All three species have a moderately elongated hemipenis, but $A$. arafurae differs conspicuously from the other two in that: (1) the organ is bilobated only at the extreme tip, rather than being forked for a third to a half of its length; (2) the sulcus is forked near the tip of the organ, rather than near the middle; (3) there are no spines, papillae, calyces, or flounces, in contrast to the other two species in which the sulcus is forked more proximally and there are numerous spines or papillae (probably depending on age) on the lobes excepting the distal ends, with a few spinules extending more proximally along the sides of the sulcus on the unforked portions of the organ.

Acrochordus arafurae might differ from the other species in a single developmental character-a delay in the forking of the sulcus until the hemipenis has nearly reached its limit of length-based on a few simple assumptions: (1) there is a limit imposed (perhaps by length of the retractor muscle) on how long the entire hemipenis can be; (2) furcation of the organ cannot take place until after the sulcus has forked; and (3) spines begin formation only proximal to a nude apex on a distinct hemipenial lobe, when the very short lobes of arafurae would correspond to only the nude tips of the lobes of javanicus and granulatus and a threshold for initiating spine formation had not been reached. Thus, differences between the three living species of Acrochordus could all be expressed as quantitative differences in the timing of furcation of the sulcus (earliest in $A$. javanicus, latest in $A$. arafurae, with $A$. granulatus intermediate) relative to the time when the sulcus reaches the end of the organ. Descriptively, $A$. arafurae has lost hemipenial spines and those who construct phylogenetic hypotheses from descriptive characters would probably regard it as impossible for $A$. arafurae to give rise to a species having spinose hemipenial lobes. But considered from a developmental scenario, it is not known whether $A$. arafurae has hemipenial spines or not; the area where spines would be expected is not formed and we are as ignorant of this particular feature of the hemipenis as we would be if all available specimens were females. It is conceivable that if a species derived from $A$. arafurae were to speed up sulcus furcation, long hemipenial lobes with spines would reappear. Considering developmental scenarios rather than descriptive characters seems to introduce doubt where previously there was certainty, but if the certainty was an illusion, then this is all for the good.

ENULIUS AND "ENULIOPHIS": Enulius flavitorques (Cope) and Enulius sclateri (Boulenger) share very distinctively modified maxillae and seem to differ only slightly in scutellation and color pattern (fig. 26). The close similarities were pointed out by Dunn (1938: 417), who first recognized the two species as congeneric and applied the available name Enulius; Dunn described the maxillary dentition as "3-4 small teeth increasing posteriorly, followed immediately by one or two relatively enormous flattened (ungrooved) fangs.... No American snake is known with ... similar dentition." See McCranie and Villa (1993: fig. 2) for a drawing of the dentition, which is reminiscent of the Malagasy Exallodontophis albignaci, except that the latter has two large teeth intervening between the anterior small teeth and the posterior large fangs (see Cadle, 1999: fig. 10). Dunn (op. cit.) did not know the hemipenis of Enulius sclateri, but described that of E. flavitorques as "slightly bifurcate, sulcus forked at extreme distal end, no calyces, organ with minute uniform spines." This is accurate except for the presence of distinct apical projections or awns, shown for the first time in figure 27A, B.

McCranie and Villa (1993) found that the hemipenis of Enulius sclateri has a scattering of large spines in additional to small spines that are not uniformly distributed. Their illustration is reproduced here as figure $27 \mathrm{C}$; it looks as though the bilobed hemipenis is completely everted, without evidence of terminal projections. In following prevailing views on the taxonomic importance of the hemipenis, McCranie and Villa (1993: 262) thought that the "distinctiveness of the sclateri hemipenis warrants the designation of a new genus to accommodate the species." In not recognizing "Enuliophis" as a valid genus based solely on the hemipenis, we agree with Savage (2002: 590), who succinctly stated: "In all other features E. sclateri clusters with 


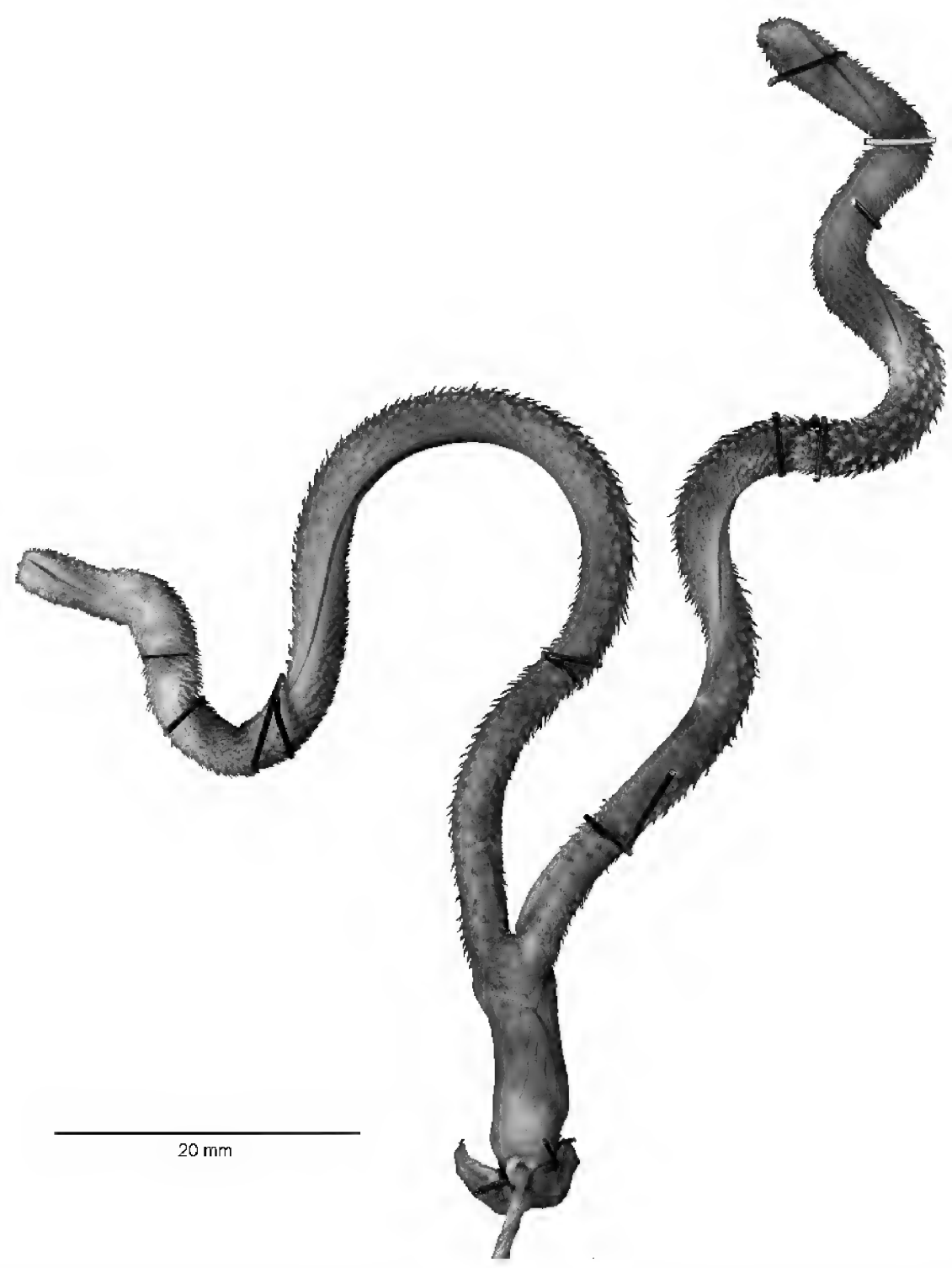

Fig. 28. The deeply divided, exceedingly long-lobed hemipenis of Pseudaspis cana (Linnaeus) (AMNH $\mathrm{R}-49948$, right hemipenis). The contralateral (left) organ of this snake originates near the end of the tail at subcaudal 44 (there are 55 subcaudals total); although the left organ was partially everted, its retractor muscle retained a series of sinuous folds that seemed to straighten somewhat after being freed from membranous tissue. The branches of the sulcus spermaticus orbit each lobe several times; the sulcus orientation is "centrifugal-orbital" following the classification proposed herein. (The orbiting nature of the sulcus is not clearly evident in a partially everted organ illustrated by Cope, 1895: pl. 24, figs 9, 9a.)

Enulius when compared with other colubrid snakes. Since all evidence indicates that $E$. sclateri is the sister species to all other Enulius, taxonomic efficiency is best served by avoiding monotypic genera and including the known species in an inclusive taxon."
COILED AND Folded RETRACTOR MUSCLES AND A FOLDING HEMIPENIS: If the maxim "size matters" is sometimes true, how does a snake balance selection for a long hemipenis against selection for a short tail, since both sometimes seem to be advantageous? It is 
been done differently in clearly unrelated snakes, in which hemipenes are nearly as long or even longer than the tails that must house them.

In Scolecophidia, McDowell (1974: 6-7) summarized ways in which maximum-length hemipenes are housed in short tails of species from New Guinea and adjacent regions:

The hemipenis of Typhlops has the long retractor muscle inserted at the extreme tip of the relatively short and broad organ; hence the entire organ is inverted when the organ is retracted. In Typhlina, the long retractor is inserted at about the middle of the organ and the distal part of the organ remains permanently everted and is an essentially solid awn bearing the distal part of the sulcus spermaticus; the proximal, inversible part of the organ acts as a sheath for the permanently everted portion when the hemipenis is retracted. Usually the hemipenis and its retractor are straight in Typhlops, but in the single $T$. inornatus examined ... the retractor has a zigzag bend. Usually the hemipenis and its long retractor show helical coiling in Typhlina (at least 2 coils in all New Guinea and Solomons species), but in the [longtailed] Philippine $T$. cumingii ... the organ and its retractor are either perfectly straight or have a single Z-shaped flexure in a single plane.

Some Alethinophidia are unusual in having the major retractor muscle originate close to or even at the tail tip, which correlates with a relatively longer hemipenis. The African colubrid Mehelya poensis, for example, is not a particularly short-tailed snake, but its deeply divided, long-lobed hemipenis (fig. 16) extends to about the level of subcaudal 21 and the long retractor has a broad anchorage between subcaudals 46-49, only 10 subcaudals before the terminal spine.

Another colubrid, Pseudaspis cana, has an impressively large, more deeply divided and longer lobed hemipenis, as seen in figure 28 . In the specimen figured, the contralateral hemipenis originates at the level of subcaudal 44 (total paired subcaudals $=55$ ). Bogert (1940: 42) dissected another specimen with retracted hemipenes in which "The separate muscles attached to each fork are not straight, but are drawn back in a series of sinuous folds, as though there were insufficient space for both the hemipenis and the muscles within the sheath in the tail." The contralateral hemipenis to the one in figure 28 is partially everted, but even so there was still evidence of the sinuous folding mentioned by Bogert.

Folding of the retractor muscle seems commonplace in still another African genus, Prosymna. Battersby (1951: 829) wrote:

It was noted, whilst sexing the two specimens [of Prosymna pitmani, sp. n.] that the retractor muscles were very large and lay in many convolutions from the hemipenis to practically the tip of the tail. In the paratype the right hemipenis is evaginated, the convolutions are straightened out, and the muscle is so much stretched that it is threadlike. Examination of several males of Prosymna ambigua stuhlmanni, $P$. melegris and $P$. somalica showed the same convoluted condition, but in specimens of $P$. sundevallii the retractor muscle was quite straight.

W.R. Branch (fide Broadley, 1980: 493-494) seems to have confirmed that a straight retractor muscle in Prosymna is correlated with the relatively short hemipenes of $P$. sundevallii subspp., $P$. angolensis, and $P$. bivittata; the straight retractor muscle in $P$. frontalis "is permitted by the relatively long tail of this species."

Bogert (1940: 43) suggested that the sinuous folding of the retractor in Pseudaspis cana "is comparable to what must exist in Prosymna, the remarkable 'telescoped' hemipenis of which is longer when everted than the tail (vide Schmidt, 1923...)." Bogert was referring to Schmidt's description of a specimen of Prosymna ambigua bocagii (AMNH R-12145). However, dissection of that specimen by Myers shows a small Z-shaped fold in each retractor and a large Z-shaped fold situated posteriad in the left retractor. Although the last mentioned fold would have to contribute significantly to the unfolding and lengthening of the still retracted left hemipenis, there is no sinuous folding along the length of that retractor as expected by Bogert. Instead, the hemipenis itself is remarkably folded!

Figure 29A shows the everted hemipenis of Prosymna ambigua bocagii as illustrated by Schmidt; the tip of the organ was broken off and stored with the specimen in a vial. Figure 29B shows the same specimen as 

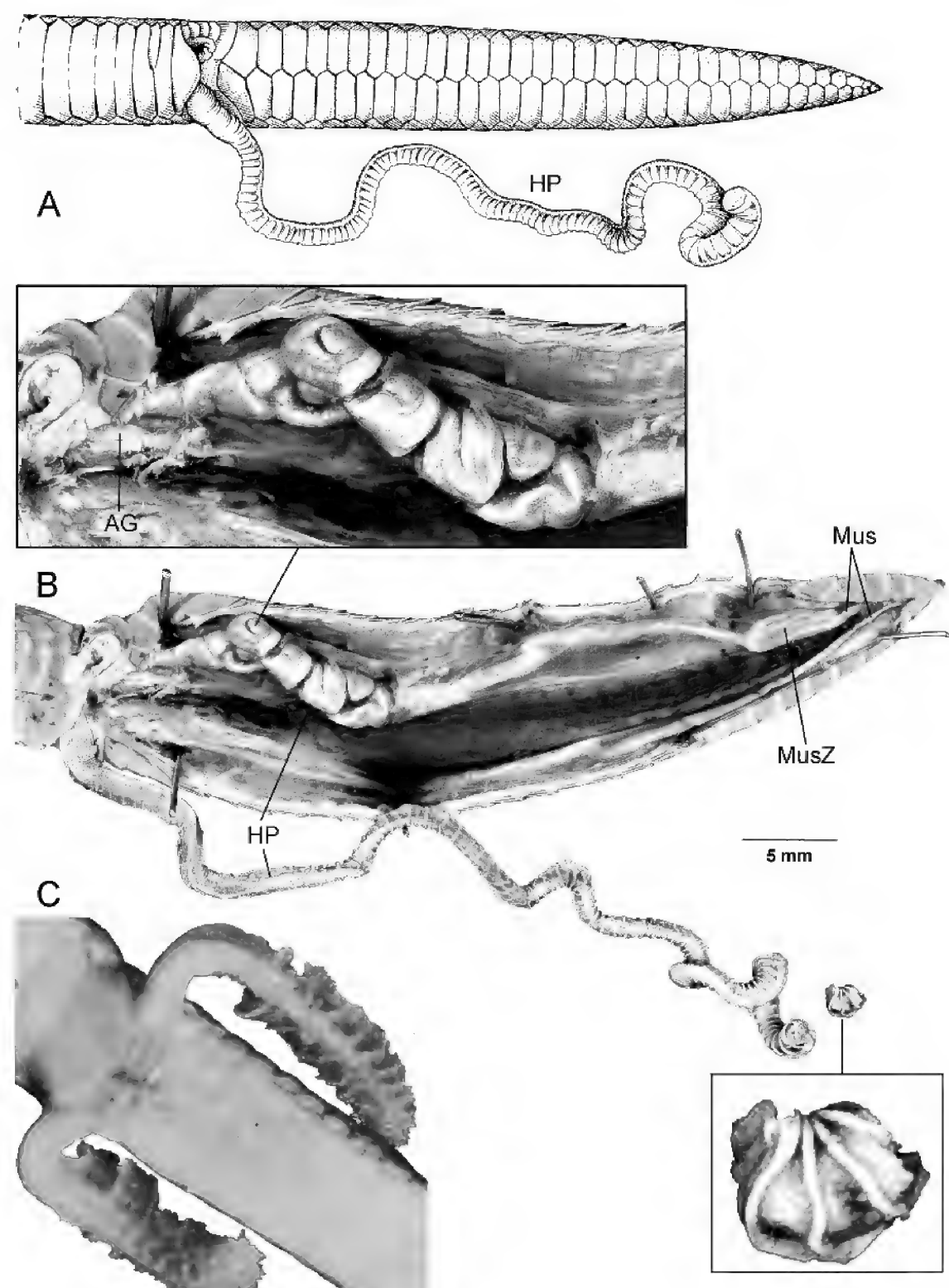

Fig. 29. The African genus Prosymna includes examples of extreme hemipenial diversity. A. Prosymna ambigua bocagii Boulenger, a snake with a slender, single (unforked) hemipenis longer than the tail when everted. Drawing of AMNH R-12145, reproduced from Schmidt (1923: 89). B. Same specimen as above, with tail opened, showing complex "accordion" folding of the uneverted contralateral hemipenis. The retractor muscles originate threadlike at the very tip of the tail, both with a small Z-shaped fold toward the hemipenis. Notice at the bottom side that the everted right hemipenis has the tip broken off. Inset at top: Greatly enlarged view of the folded part of the inverted hemipenis. Inset at lower right: Enlarged view of the tip of the broken right hemipenis, showing ridgelike structures at the terminus. C. Prosymna sundevallii (A. Smith) hemipenes showing peculiar anastomosing flouncing, from Broadley (1980: pl. IIA). Abbreviations: AG, presumed small anal gland; HP, hemipenis; Mus, termini of left and right retractor muscles; MusZ, large Z-shaped fold in left retractor muscle; SS, sulcus spermaticus. 
recently dissected, with an insert at the lower right showing a greatly enlarged view of the broken tip of the right hemipenis. The folding of the uneverted left hemipenis may be a bit more complex than "accordionlike," but further dissection would be necessary to unfold or accurately describe it. The place of insertion of the retractor muscle on the uneverted hemipenis is not clear; a long area is enveloped in membranous and tough connective tissue and there seemed no compelling reason for destructive dissection of the only available specimen.

The divergence between the hemipenes of Eutrachelophis bassleri and E. steinbachialong with the several extremely different hemipenes discussed and illustrated aboveare indeed much more elaborate than would seem necessary for the "simple function of gamete transfer." Such unexpected, unpredictable variation strikes a discordant note in the usual systematic utility of hemipenial data, in which genitalic divergence normally has inherent high stability, but such stability "may be overridden at times by direct selection on the organs themselves or pleiotropic events" (Arnold, 1986: 263). Truly extreme genitalic divergence appears remarkable when it occurs, but is not by itself sufficient reason to generically separate close relatives - particularly sister species.

\section{THEORETICAL BASES FOR HEMIPENIAL EVOLUTION}

A systematic approach to discussion of hemipenial evolution might include a demonstration of differences between or among genitalia of purportedly related species - to be followed by a polarity judgment of character states. But it is a different matter when hemipenes of presumably (or demonstrably) related taxa are dramatically different and lack evidence for gradual or polarizable change. The usual result in such cases is the naming of a monotypic genus, which might (and sometimes does) obscure actual affinities. We have thought about this problem especially as it concerns the new genus Eutrachelophis, which is supported by all global anatomical comparisons except for the radically different hemipenes. We think that it is worth considering two theoretical constructs that might help explain hemipenial novelties that seem inexplicable at first glance.

\section{EBERHARD'S THESIS}

In 1985, William Eberhard called to attention an evolutionary trend so pervasive that many taxonomists were led to wonder, How has this been overlooked for so long? Eberhard postulated that male genitalia both of invertebrates and vertebrates diverge rapidly relative to other characters. Male genitalia do not ordinarily show speciesspecific differences in animals with external fertilization, but the situation is exactly the opposite for those species that are dependent on internal fertilization. Eberhard (1985) dwelt on the topic of rapid divergence in genitalia of the latter. In a broad overview of animal genitalia, Eberhard considered a variety of hypotheses related to copulation and diversification of genitalia (e.g., lock and key, male conflict, pleiotropism, etc.); he admitted that various factors were likely to be operative in different groups, but concluded that sexual selection was the most likely general explanation.

Eberhard has not been entrenched in the idea of selection by female choice and his later papers (e.g., 2004, 2009, and 2010) continue to explore topics as diverse as "antagonistic coevolution," "cryptic female choice," and "static allometry" of genitalia. It is a complicated and active field of research not to be summarized here, but the citations in Eberhard's papers provide a good introduction to the literature. Eberhard's thesis seems to have been generally accepted as a truism, with little or no opposition. The burgeoning literature mainly seeks explanations. It follows that the bulk of this literature stems from arachnologists and entomologists, since the intricate and diverse nature of genitalia in these huge groups have long been known.

Selection somehow involving sex (not merely female choice), or a combination of sexual and natural selection, often is invoked in the new literature, along with tests and examinations of the premises involved. Among the latter, Huber (2003: 69) concluded: "The taxonomic evidence in favor of rapid evolution and species-specificity seems 
overwhelming," but he called for rigorous examination and implied that molecular phylogenies are best suited "to test relative rates of evolution in different character systems."

Arachnologist Jonathan Coddington, in an early review of Eberhard's book, made the following observation:

Convergent morphologies that are the result of natural selection generally look the same. However, despite so many instances of independent convergences (genitalia) over such a wide array of taxa, no male genitalia, at least I am aware of, have converged to resemble each other strongly. One could argue that this is strong evidence that they evolve under sexual as opposed to natural selection. (Coddington, 1987: 198)

Species specific differences between hemipenes of closely related snakes usually can be found without difficulty; paradoxically, possible convergence in hemipenial features of unrelated snakes are sometimes more evident (e.g., as mentioned herein, resemblances between the hemipenes of Rhadinaea vermiculaticeps and Rhadinella schistosa, and between those of Eutrachelophis steinbachi and Mehelya poensis).

The herpetological literature recently contributed to the complexity of the selection problem with a paper by King et al. (2009:110), who suggest that "sexual conflict over copulation duration may have shaped the evolution of hemipenis morphology, favoring more elaborate organs in species in which a long duration of copulation is especially beneficial to males, despite the associated cost to females." Two species were tested and compared, Thamnophis sirtalis and T. radix. Copulation duration was shorter in $T$. sirtalis, which has a simple subcylindrical organ that is more easily disengaged by females. Duration was longer in $T$. radix, which has a larger, bilobed (T-shaped) hemipenis that is hard to disengage, causing the male to be dragged if the female moves. The difficult job of associating benefits to females on one hand and males on the other is discussed by the authors; their comments on evolutionary plasticity in hemipenis morphology of New World natricines is a reasoned judgment deserving consideration.
But, whatever the selection processes that are in play among different animals, the underlying mechanisms for change are less well understood. Eberhard's thesis of genitalic divergence includes evolutionary changes that (from a taxonomic perspective) appear relatively stable and informative on one hand and, on the other hand, seemingly inexplicable changes that are discordant and uninformative. Referring to the "extravagance or apparently superfluous complexity of many genitalia," Eberhard (1985: 81-82) suggested "the potentially cumulative nature of complex modifications mean that there is no predictable upper limit to genitalic complexity" [emphasis added]. The last point is perhaps exemplified by the extreme hemipenial divergences described and illustrated herein for Eutrachelophis, Enulius, and Prosymna.

Are such novelties to be explained by natural selection of random mutations? Or can rapidly increasing knowledge of the regulation and expression of Hox genes provide a more direct explanation, at least in some cases?

\section{Hox GENE EXPRESSION}

Studies of evolutionary development were unified by last century's discoveries of Hox genes, their chromosomal locations, methods of their regulation and expression, and their universal taxonomic distribution among metazoans. These genes regulate embryonic development of all vertebrates and were crucial to the evolutionary origin of external genitalia (note: hemipenes are developmentally external) - an event linked to terrestrialism and internal fertilization. The earliest genital appendage is thought to have occurred either at the base of the tetrapods or at the base of the amniotes (Kondo et al., 1997; Perriton et al., 2002: 42-43). There are close parallels in development of the genital tubercle in rodents and reptiles. And the past few decades have witnessed an accumulation of data encompassing the Squamata (e.g., Cohn and Tickle, 1999; Di-Poi et al., 2009, 2010; Polly et al., 2001; Woltering et al., 2009); ongoing work involving hemipenes is awaited with interest.

Cohn and Tickle (1999) invoked complex collinear expression patterns of Hox genes to 
describe the developmental basis of limblessness and axial patterning in snakes-in part by homeotic mutations (transformations) along the body axis. Cohn (2002: 508) noted that "Although Hox genes are generally associated with regionalization of the primary body axis of the embryo, they are also involved in ... secondary axes [including legs and genitalia]." He went on (loc. cit.: 509) to say that "Undoubtedly, morphological evolution does not occur solely by homeosis, and as the field develops, we can expect to discover more fine-scale anatomical changes that are the results of evolving Hox gene regulation."

Although the evidence is not yet here, we suggest that the occasionally dramatic differences between hemipenes of closely affiliated snakes may one day be explained by finescale Hox gene regulation. At the moment, it seems to be the best guess we have to account for anatomical structures that seem otherwise inexplicable. Meanwhile, we look forward to the availability of molecular data for testing hypothesized relationships.

\section{TAXONOMIC USE OF HEMIPENIAL DATA}

We hope to have made it clear that we do not, can not, deny the taxonomic and phylogenetic importance of most hemipenial data. Cope's (1895: 187) conclusion that "No one hereafter can be sure of the place of a serpent until the hemipenis has been examined" needs a little qualification perhaps, but his point remains well taken. Simple proofs are easy to find. For example, the Venezuelan snake Urotheca williamsi Roze (1958: 4) was described with the mistaken notion that its copulatory organ was apically calyculate, but one look at its everted hemipenis, shown in figure 17A, indicates that it is now more correctly known as Liophis williamsi (Roze) fide Myers (1974: 20; 1986: 8). Hemipenial data are normally important and useful in identification, in buttressing relationships, and in working out phylogenies.

However, the hemipenis is not some kind of intrinsically natural character on which one can depend to show truth. Overall it is a truly important taxonomic character, but it should be treated objectively and not given automatic preference over such other characters as dentition, color pattern, etc. Although the hemipenis often proves the most useful character, it can also be misleading and suggest lack of relationship between sister species. Thoughtful authorities such as Bogert (1940) and Inger and Marx (1962) have warned against uncritical acceptance of hemipenial data, and Ziegler and Böhme (1997: 187) more recently stated that "the hypothesis of selective neutrality [of genital structures] can no longer be maintained." In reality, there never seems to have been a well-stated "hypothesis of selective neutrality," although it might seem implicit in the writings of Dowling (e.g., 1967; 138), who said:

The squamate hemipenis is a structure that (unlike teeth, skull, or scutellation) has no obvious correlation with the ecology, food habits, or locomotion of the animal. Such an uncorrelated structure may give better information on genetic relationships than some habitor habitat-correlated characteristic.

As already pointed out, Bogert and Dunn believed that there are correlations between hemipenes and adaptive change, at least in some snakes. Much later, Dowling (2004: 324) also suggested an adaptive correlation in the case of Old World Psamophiidae, the hemipenes of which lack ornamentation "apparently as an adaptation to rapid withdrawal of that organ when the copulating pair is threatened."

In rejecting a report of intraspecific hemipenial variation, Dowling (2002: 12) elsewhere had commented that (emphasis added):

minor interspecific hemipenis variation is often used as one of the characters for the recognition of the individual species in a genus (e.g., Duellman, 1958). Also, although intraspecific variation is usually found in minor characters (size of spines, numbers of calyces; e.g. Keiser (1969) and has not often been studied in detail, it has been recognized for many years and it occasionally has been used as a taxonomic feature for the recognition of subspecies (e.g., the description of Coluber constrictor priapus Dunn and Wood, 1939). [The degree of intraspecific variation reported for the hemipenis (and female cloaca) in Calamaria lumbricoidea (Inger and Marx, 1962) has not been found in any other taxon, and may be unique.] 
In seemingly rejecting the importance of intraspecific variation, Dowling understandably pays little attention to the obvious correlation, that of reproduction, which he probably believes to be self evident: "The value of hemipenes as indicator of relationships is primarily that they all have the same purpose and are used in the same fashion; to introduce sperm into the oviducts of the females of the same species" (Dowling, 2004: 324). But successful reproduction depends on successful copulation, which is a complex matter, as might be imagined just from the variety of hemipenes illustrated in this paper.

We disagree with Dowling who seems to believe that intraspecific hemipenial variation is a minor or trivial matter. And we especially disagree with the common interpretation that hemipenes are neutral or "uncorrelated" characters. Even discarding for the moment the extent to which they might be correlated with adaptive change related to locomotion and feeding, we believe that hemipenes must be subject to intense selection related to successful copulation, hence successful reproduction.

Like the genitalia of many other animal forms, evolutionary changes in some hemipenes may be more rapid than changes in other characters; and the end results of such changes may be more elaborately complex than is necessary for the simple introduction of sperm to oviducts. Our recognition of this has influenced our taxonomy in this paper, although we still have minimal understanding of the processes involved.

Following the deserved praise for Dowling and Savage's 1960 paper, Dowling (2002, 2004: 320, 324) took on the mantle of the seasoned professional whose criticisms of badly everted organs were based on "long experience and careful observation [having] acquired an 'eye' for details that suggest problems in the preparation of hemipenis specimens." Dowling's criticisms of purportedly ill-prepared hemipenes and his admonishments on how to preserve them revealed a reluctance to accept hemipenial features and techniques with which he had had little or no personal experience. Nonetheless, he is experienced and openly admits his own mistakes. Dowling's criticisms, although off the mark, were well intended and perhaps useful in soliciting better explanations from Zaher and Prudente (1999, 2003), Myers and Cadle (2003), and Myers (2011: 16). In his own research, Dowling used hemipenial data objectively and in combination with other characters, as when naming the genera Bogertophis Dowling and Price (1988) and Senticolis Dowling and Fries (1987).

In moving forward, however, it is now realized that there must be intense selection pressure on hemipenes (and most likely on the female cloaca as well). Arnold (1986: 275) observed that hemipenial differences in lacertid lizards have allowed recognition of a number of species previously unnoticed or named as subspecies. "In particular, it is common for copulatory organs of otherwise quite similar populations to be very different in size ... where two species are truly sympatric, with extensive geographic overlap rather than mere abutment, such size differences are usual, being found in nine out of 10 cases." Such generalizations cannot yet be made about snake hemipenes, but there is much to be learned.

\section{CONCLUSIONS AND BRIEF SUMMATION}

The snake hemipenis is not a neutral or "uncorrelated" structure. Neither can it be depended on to reveal generic or higher-level relationships (even though it often seems to fill that role nicely). It is subject to selection pressure that probably varies in intensity. Selection pressure furthermore probably is stronger on snake hemipenes than on lizard hemipenes. Snakes generally have more spinous and larger hemipenes (Cope, 1896: 461; Olsson and Madsen, 1998: 528; personal obs.) and generally also have lengthier copulations. Literature data compiled by Olson and Madsen (1998: 528) showed that:

Snake copulations last $3 \mathrm{~min}$ to $28 \mathrm{~h}$ whereas lizard copulations last $0.05 \mathrm{~min}$ to $1 \mathrm{~h} 6 \mathrm{~min}$, but the bias towards longer copulations in snakes is much stronger than these ranges suggest (Fig. 13.5; Appendix A). An 'outlier lizard,' the legless Anguis fragilis, with spined hemipenises may copulate for $20 \mathrm{~h}$.

Intraspecific variation in all aspects of the hemipenis is common (at least in snakes) and 
may be the rule for those species that are geographically widespread.

Hemipenial variation, whether subtle or extreme, sometimes reveals the existence of cryptic species, as is the case with Xenodon "rabdocephalus" (Wied, 1824). The lectotype of that composite species is shown to have a small apical disc-a diagnostic hemipenial character of the tribe Xenodontini-although other populations have lost the apical disc, including the species Xenodon angustirostris W. Peters from Panama and X. suspectus Cope from western South America (both raised from the synonymy of "rabdocephalus" herein). Other South American and perhaps (?) other Central American populations of $X$. "rabdocephalus" collectively include an unknown number of species (named and unnamed), but hemipenial data are too sparse to allow separation of ranges because the Bothrops-like color pattern of adults, although variable, maintains a degree of geographic consistency from Mexico to Bolivia and Brazil; an intensive revision is needed.

Loss characters such as the apical disc are helpful in defining species. They do not, however, warrant establishment of monotypic genera, which may actually obscure relationships. Several such genera belong in the synonymy of Xenodon Boie (in Schlegel, 1827: 293), including Acanthophallus Cope, 1894, Thalesius Yuki, 1993, and Waglerophis Romano and Hoge, 1972. The last genus has apical discs, but they are on the tips of long lobes that seem to be a precursor for disc attrition.

Despite the day-to-day taxonomic importance and usefulness of hemipenial data in assessing generic relationships, the hemipenis fails in instances of extreme divergence. Illustrated examples include the divergent hemipenes of Central American Enulius and African Prosymna. Folding or coiling of the retractor muscle allows some long hemipenes to fit within short tails, but the hemipenis of Prosymna ambigua bocagii is longer than the tail and is itself folded. The best documentation for extreme hemipenial diversity in the same genus is provided for the new South American genus Eutrachelophis ("beautifulnecked snakes"): E. bassleri, n. sp., and E. steinbachi (Boulenger) have very different looking hemipenes, but the two species are virtually identical in global comparisons of viscera, head glands, head muscles, and skull and dentition; their species-specific differences in ocellar head and neck markings are included within the variation of similar markings in other genera or even in single species (Rhadinaea decorata).

Eutrachelophis bassleri is unique among "xenodontines" in having a spiny noncalyculate hemipenis with a well-formed noncapitate nude capitulum. The hemipenis of E. steinbachi on the other hand resembles those of a few unrelated colubrids (e.g., South American Xenodon suspectus; African Mehelya poensis) in being deeply divided with long spiny lobes ending in an apical tuff of differentiated spines. An explanatory hypothesis for congeneric status has $E$. bassleri and E. steinbachi derived from common stock in which embryonic development of the lobes was suppressed in the bassleri lineage. The resulting broad, hemispherical nude apex of $E$. bassleri is homologous with the E. steinbachi smooth terminal basin (judged from the presence of expansion folds, the size of this basin in the everted organ might approach the size of the smooth dome of E. bassleri). Thus, a simple change in the embryonic growth rate may have resulted in very different looking hemipenes.

Eberhard's thesis that male genitalia evolve relatively more rapidly than other characters has been borne out in many animal groups and is consistent with evidence presented for Eutrachelophis. We suggest that fine-scale Hox gene expression might account for the novel hemipenis of E. bassleri and perhaps also for the other extremely divergent hemipenes discussed and illustrated.

\section{MUSEUM ABBREVIATIONS}

The following collection abbreviations are used in this paper:

AMNH American Museum of Natural BMNH $\quad$ Natural History Museum, London CM Carnegie Museum, Pittsburg

FMNH Field Museum of Natural History, Chicago

MZUSP Museu de Zoologia da Universidade de São Paulo

NMW Naturhistorisches Museum, Vienna 


$\begin{array}{ll}\text { PEM } & \begin{array}{l}\text { Port Elizabeth Museum, South } \\ \text { Africa } \\ \text { Queensland Museum, Brisbane } \\ \text { QM }\end{array} \\ \text { TCWC } & \begin{array}{l}\text { Texas Cooperative Wildlife Col- } \\ \text { lection, College Station }\end{array} \\ \text { UMMZ } & \begin{array}{l}\text { University of Michigan Museum } \\ \text { of Zoology, Ann Arbor } \\ \text { National Museum of Natural } \\ \text { USNM }\end{array} \\ \text { Uistory, Washington, D.C. } \\ \text { University of Texas at Arlington }\end{array}$

\section{ACKNOWLEDGMENTS}

For lending important material in their care and other courtesies we thank Kevin de Queiroz, Jeremy J. Jacobs, and Robert V. Wilson (USNM), James R. Dixon (TCWC), Martin Henzl (NMW), Robert F. Inger and Alan Resetar (FMNH), Arnold G. Kluge (UMMZ), Colin J. McCarthy and Andrew F. Stimson (BMNH), the late Clarence J. McCoy and Ellen J. Censky (CM), and the late Paulo E. Vanzolini (MZUSP).

We thank Herndon G. Dowling, Jay M. Savage, and Hussam Zaher for their published contributions and for profitable discussions over a number of years. Although we disagree among ourselves on a few issues, their open-minded collegiality is something treasured. In continuing to actively explore the byways of hemipenial diversity, John E. Cadle has advanced the field tremendously; we value his counsel.

McDowell particularly thanks A.C. Ziegler of the Bernice P. Bishop Museum, Honolulu, for providing material that resulted in several reports on snakes of New Guinea and Solomons (McDowell, 1974, 1975, 1979), and J. Covacevich of the Queensland Museum for providing unpublished locality records and the loan of elapid specimens.

For supporting his research agenda, Myers particularly thanks Robert G. Goelet, former president and Chairman Emeritus of the Board of Trustees of the American Museum of Natural History; Mr. Goelet provided funding for preparation of most of the illustrations used in this paper. Myers is grateful to his late friend and colleague Paulo E. Vanzolini for facilitating his work in Brazil, including trips made with Vanzolini and Francisca do Val in the Brazilian back country.
Some of the drawings used herein were originally prepared by Myers (figs. 3,12) and by McDowell (figs. 10-11, 37-40). The painstaking drawing in figure 9, previously unpublished, was made some years ago by Ellen E. Bowler, who also was responsible for some of the artwork in Myers (1974). Myers took most of the photos of live specimens; other photographs were generously provided by James R. Dixon (fig. 7) and Marcio Martins (figs. 15A, B). Peter Goldberg photographed preserved specimens for this paper. Patricia J. Wynne finessed and improved the electronic images and was always ready to update a drawing and offer ideas. Grace M. Tilger watched over Myers' office during his absences and provided archival assistance; her support is invaluable.

We thank Sydney Anderson for sharing his knowledge of Bolivian geography. For reading and critically commenting on the manuscript, we owe more than the usual thanks to John E. Cadle, Jonathan A. Campbell, and Grace M. Tilger.

\section{APPENDIX 1 \\ Nomenclatural Considerations}

\section{C.W. MYERS}

\section{Notes on the Tribe \\ Xenodontini Bonaparte}

The colubrid tribe Xenodontini nomenclaturally dates from Bonaparte, $1845 .{ }^{27}$ It is based on Bonaparte's "Xenodontina," whence come the subfamily name Xenodontinae and the nominotypical tribal name Xenodontini. Based on a combination of characters, Cope (1894: 840-842; 1895: 200$201,207)$ separated species with an apical disc ("disciferi") in two subfamilies, under Xenodontinae and Erythrolamprinae. Dunn (1928: 21) modified and simplified Cope's arrangement by placing species purportedly with apical discs in the subfamily Ophiinae ( $=$ Xenodontinae, since Ophis is a preoccupied fish name). The tribe Xenodontini was recognized by Dowling (1975: 192, 198, 202), who mentioned or showed hemipenes of Xenodon, Liophis, Erythrolamprus, and (mistakenly) Oxyrhopus. Dowling and Duellman ("1974-1978" [1978]: 112a.3) listed nine genera. It subsequently was

${ }^{27}$ That is: Bonaparte, $1845 \mathrm{a}$, or $1845 \mathrm{~b}$, depending on whether the latter is a reprint or a preprint of the former. 
treated by Dixon (1980: 24, 26) and Myers (1986: 6). After revisionary work by the former, the six genera of Xenodontini recognized by Dixon (1980: 26) and Myers (1986: 2) were Xenodon, Erythrolamprus, Liophis, Lystrophis, Umbrivaga, and Waglerophis. There has been little substantive discussion. Myers (1986: 1) added a supporting character and summarized:

hemipenial variation among the Xenodontini is much greater than has been indicated in the literature, and that the tribe is based essentially on a single character-the paired apical discs [but that] Defensive neck flattening or hood display is widespread in the Xenodontini, having been recorded for at least five of the six genera currently assigned, and seems to provide a behavioral synapomorphy that corroborates the validity of the group.

Zaher (1999: 39-40) discussed and illustrated the hemipenial morphology of the Xenodontini sensu Dixon. Zaher (op. cit.: 40) declined to recognize the recently named Thalesius Yuki (1993), pointing out resemblances and morphological synapomorphy that place $T$. werneri "unambiguously within the Xenodontini." Zaher perceptively viewed absence of the apical disc in $T$. werneri as a secondary loss (see below under Named Genera Based on Loss of the Apical Disc).

Zaher et al. (2009: 146-147), however, suggested major changes to the generic composition of the Xenodontini based on a new molecular phylogeny. They resurrected Lygophis ${ }^{28}$ from the synonymy of Liophis and synonymized Lystrophis and Waglerophis under Xenodon. But they also synonymized Erythrolamprus with Liophis, saying:

Although there is no apparently known morphological evidence supporting this grouping, we here synonymize the genus Erythrolamprus Boie, 1826 with Liophis Wagler, 1830 in order to retrieve a monophyletic Liophis Boie, 1826 [sic]. However, Liophis is a highly speciose and diverse group of snake[s] and we expect a more comprehensive sampling than ours within the whole diversity of Liophis will provide more stable support for the taxonomic decisions taken here.

This is a case study for my belief that rushing to print with provisional classifications is disruptive to fruitful discourse and no help in the long run. Although taxonomy needs to reflect phylogeny, trying to change taxonomy with each new insight or new set of molecular data only leads to

\footnotetext{
${ }^{28}$ All eight species included in Lygophis are shown as "new combination." Most (5 of 8), however, were previously associated with Lygophis (e.g., in Peters and Orejas-Miranda, 1970: 185-185).
}

confusion (see also introductory commentary on Higher-level Taxonomy). Aside from momentarily confusing authorship and dates, Zaher et al. do not simply "retrieve a monophyletic Liophis" - they have instead recommended the muddling of Erythrolamprus (Boie, 1826) by dumping some 40 Liophis (Wagler, 1830) species names into it. The unrevised Erythrolamprus has contained six recognized taxa since listings by Peters and Orejas-Miranda (1970) and Curcio et al. (2009a), only one of which is in Zaher et al.'s molecular data base.

Curcio et al. (2009b) responded to the changes wanted by Zaher et al. (2009) and suggested that current taxonomy should be maintained until future studies provide adequate bases for major nomenclatural change. They commented:

Beyond the priority of Erythrolamprus, we believe that taxonomic changes in any direction would be premature. In our view, this particular systematic problem is too complex to be solved by simple synonymization based on the results of phylogenetic analyses including no more than five Liophis species [and one nomenclaturally poorly known Erythrolamprus]....

It can be argued that in proposing taxonomic changes based on phylogenetic evidence, Article 42.3 of the Code should be followed, i.e., application of genus-group names should be determined by reference to type species... The absence of type species ... prevents an objective conclusion being drawn from ... phylogenies regarding precise nomenclatural relationship.... (Curcio et al., 2009b: 66)

Curcio et al. (2009b) admitted that inclusion of type species in molecular databases can be impractical, but, when possible, their point should be kept in mind. It should also be kept in mind that Erythrolamprus itself has a distinctive albeit variable color pattern "synapomorphy" that is linked with coral snake mimicry (Greene and McDiarmid, 1981). The resulting geographic variation concordant between populations of Erythrolamprus and Micrurus complicates the resulting taxonomy; a revision of Erythrolamprus is needed. If or when paraphyly with Liophis becomes a taxonomic problem, the use of subgenera ${ }^{29}$ might usefully

${ }^{29}$ Under the Principle of Coordination (ICZN 1999: Art. 43) genera and subgenera are deemed to be simultaneously established with the same author and same type species. Use of subgenera does not disturb monophyletic underpinnings and is not a major nomenclatural act; it is simply an available taxonomic option that retains phylogenetic information without a mandate that it must be used. 
preserve the names of distinctive monophyletic clusters such as Erythrolamprus, Lystrophis, and Lygophis.

The present study has brought to light a need for several nomenclatural actions involving species of Xenodon. The first action includes a brief overview of Xenodon rabdocephalus, sensu lato, and resurrection of $X$. suspectus from its synonymy. The second action involves a lectotype designation for Xenodon "rabdocephalus," which has an enormous geographic distribution when an unknown number of cryptic species are included. Thirdly, the name Xenodon angustirostris W. Peters is tentatively resurrected for the cryptic or sibling species in Central America and western Colombia. Finally to be considered will be monotypic generic names that seem to be based primarily on hemipenial characters, especially (in two of three cases) the loss character of the apical disc. Here, I am in agreement with synonymies already suggested by Zaher (1999) and Zaher et al. (2009), although not necessarily for the same reasons.

\section{Color Pattern VARIATION IN $X_{\text {ENODON }}$ $R A B D O C E P H A L U S$, SENSU LATO, WITH $X$. SUSPECTUS COPE REMOVED FROM SYNONYMY}

The name Xenodon suspectus Cope, 1868, was placed in the synonymy of $X$. rabdocephalus (Wied, 1824) by Dixon (1983: 258), who considered the two species to be "essentially identical in scutellation and color pattern." Dixon (op. cit.: 257, 260) stated:

A review of the literature indicates that only one specimen of $X$. suspectus, other than the holotype, has been recorded ... from Moyobamba, N.E. Peru ... [and it] and the holotype of $X$. suspectus (Fig. 1B) appear very similar to the dark phase color pattern of $X$. rabdocephalus (Fig. 1A).

However, based on the hemipenis alone (fig. 20), I would recognize Xenodon suspectus as a species distinct from $X$. rabdocephalus, sensu stricto. But the color pattern also differs from that of $X$. rabdocephalus, sensu lato. Dixon was dealing mainly with intrapopulational variation in $X$. suspectus, which is not definitely known to occur sympatrically with $X$. "rabdocephalus"; however, a photograph of a Peruvian specimen (Dixon and Soini, 1977: 134, fig. 89; 1997: 134, fig. 89) from the "Iquitos Region" might well be "rabdocephalus," in which case sympatry seems likely.

Although Xenodon "rabdocephalus is a composite of cryptic species, it nonetheless is a wideranging and easily distinguished kind of snake often mistaken for a fer-de-lance (Bothrops asper/ atrox complex), which it mimics well. Even Prince
Maximilian evidently mistook a specimen of his Xenodon rabdocephalus for a venomous viper, when he named Cophias holosericeus [Bothrops] from Bahia (Wied, 1821: 243). The specimen was missing when he later treated "? C[ophias] holosericeus" under the heading Unbestimmte Arten ("doubtful species") and suggested that it might have been Coluber rabdocephalus (Wied, 1825: 490-493).

Although variable in detail, the "rabdocephalus" pattern is essentially one of dark brown, paleedged crossbands on a lighter brown ground; the pattern tends to be more vivid in juveniles (e.g., figs. 30B, 31A). This simplified description of an often-photographed serpent is best augmented visually with photographs from different parts of its large range- e.g., from north to south:

Yucatán Peninsula (Lee, 1996: fig. 394)

Belize (Köhler, 2008: fig. 817)

Honduras (McCranie, 2011: pl. 17F; Wilson and Meyer, 1985: fig. 105)

Costa Rica (Campbell and Lamar, 1989: figs. 563, 564; Greene, 1997: 114; Savage, 2002: photo 354; Solórzano, 2004: fig. 2070)

Colombia, western and central (this paper, fig. 30; Campbell and Lamar, 1989: fig. 565)

Peru (Duellman, 2005: photo 227; Dixon and Soini, 1977: 134, fig. 39 [see text above])

Guyana (Starace, 1998: 255-256)

Brazil, eastern (Cunha and Nascimento, 1993: fig. 74; Wied, 1827: Lief. 18 [see fig. 36 this paper])

Brazil, central (Martins and Oliveira (1998: photo 96)

The main color variation in $X$. rabdocephalus concerns the pale blotch-edging that varies from nearly absent through shades of pale brown or yellow to (rarely) vivid white - the overall pattern tending to be more vivid in life than in preservative. Some specimens have dark crossbands on a lighter ground, whereas others have lighter brown bands on a blackish ground. The pattern tends to be brighter and to have greatest contrast in juveniles. I have not seen patternless or melanistic or exceptionally pale specimens; such variants are rare in $X$. rabdocephalus, but Martins and Oliveira (1998: 128) mentioned that one had a "uniform greenish brown dorsum." The overall rabdocephalus pattern is consistent with that of the lectotype of Prince Maximilian's Coluber rabdocephalus, as will be seen in figure 36 .

Xenodon suspectus, on the other hand, is so highly variable in color pattern that the variation itself appears to be diagnostic. This is well shown by Dixon's (1983, fig. 1) illustrations of the head patterns of the suspectus holotype and three "rabdocephalus" from the Iquitos region. Such variability extends to the entire body, as shown by the seven specimens held by the American 

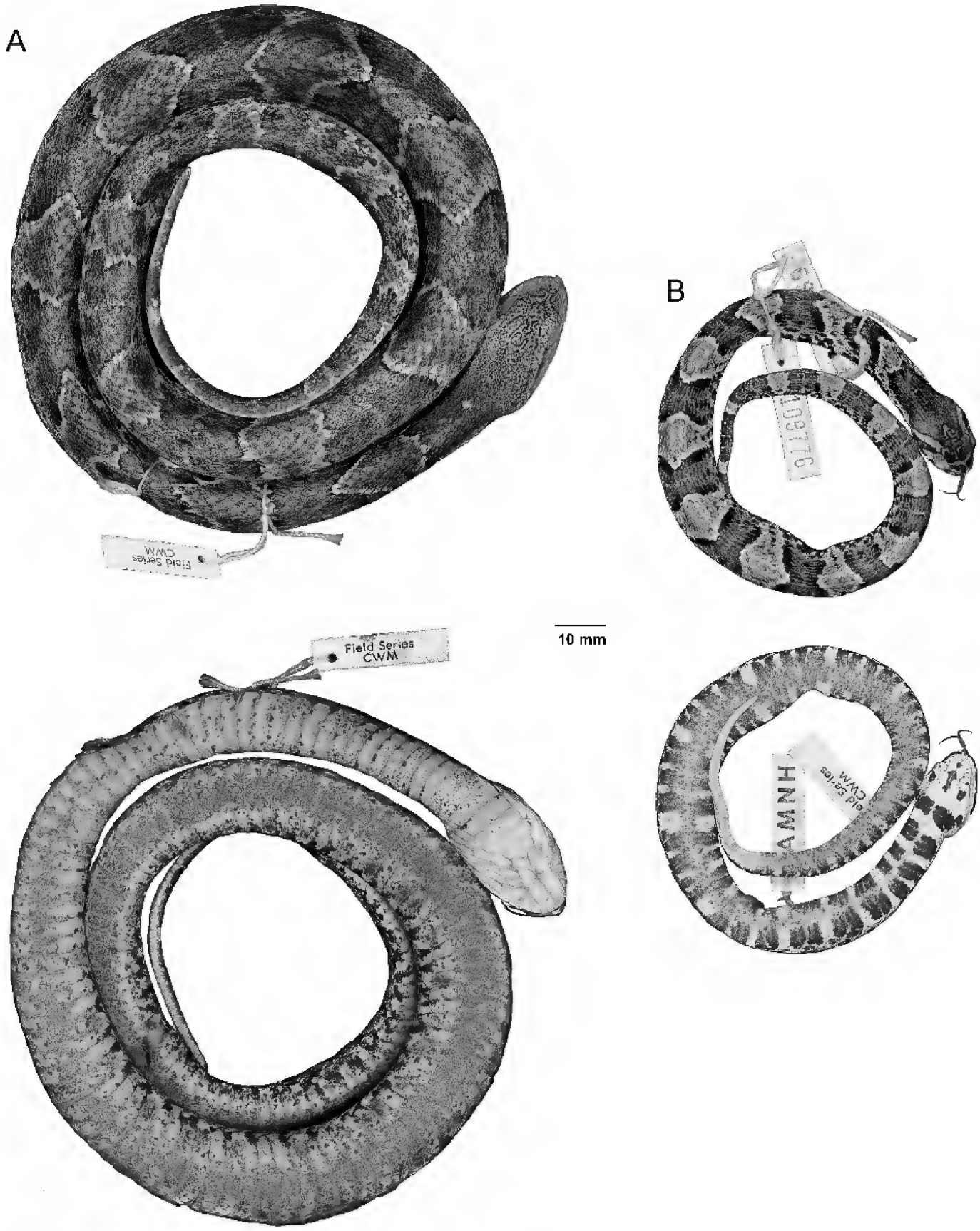

Fig. 30. Xenodon rabdocephalus, sensu lato (these specimens tentatively assigned to $X$. angustirostris W. Peters). Dorsal and ventral views of young specimens from western coastal Colombia (Quebrada Guanguí, Dept. Cauca, 100-200 m. A. AMNH R-109777 subadult female. B. AMNH R-109776 juvenile). See also figure 31 for specimens from Panama and Venezuela. 


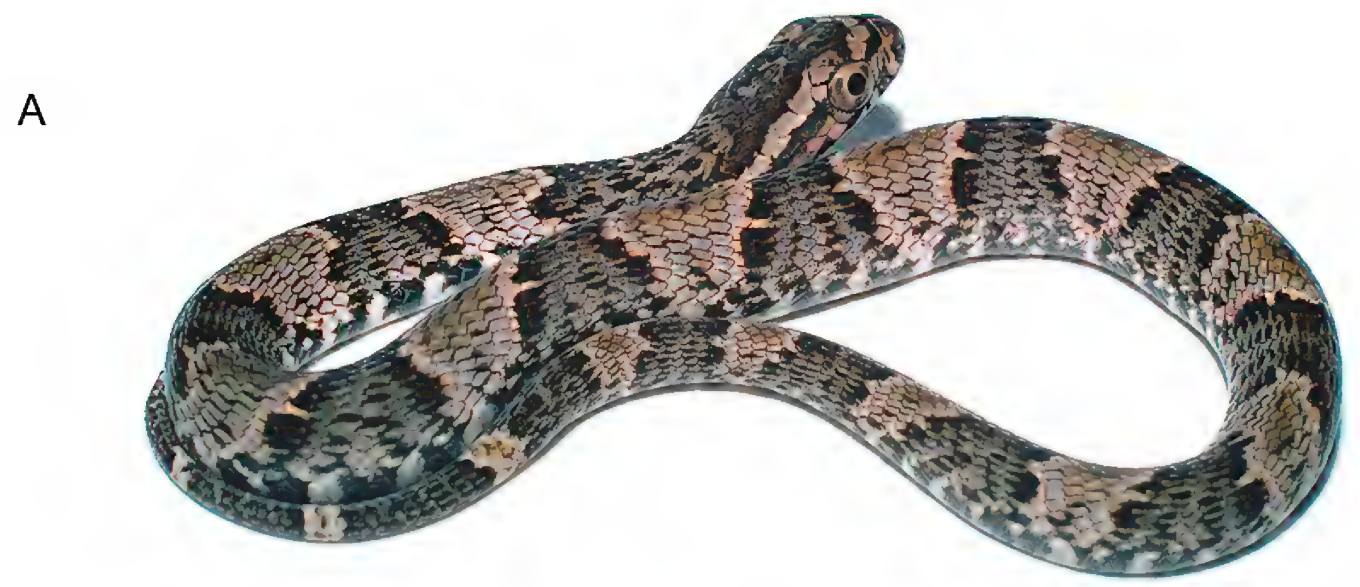

B

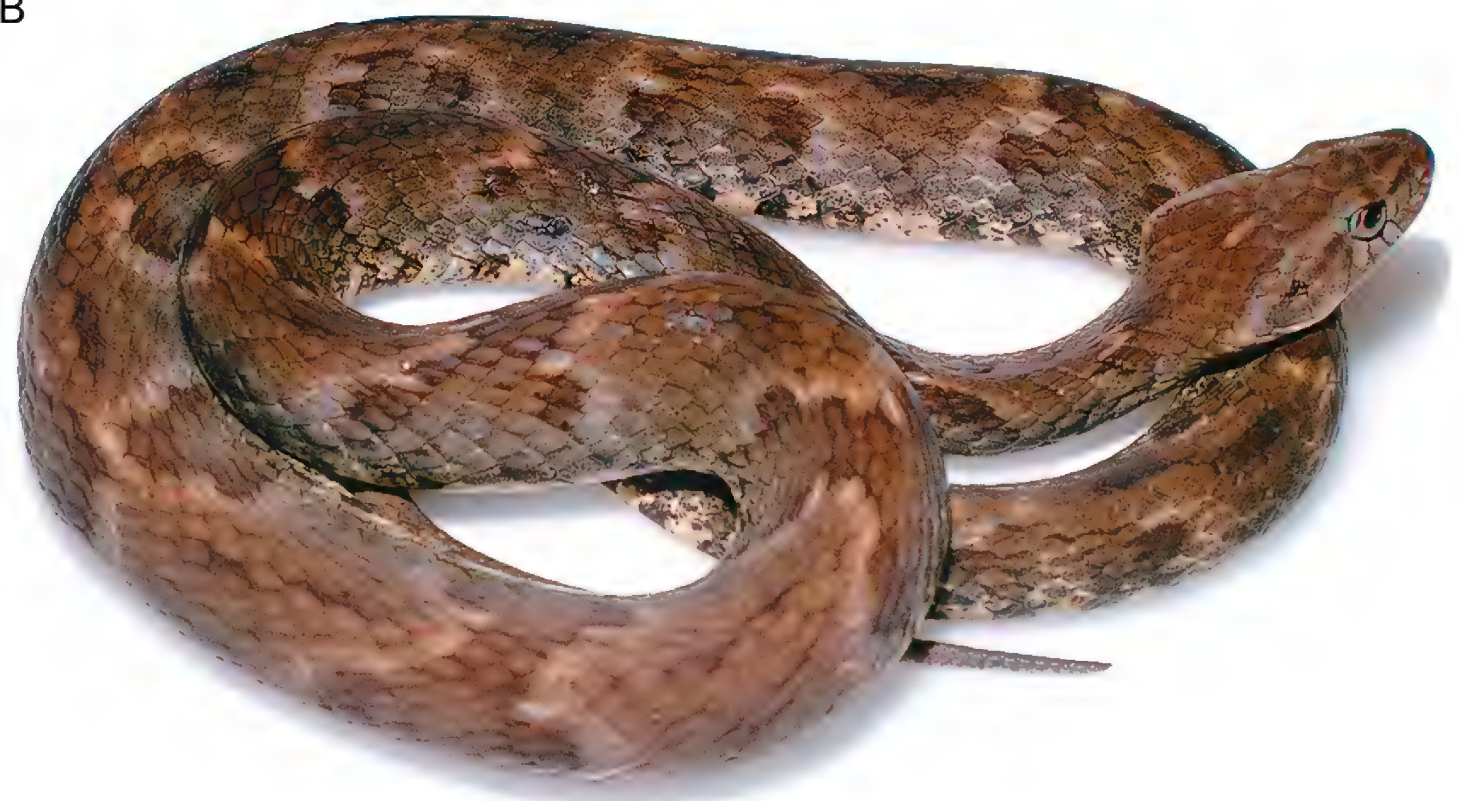

Fig. 31. Xenodon rabdocephalus, sensu lato. Living specimens from widely separated parts of its geographic range. A. A juvenile from eastern Panama (Darién, Río Jaqué, $1.5 \mathrm{~km}$ above Río Imamadó, 50 m; AMNH R-113392; tentatively assigned to $X$. angustirostris W. Peters; compare juvenile in figure 30B from western Colombia). B. An adult from Venezuela (Tapirapeco Expedition base camp, $150 \mathrm{~m}$, upper Río Mavaca, Amazonas; AMNH R-134207. Not assigned to species; $X$. "rabdocephalus" barely enters Venezuela.) Photographs by C.W. Myers.

Museum (e.g., see figs. 32 and 33), all from the Harvey Bassler collection and all identified as suspectus by Bassler himself (see fn. 3).

Based on the few specimens obtained by Bassler, Xenodon suspectus is an uncommon snake. His material includes only the following localities, to which one literature record is appended:
[Junín]: Chanchamayo, $1800 \mathrm{~m}$ [about $11^{\circ} \mathrm{S}, 75^{\prime} \mathrm{W}$ (AMNH R-52175), fig. 31.

[Loreto]: Contamana, Río Ucayali $\left[7^{\circ} 15^{\prime} \mathrm{S}\right.$, $\left.74^{\circ} 14^{\prime} \mathrm{W}\right]$ (AMNH R-52244), fig. 33A.

[Loreto]: Río Itaya, [near] Iquitos [about $4^{\circ} \mathrm{S}, 73^{\circ} \mathrm{W}$ ] (AMNH R-53636, 53815, 54070, 54552), figs. 33B-E.

[Loreto]: Monte Carmelo, Requena (Uresti) [about $5^{\circ}$ S, $74^{\circ} \mathrm{W}$ ] (AMNH R-55558), fig. 33F. 

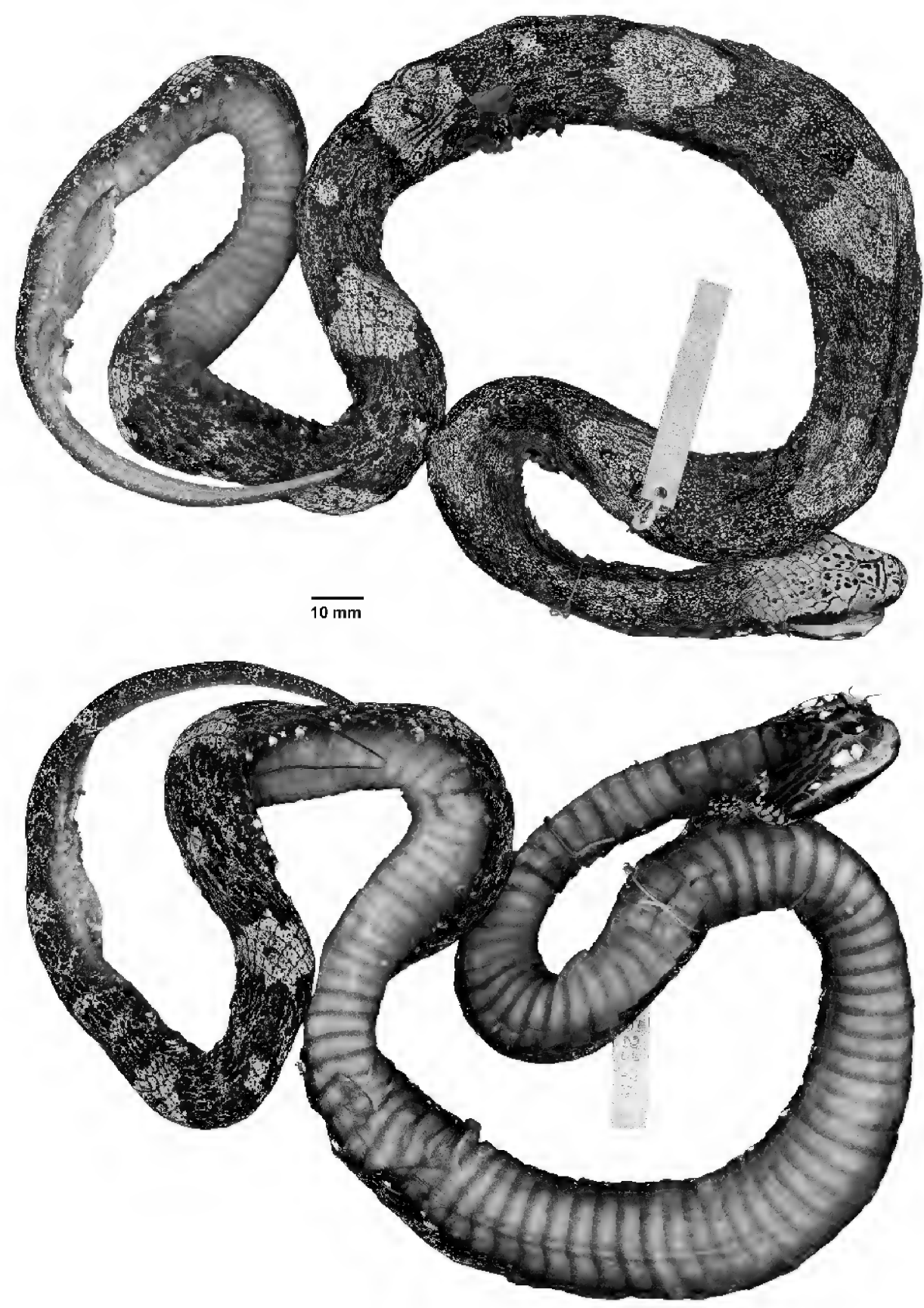

Fig. 32. Xenodon suspectus Cope in dorsal and ventral view. AMNH R-52175, an adult male from Chanchamayo, (Junín), Peru; hemipenis from this specimen shown in figure 20.

[San Martín]: Moyobamba, Rio Huallaga drainage [6 $\left.6^{\circ} .02^{\prime} \mathrm{S}, 76^{\circ} 58^{\prime} \mathrm{W}\right]$ (Boulenger, 1894: 147).

Such a distribution, in the upper Amazon and Andean foothills, does not fit, however, with the published type locality of Xenodon suspectus. Cope
(1868: 33-134) described Xenodon suspectus as "the brightest species of the genus ... brought from Lake Jose Assu by the Thayer Expedition to Brazil, under direction of Professor Agassiz. MCZ 362." Dixon (1983) cited the same MCZ number and referenced the locality as approximately $2^{\circ} 51^{\prime} \mathrm{S}$, 
$57^{\circ} 00^{\prime} \mathrm{W}$, in Brazil - far to the east of localities for specimens shown in figures 32-33, although Dixon's illustration of the head of holotype $\mathrm{MCZ}$ " 362 " is in agreement with the variation shown in our figures. The correct holotype number, however, is MCZ R-3649 according to José Rosado (personal comun.), who suspected that the number " 362 " was a collector number. The Thayer Expedition Papers are available online (http://library.mcz.harvard.edu/ thayer); a search at that site for that number or a field catalog that might contain it was unsuccessful. Amaral (1929a, 1936) did not consider Xenodon suspectus as belonging to the Brazilian snake fauna. Instead, without explanation, Amaral (1929b [1930]: 176) cited its distribution as "Peru oriental." That is consistent with current knowledge and I suspect that it is correct, though I wish that Amaral had shared the source of his insight. Meanwhile, I consider the type locality of $X$. suspectus to be unknown, but probably in eastern Peru.

\section{LECTOTYPE DESIGNATION FOR XENODON RABDOCEPHALUS (WIED)}

Overview: As indicated above Xenodon "rabdocephalus" is a well-known serpent that has an unusually large distribution and shows extensive variation in hemipenial features, including apparent interpopulational loss of the apical disc. Such variation is consistent with my belief that $X$. rabdocephalus is a composite of sibling species. An obvious, but only partial, solution is to examine the hemipenes from additional populations and apply the name $X$. rabdocephalus, sensu stricto, to those having an apical disc; then find any available junior synonyms for the others.

The problem with geographic variation in Xenodon rabdocephalus, sensu lato, however, is not simply one of hemipenes. Preliminary results of the unpublished study initiated by Garth Underwood and Clive Moncrieff (see above under Loss of a "Generic Character") indicate a complex pattern. In a second letter, Underwood wrote:

We have run a preliminary principal components analysis on the basis of 17 characters. The 52 specimens come out as a somewhat diffuse scatter of points-no indication of clusters. However there is a geographical component to the spread along the second axis, with the sequence Colombia, the rest of South America, Central America-i.e. it looks as though there is a measure of discontinuity across the isthmus.

All specimens have a lateral scale row reduction at about $50-60 \%$ of the ventral count. Most have a paravertebral reduction from $50-65 \%$, one is at $75 \%$. The Central American specimens have reductions far posterior from 95-100\% (i.e. "dropped off the end"). This gives a clearer separation than the ventral count.
In Liophis the scale rows on the tail drop: 8, 6, 4, 2 . In most of the Xenodon group the tail terminates at 4 rows, except merremii, neuwiedii and the Ecuador to Bolivia rabdocephalus.

We will rerun the PCA with ratios rather than raw scores to see whether we get any sharper resolution. We still have to decide whether to treat rabdocephalus as one unit or several. (letter, Underwood to C.W.M., October 6, 2001. AMNH Herpetology Archives, Myers Collection)

Wilson and Meyer (1985: 110) asserted that number of ventrals in $X$. rabdocephalus "gradually increase clinally from south to north." They provided no statistical support or geographic context, except that the range of ventral counts in Honduras (for an unknown number of males and females combined) is intermediate between the similarly vague ranges supposed to separate the subspecies $X, r$, rabdocephalus and $X, r$ mexicanus (fide Peters and Orejas-Miranda, 1970: 324). Nonetheless, the current synonym Xenodon mexicanus Smith (1940: 57) remains available for assignment if needed.

Xenodon rabdocephalus, sensu lato, has a large geographic range, over which it maintains relative phenotypic similarity in color pattern. It evidently pays to look like a fer-de-lance. ${ }^{30}$ The color pattern seems to be maintained by strong selection over the entire "rabdocephalus" species complex, with signs of speciation events signaled primarily by hemipenial changes. The aforesaid geographic

\footnotetext{
${ }^{30}$ It is a "fer-de-lance mimic": No other phrase so succinctly conveys this hypothesis. The name "fer-delance" is well known in English natural history and literary writing (e.g., as the title of Rex Stout's first [1934] Nero Wolfe novel). The name most often is applied by English speakers to Bothrops asper and $B$. atrox (mainland Neotropics) or to Bothrops caribbaeus and $B$. lanceolatus (Antilles). It is not used as a common name by Hispanic speakers, who have a huge variety of local names for Neotropical vipers. Campbell and Lamar (1989) usefully compiled many true common names for these species, but for English names they give mainly seldom-used book names such as "Common Lancehead" for B. atrox (one exception is "Terciopelo," given both as an English name and as one of numerous local names for $B$. asper). Campbell and Lamar (op. cit.: 208) commented on the origin of the name fer-de-lance, noting that "it has been applied most often to mainland forms [and that] it has become moderately entrenched in the English language." They otherwise seem to dismiss it as a usable vernacular English name. Probably it is a matter of childhood reading, but, whenever coming close to one of these imposing snakes, it is "fer-de-lance!" that leaps to my mind--not "Bothrops," and certainly not "Lancehead." In any case, "fer-de-lance" applies to those species of Bothrops often confuised with Xenodon rabdocephalus sensu lato.
} 

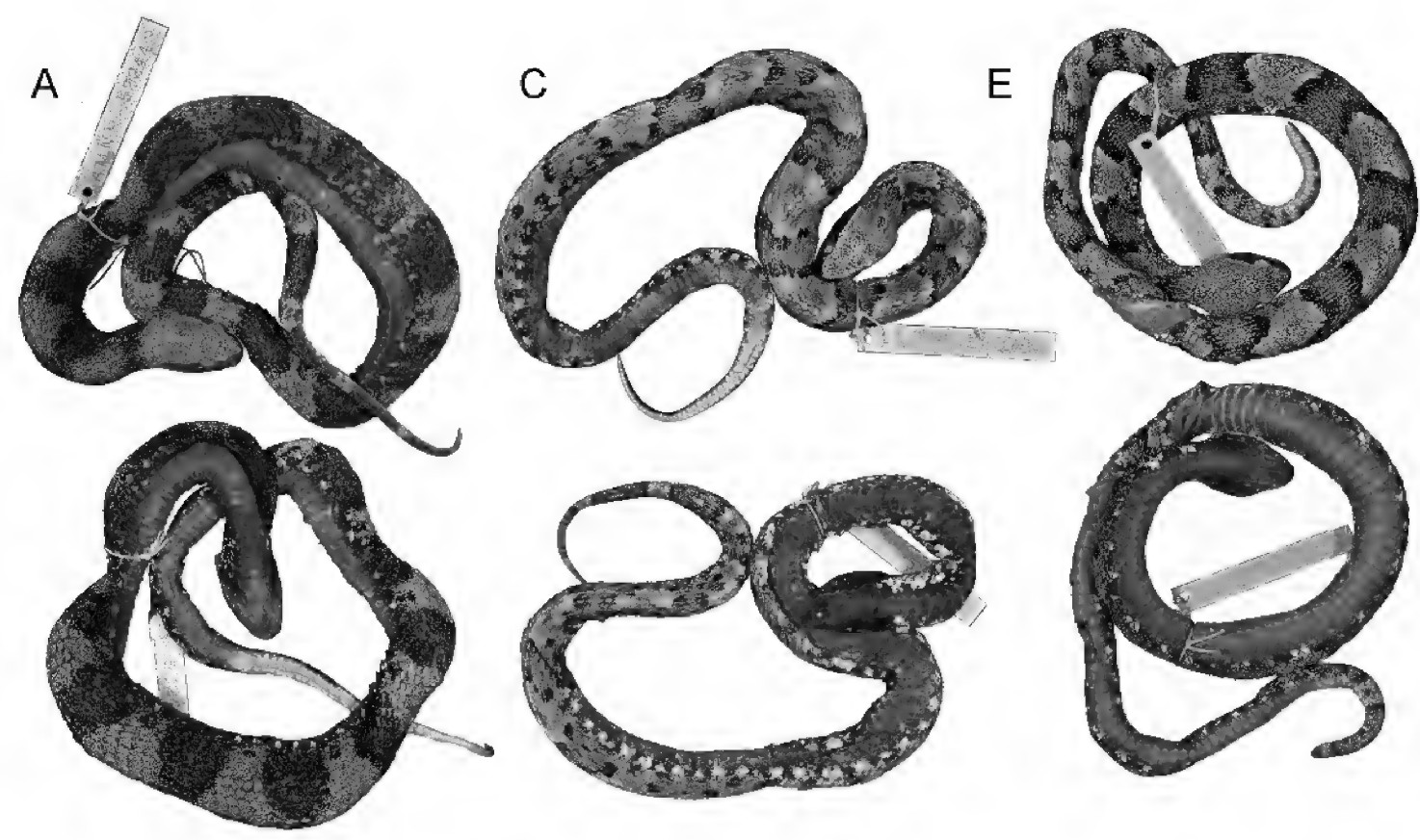

$10 \overline{\mathrm{mm}}$
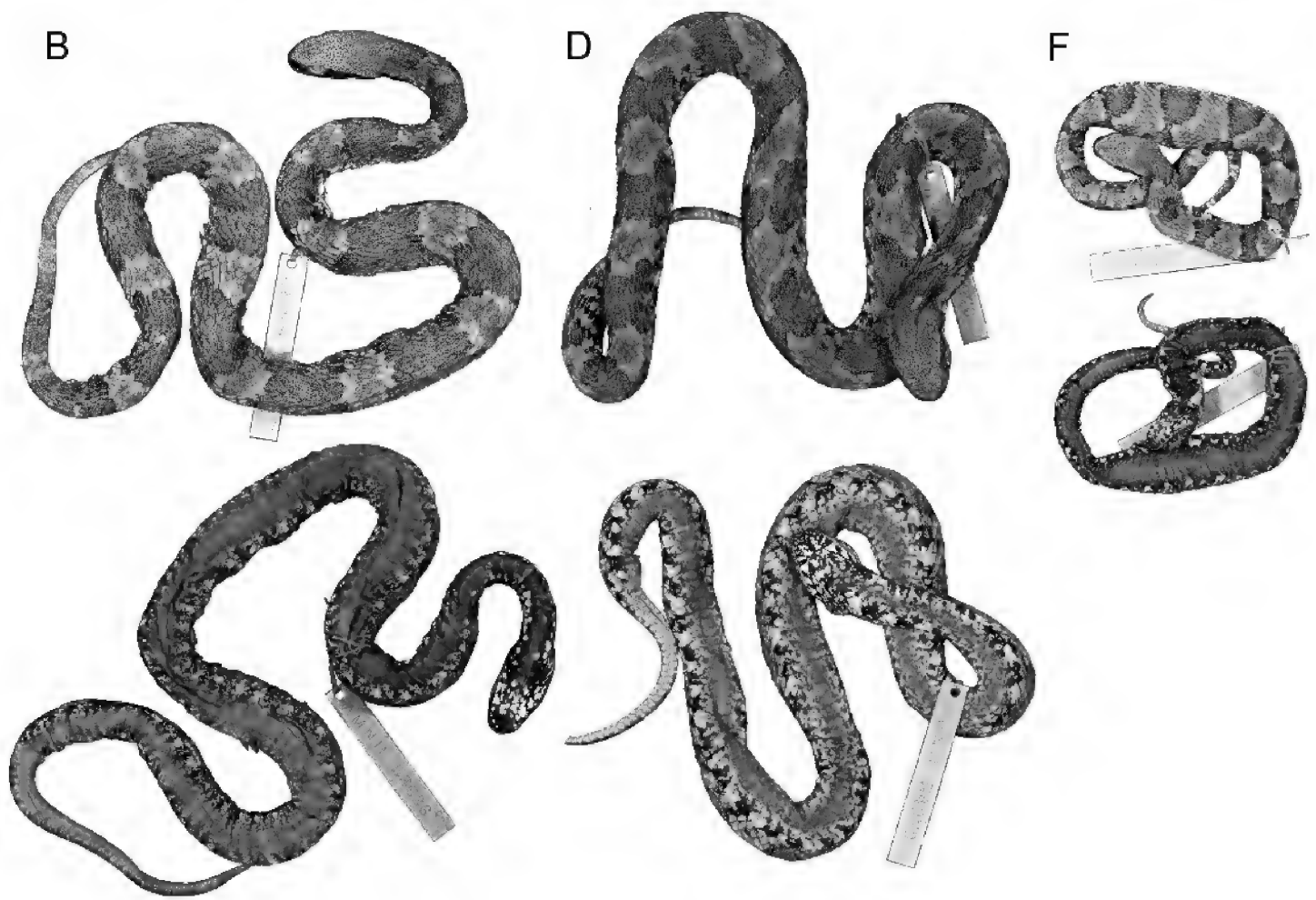

Fig. 33. Xenodon suspectus Cope. Dorsal and ventral views of the six additional American Museum specimens of $X$. suspectus, gathered in the 1920s by Harvey Bassler. A. AMNH R-52244, Contamana, Río Ucayali (Loreto); B-E. All from Río Itaya, near Iquitos (in Loreto); B. AMNH R-53636; C. AMNH R- 
variation associated with segmental counts (fide Underwood and Wilson and Meyer) may be distance effects that are poorly or not correlated with speciation.

The species first known as Coluber rabdocephalus was named, described, and illustrated by Prince Maximilian zu Wied (see Myers et al., 2011: fn. 4; or Myers, 2012: 86, for correct citation of his family name). Wied first introduced the species name rabdocephalus and provided a diagnosis in the Isis von Oken (Wied, 1824: 668), followed by a description in the Beiträge zur Naturgeschichte von Brasilien (Wied, 1825: 351-359), and two unnumbered color plates in the Abbildungen zur Naturgeschichte Brasiliens (Wied, 1827 [1822-1831]: Lief. 10). The two plates, at reduced size, are reproduced herein as figures 35 and 36.

CAtaloging History: Reidentification of the Maximilian collection at the American Museum started in 1885, with a "final cataloguing of species ... [and a] permanent record [presumably on cards]" of reptiles being completed in 1886-1887 (Myers, 2000: 100). This was followed by establishment of a series of at least three primary herpetological card catalogs made during 1910 1918 in the early Department of Ichthyology and Herpetology. The early card catalogs were each destroyed in turn and finally replaced starting in 1920 by bound book catalogs for Amphibians and Reptiles (for details of the foregoing, see Myers, 2000: 100-101). The first Reptile book shows entries for four specimens of Xenodon "collected by Maximilian"; the prince usually was the collector of record for Brazilian specimens, but some non-Brazilian material is more accurately read as being "from the Maximilian Collection."

Prince Maximilian of Wied did not collect in South America outside of Brazil. Most nonBrazilian entries should be discarded as probable misinterpretations of his collection catalog. In additional to his collecting efforts, however, Wied's collection does include specimens obtained by purchase, trade, or gift, but these probably are mostly Old World taxa. Wied was an accomplished explorer and chronicler, who also discovered and ably described new animals in technical detail. He recognized, however, that he was not trained in taxonomy or nomenclature-fields in which he considered his superiors especially to be Gabriel Bibron, A. M. Constant Duméril, Giorgio Jan, and Blasius Merrem. This is indicated by his descriptions, which frequently cite Merrem as an authority, and by the imprinted title on the cover of his handwritten catalog: Verzeichniss der Reptilien-Sammlung nach Dumeril Bibron und Jan ("Catalog of the Reptile Collection following Duméril, Bibron, and Jan"). This catalog includes taxa in the Prince's collection, but it is not specifically a catalog of specimens. A taxon might be represented by specimens from several localities, which have to be researched from Wied's publications. The American Museum cataloged localities for Brazilian taxa described by Wied are sometimes accurate and based on his publications; locality data otherwise appear mostly to have been derived from his collection catalog and/or surmise, which has led to unfortunate confusion.

American Museum cataloging errors and inaccurate annotations affect data for Wied's Xenodon "rhabdocephalus" [= rabdocephalus], a spelling emendation-used by Schlegel (1837: 87-89, p1. 3), Duméril, Bibron, and Duméril (1854 [1834 1851]: 758-759), and by Jan and Sordelli (1866 [1860-1881]: pls. 4-5) - and so followed in Wied's collection catalog and thence copied to the AMNH Reptile catalog. Four specimens of Xenodon from his collection have adjacent entries, as follow:

AMNH R-3606, Coluber "rhabdocephalus" from "Surinam, Dutch Guiana"

AMNH R-3607, Xenodon severus from "Brazil, Guiana"

AMNH R-3608, Xenodon "rhabdocephalus" from "Brazilia" - "Type"

AMNH R-3609, Xenodon "rhabdocephalus" from "Surinam"

Most of these entries are cataloging errors or bear erroneous annotations, as is the case for AMNH R-3306, which was cataloged as "rhabdocephalus" from "Surinam, Dutch Guiana ... Type." As shown here (fig. 34), this actually is a specimen of $X$. severus, presumably from Brazil since it does appear to be a Wied specimen; the catalog entry showing it as "Type" seems inexplicable and not supported by Wied's descriptions or illustrations. The entry following, AMNH R-3607 from "Brazil,

53815; D. AMNH R-54070; E. AMNH R-54552. F. AMNH R-55558, Monte Carmelo, Requena, (Loreto). See also fig. 32 for the seventh Bassler specimen. These specimens in total exhibit a varied but nonetheless unifying kind of color pattern that we have not seen in the less variable Xenodon rabdocephalus, s.1., which occurs from Mexico to Bolivia (e.g., compare with figs. 30-31 or any of the published photographs cited herein). The two taxa appear to be mainly if not entirely allopatric, although "rabdocephalus" is a complex of sibling species. 

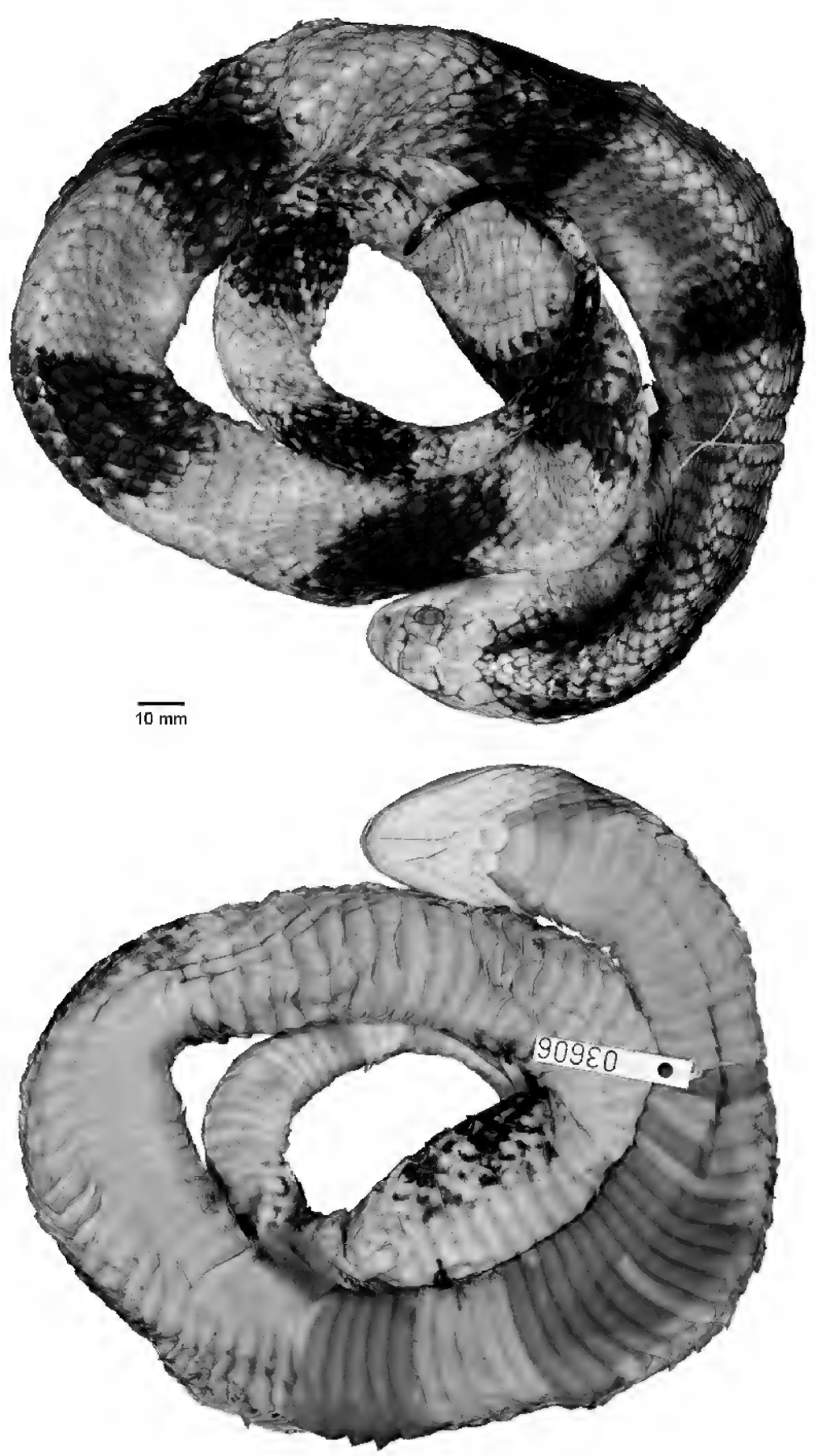

Fig. 34. Xenodon. severus (Linnaeus), AMNH R-3606. This is one of two existing specimens of Xenodon in Prince Maximilian's Brazilian collection at the American Museum. It is cataloged as "Xenodon rhabocephalus [= rabdocephalus]," but it is not one of the two specimens illustrated in the Abbildungen (see figs. 35-36). The cataloged locality for this specimen is "Guiana," which seems to have been copied from the Prince's collection catalog (of taxa, not specimens; see text). 


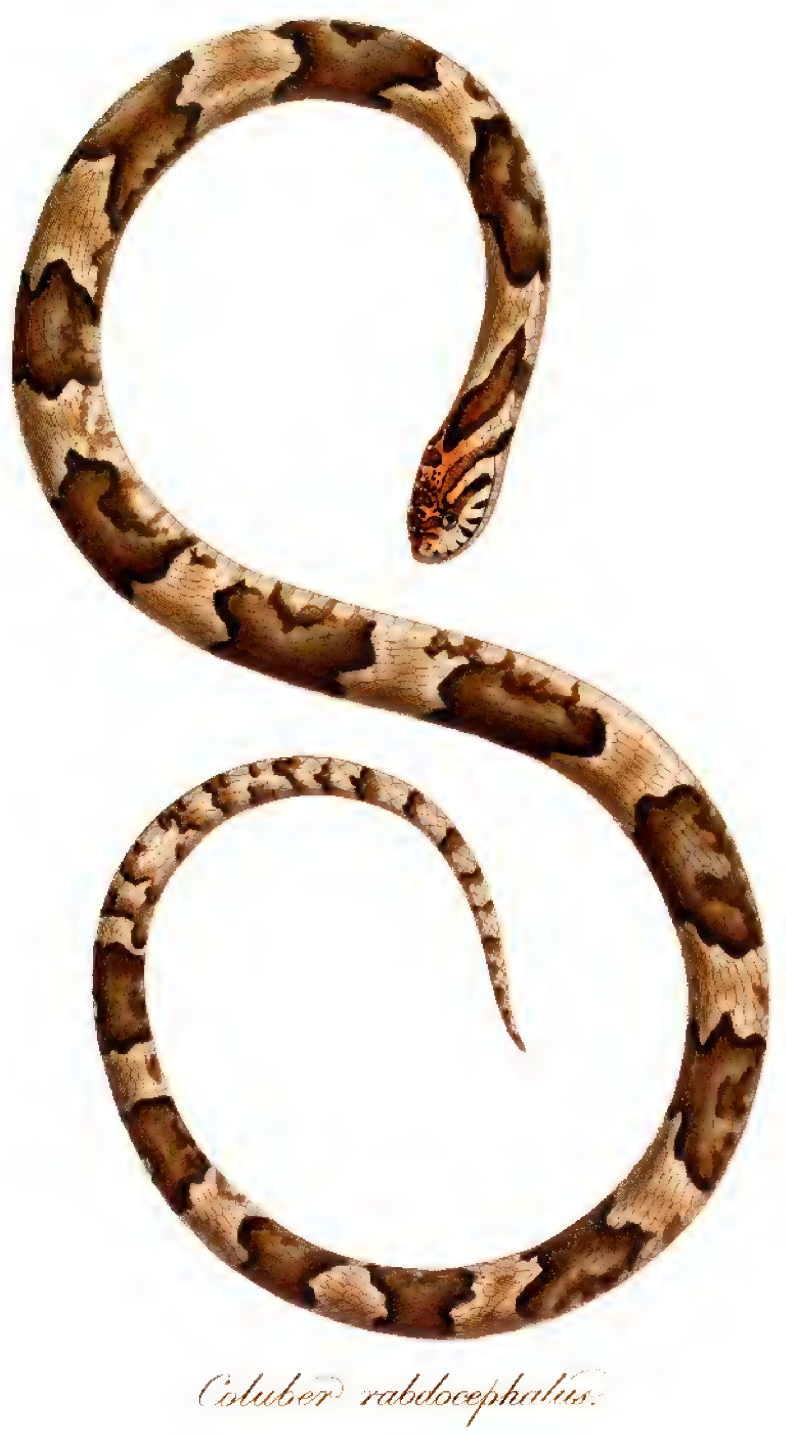

Fig. 35. One of two unnumbered folio plates labeled "Coluber rabdocephalus" in the Abbildungen zur Naturgeschichte Brasiliens by Wied (1827 [1822-1831], Lief. 10). The specimen portrayed is no longer extant; it would be a syntype by modern standards.

Guiana," also is $X$. severus as cataloged; it is a juvenile about $260 \mathrm{~mm}$ total length, $39 \mathrm{~mm}$ tail length, with markings similar to those in figure 34 , including a dark nape blotch, 9 dark body crossbands, and 3 tail blotches.

The third entry, for $X$. "rhabdocephalus" from "Brazilia" (AMNH R-3608) bears the note "Data erroneous. Specimen destroyed." But for a Maximilian specimen to have been destroyed suggests that it also was in truly bad condition; unfortunately this specimen may have been one of the two syntypes illustrated by Wied, shown herein as figure 35 . The absolute identity of the snake above (fig. 35) is not confirmed, inasmuch as Wied (1827: plate captions) considered rabdocephalus as somewhat variable in color, for which reason he illustrated two different examples; the larger of the two (see fig. 36) corresponds roughly to measurements earlier in the Abbildungen (Wied, 1825: 351). Wied (op. cit.: 356-359) described varieties called to his attention by Boie in Leiden (Boie's mentioned "Coluber perspicillatus" is a nomen nudum). As mentioned earlier in this appendix, Wied's (1821: 243) Cophias holosericeus, a nomen oblitum, probably is a 

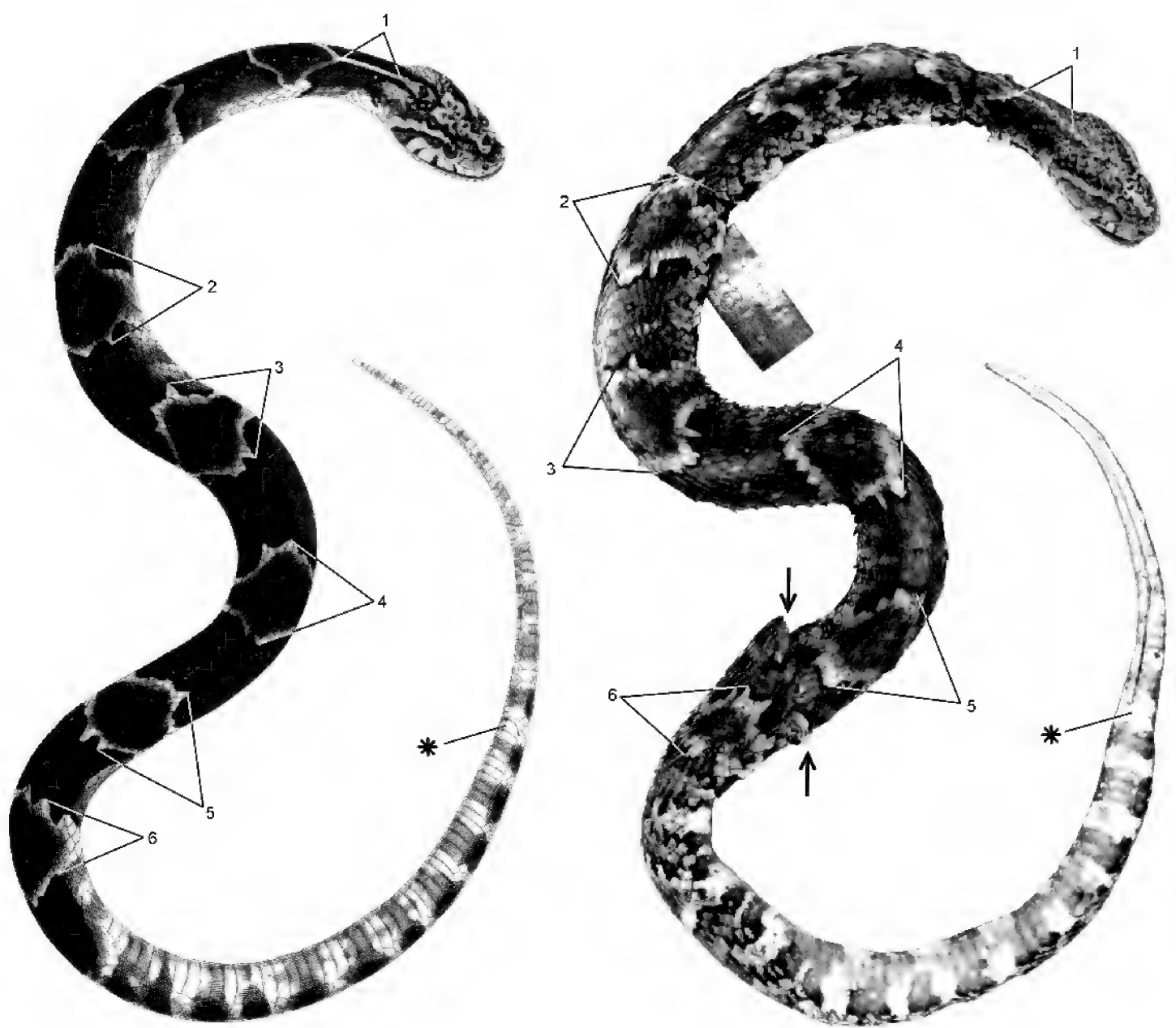

$$
\text { Doluber rabdoaphatur. }
$$

Fig. 36. Xenodon rabdocephalus (Wied, 1824). Left. One of two unnumbered folio plates showing "Coluber rabdocephalus" in the Abbildungen zur Naturgeschichte Brasiliens (Wied, 1827 [1822-1831], Lief. 10). Right. Same specimen, now AMNH R-3609, lectotype by present designation. This specimen suffered some decomposition in the past, with the body becoming very soft and breaking completely in two parts (arrows show place of break). Telling points of resemblance between painting and specimen are numbered: 1. Longitudinal white line on neck, terminating Y-shaped at first dorsal crossband; 2-6. Anterior and posterior pale edges of dorsal crossbands, showing both resemblances and minor copying errors; asterisk (*) denotes the undivided anal plate. The resemblance between the painting and specimen is very close, allowing for the inevitable accumulated copying errors (i.e., Wied's original pen-and-ink watercolor was copied from life and it in turn was copied by an artist for the published plate).

synonym of Xenodon rabdocephalus. Wied's (1825: 359) Coluber saurocephalus is a synonym of Xenodon severus (Linnaeus).

Turning to the fourth and final "rhabdocephalus" in the American Museum catalog (AMNH R3609): this specimen is correctly identified as
Xenodon rabdocephalus. It is no longer well preserved but fortunately survived being "destroyed" like the one (AMNH R-3608) mentioned above. Therefore, AMNH R-3609, the only surviving syntype, is here designated lectotype of Coluber rabdocephalus Wied (1825). 
TyPE LOCALITY: The type locality is in the interior of Bahia, Brazil-specifically in the "Innern Sertong [Sertam] der Provinz Bahía [the inner bush country of Bahia Province]." This wording of the locality is as specific as possible, being combined from Wied (1825: 355; and 1827, letterpress plate caption) and Myers (2011, fn. 2).

NOTES ON THE LECTOTYPE: Although the catalog locality for AMNH R-3609 is "Surinam," it clearly is an illustrated Wied specimen from Brazil. A copy of the Abbildung painting (without color) and the preserved specimen are compared side-by-side in figure 36; allowing for minor copying errors, the match is excellent. The body is too soft to obtain accurate scale counts without further damage to the specimen, but it has an undivided anal plate (with a short tear that should not be mistaken for a division) and 47 pairs of subcaudals; it is in two parts, measuring about $290 \mathrm{~mm}+295 \mathrm{~mm}=$ approximately $585 \mathrm{~mm}$ total length, of which about $86 \mathrm{~mm}(14.7 \%)$ is tail length.

HEMIPENIS OF LECTOTYPE: AMNH R-3609 is an adult male with mineralized hemipenial spines. The left retracted hemipenis had been earlier examined in situ, when it was noted that the apical disc was present ("disc +! [free edge]"); it was further noted that it bifurcated at the level of the base of subcaudal 6 and ended at the base of subcaudal 11, with the slips of retractor muscle fusing at midsubcaudal 13. This organ was removed in 1989 and pinned flat for illustration, with temporary storage in a covered dish of $70 \%$ ethanol. Unfortunately an attack of drug-resistant malaria intervened and the hemipenis dried beyond recovery in the weeks following.

The right hemipenis was removed in 2013, after noting that it bifurcated at the base of subcaudal 5 , with lobes extending to the base of subcaudal 11 , with slips of retractor muscle merging at subcaudal 13. The organ was opened slightly laterad from the midline, before being removed and pinned flat for illustration (in the interim its dish was submerged in a sealed container holding a large volume of alcohol [a lesson learned]). The base of the organ has medium-size spines; the interlobular crotch (i.e., the smooth terminal basin) is nude and the lobes are covered with smaller slender spines up to the wall or lip encircling the small nude apical disc; it is a relatively small, slender organ, measuring $24 \mathrm{~mm}$ from base to apex, with the lobes comprising about $23 \%$ of the total length; the opened organ, spread flat, is about $4 \mathrm{~mm}$ across the base, tapering distally to $2 \mathrm{~mm}$ across the apical disc. See figure 18 (under Loss of a "Generic Character"), where the sulcuslike smoothness of the interlobular terminal basin is evident.

\section{Xenodon angustirostris W. Peters REMOVED FROM SYNONYMY}

A junior synonym almost certainly outside the range of Xenodon rabdocephalus, sensu stricto, is $X$. angustirostris Peters (1864: 399), which is tentatively resurrected for Central American and some Colombian populations. The holotype, presumably in the Berlin Museum, has not yet been examined. It was collected by Josef Warszewicz in Veragua. Warszewicz's journey across western Panama, from David north to Chiriquí Lagoon, is mapped in Savage (1970: 276).

In the field I everted the hemipenes of a western Panamanian specimen collected in Bocas del Toro, in the lower Río Changuinola drainage - about $35 \mathrm{~km}$ northwest of the Atlantic terminus of Warszewicz's route. The hemipenes of this specimen (AMNH R-119091) and one each from Honduras (USNM 559716) and Guatemala (AMNH R140265, right organ ${ }^{31}$ ) are similar, but not identical, to the one shown in figure 19 from Central Panama. The last specimen differs from the three more northern specimens in having the terminal $1.5 \mathrm{~mm}$ of a lobe completely nude; it differs also in lacking tiny spines between the sulcus branches just below the lobular crotch. More significantly, perhaps, the figured specimen has the hemipenis more deeply divided; the lobes are $59 \%$ the length of the entire organ, compared to about $43-47 \%$ of total hemipenial length in the three "northern specimens."

Hemipenes similar to the above appear also to characterize rabdocephalus-like snakes from the Río San Juan drainage in northwestern (Chocoan) Colombia. A specimen (AMNH R-123787) from the lower San Juan, at Quebrada Taparal, has the right hemipenis differing from the Central American ones in being noticeably less divided (lobes only $17 \%$ of total) and in having a few minute spines distributed sparsely onto the otherwise nude apex. (The contralateral left organ had been cut short in order to facilitate internal manipulation of the retractors; the lobes were later opened to the apices in order to examine the retractor insertions.)

Hemipenes of the one Colombian and five Central American snakes, briefly described above, had all been field everted. The apices, however, had resisted eversion because of the attachment of a stout retractor muscle in each lobe. After severing the muscles as far distad as possible, the tips of the

\footnotetext{
${ }^{31}$ The partially everted contralateral (left) hemipenis of this specimen is shown in Zaher (1999: 155, fig. 82) under the name Xenodon rabdocephalus. It presumably is the basis for his statement (op. cit.: 40) that the tips of the hemipenial lobes in $X$. rabdocephalus "are nude, a condition regarded as representing poorly developed apical discs."
} 
lobes were manually everted with petroleum jelly after softening in $3-4 \% \mathrm{KOH}$.

HEMIPENIS OF XENODON ANGUSTIROSTRIS: Briefly, these organs have the following characteristics: Hemipenes divided for $17-59 \%$ of total hemipenial length, lacking apical discs; lobes with a sparse covering of small or medium-size spines virtually to the tips; apices of lobes nude or bearing a few minute, slender spines; a few tiny spines present or absent between sulcus branches at base of lobes. Sulcus spermaticus centrifugal, each branch extending onto the tip of lobe, terminating about halfway across the apex. The basal part of the organ is nearly nude except for several mediumsize spines positioned laterally on each side.

REMARKS: Although snakes here assigned to Xenodon angustirostris conceivably represent more than one species, it would be guesswork to claim that one or more of the aforesaid hemipenial differences (e.g., degree of bilobation) are species specific; geographic variation might also be involved. Some intraspecific hemipenial variation seemingly occurs in most (all?) snakes having wide geographic ranges. The specimens discussed share the loss of an apical disc and we tentatively resurrect Xenodon angustirostris Peters, 1864, for Central American and western Colombian snakes formerly known as $X$. rabdocephalus. The distribution from Central America into the Pacific versant of South America is zoogeographically plausible. Nonetheless, we urge caution in applying the name angustirostris until comparative hemipenial and other data can be accrued from populations throughout western Colombia and especially Middle America.

\section{NAmed Genera Based on Loss of the ApICAL DisC}

Loss of distinctive characters can usefully help define species, especially including cryptic species as well as those otherwise easily recognizable. However, loss characters do not generally qualify as generic synapomorphies, although they understandably often masquerade as such. The following three genera seem to have been based on hemipenial differences, loss of the apical disc in two cases and length of the hemipenis lobes in another. In my estimation, these names should stay in the synonymy of Xenodon unless a case can be made for generic recognition on other grounds.

ACANTHOPHALLUS Cope, 1893: Over 100 years ago, Cope (1893: 482; 1894: 841) recognized and intended to solve a perceived generic problem by naming Acanthophallus, "designed to include the species formerly referred to Xenodon in which the hemipenis is spinous to the extremity. The type is
X. colubrinus Gthr." Although Acanthophallus belongs in the synonymy of Xenodon, the type species $X$. colubrinus Günther (1858: 55) - currently in the synonymy of rabdocephalus - probably is a valid species if specimens from near the type locality (in Pará) have the hemipenis ascribed to colubrinus by Cope (the type specimen of colubrinus is a female according to Boulenger, 1894: 146). The "Acanthophallus" hemipenis was illustrated diagrammatically by Cope (1895: pl. 21, fig. 11); it is similar to that of Xenodon suspectus (fig. 20), which has longer lobes than shown by Cope.

WAGLEROPHIS RoMANO AND Hoge, 1972: The type species of Waglerophis is Xenodon merremii (Wagler, 1824: 47, pl. 17), which has apical discs atop relatively long hemipenial lobes. The type species of Xenodon is Coluber severus (Linnaeus, 1758: 219), which has apical discs on short lobes. Anatomically, Xenodon merremii is one of the bestknown xenodontines thanks to the work of Anthony and Serra (1949, 1951). Romano and Hoge (1972) therefore had no trouble in showing differences between the two species, but they did not probe relationships within Xenodon and failed to justify why $X$. merremii should be set completely apart as a monotypic genus. Waglerophis fails justification at that level. Additionally, Zaher et al. (2009: 146-147) synonymized Waglerophis with Xenodon based on its position in a provisional molecular phylogeny.

THALESIUS YUKI, 1993: Gasc and Rodrigues (1980: 589), and Hoogmoed (1985: 83) described the retracted hemipenis of Xenodon werneri Eiselt; the lobes of the deeply divided organ are "densely covered with small straight spines, diminishing in size to the tip." Yuki (1993: figs. 3-4) illustrated a manually everted organ that agrees reasonably with the previous descriptions; this organ looks to be completely everted, although the lobes probably are not completely inflated.

Based on the hemipenial morphology (lack of the apical disc), Yuki (1993) provided the new generic name Thalesius as a replacement for Eiselt's (1963: 282) "Xenodon werneri nom. nov. (= Procteria viridis Werner ... Terra typical dubiosissima; ... Südwestafrika [Eiselt, loc. cit., just considered the type locality as unknown])." The African locality evidently led Dowling and Duellman (1978: [1974-1978]: 112b.2) to consider Procteria as a possible member of the Old World Lycodontinae, tribe Lycophidini. Yuki (op. cit.: 45) commented on that assignment, saying that Dowling and Duellman probably were unaware of Eiselt's work and that the characters of Thalesius were closer to the subfamily Natricinae. Finally, Zaher (1999: 40) pointed to evidence that Thalesius unambiguously belongs within the Neotropical 

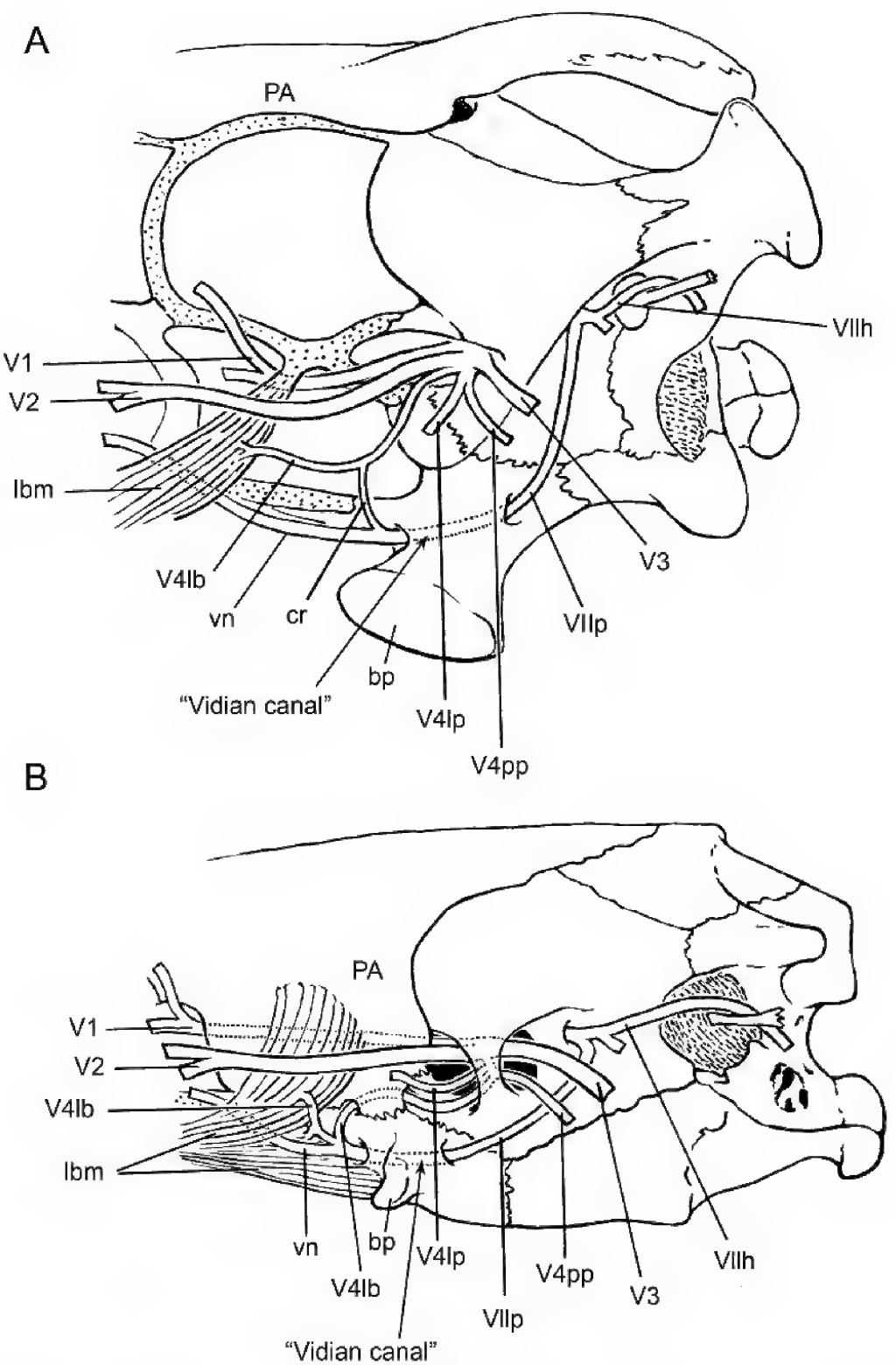

Fig. 37. Diagrams of the braincase, with parietal bone attached, showing the pathways of trigeminal and facial nerve branches. A. Ctenosaura, a generalized lizard (after Oelrich, 1956, and a specimen from Carolina Biological Supply Co.). B. An alethinophidian snake (simplified and composite, but essentially as in Python). Abbreviations: bp, basipterygoid process; cr, communicating ramus between levator bulbi nerves and palatine ramus of the facial nerve; lbm, levator bulbi muscle (retractor arcus palatini and retractor vomeris muscles in snake); PA, parietal bone; vn, Vidian nerve in strict sense of mammalian anatomy, formed from conjoined palatine ramus of facial nerve and levator bulbi (deep petrosal) nerve; $\mathbf{V 1}$, deep ophthalmic ramus of trigeminal nerve; V2, maxillary ramus of trigeminal nerve; V3, mandibular ramus of trigeminal nerve; V41b, levator bulbi nerve (probably homologous to the mammalian deep petrosal nerve); V41p, levator pterygoideus nerve; V4pp, protractor pterygoideus nerve; VIIh, hyomandibular ramus of facial nerve; VIIp, palatine ramus of facial nerve (homologous to the greater superficial petrosal nerve of mammals). 
Xenodontini and recognized that absence of the apical disc was a secondary loss.

\section{POSTSCRIPT}

That probably should be the end of it concerning the generic placement of Xenodon werneri, but certainly there are additional populations of Xenodon "rabdocephalus" that have lost the apical disc. In South America there may be at least five hemipenial types of "rabdocephalus" (including $X$. angustirostris, $X$. suspectus, and $X$. rabdocephalus sensu stricto); the number in Middle America is unknown except for $X$. angustirostris.

There, of course, needs to be a general revision of the rabdocephalus complex, but examination of more hemipenes may at least give a clue to the number of taxa and their geographic ranges, of which only $X$. suspectus seems to have a somewhat distinctive appearance, although it too may be mistaken for Bothrops atrox. The working hypothesis is that this is a complex of an unknown number of cryptic species. All these hidden species seem to be under strong selection pressure to maintain their Bothrops-like appearance throughout an enormous geographic area.

\section{APPENDIX 2}

\section{The Vidian Canal and Venous Foramina IN THE PROOTIC OF Alethinophidian SNakes}

\section{S.B. MCDOWELL}

\section{"The Vidian Canal"}

In order to understand the differences in pattern of the bony canals of the sphenoid of snakes utilized taxonomically by Underwood (1967), Rieppel (1979), and here, some discussion is necessary of the nerves around which these canals form. It should be noted that the Vidian canal of Squamata is not the homolog of the Vidian (or pterygoid) canal of mammals and therapsids (some authors give the name "parabasal canal" to the squamatan structures, because of this lack of homology). The mammalian Vidian canal is formed by the appression of the pterygoid bone against the braincase, so enclosing the Vidian nerve (or "nerve of the pterygoid canal"). The mammalian Vidian nerve is formed from two nerves: the palatine ramus of the facial nerve, also called the greater superficial petrosal nerve; and a sympathetic nerve from the trigeminal ganglion, the deep petrosal nerve.
In Squamata, where the pterygoid bone is widely separated from the primary braincase except at the articulation of the basipterygoid process with the pterygoid, the equivalent of the mammalian (and therapsid) Vidian canal is open space. The bony canal called Vidian canal in lizards (see fig. 37A) is a longitudinal canal in the base of the basipterygoid process, formed between the more dorsal basitrabecular process of the cartilaginous embryonic skull and the more ventral dermal component (parasphenoid) of the sphenoid bone. This canal is occupied by the internal carotid artery (and its lateral branch, the palatine or nasopalatine artery) and the palatine ramus of the facialis (that is, by the strict homolog of the greater superficial petrosal nerve of mammals).

Anterior to the passage through this canal in the basipterygoid process, the palatine ramus of the facialis is joined by an anastomotic nerve that connects it with the special branch of the first dorsal constrictor $\left(\mathrm{V}_{4}\right)$ nerve for the levator bulbi musculature. In most lizards, including Anolis (described by Willard, 1915) and Ctenosaura (described by Oelrich, 1956), the major part of this levator bulbi musculature is involved in depressing the lower eyelid, but some fibers attach to the roof of the mouth. Mammals lack a levator bulbi, but the sympathetic component of the lizard levator bulbi nerve (including the anastomotic connection to the palatine ramus of the facialis) appears to have the connections and position of the mammalian deep petrosal nerve, except that mammals have lost the special motor component for the levator bulbi muscle.

By this interpretation of the homology of the levator bulbi nerve, the portion of the palatine ramus of the facialis of lizards that lies anterior to the anastomosis with the levator bulbi nerve (= deep petrosal nerve) would be the strict homolog of the Vidian nerve (= nerve of the pterygoid canal) of mammals. In lizards, this nerve is quite unenclosed by bone, since this anastomosis of deep petrosal and greater superficial petrosal nerves is anterior to the bony braincase, opposite the flexible trellis of cartilaginous bars representing the embryonic orbital cartilages in the adult skull, and the mobile pterygoid bone lies well ventral to the nerve. At least in Ctenosaura (Carolina Biological Supply Company specimen, doubly injected, no data), the portion of the main head vein receiving the middle cerebral and pituitary veins lies just deep (medial) to the levator bulbi (deep petrosal) nerve in the region of the anastomosis of that nerve with the palatine ramus of the facialis.

The pattern of the nerves in alethinophidian snakes (fig. 37B) is essentially as in lizards, except that the special motor fibers for the levator bulbi 
muscles do not separate from the sympathetic component of the levator bulbi nerve; instead, they accompany the sympathetic component all the way to the juncture the palatine ramus of the facialis. As discussed by Haas (1974), snakes resemble amphisbaenians and the varanoid lizard Lanthanotus, but differ from most lizards, in having converted the levator bulbi into palatal retractor muscles (retractor arcus palatini, retractor vomeris) inserting on palatal bones rather than on the immobile lower eyelid (the spectacle of snakes). The major difference between snakes and lizards in the pattern of the Vidian nerve complex is produced by a new bony wall of the braincase in this region of snakes. The flexible trellis of orbital cartilage derivatives has been lost in snakes and a new rigid, bony wall has been formed by ventral extension of the parietal bone to meet the lateral edge of the sphenoid. This enlarged descending process of the parietal is more laterally placed than the lizard orbital cartilage trellis: the ophthalmic ramus of the trigeminal $\left(\mathrm{V}_{1}\right)$ lies enclosed, deep to the parietal bone in snakes, but is exposed external to the orbital cartilage trellis in lizards, and the levator bulbi nerve of snakes is, for part of its course, enclosed deep to the parietal. Although some authors, such as Rieppel, deny that there is a cavum epiptericum in snakes, because the space is not precisely homologous, either phylogenetically or in position and contents, to the cavum epiptericum (cavum Meckeli) of mammals, I prefer to use that name for the space in snakes occupied by the ophthalmic $\left(\mathrm{V}_{1}\right)$, trochlear, oculomotor, abducens, and levator bulbi nerves, now enclosed within the apparent cranial cavity of the dried bony skull, but external to the original braincase wall (represented in lizards by the cartilaginous orbital cartilage trellis and tough dura mater membrane). By this looser and purely descriptive (rather than phylogenetic) use of the term, the levator bulbi nerve of alethinophidian snakes usually enters and then leaves the cavum epiptericum; the foramina for this entry and exit offer taxonomically useful characters.

At least the most superficially lizardlike condition is that seen in Pythonidae (sensu McDowell, 1975) and, as noted by Rieppel (1979), probably also in the Cretaceous Dinilysia. Here, the palatine ramus of the facialis passes through a canal in the base of a recognizable basipterygoid process, emerging anteriorly from this canal through a foramen near the lateral (parietal) border of the sphenoid (the "primary anterior opening of the Vidian canal" of Rieppel, 1979). The levator bulbi nerve runs forward from the trigeminal ganglion (within the fossa of the prootic bone that is walled externally by the alethinophidian bridge [= Rieppel's "laterosphenoid" but not the homolog of ossification of the orbital cartilage so-named in lizards]) to enter a foramen between the parietal and the prootic shared with a small vein. Rieppel (1979) terms this the "foramen for the re-entry of the cid nerve," but the briefer "pituitary vein foramen" seems applicable, because the vein accompanying the nerve drains the middle cerebral vein and pituitary vein within the cranial cavity. The levator bulbi nerve continues forward on the floor of the cavum epiptericum medial to the ventral extremity of the parietal, to pass through a foramen in the parietal-sphenoid suture just dorsolateral to the anterior orifice of the canal for the palatine ramus of the facialis in the sphenoid. The palatine ramus of the facialis (mammalian "greater superficial petrosal nerve") and the levator bulbi nerve (mammalian "deep petrosal nerve") join on the surface of the skull to form the Vidian nerve, sensu stricto. This exposure of the juncture of the palatine and levator bulbi nerves anterior to the passage of the palatine nerve through a canal in the basipterygoid process is lizardlike; however, even in Dinilysia there is a difference from lizards: the parietal and sphenoid meet in a tight suture medial (deep) to this nerve juncture.

As described by Rieppel (1979), in Lichanura (and also Charina), the anterior orifice of the canal for the palatine nerve is in a common funnelshaped fossa with the foramen for the exit of the levator bulbi nerve from the cavum epiptericum, so that the juncture of the nerves takes place in this funnellike fossa, rather than on the flat external surface of the sphenoid. Since Lichanura and Charina differ from the majority of Booidea in seeming to lack a basipterygoid process, I would interpret the rim of this funnel like fossa as the disguised basipterygoid process and the canals as otherwise similar to those of other Booidea. Although pythons have a distinct articular surface on the basipterygoid process that rests against the pterygoid bone, in boas this surface is lost because the insertion of the levator pterygoideus has expanded to cover the portion of the pterygoid that articulates with the basipterygoid process in pythons. The basipterygoid process of boas has become an intermuscular crest, with the retractor vomeris originating on its anterior face. In Lichanura and Charina the levator bulbi musculature seems reduced as compared to their probable relative, Eryx, with the retractor arcus palatini lost entirely and the retractor vomeris less fleshy than in Eryx, but originating from the rim of the anterior orifice of the Vidian canal. Even in Sanzinia, Acrantophis, Boa, Eunectes, Epicrates, and Corallus, the foramen for the levator bulbi (= deep petrosal) nerve lies just posterior to or just within the intermuscular flange that is called a 

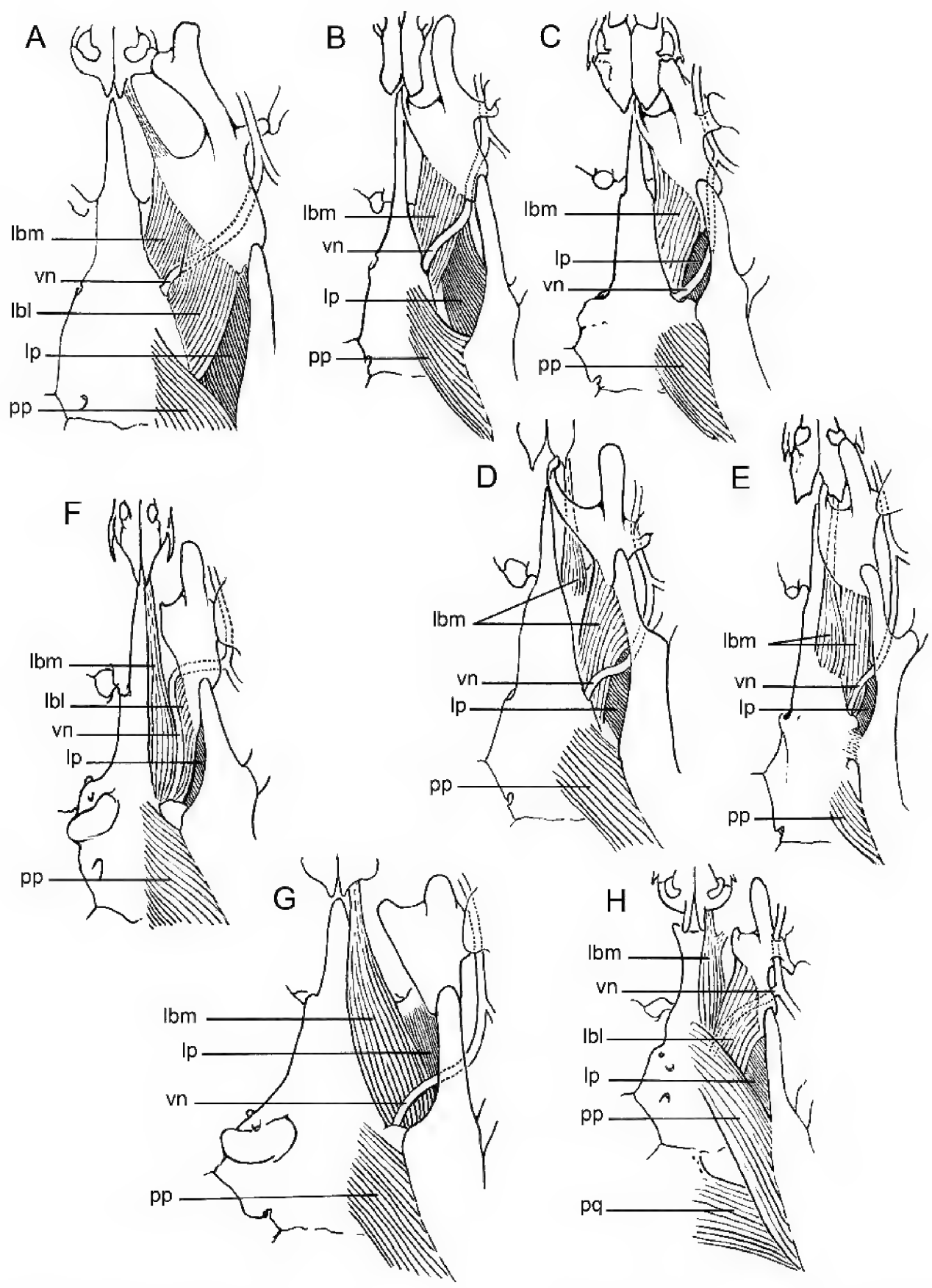

Fig. 38. Relationships of lateral levator bulbi (Ibl) and medial levator bulbi (lbm) muscles to the Vidian nerve (vn) in some elethinophidian snakes: A. Acrochordus granulatus (AMNH R-14185); B. Tropidophis melanurus (AMNH R-82878); C. Loxocemus bicolor (AMNH R-99151); D. Ungaliophis continentalis (AMNH R-93813); E. Anilius scytale (AMNH R-54986); F. Python molurus (AMNH R- 3224); G. Calabaria reinhardtii (AMNH R-11718); H. Nerodia cyclopion (Carolina Biological Supply Co.). Other abbreviations: lp, levator pterygoideus; pp, protractor pterygoideus; pq, protractor quadrati. 
"basipterygoid process," rather than anterior to the projecting crest as in Pythonidae. The so-called basipterygoid process of Boidae seems more anteriorly placed than the basipterygoid process of lizards, Dinilysia, and Pythonidae. In Boidae, a separate cartilaginous nodule just behind the intermuscular crest, present at least in some boid embryos (see Bellairs and Kamal, 1981, for review), would seem to be the more precise homolog of the pythonid and lizard basipterygoid process.

Perhaps a similar modification has taken place in Acrochordus, where there is a somewhat deeper and narrower common fossa for the anterior emergence (and fusion) of the levator bulbi and palatine nerves than seen in Lichanura. As in Lichanura, the basipterygoid process seems to be absent in Acrochordus and certainly there is no sphenoid-pterygoid articulation, but the ventral rim of the fossa in which the palatine and levator bulbi nerves join would have the positional relationships of a very much reduced basipterygoid process.

In anilioids (including Xenopeltis and Loxocemus), tropidopheoids, and bolyerioids there is a different condition, possibly merely more extreme than that of Lichanura and Acrochordus, but at least appearing rather different: there is a "secondary Vidian canal" with a "secondary anterior opening" (Rieppel's, 1979, nomenclature). The palatine branch of the facialis, after entering the sphenoid posteriorly, does not reemerge anteriorly. Instead, it makes a juncture with the levator bulbi nerve within the cavum epiptericum and this combined nerve (Vidian nerve, sensu stricto) extends forward in a narrow groove on the intracranial surface of the sphenoid to emerge by a foramen in the parietal-sphenoid suture (that is, in a position most comparable to that of the foramen by which the levator bulbi nerve of Python emerges from the cavum epiptericum). None of these forms with a "secondary Vidian canal" has a clearly identifiable basipterygoid process and, conceivably, the bony floor of this "secondary Vidian canal" could represent a muchmodified basipterygoid process, as here suggested for the lower rim of the funnel-shaped fossa in which the palatine nerve and levator bulbi nerve join in Lichanura and Acrochordus; if so, this "secondary Vidian canal" would merely be a very much narrowed and deepened "funnel-shaped fossa." But the appearance is quite different and such homology is not particularly convincing.

Rieppel (1979) regards the "secondary Vidian canal" as a primitive feature, from which the condition of booids is derived by a secondary shortening of the secondary canal, presumably from its anterior orifice backward, until it disap- pears altogether and leaves the juncture of the levator bulbi and palatine nerves exposed. Rieppel's phylogenetic interpretation appears to be based on his belief that anilioids are the most primitive alethinophidians, and so presence of an anilioidlike "secondary Vidian canal" in snakes that he regards as booids, rather than anilioids (e.g., Xenopeltis, Loxocemus, Tropidopheidae), could most easily be interpreted as retention of a primitive character; further, a similar "secondary Vidian canal" is found in many colubrids, including many xenodontines (Rieppel figures Pseudoboa as an example of a colubrid secondary Vidian canal). Although Rieppel does not discuss the levator bulbi-palatine nerve anastomosis of lizards, it might be mentioned in favor of Rieppel's interpretation that, although the pattern in anilioids, etc., is less lizardlike than that of pythons and boas in having this nerve anastomosis concealed by bone externally, the anilioids are more lizardlike than is Python in lacking a bony wall deep to this nerve anastomosis.

However, I am not convinced by Rieppel's (1979) argument. As Rieppel notes, the pattern of foramina (and presumably the nerves) of Dinilysia is as in Python, rather than as in anilioids. Further, both Dinilysia and pythons have a very lizardlike architecture of this region, including a basipterygoid process with an articular surface for the pterygoid (as well as a canal through its base for the palatine nerve); the nearest approach to a "basipterygoid process" among anilioids is a longitudinal blunt ridge without an articular surface (but with a ligamentous tie to the pterygoid), and even this ridge is absent in tropidopheids and bolyereids. It is difficult for me to accept the reinvention of a lizardlike basipterygoid process in pythons from the morphology of this region seen in anilioids.

The arrangement of the levator bulbi musculature relative to the Vidian nerve (sensu stricto, see McDowell, 1987) also seems less lizardlike in anilioids, tropidopheids, and bolyeriids than in other alethinophidians (fig. 38). In lizards, the levator bulbi most typically originates on the cartilaginous trellis of the orbital cartilage and extends downward and forward to insert on the roof of the mouth and (mostly) on the lower eyelid. In this passage, the muscle lies to the lateral side of Vidian nerve, which shows complex branching but has its lateral branch joined to the maxillary $\left(V_{2}\right)$ nerve in the front of the orbit. The Vidian nerve of snakes is a simple and concentrated nerve that extends forward and laterally to join the maxillary $\left(V_{2}\right)$ nerve in the floor of the orbit, this resembling the lateral branch of the lizard Vidian nerve. In most Alethinophidia, but not in anilioids, tropidopheids, or bolyeriids, the major part of the 

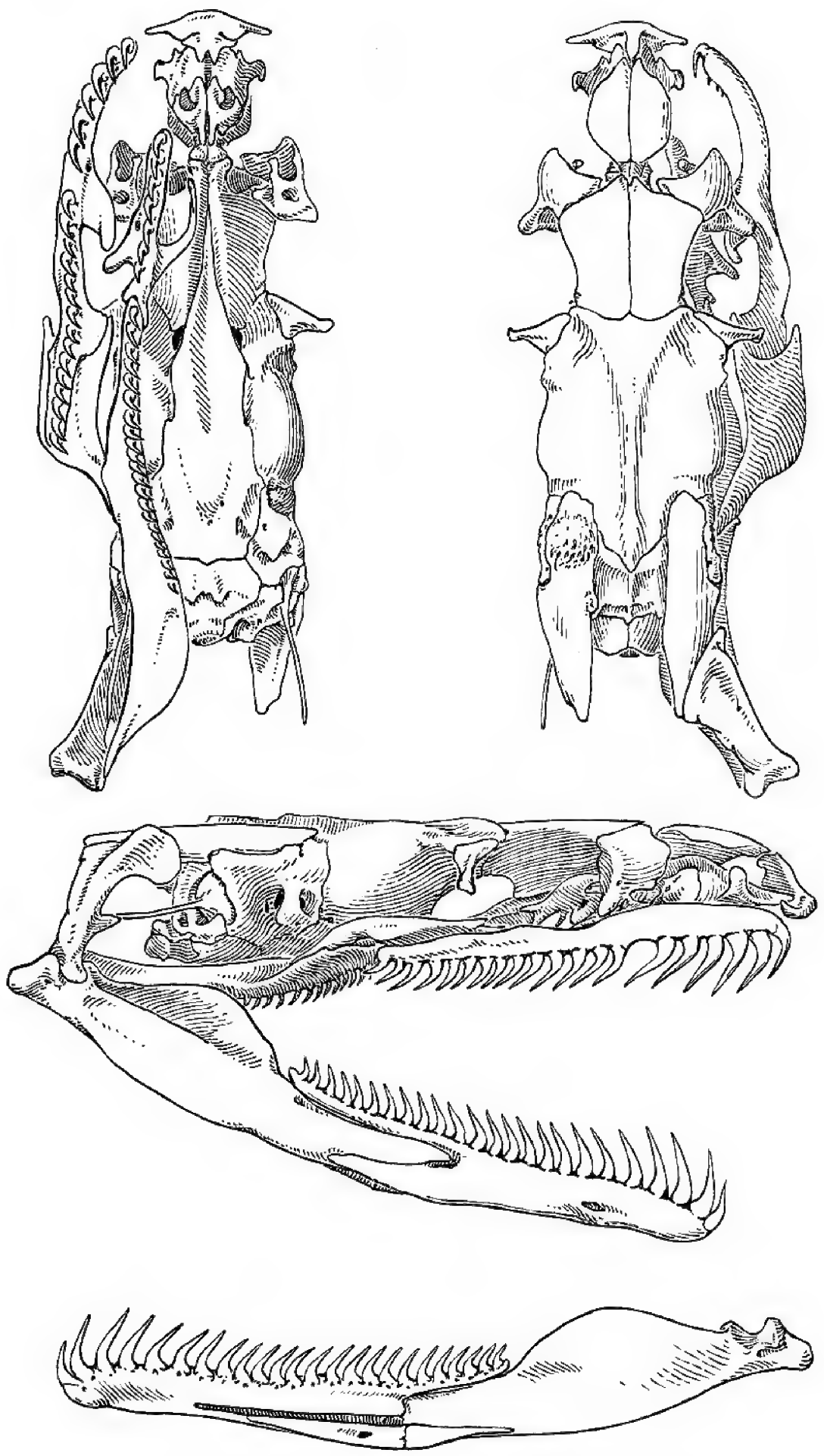

Fig. 39. Boaedon fuliginosus (Boie), skull of AMNH R-11996, ×3.7. 

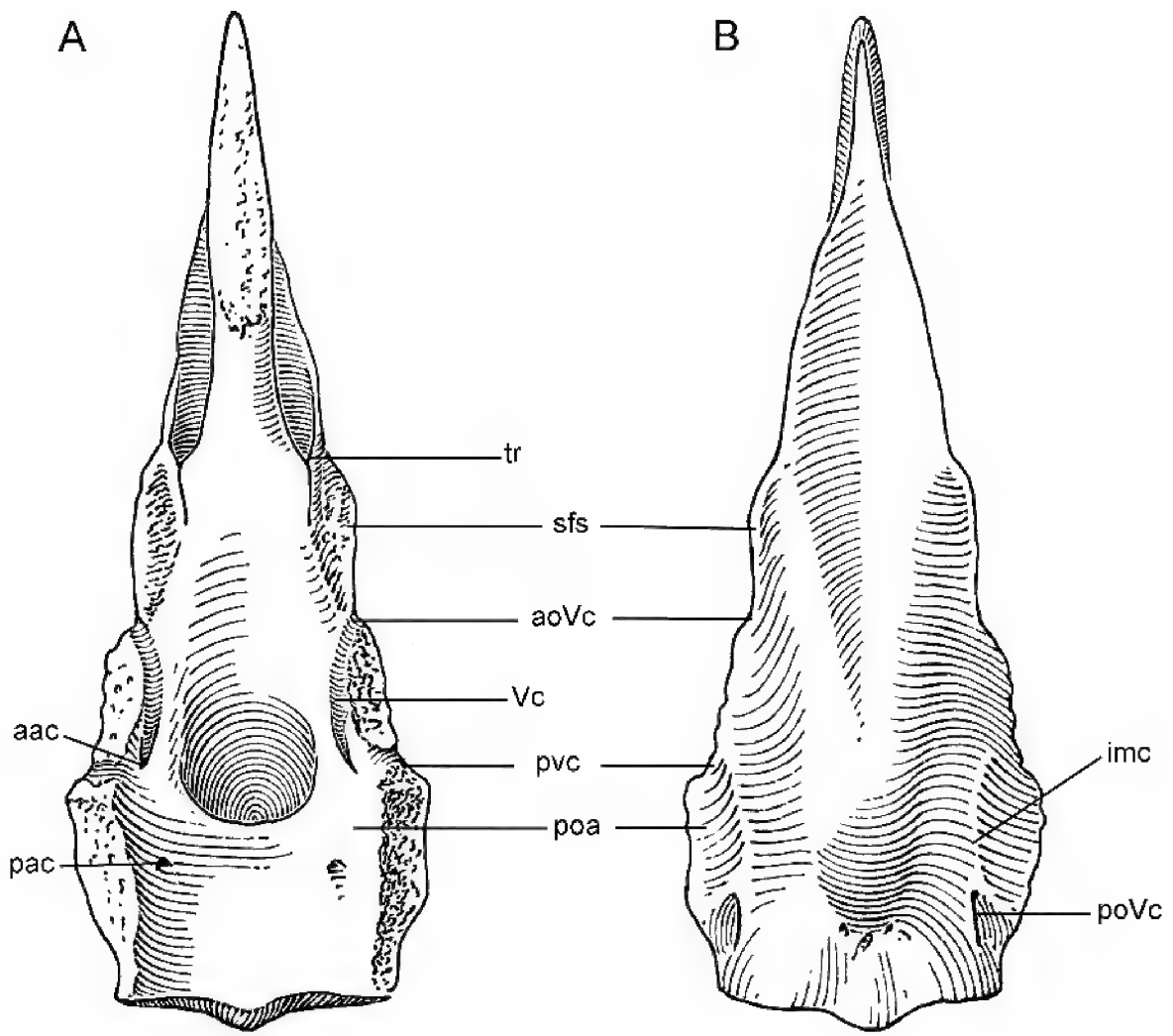

Fig. 40. Boaedon fuliginosus (Boie), sphenoid bone from AMNH R-11996, ×8.7. A. Ventral (external) side. B. Dorsal (intracranial) side. Abbreviations: aac, anterior orifice of abducens canal (opening into Vidian canal); aoVc, anterior orifice of Vidian canal for the conjoined VII palatine and $\mathrm{V}_{4}$ levator bulbi nerves; imc, intermuscular crest, between deep and superficial heads of the protractor pterygoideus; pac, posterior orifice of abducens canal; poVc, posterior orifice of Vidian canal, shared by carotid artery and VII palatine; pve, pituitary vein canal, also for entry of $\mathrm{V}_{4}$ levator bulbi into the cavum epiptericum; sfs, feebly developed suborbital flange, which barely extends lateral to the sphenoid-parietal contact and is medial to the retractor vomeris; tr, pit for trabecular cartilage; Vc, Vidian canal, an unroofed grove containing the joined VII palatine and $\mathrm{V}_{4}$ levator bulbi (retractor pterygoideus or mammalian deep petrosal) nerves, which together form a Vidian nerve, sensu stricto.

levator bulbi lies lateral to the Vidian nerve, but there is also a portion that lies medial to the Vidian nerve, and so, in its forward course to join the maxillary nerve, the Vidian nerve passes between what will here be called, respectively, the medial levator bulbi and lateral levator bulbi. Both these muscles receive their innervation from a twig of the Vidian nerve (sensu stricto), given off near the emergence from the sphenoid of that nerve or its formation by fusion of the levator bulbi and palatine nerves and it seems likely that the position of the foramen for the Vidian nerve is influenced by the position of the levator bulbi muscles.

The simplest condition descriptively (but not necessarily the most primitive phylogenetically) is that of Acrochordus. Here, the lateral levator bulbi originates from the ventral edge of the parietal, posterior to the funnel-shaped pit for the emergence of the Vidian nerve on the sphenoid-parietal suture, and the (smaller) medial levator bulbi arises from the ventral edge of the parietal lateral and anterior to the foramen for emergence of the Vidian nerve. The Vidian nerve passes between the two muscles, but otherwise they are in contact and parallel and both insert on the choanal process of the palatine (there are no fibers to the vomer). The lateral levator bulbi has its origin as in a lizard except that the descending process of the parietal has captured this origin from the orbital cartilage, which has been lost, and the insertion has been shifted from the lower eyelid to the palatine bone. The medial levator bulbi appears to be merely an anterior expansion of the lateral levator bulbi and the origins, as well as the insertions, of the two 
muscles are essentially continuous. They are separated only by the passage of the Vidian nerve between them. If the muscles had remained attached to a lower eyelid, dorsal to the path of the Vidian nerve, then no perforation of the muscle by the Vidian nerve would be necessary, but because the insertion has been shifted to a structure lying ventral to the Vidian nerve (that is, to the palatine bone), the more anterior fibers of the muscle pass anteromedial to the Vidian nerve. Acrochordus does not have a basipterygoid facet, or even a ligament from the sphenoid to the pterygoid, probably because the peculiar enlargement of the oral skeleton relative to the braincase has moved the normal point of articulation on the pterygoid (behind the pterygoid-ectopterygoid articulation) to a point behind the sphenoid. Except for this loss of a basipterygoid articulation, Acrochordus can serve diagrammatically as a starting point in the diverse patterns of the levator bulbi muscle among alethinophidians. It should be noted that the point of emergence of the Vidian nerve, on the parietal-sphenoid suture, is nearly at the closest point in the sphenoid to the two muscles (the medial and lateral levator bulbi muscles) that are innervated from this nerve.

In Aniloidea (including Loxocemus and Xenopeltis), Tropidopheidae, and Bolyeriidae, the lateral levator bulbi is absent. In Loxocemus (AMNH R99151), Xenopeltis (AMNH R-114566), and Tropidophis ( $T$. melanurus, AMNH R-82878) the medial levator bulbi is a large muscle with essentially the same relations as that of Acrochordus, originating on the parietal and inserting on the palatine; Cylindrophis (C. maculatus, AMNH R-126605) is similar in positional relations, but the muscle is reduced and essentially vestigial. In Anilius (AMNH R54936), Ungaliophis (U. continentalis, AMNH R93812) and at least Casarea of the Bolyeriidae (F. Irish, personal commun.), the anteriormost of the fibers of the medial levator bulbi have been set off as a distinct retractor vomeris, inserting on the vomer, with the (larger) remainder of the muscle attached to the palatine (Anilius) or to the palatine and pterygoid (Ungaliophis, Casarea).

In Booidea and in the Colubroidea, the medial levator bulbi is the retractor vomeris (often with an attachment to the prefrontal as well as to the vomer) and the lateral levator bulbi is the retractor arcus palatini (most often inserted on the palatine, but not infrequently inserted on the pterygoid). In a few Booidea (Calabaria, Lichanura, Charina) that have reduced or lost palatal dentition and mobility, the lateral levator bulbi has been lost, and so these forms resemble Anilioidea, tropidopheids, and bolyeriids in the relationships of what remains of the levator bulbi to the Vidian nerve. However, the consequences with respect to the palatal muscula- ture are quite different: loss of the lateral levator bulbi in Booidea (and the few colubroids, such as Amblyodipsas, with similar loss) leaves the palatinepterygoid arch without a retractor muscle, even though the medial levator bulbi persists as a retractor of the vomer; in anilioids, tropidopheids and bolyeriids, the palatine-pterygoid arch receives a retractor, even though the lateral levator bulbi is lost, but only in a few (Anilius, Ungaliophis, Casarea) are there any fibers to the vomer.

In pythons, including Calabaria, the basipterygoid process is lizardlike in having a distinct articular facet for the pterygoid bone, but it is not lizardlike in its relationship to palatal muscles. The anterior face of the basipterygoid process gives origin to the retractor vomeris (in lizards, an invagination of the oral mucosa lies against the anterior face of the basipterygoid process). The posterior face of the basipterygoid process gives origin to the protractor pterygoideus in pythons. In most lizards the origin of the protractor pterygoideus is confined to the lateral corner of the (much more projecting) basipterygoid process and to a flange ("crista prootica") on the lateral face of the prootic; usually the rear edge of the lizard basipterygoid process is pressed against the anterior rim of the eustachian tube, a structure absent in snakes, where its former position has been usurped by the expanded origin of the protractor pterygoideus. The basipterygoid process of pythons thus becomes a strong intermuscular crest, between the origin of the retractor vomeris (and the ventralmost part of the retractor arcus palatini origin, which is mainly on the parietal) on its anterior face, and the protractor pterygoideus on its posterior face; mounted on this intermuscular crest there is still a smooth articular facet (but unlike that of Dinilysia, this facet is oriented nearly transversely, rather than longitudinally).

In boas, the articular facet is missing, because the corresponding area on the pterygoid has been occupied by the enlarged insertion of the levator pterygoideus and, often, the protractor pterygoideus has its anterior edge extended forward, underlapping the rear of the retractor vomeris and rear of the retractor arcus palatini, thus burying the basipterygoid process. Nevertheless, even when this basipterygoid process is buried by a forwardly extended protractor pterygoideus, a long ligament may extend from the edge of the ridgelike basipterygoid process to the pterygoid, as I observed in preparing a skull of Xenoboa cropanii ${ }^{32}$ (AMNH R-

\footnotetext{
${ }^{32}$ Xenoboa is an unusual snake. Kluge (1991: 47) synonymized it with Corallus, "which would be paraphyletic if Xenoboa were recognized ... I synonymize Xenoboa with Corallus and thereby avoid a paraphyletic taxon." Kluge's action has been corroborated by Colston et al. (2013).
} 
92997), where this ligament contained a nodule of cartilage that I would regard as the true homolog of the pythonid basipterygoid process. Such replacement of a synovial surface by a ligament suggests the precise homology for the "secondary Vidian canal" of at least Anilius and Cylindrophis. In these two anilioids the sphenoid has a strong longitudinal crest that is tied to the pterygoid by ligament, thus suggesting the (nearly transverse) basipterygoid process of Xenoboa (and other boas). This longitudinal crest of Anilius and Cylindrophis is also the floor of the "secondary Vidian canal" and it seems likely that the "secondary Vidian canal" represents a basipterygoid process that has been extended forward, without a synovial facet for the pterygoid, but with (at least in Anilius and Cylindrophis) a ligament replacing the synovial facet. The longitudinal, rather than nearly transverse orientation in the anilioids reflects a difference from booids in muscular relations: the retractor vomeris is absent (Cylindrophis) or arises much farther forward on the sphenoid rostrum (Anilius) and the protractor pterygoideus lies posterior to this crest; the origin in booids of the retractor vomeris on the lateral wing of the sphenoid, just ventromedial to the origin of the retractor arcus palatini (the latter extending onto the lateral corner of the basipterygoid process), limits the forward extent of the basipterygoid process. In booids, the muscles (retractor vomeris and usually a retractor arcus palatini) supplied by the motor twig given off from the rear of the Vidian nerve (strict sense) are more posteriorly located than the levator bulbi musculature of anilioids (and tropidopheids and bolyeriids) and the lack of any "secondary Vidian canal" in booids results in a correspondingly more posterior position for the nerve supplying them. I would interpret the opening that deprives the "secondary Vidian canal" of a roof in anilioids and tropidopheids as the homolog of the foramen for the levator bulbi nerve exit from the cavum epiptericum, in the sphenoid-parietal suture of booids and Dinilysia.

The reduction of the basipterygoid process to an intermuscular crest in boas gives some insight in interpreting the Vidian canals of colubroids. No colubroid is known to have a synovial facet for the pterygoid on the sphenoid bone, but many colubroids (e.g., Bungarus among proteroglyphs, Natrix, Elaphe, and Coluber among Colubridae) have an intermuscular crest across the canal for the palatine nerve that may be so strong that it suggests the basipterygoid process of boas; at least in Elaphe obsoleta (Haluska and Alberch, 1983), this region of the sphenoid is, indeed, extended to the pterygoid of the embryo by a distinct and unequivocal basipterygoid process that becomes reduced in later development. This intermuscular crest is similar in general position to the basipterygoid process of booids (it separates levator bulbi musculature from the protractor pterygoideus and lies across the path of the palatine, or greater superficial petrosal, nerve). Its development in Elaphe puts homology with the basipterygoid process of booids and lizards beyond reasonable doubt, but there are some differences in detail between the intermuscular crest of colubroids and the basipterygoid process of boas and pythons. In the latter, the retractor vomeris (medial levator bulbi) muscle originates on most or all of the anterior face of the basipterygoid process and the retractor arcus palatini (lateral levator bulbi) muscle originates almost entirely on the parietal, with only the most ventral part of its origin extending onto the basipterygoid process of the [para]sphenoid. In colubroids such as Natrix or Nerodia or Elaphe with a nearly transverse intermuscular crest most resembling the booid basipterygoid process, it is the retractor arcus palatini that originates from this crest and the retractor vomeris usually has a more anterior origin, deep to that of retractor arcus palatini. Further, booids agree with Dinilysia in having the foramen for exit of the levator bulbi nerve from the cavum epiptericum in the sphenoid-parietal suture; usually colubroids, such as Natrix, that have the juncture of the palatine and levator bulbi nerves on the external surface of the sphenoid (as in booids and, to judge from the foramina, Dinilysia) have the foramen for the levator bulbi nerve well within the border of the sphenoid; however, in Dromicodryas bernieri (AMNH R-60703) this foramen is on the lateral edge of the sphenoid on the right side, and one (AMNH R-60715) of three Thamnosophis lateralis showed this condition on the left.

In many colubroids there is a "secondary Vidian canal": the palatine nerve enters a foramen in the posterior part of the sphenoid and does not emerge again as such; instead it is a true Vidian nerve, formed by fusion of the levator bulbi and palatine nerves that emerges anteriorly from the "anterior orifice of the Vidian canal." Among these colubroids with a "secondary Vidian canal" are genera such as Boaedon with the levator bulbi musculature originating on the parietal and only the protractor pterygoideus of the first dorsal constrictor musculature arising from the sphenoid; thus, there is no transverse intermuscular crest and the only thing that could correspond to such a crest would be the nearly longitudinal lateral edge of the sphenoid itself (figs. 39, 40). Although lack of a "secondary Vidian canal" is lizardlike (and Dinilysia-like) and may be primary in pythons, where it is associated with a basipterygoid process bearing an articular surface. In pythons the transverse orientation of this articular surface is 
neither lizardlike nor Dinilysia-like and is associated with ventral extension of the origin of the levator bulbi musculature onto the sphenoid, seemingly a greater departure from the lizard condition than origin of that musculature from the descending process of the parietal that has replaced the orbital cartilage (the usual site of origin of the levator bulbi in lizards). The most pythonlike feature of the intermuscular crest in Natrix, Elaphe, etc., is its nearly transverse orientation, imposed by the extension of the origin of the levator bulbi musculature (but not the same part of the musculature as in booids) onto the sphenoid.

I believe the resemblance between Elaphe or Natrix and Python in these features is convergent (thus, the lack of detail in the resemblance) and that the primitive condition among Colubroidea is presence of a long "secondary Vidian canal" opening on the parietal-sphenoid suture (as in Anilioidea, Tropidopheidae, and Bolyeriidae). It is possible to arrange observed Vidian canals among colubroids in a series leading from a long "secondary Vidian canal" that is an open groove intracranially to total absence of "secondary Vidian canal" or even absence of any external enclosure of the nerves involved. This series is morphological rather than phylogenetic, since several stages can be found within a single, apparently homogeneous group (e.g., the subfamily Homalopsinae) and the same stage may appear in unrelated species. Moreover, since these stages appear to reflect quantitative differences in ossification of the parasphenoid component of the sphenoid, there does not seem to be any biological reason why a phyletic lineage could not go in either direction (or meander backward and forward) from stage to stage.

1. Boaedon pattern: ${ }^{33}$ Much as in Tropidophis, there is a long gutterlike groove on the dorsal (intracranial or more precisely, intracavum epiptericum) surface of the sphenoid leading from the "posterior orifice of the Vidian canal" for entry of the palatine nerve in the rear of the sphenoid (immediately anterolateral to the foramen into the pituitary fossa for the carotid artery or confluent externally with the carotid foramen), and extending forward to the "anterior orifice of the Vidian canal" in the sphenoid-parietal suture (anterior to the origin of the retractor vomeris). The entire course of the palatine nerve within the skull is accessible to the levator bulbi nerve, from the entry of that nerve into the cavum epiptericum forward, and it is impossible to say from examination of the dried skull just where the

\footnotetext{
${ }^{33}$ The genus Boaedon was resurrected from Lamprophis for African snakes by Kelly et al. (2011: 424).
}

juncture of the two nerves takes place. Rieppel (1979) has figured this pattern in Pseudoboa, and it also occurs in Oxyrhopus petola (AMNH R-52640), probably related to Pseudoboa, but also in Rhadinaea taeniata (AMNH R-106933); this pattern also occurs in the homalopsines Fordonia leucobalia (AMNH R-103993, 111775), and "Cantoria" annulata (AMNH R-111805), but not other homalopsines; Boaedon, Lamprophis, Bothrophthalmus, and Lycodonomorphus also show this pattern; so do Bothrolycus, Lycophidion, Hormonotus, Gonionotophis, Mehelya, and Aparallactus, but among these genera the posterior clinoid process of the sphenoid is produced somewhat forward above the rear of the canal but below the pituitary vein foramen (for entry of the levator bulbi nerve), so that the region of possible juncture of the palatine and levator bulbi nerves is limited to about the anterior half to two-thirds of intracranial course of the canal. Pareas margaritophorus (AMNH R-27772) and Aplopeltura boa (AMNH R-2886) are as in Bothrolycus, Lycophidion, etc., as is Lycodryas gaimardi (AMNH R-60670 [for use of name see Cadle, 2003: 1000]), but in Madagascarophis colubrinus (AMNH R-60685) the roofing of the rear part of the canal is slightly more extensive, for nearly the posterior half of the canal; it should be noted that although smoothly continuous with the posterior clinoid process (forming the lateral flank of the pituitary fossa, pierced or grooved by the abducens nerve, and obviously homologous with the part of the sphenoid to which the cartilage trellis attaches in lizards), this portion of the sphenoid that roofs the rear of the canal for the palatine nerve and lies ventral to the pituitary vein foramen has the connections of the basitrabecular process (endochondral component of the basipterygoid process) of lizards, but whether it develops from a cartilaginous rudiment or is entirely intramembranous ossification is not known.

2. Diadophis pattern: Basically as in the Boaedon pattern, particularly as that pattern is expressed in Lycophidion, but with the roof of the "secondary Vidian canal" ossified; the path of the levator bulbi nerve within the cavum epiptericum is not roofed by bone, but a defect in the bony roof of the canal for the palatine nerve indicates the point where the levator bulbi (retractor pterygoideus) nerve enters the Vidian canal to join with the palatine nerve and form the Vidian nerve (strict sense); the part of the Vidian canal anterior to this defect is presumably the "secondary Vidian canal" (canal for the 
Vidian nerve, strict sense) and is relatively large, with its anterior opening in the sphenoidparietal suture, as in the Boaedon pattern, but with the canal completely enclosed in the sphenoid. This pattern is seen in Diadophis punctatus (AMNH R-74560) and Contia tenuis (AMNH R- 69062) and also in Lycodon, Cercaspis, ${ }^{34}$ Dinodon, and Stegonotus; also, in the homalopsine Gerarda prevostiana (BMNH 95.1.3.1) and many Australian proteroglyphs (e.g., Tropidechis carinatus, QM 7492; Notechis scutatus, AMNH R-77589).

3. Compsophis pattern: This pattern differs from the Diadophis pattern only in that there is less ossification of the ventral (external) "secondary Vidian canal," so that the anterior orifice of this canal is medial to the sphenoidparietal suture. There may also be a posterior extension of ossification of the roof of this canal to enclose the anterior end of the levator bulbi nerve intracranially in its own canal (the palatine nerve canal, levator bulbi canal and "secondary Vidian canal" thus forming a Y-shaped tube), as in Compsophis infralineatus (AMNH R-60682). The "secondary Vidian canal" (= stem of the Y) may be relatively long, as in Brachyorrhos albus (AMNH R-21125) and Coniophanes fissidens (AMNH R-69977), so that its anterior orifice is nearly on the parietal-sphenoid suture, or moderate (e.g., Rhadinaea flavilata, AMNH R-50491; Amastridium veliferum, AMNH R114309; Cantoria violacea, BMNH 1930.5.8.642), so that its orifice is set well within the border of the sphenoid but the "secondary Vidian canal" is clearly recognizable; or the secondary canal may be very short (the $\mathrm{Y}$ is nearly a $\mathrm{V}$ ) and distinguishing this pattern from the next is rather arbitrary (examples are Amplorhinus multimaculatus, PEM R 1922; Pythonodipsas carinatus, PEM 2774; Grayia ornata, AMNH R-12174). These differences in position of the anterior orifice of the "secondary Vidian canal" seem to reflect the degree to which the retractor arcus palatini origin extends ventrally onto the sphenoid; where the extension is greatest (as in Amplorhinus, where the intermuscular crest, for origin of this muscle, is nearly transverse and very strong, suggesting the basipterygoid process of a boa), the second-

\footnotetext{
${ }^{34}$ Based on AMNH R-94533 (Cercaspis carinatus), in which the anterior opening of the Vidian canal is in the sphenoid-parietal suture as mentioned above. Underwood's (1967: 17, fig. 5i) drawing of $C$. carinatus shows this foramen as being in the parietal, well away from the sphenoid suture. -C.W.M.
}

ary canal is shortest. Underwood (1967) has illustrated the Vidian canal system of Alsophis, fitting the Compsophis pattern; it should be noted that the nerve called a sympathetic nerve by Underwood is the nerve here called the levator bulbi nerve.

4. Natrix pattern: Rieppel (1979) illustrates Natrix as an example of this pattern, in which the bony floor of the "secondary Vidian canal" is altogether absent and the canals for the palatine nerve and for the levator bulbi nerve open separately. The two openings may be in a common transverse groove (e.g., Liophidium torquatum, AMNH $\mathrm{R}-24902)$ or quite separate from each other (e.g., Thamnosophis lateralis, AMNH R60676; but another specimen, AMNH R60689, of this species has the Compsophis pattern).

Some snakes showing the Natrix pattern may have an extremely short primary Vidian canal (for the palatine nerve) and in Afronatrix anoscopus (AMNH R-50526) it has disappeared entirely, so that the palatine nerve lies in an open groove on the external surface of the sphenoid, with the levator bulbi nerve exiting from the cavum epiptericum by a foramen in the sphenoid immediately lateral to the short groove for the palatine nerve. Lack of a primary Vidian canal can take place in other ways, not necessarily from a Natrix pattern. In Oxyrhabdium leporinum (AMNH R63379 ), the palatine nerve was in an open groove on the external surface of the sphenoid and met the levator palatini at the foramen for emergence of that nerve, on the parietal-sphenoid suture; thus, neither a primary nor a secondary Vidian canal was formed. In another specimen of this species (AMNH R-63378), dissection revealed a small tab of the sphenoid extending beneath the extreme anterior end of the palatine nerve and the juncture of that nerve with the levator bulbi nerve, on the lateral edge of the sphenoid; this tab of the sphenoid, defining a "primary Vidian canal" but in an unusual place, was set off posteriorly (but not anteriorly) from the rest of the sphenoid by a suture, perhaps representing a separation of the parasphenoid from the endochondral portion of the sphenoid.

Dissection of Heterodon nasicus (AMNH R109431) showed the palatine nerve failing to appear on the external surface of the skull. Instead, this nerve entered the dorsal side of the sphenoid from deep within the recess of the prootic for the trigeminal and facial nerves; the levator bulbi nerve was not found in this dissection, but presumably joined the palatine nerve within the 
trigeminal-facial recess of the prootic, because the nerve that passed the canal in the sphenoid gave off a twig to the retractor vomeris immediately after emerging from a foramen anterior to the origin of the retractor arcus palatini and posterolateral to the origin of the retractor vomeris. Apparently, the only Vidian canal in the sphenoid of Heterodon nasicus is a "secondary canal" for the Vidian nerve (strict sense). Examination of a disarticulated dry skull of H. platyrhinos (AMNH R-63590) showed no Vidian canal in the sphenoid (but a carotid canal into the pituitary fossa was present, as in $H$. nasicus and other snakes); instead, the foramen corresponding to the "secondary Vidian canal" of $H$. nasicus pierced the outer wall of the trigeminalfacial recess of the prootic - that is, the more ventral portion of the alethinophidian bridge of the prootic (although the dorsal part of the alethinophidian bridge, between the maxillary and mandibular rami of the trigeminal nerve, is poorly developed in Heterodon and often absent, the more ventral part, lying lateral to the first dorsal constrictor $\left(\mathrm{V}_{4}\right)$ nerves is unusually large in this genus).

The peculiar pattern in Heterodon seems to involve loss of a part of the sphenoid that normally keeps the levator bulbi and palatine nerves apart until those nerves have entered the sphenoid: the lobe of the sphenoid anterior to the posterior clinoid process, ventral to the pituitary (and middle cerebral) vein and levator bulbi nerves, dorsal to the palatine nerve, and with at least the positional relations of the basitrabecular process of the chondrocranium of lizards and other vertebrates. The extreme shortening of the braincase in Heterodon seems to have involved total loss of the basipterygoid process.

In preparing the skull of Fimbrios klossi (FMNH 71698), I found both the levator bulbi nerve and palatine nerve to emerge from the trigeminal-facial recess of the prootic, extend forward over the external surface of the sphenoid (deep to the protractor pterygoideus) and join to form the Vidian nerve (strict sense) on the external surface of the sphenoid. The pattern resembles that of Oxyrhabdium except that there is neither a primary Vidian (palatine nerve) canal nor any pituitary vein-levator bulbi nerve foramen and the levator bulbi never enters the cavum epiptericum. The simplest way to derive the pattern of Fimbrios would be from some condition where the levator bulbi nerve has a bony roof in its passage through the cavum epiptericum (e.g., Thamnosophis lateralis, AMNH R-60689); erosion of the ventral (external) wall of such a roofed levator bulbi nerve canal would then produce the exposed Vidian nerve system of Fimbrios. It is usual in snakes for the chondrocranium forming the lateral wing of the sphenoid to become lysed and then ossified during development. The canals in this region may be rebuilt by membranous ossification even when morphological relationships of the chondrocranium appear to be retained and the departure from the normal pattern seen in Fimbrios (and, to judge from dried skulls, Aspidura and Blythia) may reflect merely a difference in detail in the rebuilding of the lateral wing of the sphenoid.

\section{Venous Drainage AND ForAmina}

The precise course of the levator bulbi nerve in the adult snake skull may largely be determined by the vein that this nerve normally accompanies, the small vein draining the middle cerebral and pituitary veins. In snakes, this is not a "necessary" venous drainage, since the middle cerebral vein is connected to the occipital vein (through remnants of the embryonic posterior cerebral vein) and most, or all, of the blood from the brain passes through the occipital vein that emerges from the foramen magnum. Unfortunately, the small veins of snakes are extremely difficult to study by dissection of ordinary museum material and the only snake for which the details are known, both for definitive pattern and for development, is Natrix natrix, studied developmentally by Grosser and Brezina (1895) and for the adult by Bruner (1907), a snake that may differ in some important respects from many other alethinophidians, although injected Nerodia cyclopion (Carolina Biological Supply Co.) that I examined fit Bruner's account of Natrix.

In most lizards - at least, Lacerta as studied by Grosser and Brezina (1895) and Bruner (1907), and Ctenosaura, as I have observed on a Carolina Biological Supply Co. specimen - the lateral head vein is a large vessel in the roof of the eustachian tube, roofed in turn by a bony shelf (crista prootica) of the prootic bone. The more anterior part of this vein drains the orbital sinus, receives the pituitary-middle cerebral vein and continues backward, ventral to the trigeminal nerve and pressed close against the outer surface of the endochondral braincase; this portion of the lateral head vein is either a retention of the embryonic anterior cardinal vein or a new vein so close to the position of the anterior cardinal that it has the same morphological connections and the replacement is undetectable from adult morphology. Behind the trigeminal nerve, the lateral head vein is a vena capitis lateralis in the strict sense, formed from the dorsal parts of loops of the embryonic anterior cardinal that develop around the dorsal 
root cranial nerves; thus, the lateral head vein passes dorsal (or dorsolateral) to the facial nerve and dorsal to the glossopharyngial and vagus, rather than following the path ventral to these nerves taken by the anterior cardinal. In the Ctenosaura I dissected, the connection between the anterior part of the vein and the more posterior portion formed a small loop around the mandibular ramus $\left(\mathrm{V}_{3}\right)$ of the trigeminal (a "petrosal sinus").

Perhaps because of the lack of a eustachian tube, the lateral head vein of alethinophidian snakes is considerably modified anteriorly. The orbital sinus (including its extension into the temporal region in the Harderian gland) is drained by a new anastomotic vein that passes dorsal to the trigeminal ganglion and is also much more laterally placed than its functional analog in lizards: this anterior part of the "lateral head vein" is not only lateral (rather than deep) to the first dorsal constrictor muscle, but is also lateral to a portion (the pseudotemporalis) of the mandibular adductor. In Natrix natrix and Nerodia cyclopion, the homolog of the more anterior part of the lizard lateral head vein is represented by some very small veins that lie ventral to the trigeminal ganglion and are pressed tight against the outer surface of the sphenoid and prootic bones. The vein receiving the pituitarymiddle cerebral vein drainage passes ventral to the trigeminal ganglion (but, in my Nerodia cyclopion, extended dorsoposteriorly on the outer side of the alethinophidian bridge and so lay between the maxillary and mandibular rami of the trigeminal nerve) to connect with the main lateral head vein posterodorsal to the foramen for the facial nerve. Presumably, all of the large "lateral head vein" anterior to this juncture represents the new anastomotic vein of snakes.

The small veins ventral to the trigeminal ganglion (of Natrix, at least) seem to be secondary vessels, rather than a true persistence of the anterior cardinal, to judge from Grosser and Brezina (1895) and Bruner (1907), but this is also true (to judge from the same authors) of the corresponding veins in Lacerta agilis. The pituitary-middle cerebral vein is also connected in Natrix natrix and Nerodia cyclopion, with a small vein that does not have any certain homolog among lizards that are well studied. A small vein (vena palatocerebralis of Bruner) extends forward and downward from external emergence of the pituitary vein and joins a vein called the vena palatina obliqua by Bruner. The vena palatina obliqua joins its fellow on the midline and laterally joins a vein (Bruner's vena maxillaris) that runs along the pterygoid bone to unite posteriorly with the mandibular vein and open into the anterior vena cava just behind the head. The maxillarymandibular vein system of snakes seems to correspond to the external jugular vein system of lizards, but with its junction with the anterior vena cava shifted forward because there is no shoulder region to be drained and the vein has become entirely a vein of the head in snakes.

The connection between the pituitary-middle cerebral vein and the maxillary vein, formed by the vena palato-cerebralis, is less easily homologized with any lizard vessel. The vena palatocerebralis of Nerodia lies along the line of contact of origin of the retractor arcus palatini with the origin of the protractor pterygoideus, that is, in the position, relative to muscles, of the basipterygoid facet of Python. To judge from the cranial foramina, many snakes lack this venous connection between the pituitary-middle cerebral vein and the maxillary vein.

In many Australian proteroglyphs (e.g., Tropidechis) the pituitary vein foramen is in the prootic, within the chamber for the trigeminal ganglion and concealed from lateral view by the anteroventral portion of the alethinophidian bridge ossification (as a consequence, the levator bulbi nerve does not extend onto the external surface of the braincase, but enters the cavum epiptericum directly from the trigeminal fossa of the prootic, entirely medial to the alethinophidian bridge). This position of the pituitary vein foramen would not allow any venous anastomosis between the pituitary vein and maxillary vein; at least, no such anastomosis in the position of the vena palato-cerebralis of Natrix and Nerodia. I have not found any such vein in gross dissection and skull preparation of Australian elapids (but this means little, because a small vein would be undetectable in uninjected material) and functional considerations make it unlikely that such an anastomosis of the pituitary and maxillary veins would exist in the adult of an Australian proteroglyph. The Australian proteroglyphs are adapted to an unusually long anteroposterior excursion of the palate relative to the braincase.

Other indications of this include the freeing of the palatine from both the vomer and from the prefrontal-the maxillary or lateral process of the palatine has been lost and its articulation with the prefrontal in most snakes is absent. Instead, the flat lateral surface of the palatine forms a gliding articulation with the anterior medial process of the maxilla. The protractor pterygoideus extends far anterior to its origin on the lateral wing of the sphenoid, thus of the retractor arcus palatini, making the protractor a muscle composed entirely of long fibers, permitting considerable stretching. If the braincase were tethered to the pterygoid bone by a vein connecting the pituitary 
and maxillary veins, these adaptations to extensive forward and backward excursion of the palate would be negated, but I doubt that any such venous connection exists among Australian proteroglyphs.

The lack of any pituitary vein foramen in Fimbrios and Achalinus is also associated with a palate that seems adapted to long anterior and posterior excursion relative to the braincase. Just as in the case of Australian proteroglyphs, a tethering of the palate to the braincase by a vein would seem to defeat the adaptations (anteroposterior orientation of palatal muscles, loss of a choanal process of the palatine) for this long excursion, and very likely no pituitary veinmaxillary vein anastomosis exists in these forms, or in Aspidura and Blythia, with a similarly mobile palate and no pituitary vein foramen.

Dissection of the xenodontine colubrid Tantalophis discolor (AMNH R-103130) revealed a vein accompanying the levator bulbi nerve, exposed between the foramen in the ventro-anterior end of the alethinophidian bridge of the prootic and the pituitary vein foramen in the sphenoid. No lateral branch of the vein for anastomosis with the maxillary vein was seen, and the foramina by which the vein (and levator bulbi nerve) emerged upon the surface and left the surface were of about the same size (if any substantial amount of blood were directed into an anastomic branch, the foramen in the prootic should be conspicuously smaller than the foramen in the sphenoid). It seems almost certain that no anastomosis was present in the specimen examined, although the exposure of the vein makes it possible that such an anastomosis could have been present at a different ontogenetic stage. In all the xenodontine colubrid skulls that I have examined, a similar state of affairs exists: the passageway for the vein into the trigeminal chamber of the prootic (deep to the alethinophidian bridge) appears large enough to accommodate the entire blood volume that could pass through the pituitary vein foramen. Thus, there is no necessity for believing the pituitary vein-maxillary vein anastomosis exists in xenodontines, at least as an adult vessel of any considerable size.

In contrast, skulls of many natricine and pseudoxenodontine (sensu McDowell, 1987: 3839) colubrids show a large pituitary vein foramen and only a small levator bulbi nerve foramen in the prootic. This is consistent with some of the blood from the pituitary vein being diverted to an anastomosis with the maxillary vein, but does not prove that such a channel exists: in Nerodia cyclopion and Natrix natrix there is a venous channel on the outer side of the prootic bridge and possibly this channel could account for the difference in blood flow between that passing through the pituitary vein foramen and that passing through the foramen in the prootic for the levator bulbi nerve. In this discussion, I have avoided any implication as to which way the blood flows in the veins in question; I could find no valves in the head veins of Nerodia cyclopion by dissection, and Lillywhite (1987a, 1987b) found no valves in the major veins of a variety of snakes, where local tonus in the muscular walls of the veins and conformations, such as hairpin loops and angulations, seem to control direction of flow. Quite possibly, the anastomosis between the pituitary and maxillary veins, when it exists, carries blood in either direction, depending on the position of the palato-pterygoid arch relative to the braincase.

\section{REFERENCES}

Note: There seems to be a recent tendency to cite unpublished dissertations that were submitted for degree requirements perhaps a decade or more previously but never formally published. A few of these citations came to our attention recently and were not pursued for lack of time. Authors thinking it truly important to cite an unpublished dissertation would do a service by providing a few lines of context and a method for obtaining the work (e.g., by a bibliographic reference to Dissertation Abstracts International or a catalog number for University Microfilms International). Nomenclatural actions in such works cannot be considered published under standards set in the International Code on Zoological Nomenclature, nor can such works be used for subsequent indication or bibliographic reference in order to confer availability of names or actions (for problems associated with one commonly cited 33year-old dissertation, see Myers, 2011: 21-22).

Aldridge, Robert D., and David M. Sever (editors). 2011. Reproductive biology and phylogeny of snakes. Endfield, NH: Science Publishers, xii +759 pp.

Amaral, Afrânio do. 1929a [1930]. Contribuição ao conhecimento dos ophidios do Brasil IV. Lista remissiva dos ophidios do Brasil. Memorias do Instituto Butantan 4: 69-70 + i-iv, 71125.

Amaral, Afrânio do. 1929b [1930]. Estudos sobre ophidios neotropicos XVIII. Lista remissiva dos ophidios da Região Neotropica. Memorias do Instituto Butantan 4: 127-128 + i-viii, 129-271.

Amaral, Afrânio do. 1936. Contribuição ao conhecimento dos ophidios do Brasil VIII. Lista remissiva dos ophidios do Brasil. 2.a edição. Memorias do Instituto Butantan 10: 87-162+ i-xix. 
Anthony, Jean, and Rachel G. Serra. 1949. Sur une particularité remarquable de l'appareil de la morsure chez un serpent aglyphe de l'Amérique tropicale, "Xenodon merremii." Revista Brasileira de Biologia 9 (2): 153-160.

Anthony, Jean, and Rachel G. Serra. 1951. Anatomie de l'appareil de la morsure chez Xenodon merremii B., serpent aglyphe de l'Amérique tropicale. Arquivos do Museu Nacional 42 (pt. 1): 21-47. [vol. 42 for 1955, this article distributed November 27, 1951]

Arnold, E.N. 1984. Variation in the cloacal and hemipenial muscles of lizards and its bearing on their relationships. Symposia of the Zoological Society of London 52: 47-85.

Arnold, E.N. 1986. Why copulatory organs provide so many useful taxonomic characters: the origin and maintenance of hemipenial differences in lacertid lizards. Biological Journal of the Linnean Society 29: 263-281.

Auth, David L., et al. (with 5 coauthors). 1998. The report of the snake genus Conophis in South America is erroneous. Bulletin of the Maryland Herpetological Society 34 (4): 107-112.

Bassler, Harvey. MS. Geological report on parts of Rio Ucayali drainage basin in eastern Peru examined during expedition of 1923. [67 pp. + maps and photographs covering exploration of four tributary streams during some $10,000 \mathrm{~km}$ of travel by river and $400 \mathrm{~km}$ on foot in forest (written in Iquitos and dated July 26, 1924). (Bassler's reports examined by C.W.M. in the early 1980s, courtesy of the Exxon Corporation)]

Battersby, James C. 1951. Description of a new species of snake, Prosymna pitmani, sp. n., from Tanganyika Territory and notes on the genus. Annals and Magazine of Natural History (12) 4: 828-829.

Bellairs, Angus d'A., and J.D. Boyd. 1947. The lachrymal apparatus in lizards and snakes.-I. The brille, the orbital glands, lachrymal canaliculi and origin of the lachrymal duct. Proceedings of the Zoological Society of London 117 (1): $81-108$

Bellairs, Angus d'A., and J.D. Boyd. 1950. The lachrymal apparatus in lizards and snakes.-II. The anterior part of the lachrymal duct and its relationship with the palate and with the nasal and vomeronasal organs. Proceedings of the Zoological Society of London 120 (2): 269310.

Bellairs, Angus d'A., and A.M. Kamal. 1981. The chrondrocranium and the development of the skull in Recent reptiles. In C. Gans and T.S. Parsons (editors), Biology of the Reptilia 2 (Morphology F): 1-263. London: Academic Press.
Beuchelt, Hans. 1936. Bau, Funktion und Entwicklung der Begattungs-organe der männlichen Ringelnatter (Natrix natrix L.) und Kreuzotter (Vipera berus L.). Gegenbaurs Morphologisches Jahrbuch 78: 445-516.

Bogert, C.M. 1940. Herpetological results of the Vernay Angola Expedition with notes on African reptiles in other collections. Part I. Snakes, including an arrangement of African Colubridae. Bulletin of the American Museum of Natural History 77 (1): 1-107 + p1. 1 .

Bogert, Charles M. 1964. Snakes of the genera Diaphorolepis and Synophis and the colubrid subfamily Xenoderminae (Reptilia, Colubridae). Senckenbergiana Biologica 45 (3/5): 509-531.

Bogert, Charles M. 1966. Index to species for which hemipenes are depicted in "Crocodilians, lizards, and snakes of North America" by E.D. Cope [in] Annual Report United States National Museum for 1898, pp. 155-1294.

Boie, Friedrich. 1826. Generalübersich der Familien und Gattungen der Ophidier. Isis von Oken 19 (10): "981-982" [= 1 page with 4 columns; cols. 1-2 include new genus Erythrolamprus. (Type species) Col. venustissimus Pr. Max. (Wied)]

Boie, Friedrich. 1827. N.G. Xenodon Boie: col. 293. In Hermann Schlegel, Erpetologische Nachrichten. Isis von Oken 20 (3): cols. 281-294. [included in Xenodon are "Col. severus, versicolor, Linn., rhabdocephalus Pr. M., schotti Fitz., Xenod. aeneus Boie n. sp., inornatus K.H. n. sp., ocellatus Boie n. sp.']

Bonaparte, Charles-Lucian. 1845a. Specchio generale dei sistemi erpetologico ed anfibiologico. Atti della Sesta Riunione degli Scienziati Italiani Tenuta in Milano nel Settembre del MDCCCXLIV: 376378. Milan: Coi Tipi di Luigi di Giacoma Pirola.

Bonaparte, Charles-Lucian. 1845b. Specchio generale dei sistemi erpetologico, anfibiologico ed ittiologico. Milan: Coi Tipi di Luigi di Giacoma Pirola, 11 pp. [Reprint or preprint of preceding article, with added title page, some changes in font for a few headings, and added ichthyological part from pp. 386-390 of vol.]

Boulenger, George Albert. 1894. Catalogue of the snakes in the British Museum (Natural History). London: British Museum (Natural History), vol. 2, xi, 382 pp. +20 pls.

Boulenger, George Albert. 1905. Descriptions of new snakes in the collection of the British Museum. Annals and Magazine of Natural History (7) 15: 453-456.

Brain, C.K. 1959. Mating in the South African mole snake, Pseudaspis cana (Linnaeus). Copeia 1959 (1): 71-72.

Branch, W.R. 1986. Hemipenial morphology of African snakes: a taxonomic review part 1 . 
Scolecophidia and Boidae. Journal of Herpetology 20 (3): 285-299.

Broadley, Donald G. 1980. A revision of the African snake genus Prosymna Gray (Colubridae). Occasional Papers of the National Museums and Monuments [Rhodesia], series B, Natural Sciences 6 (7): 481-556.

Bruner, Henry L. 1907. On the cephalic veins and sinuses of reptiles, with description of a mechanism for raising the venous blood-pressure in the head. American Journal of Anatomy 7 (1): $1-117+$ pls. $1-3$.

Cadle, John E. 1984a. Molecular systematics of Neotropical xenodontine snakes: I. South American xenodontines. Herpetologica 40 (1): 8-20.

Cadle, John E. 1984b. Molecular systematics of Neotropical xenodontine snakes: II. Central American xenodontines. Herpetologica 40 (1): 21-30.

Cadle, John E. 1984c. Molecular systematics of Neotropical xenodontine snakes: III. Overview of xenodontine phylogeny and the history of New World snakes. Copeia 1984 (3): 641-652.

Cadle, John E. 1985. The Neotropical colubrid snake fauna (Serpentes: Colubridae): lineage components and biogeography. Systematic Zoology 34 (1): 1-20.

Cadle, John E. 1996a. Snakes of the genus Liopholidophis (Colubridae) from eastern Madagascar: new species, revisionary notes, and an estimate of phylogeny. Bulletin of the Museum of Comparative Zoology 154 (5): 369-464.

Cadle, John E. 1996b. Systematics of snakes of the genus Geodipsas (Colubridae) from Madagascar, with descriptions of new species and observations on natural history. Bulletin of the Museum of Comparative Zoology 155 (2): 33-87.

Cadle, John E. 1999. The dentition, systematics, and phylogeny of Pseudoxyrhopus and related genera from Madagascar (Serpentes: Colubridae), with descriptions of a new species and a new genus. Bulletin of the Museum of Comparative Zoology 155 (8): 381-443.

Cadle, John E. 2003. Colubridae snakes. In Steven M. Goodman and Jonathan P. Benstead (editors), Natural History of Madagascar, 997-1004. Chicago: University of Chicago Press.

Cadle, John E. 2010. Systematics, natural history, and hemipenial morphology of Dendrophidion brunneum (Günther) (Serpentes: Colubridae), a poorly known snake from the Andes of Ecuador and Peru. Zootaxa 2433: 1-24.

Cadle, John E. 2011. Hemipenial morphology in the North American snake genus Phyllorhynchus (Serpentes: Colubridae), with a review of and comparisons with natricid hemipenes. Zootaxa 3092: 1-25.
Cadle, John E. 2012a. Cryptic species within the Dendrophidion vinitor complex in Middle America (Serpentes: Colubridae). Bulletin of the Museum of Comparative Zoology 160 (4): $183-240$.

Cadle, John E. 2012b. Systematics of the Neotropical snake Dendrophidion percarinatum (Serpentes: Colubridae), with descriptions of two new species from western Colombia and Ecuador and supplementary data on D. brunneum. Bulletin of the Museum of Comparative Zoology 160 (6): 1-344.

Cadle, John E., and Jay M. Savage. 2012. Systematics of the Dendrophidion nuchale complex (Serpentes; Colubridae) with the description of a new species from Central America. Zootaxa 3513: 1-50.

Campbell, Jonathan A., and William W. Lamar. 1989. The venomous reptiles of Latin America. Ithaca: Comstock Publishing Associates, xii + 425 pp.

Clark, Hugh. 1945. The anatomy and embryology of the hemipenis of Lampropeltis, Diadophis and Thamnophis and their value as criteria of relationship in the family Colubridae. Proceedings of the Iowa Academy of Science for 1944 51: 411-445.

Coddington, Jonathan A. 1987. [Review of] Sexual selection and animal genitalia, by William G. Eberhard. Cladistics 3 (2): 196-198.

Cole, Charles J., and Laurence M. Hardy. 1981. Systematics of North American colubrid snakes related to Tantilla planiceps (Blainville). Bulletin of the American Museum of Natural History 171 (3): 199-284.

Cohn, Martin J. 2002. Hox genes. In M. Pagel (editor), Evolution, vol. 1: 506-510. New York: Oxford University Press.

Cohn, Martin J., and Cheryll Tickle. 1999. Developmental basis of limblessness and axial patterning in snakes. Nature 399: 474478.

Colston, Timothy J., et al. (with 10 coauthors). 2013. Molecular systematics and historical biogeography of tree boas (Corallus spp.). Molecular Phylogenetics and Evolution 66 (3): 953-959.

Cope, Edward Drinker. 1868. An examination of the Reptilia and Batrachia obtained by the Orton Expedition to Equador and the upper Amazon, with notes on other species. Proceedings of the Academy of Natural Sciences of Philadelphia 20: 96-140.

Cope, Edward Drinker. 1893. Prodromus of a new system of the non-venomous snakes. American Naturalist 27 (317): 447-483.

Cope, Edward Drinker. 1894. The classification of snakes. American Naturalist 28 (334): 831-844+ pls. 27-28. 
Cope, Edward Drinker. 1895. The classification of the Ophidia. Transactions of the American Philosophical Society, n.s., 18 (pt. 2, art. 3): 186-219 + pls. 14-33. [reprint issued April 15, 1895, with identical pagination]

Cope, Edward Drinker. 1896. On the hemipenes of the Sauria. Proceedings of the Academy of Natural Sciences of Philadelphia 48: 461-467.

Cope, Edward Drinker. 1900. The crocodilians, lizards, and snakes of North America. Annual Report of the United States National Museum for 1898: 155-1270, pls. 1-36.

Cunha, Osvaldo Rodrigues da, and Francisco Paiva do Nascimento. 1993. Ofídios da Amazônia. As cobras da região leste do Pará, 2nd ed. Boletim Museu Emílio Goeldi 9 (1): 1-191.

Curcio, Felipe F., Santiago J. Sanchez-Pacheco, Joni Jairo Mueses-Cisneros, and Miguel Trefaut Rodrigues. 2009a. Notes on distribution, variation and characterization of Erythrolamprus pseudocorallus Roze, 1959 (Serpentes: Colubridae) with the first records from Colombia. Zootaxa 2045: 33-42.

Curcio, Felipe Franco, Vitor de Q. Placentini, and Daniel S. Fernandes. 2009b. On the status of the snake genera Erythrolamprus Boie, Liophis Wagler and Lygophis Fitzinger (Serpentes, Xenodontinae). Zootaxa 2173: 66-68.

Davis, D. Dwight. 1936. Courtship and mating behavior in snakes. Field Museum of Natural History, Zoological Series 20 (22): 257-290.

Di-Poi, Nicolas, Juan I. Montoya-Burgos, and Denis Duboule. 2009. Atypical relaxation of structural constraints in Hox gene clusters of the green anole lizard. Genome Research 19: 602-610.

Di-Poi, Nicolas, et al. (+ 5 coauthors). 2010. Changes in Hox genes' structure and function during the evolution of the squamate body plan. Nature 464: 99-103.

Dixon, James R. 1980. The Neotropical colubrid snake genus Liophis. The generic concept. Milwaukee Public Museum, Contributions in Biology and Geology 31: 1-40.

Dixon, James R. 1983. Taxonomic status of the Brazilian colubrid snake Xenodon suspectus Cope. Texas Journal of Science 35 (3): 257-260.

Dixon, James R., and Pekka Soini. 1977. The reptiles of the upper Amazon Basin, Iquitos region, Peru II. Crocodilians, turtles and snakes. Milwaukee Public Museum, Contributions in Biology and Geology 12: 1-91. [reprinted 1986 including parts I and II, Milwaukee Public Museum, vii, 154 pp.]

Dixon, James R., and Pekka Soini. 1986. The reptiles of the upper Amazon Basin, Iquitos region, Peru. Milwaukee Public Museum, vii + 154 pp.
Dowling, Herndon G. 1967. Hemipenes and other characters in colubrid classification. Herpetologica 23 (2): 138-142.

Dowling, Herndon G. 1975. The Nearctic snake fauna. In H.G. Dowling (editor). Yearbook of herpetology, 1974. Publications in Herpetology 8: 190-202. New York: Herpetological Information Search Systems, American Museum of Natural History.

Dowling, Herndon G. 2002. "Intraspecific variation of the hemipenis," a correction, with comments on other erroneous descriptions. Herpetological Review 33 (1): 12-14.

Dowling, Herndon G. 2004. On the structure of snake hemipenes with comments on their proper preparation for analysis: a reply to Cadle, Myers, Prudente, and Zaher. Herpetological Review 35 (4): 320-328.

Dowling, Herndon G., and William E. Duellman. "1974-1978" [1978]. Systematic herpetology: a synopsis of families and higher categories. New York: privately printed by senior author (as HISS Publications, Publications in Herpetology 7, "with minor revisions, 1975-1978"); issued in loose-leaf format in 1978, $302 \mathrm{pp}$.

Dowling, Herndon G., and Isabelle Fries. 1987. A taxonomic study of the ratsnakes VIII. A proposed new genus for Elaphe triaspis (Cope). Herpetologica 43 (2): 200-207.

Dowling, Herndon G., and Robert M. Price. 1988. A proposed new genus for Elaphe subocularis and Elaphe rosaliae. Snake 20: 52-63.

Dowling, Herndon G., and Jay M. Savage. 1960. A guide to the snake hemipenis: a survey of basic structure and systematic characteristics. Zoologica, Scientific Contributions of the New York Zoological Society 45, pt. 17: 1-28+ 3 pls.

Downs, Floyd Leslie. 1967. Intrageneric relationships among colubrid snakes of the genus Geophis Wagler. Miscellaneous Publications, Museum of Zoology, University of Michigan 131: iv, 1-193.

Duellman, William E. 1958. A monographic study of the colubrid snake genus Leptodeira. Bulletin of the American Museum of Natural History 114 (1): 1-152 + pls. 1-31.

Duellman, William E. 2005. Cusco Amazónico. Ithaca, New York: Comstock, xvi, 433 pp.

Duméril, A.M., Constant. Gabriel Bibron, and Auguste H.A. Duméril. 1854 [1834-1854]. Erpétologie générale ou histoire naturelle complète des reptiles. Vol. 7, pt. 1, [xii] + xvi, 780 pp. Paris: Librairie Encyclopédique de Roret.

Dunn, Emmett Reid. 1922. Two new South American snakes. Proceedings of the Biological Society of Washington 35: 219-220. 
Dunn, Emmett Reid. 1928. A tentative key and arrangement of the American genera of Colubridae. Bulletin of the Antivenin Institute of America 2 (1): 18-24.

Dunn, Emmett Reid. 1938. The snake genus Enulius Cope. Proceedings of the Academy of Natural Sciences of Philadelphia for 1937, 89: 415-418.

Dunn, Emmett Reid, and Gilbert CongdonWood. 1939. Notes on eastern snakes of the genus Coluber. Notulae Naturae 5: 1-4.

Eberhard, William G. 1985. Sexual selection and animal genitalia. Cambridge, MA: Harvard University Press, xii, 244 pp.

Eberhard, William G. 2004. Rapid divergent evolution of sexual morphology: comparative tests of antagonistic coevolution and tradional female choice. Evolution 58 (9): 1947-1970.

Eberhard, William G. 2009. Static allometry and animal genitalia. Evoution 63 (1): 48-66.

Eberhard, William G. 2010. Rapid divergent evolution of genitalia. In J.L. Leonard and Alex Córdoba-Aguilar (editors), The evolution of primary sexual characters in animals: 40-78. New York: Oxford University Press.

Edgren, Richard A. 1953. Copulatory adjustment in snakes and its evolutionary implications. Copeia 1953 (3): 162-164.

Eiselt, Josef. 1963. Zur Kenntnis der colubriden Schlangengattungen Procteria und Xenodon. Annalen des Naturhistorischen Museums in Wien 66: 279-282.

Freire, Eliza Maria Xavier, Ulisses Caramaschi, and Ubiratan Gonçalves. 2010. A new species of Dendrophidion (Serpentes: Colubridae) from the Atlantic rain forest of northeastern Brazil. Zootaxa 2719: 62-68.

Gasc, Jean-Pierre, and M.R. Rodrigues. 1980. Liste préliminaire des serpents de la Guyane Française. Bulletin du Muséum National d'Histoire Naturelle, Paris, 4e série, vol. 2, section A, no. 2: 559-598.

Greene, Harry W. 1997. Snakes. Berkeley: University of California Press, ix + $351 \mathrm{pp}$.

Greene, Harry W., and Roy W. McDiarmid. 1981. Coral snake mimicry: does it occur? Science 213: 1207-1212.

Griffin, Lawrence Edmonds. 1916. A catalog of the Ophidia from South America at present (June, 1916) contained in the Carnegie Museum with descriptions of some new species. Memoirs of the Carnegie Museum 7 (3): 163-228 + pl. 28.

Grosser, O., and E. Brezina. 1895. Über die Entwicklung der Venen des Kopfes und Halses bei Reptilien. Morphologisches Jahrbuch 23 (2): 289-325 + pls. 20-21.

Günther, Albert C.L.G. 1858. Catalogue of colubrine snakes in the collection of the British
Museum. London: British Museum (Natural History), xvi + 281 pp.

Haas, Georg. 1974. Muscles of the jaws and associated structures in the Rhynchocephalia and Squamata. In C. Gans, and T.S. Parsons (editors), Biology of the reptilia 4 (Morphology D): 285-490. Academic Press: London.

Haluska, Frank, and Pere Alberch. 1983. The cranial development of Elaphe obsoleta (Ophidia: Colubridae). Journal of Morphology 178 (1): 37-55.

Hoogmoed, Marinus S. 1985. Xenodon werneri Eiselt, a poorly known snake from Guiana, with notes on Waglerophis merremii (Wagler) (Reptilia: Serpentes: Colubridae). Notes on the herpetofauna of Surinam IX. Zoologische Mededelingen 59 (8): 79-88.

Huber, Bernhard A. 2003. Rapid evolution and species-specificity of arthropod genitalia: fact or artifact? Organisms Diversity \& Evolution 3 (1): 63-71.

ICZN. 1999. International Code of Zoological Nomenclature, 4th ed. London: International Trust for Zoological Nomenclature.

Inger, Robert F., and Hymen Marx. 1962. Variation of hemipenis and cloaca in the colubrid snake Calamaria lumbricoidea. Systematic Zoology 11 (1): 32-38.

Inger, Robert F., and Hymen Marx. 1965. The systematics and evolution of the Oriental colubrid snakes of the genus Calamaria. Fieldiana: Zoology 49: 1-304.

Jan, Giorgio, and Ferdinando Sordelli. 1866 [18601881]. Iconographie générale des ophidiens: vol. 2, livraison 19, pls. 1-6. Milan: chez l'auteur, etc.

Kardong, Kenneth V. 1979. "Protovipers" and the evolution of snake fangs. Evolution 33 (1): 433-443.

Keiser, Edmund D., Jr. 1969. An unusual specimen of the Neotropical vine snake, Oxybelis aeneus (Wagler), from Zacatecas, Mexico. British Journal of Herpetology 4 (5): 116-117.

Keiser, Edmund D., Jr. 1974. A systematic study of the Neotropical vine snake, Oxybelis aeneus (Wagler). Bulletin of the Texas Memorial Museum 22: 1-51.

Kelly, Christopher M.R., Nigel P. Barker, Martin H. Villet, Donald G. Broadley, and William R. Branch. 2008. The snake family Psammophiidae (Reptilia: Serpentes): phylogenetics and species delimitation in the African sand snakes (Psammophis Boie, 1825) and allied genera. Molecular Phylogenetics and Evolution 47 (3): 1045-1060.

Kelly, Christopher M.R., William R. Branch, Donald G. Broadley, Nigel P. Barker, and Martin H. Villet. 2011. Molecular systematics of the African snake family Lamprophiidae 
Fitzinger, 1843 (Serpentes: Elapoidea), with particular focus on the genera Lamprophis Fitzinger, 1843 and Mehelya Csiki 1903. Molecular Phylogenetics and Evolution 58 (3): 415-426.

King, Richard B., Robert C. Jadin, Michael Grue, and Harlan D. Walley. 2009. Behavioural correlates with hemipenial morphology in New World natricine snakes. Biological Journal of the Linnean Society 98 (1): 110-120.

Kluge, Arnold G. 1991. Boine snake phylogeny and research cycles. Miscellaneous Publications Museum of Zoology, University of Michigan 178: iv +58 .

Köhler, Gunther. 2008. Reptiles of Central America. Offenbach, Germany: Herpeton, Verlag Elke Köhler, 400 pp.

Kondo, Takashi, József Zákány, Jeffrey W. Innis, and Denis Duboule. 1997. Of fingers, toes, and penises. Nature 390: 29.

Lee, Julian C. 1996. The amphibians and reptiles of the Yucatán Peninsula. Ithaca, NY: Cornell University Press, xii +500 pp. +32 color pls., figs. $218-403$.

Lillywhite, Harvey B. 1987a. Circulatory adaptations of snakes to gravity. American Zoologist 27 (1): 81-95.

Lillywhite, Harvey B. 1987b. Snakes under pressure. Natural History 96 (11): 58-67.

Linnaeus, Carl. 1758. Systema naturae per regna tria naturae, secundum classes, ordines, genera, species, cum characteribus, differentiis, synonymis, locis. 10 ed. Stockholm: L. Salvius, vol. 1: [iv], 824 pp.

Maglio, Vincent J. 1970. West Indian xenodontine colubrid snakes: their probable origin, phylogeny, and zoogeography. Bulletin of the Museum of Comparative Zoology 141 (1): 1-53.

Martins, Marcio M. Ermelinda Oliveira. 1998. Natural history of snakes in forests of the Manaus Region, central Amazonia, Brazil. Herpetological Natural History 6 (2): 78-150+ pls. [photos] 1-113.

McCranie, James R. 2011. Snakes of Honduras. Ithaca, New York: Society for the Study of Amphibians and Reptiles, $\mathrm{x}+714$ pp., 20 pls.

McCranie, James R., and Jaime Villa. 1993. A new genus for the snake Enulius sclateri (Colubridae: Xenodontinae). Amphibia-Reptilia 14 (3): 261-267.

McDowell, Samuel B. 1961. Systematic division and evolution of the colubrid snake genus Natrix, with comments on the subfamily Natricinae, by Edmond V. Malnate [review]. Copeia 1961 (4): 502-506.

McDowell, Samuel B. 1968. Affinities of the snakes usually called Elaps lacteus and $E$. dorsalis. Journal of the Linnean Society of London, Zoology 47 (313): 561-578.

McDowell, Samuel B. 1974. A catalogue of the snakes of New Guinea and the Solomons, with special reference to those in the Bernice $P$. Bishop Museum. Part I. Scolecophidia. Journal of Herpetology 8 (1): 1-57.

McDowell, Samuel B. 1975. A catalogue of the snakes of New Guinea and the Solomons, with special reference to those in the Bernice $P$. Bishop Museum. Part II. Anilioidea and Pythoninae. Journal of Herpetology 9 (1): 1-80.

McDowell, Samuel B. 1979. A catalogue of the snakes of New Guinea and the Solomons, with special reference to those in the Bernice $P$. Bishop Museum. Part III. Boinae and Acrochordoidea (Reptilia, Serpentes). Journal of Herpetology 13 (1): 1-92.

McDowell, Samuel B. 1986. The architecture of the corner of the mouth of colubroid snakes. Journal of Herpetology 20 (3): 353-407.

McDowell, Samuel B. 1987. Systematics. In R.A. Seigel, J.T. Collins, and S.S. Novak (editors), Snakes: ecology and evolutionary biology: 3-50. New York: Macmillan.

McDowell, Samuel B. 1994. Comments on the evolution of the jaw adductor musculature of snakes. Zoological Journal of the Linnean Society 111 (4): 339-384.

Minucci, Sergio, Gabriella Chieffi Baccari, and Loredana Di Matteo. 1992. Histology, histochemistry, and ultrastructure of the Harderian gland of the snake Coluber viridiflavus. Journal of Morphology 211 (2): 207-212.

Myers, Charles W. 1973. A new genus for Andean snakes related to Lygophis boursieri and a new species (Colubridae). American Museum Novitates 2522: 1-37 pp.

Myers, Charles W. 1974. The systematics of Rhadinaea (Colubridae), a genus of New World snakes. Bulletin of the American Museum of Natural History 153 (1): 1-262.

Myers, Charles W. 1982. Blunt-headed vine snakes (Imantodes) in Panama, including a new species and other revisionary notes. American Museum Novitates 2738: 1-50.

Myers, Charles W. 1986. An enigmatic new snake from the Peruvian Andes, with notes on the Xenodontini (Colubridae: Xenodontinae). American Museum Novitates 2853: 1-12.

Myers, Charles W. 2000. A history of herpetology at the American Museum of Natural History. Bulletin of the American Museum of Natural History 252: 1-232.

Myers, Charles W. 2003. Rare snakes-five new species from eastern Panama: reviews of northern Atractus and southern Geophis (Colubridae: 
Dipsadinae). American Museum Novitates 3391: 1-47.

Myers, Charles W. 2011. A new genus and new tribe for Enicognathus melanauchen Jan, 1863, a neglected South American Snake (Colubridae: Xenodontinae), with taxonomic notes on some Dipsadinae. American Museum Novitates 3715: $1-33$.

Myers, Charles W. 2012. Prince Maximilian zu Wied: a military man turned naturalist. In Tom Baione (editor), Natural Histories. Extraordinary rare book selections from the American Museum of Natural History library: 84-87. New York: Sterling Publishing.

Myers, Charles W., and John E. Cadle. 1994. A new genus for South American snakes related to Rhadinaea obtusa Cope (Colubridae) and resurrection of Taeniophallus Cope for the "Rhadinaea" brevirostris group. American Museum Novitates 3102: 1-33.

Myers, Charles W., and John E. Cadle. 2003. On the snake hemipenis, with notes on Psomophis and techniques of eversion: a response to Dowling. Herpetological Review 34 (4): 295-302.

Myers, Charles W., and Jonathan A. Campbell. 1981. A new genus and species of colubrid snake from the Sierra Madre del Sur of Guerrero, Mexico. American Museum Novitates 2708: $1-20$.

Myers, Charles W., and Linda Trueb. 1967. The hemipenis of an anomalepidid snake. Herpetologica 23 (3): 235-238.

Myers, Charles W., Miguel Trefaut Rodrigues, and Paulo E. Vanzolini. 2011. Status of early 19th-century names authored in parallel by Wied and Schinz for South American reptiles and amphibians, with designations of three nomina protecta. American Museum Novitates 3714: 1-21.

Nagy, Zoltán Tamás, Ulrich, Joger, Michael Wink, Frank Glaw, and Miguel. Vences. 2003. Multiple colonization of Madagascar and Socotra by colubrid snakes: evidence from nuclear and mitochondrial gene phylogenies. Proceedings of the Royal Society. Biological Sciences 270 (1533): 261-2621.

Oelrich, Thomas M. 1956. The anatomy of the head of Ctenosaura pectinata (Iguanidae). Miscellaneous Publications, Museum of Zoology, University of Michigan 94: 1-122 + figs. 1-59 [in 22 pls.].

Olson, M., and T. Madsen. 1998. Sexual selection and sperm competition in reptiles. In T.R. Birkhead and A.P. Møller (editors), Sperm competition and sexual selection: 501-577. San Diego: Academic Press, xiii +826 pp.

Oppel, Michael. 1811. Die Ordnungen, Familien und Gattungen der Reptilien als Prodrom einer
Naturgeschichte derselben. Munich: Joseph Lindauer, $87 \mathrm{pp}$.

Paynter, Raymond A., Jr. 1992. Ornithological gazetteer of Bolivia, 2nd ed. Cambridge, MA: Harvard College, vi +107 pp.

Perriton, Claire L., Nicola Powles, Chin Chiang, Mark K. Maconochi, and Martin J. Cohn. 2002. Sonic hedgehog signaling from the urethral epithelium controls external genital development. Developmental Biology 247: 26-46.

Peters, James A., and Braulio Orejas-Miranda. 1970. Catalogue of the Neotropical Squamata Part 1. Snakes. U.S. National Museum Bulletin 297: viii + 347 pp.

Peters, Wilhelm. 1864. Über einige neue Säugethiere (Mormops, Macrotus, Vesperus, Molossus, Capromys), Amphibien (Platydactylus, Otocryptis, Euprepes, Ungalia, Dromicus, Tropidonotus, Xenodon, Hylodes) und Fische (Sillago, Sebastes, Channa, Myctophum, Cerassis, Barbus, Capoëta, Poecilia, Saurenchelys, Leptocephaluis). Monatsberiche der Königlichen Preussische Akademie des Wissenschaften zu Berlin 1864 (Juni): 381-399.

Polly, P. David, Jason J. Head, and Martin J. Cohn. 2001. Testing modularity and dissociation: the evolution of regional proportions in snakes. In M.L. Zelditch (editor). Beyond heterochrony: the evolution of development: 305-335. Wilmington, DE: Wiley-Liss.

Pope, Clifford H. 1941. Copulatory adjustment in snakes. Zoological Series of Field Museum of Natural History 24 (22): 249-252.

Raup, David M. 1966. Geometric analysis of shell coiling: general problems. Journal of Paleontology 40 (5): 1178-1190.

Raup, David M., and Stephen J. Gould. 1966. Stochastic simulation and evolution of morphology - towards a nomothetic paleontology. Systematic Zoology 23 (3): 305-322.

Rehorek, Susan J., Mimi Halpern, Bruce T. Firth, and Mark N. Hutchinson. 2003. The Harderian gland of two species of snakes: Pseudonaja textilis (Elapidae) and Thamnophis sirtalis (Colubridae). Canadian Journal of Zoology 81 (3): 357-363.

Rieppel, Oliver. 1979. The evolution of the basicranium in the Henophidia (Reptilia: Serpentes). Zoological Journal of the Linnaean Society (London) 66 (4): 411-431.

Romano, S. Alma, R.W. de L., and Alphonse Richard Hoge. 1972. Nota sobre Xenodon e Ophis. Memorias do Instituto Butantan 36: 209-214.

Rossman, Douglas A., and W. Gary Eberle. 1977. Partition of the genus Natrix, with preliminary observations on evolutionary trends in natricine snakes. Herpetologica 33 (1): 34-43. 
Roze, Janis A. 1958. A new snake of the genus Urotheca (Serpentes: Colubridae) from Venezuela. Breviora 88: 1-5.

Savage, Jay M. 1970. On the trail of the golden frog: with Warszewicz and Gabb in Central America. Proceedings of the California Academy of Sciences 38 (14): 273-288.

Savage, Jay M. 1997. On terminology for the description of the hemipenis of squamate reptiles. Herpetological Journal 7: 23-25.

Savage, Jay M. 2002. The amphibians and reptiles of Costa Rica. Chicago: University of Chicago Press, $\mathrm{xx}+934$ pp. +516 color pls. on 48 leaves.

Savage, Jay M., and Brian I. Crother. 1989. The status of Pliocercus and Urotheca (Serpentes: Colubridae), with a review of included species of coral snake mimics. Zoological Journal of the Linnean Society 95 (4): 335-362.

Schargel, Walter E., Gilson Rivas Fuenmayor, and Charles W. Myers. 2005. An enigmatic new snake from cloud forest of the Península de Paria, Venezuela (Colubridae: genus Taeniophallus?). American Museum Novitates 3484: 1-22.

Schlegel, Hermann. 1827. Erpetologische Nachrichten. Isis von Oken 20 (3): 281-294. [New genus Xenodon Boie on p. 293]

Schlegel, Hermann. 1837. Essai sur la physionomie des serpens. [Vol. 1] Partie Générale: xxviii + 251 pp. [Vol. 2] Partie Descriptive: 606 pp. + xvi pp. (i-xv $=$ index + errata on $\mathrm{xvi})$. [Folio atlas]: 21 pls. +3 maps +2 tables. The Hague: J. Kips, J. Hz. et W.P. Van Stockum. Amsterdam: M.H. Schonekat.

Schmidt, Karl Patterson. 1923. Contributions to the herpetology of the Belgian Congo based on the collection of the American Museum Congo Expedition, 1909-1915. Part II. Snakes. Bulletin of the American Museum of Natural History 49 (1): 1-146, pls. 1-22.

Shea, Glenn M., and Gary L. Reddacliff. 1986. Ossifications in the hemipenes of varanids. Journal of Herpetology 20 (4): 566-568.

Smith, Hobart M. 1940. Descriptions of new lizards and snakes from Mexico and Guatemala. Proceedings of the Biological Society of Washington 53: 55-64.

Solórzano, Alejandro. 2004. Serpientes de Costa Rica / snakes of Costa Rica. Santo Domingo de Heredia, Costa Rica: Instituto Nacional de Biodiversidad, 792 pp. [with some 300 figures, mostly color photos, throughout]

Starace, Fausto. 1998. Guide des serpents et amphisbènes de Guyane. Guadeloupe (Guyane): Ibis Rouge Editions, 452 pp.

Taub, Aaron M. 1966. Ophidian cephalic glands. Journal of Morphology 116 (4): 529-541.

Taub, Aaron M. 1967. Comparative histological studies on Duvernoy's gland of colubrid snakes.
Bulletin of the American Museum of Natural History 138 (1): 1-50, pls. 1-8.

Tiedelmann, Franz, and Michael Häupl. 1980. Typenkatalog der Herpetologischen Sammlund Teil II: Reptilia. Kataloge der wissenschaftlichen Sammlungen des Naturhistorischen Museums in Wien. Band 4 (Vertebrata, Heft 2): 1-79.

Underwood, Garth. 1967. A contribution to the classification of snakes. London: British Museum (Natural History), publication 653: $\mathrm{x}+179 \mathrm{pp}$.

Vidal, Nicolas, et al. (+ 8 coauthors). 2008. Dissecting the major African snake radiation: a molecular phylogeny of the Lamprophiidae Fitzinger (Serpentes, Caenophidia). Zootaxa 1945: 51-66.

Wagler, Johann Georg. 1824. Serpentum brasiliensium species novae ou histoire naturelle des espèces nouvelles de serpens, recuellies et observes pendant le voyage dans l'interieur du Brésil dans les années 1817, 1818, 1819, 1820, exécuté par ordre de Sa Majesté le Roi de Bavière, publiée par Jean de Spix, ... écrite d'aprés les notes du voyageur par Jean Wagler, viii +75 pp., 26 pls. Monachii [Munich]: Franc. Seraph. Hübschmanni.

Wagler, Johann Georg. 1830. Natürliches System der Amphibien, mit vorangehender Classification der Säugthiere und Vögel. Munich: J.G. Cotta, vi + 354 pp., 9 folio pls. $[1-7+2$ unnumbered]

Wellman, John. 1963. A revision of snakes of the genus Conopsis (Family Colubridae, from Middle America). University of Kansas Publications, Museum of Natural History 15 (6): 251-295.

Wied, Maximilian Prinz zu. 1821. Reise nach Brasilien in den Jahren 1815 bis 1817 von Maximilian Prinz zu Wied-Neuwied. Frankfurt am Main: Heinrich Ludwig Brönner, vol. 2, 345 pp.

[Wied, Maximilian Prinz zu]. 1824. Verzeichniss der Amphibien, welche im zweyten Bande der Naturgeschichte Brasiliens vom Prinz Max von Neuwied werden beschrieben werden. (Nach Merrems Versuch eines System der Amphibien). Isis von Oken 14 (6): columns 661-673. [title thought to have been written by Oken; this is a synopsis not of the "zweyten Bande" but of the first vol. of the 1825 Beiträge]

Wied, Maximilian Prinz zu. 1825. Beiträge zur Naturgeschichte von Brasilien, von Maximilian, Prinzen zu Wied. Vol. 1 (Amphibien). Weimar: im Verlage Gr. H.S. priv. Landes-IndustrieComptoirs, xxii +614 pp., 3 pls.

Wied, Maximilian Prinz zu. 1827 [1822-1831]. Abbildungen zur Naturgeschichte Brasiliens, herausgegeben von Maximilian, Prinzen von Wied-Neuwied. Weimar: Im Verlag des LandesIndustrie-Comptoirs. Recueil des planches coloriées d'animaux du Brésil, publié par S.A.S. le 
Prince Maximilien de Wied-Neuwied. Weimar: au Bureau d'Industrie. [90 unnumbered folio pls., most colored, in 15 Lieferungen/livraisons of 6 pls. each; text in German and French. Lief. 10, (1827), 2 unnumbered pls. showing Coluber rabdocephalus]

Willard, William A. 1915. The cranial nerves of Anolis carolinensis. Bulletin of the Museum of Comparative Zoology 59 (2): 15-116 + pls. 1-7.

Wilson, Larry David, and John R. Meyer. 1985. The snakes of Honduras, 2nd ed Milwaukee Public Museum, $x+150$ pp.

Woltering, Joost M., et al. (+ 9 coauthors). 2009. Axial patterning in snakes and caecilians: evidence for an alternative interpretation of the Hox code. Developmental Biology 232: 82-89.

Yuki, Vanda Lúcia Ferreira. 1993. Realocação genérica de Xenodon werneri Eiselt, 1963 (Serpentes: Colubridae). Comuniações do Museu de Ciências da PUCRS (Porto Alegre) 53: 39-47.

Zaher, Hussam. 1994. Comments on the evolution of the jaw adductor musculature of snakes. Zoological Journal of the Linnean Society 111 (4): 339-384.

Zaher, Hussam. 1999. Hemipenial morphology of the South American xenodontine snakes, with a proposal for a monophyletic Xenodontinae and a reappraisal of colubroid hemipenes. Bulletin of the American Museum of Natural History 240: 1-168.

Zaher, Hussam, and Ana Lucia C. Prudente. 1999. Intraspecific variation of the hemipenis in Siphlophis and Tripanurgos. Journal of Herpetology 33 (4): 698-702.

Zaher, Hussam, and Ana Lucia C. Prudente. 2003. Hemipenes of Siphlophis (Serpentes, Xenodontinae) and techniques of hemipenial preparations in snakes: a response to Dowling. Herpetological Review 34 (4): 302-307.

Zaher, Hussam, Felipe Gobbi Grazziotin, John E. Cadle, Robert W. Murphy, Julio Cesar de Moura-Leite, and Sandro L. Bonatto. 2009. Molecular phylogeny of advanced snakes (Serpentes, Caenophidia) with an emphasis on South American xenodontines: a revised classification and descriptions of new taxa. Papéis Avulsos de Zoologia 49 (11): 115-153.

Ziegler, Thomas, and Wolfgang Böhme. 1997. Genitalstrukturen und Paarungsbiologie bei squamaten Reptilien, speziell den Platynota, mit Bemerkungen zur Systematik. Mertensiella 8: 1-210.

Zweifel, Richard G. 1997. Alternating use of hemipenes in the kingsnake, Lampropeltis getula. Journal of Herpetology 31 (3): 459-462. 